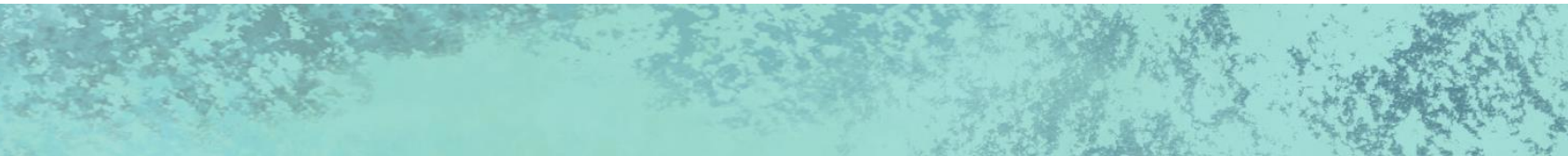 New tools for timber provenancing
}

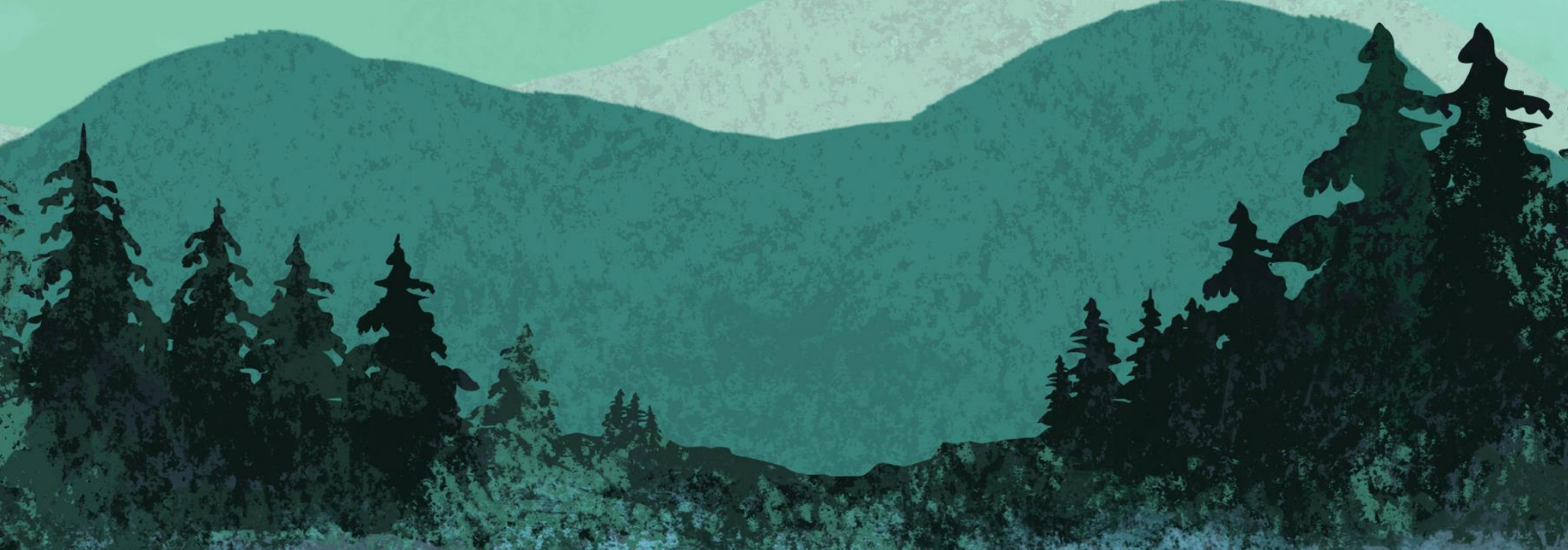

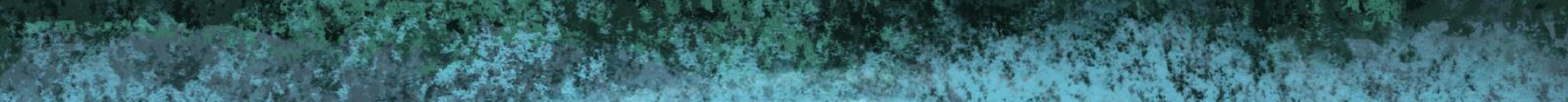

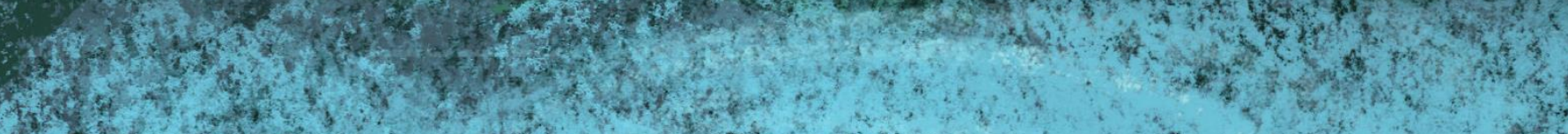

1)

1.

P.

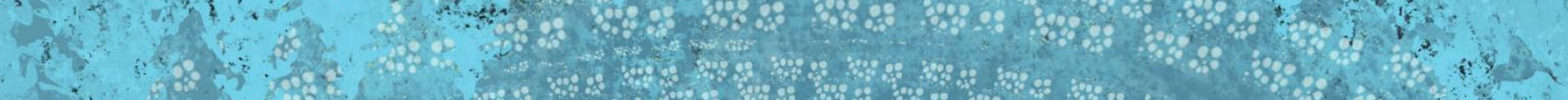

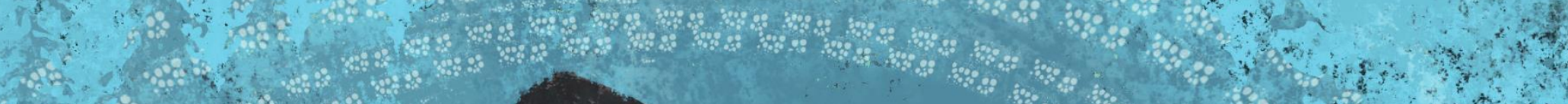

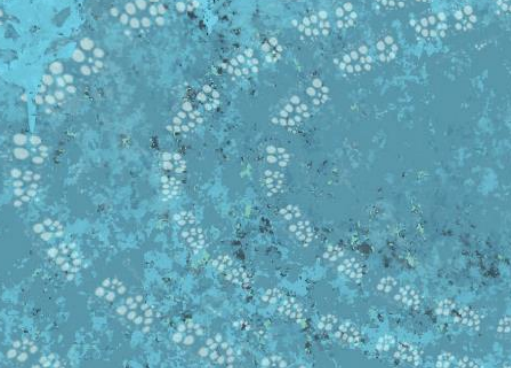

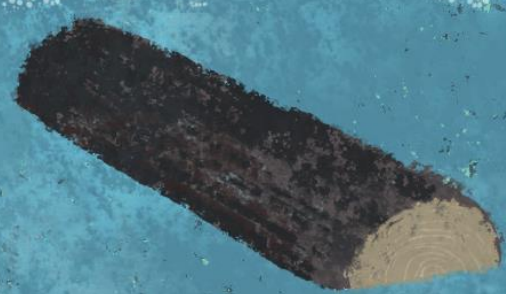

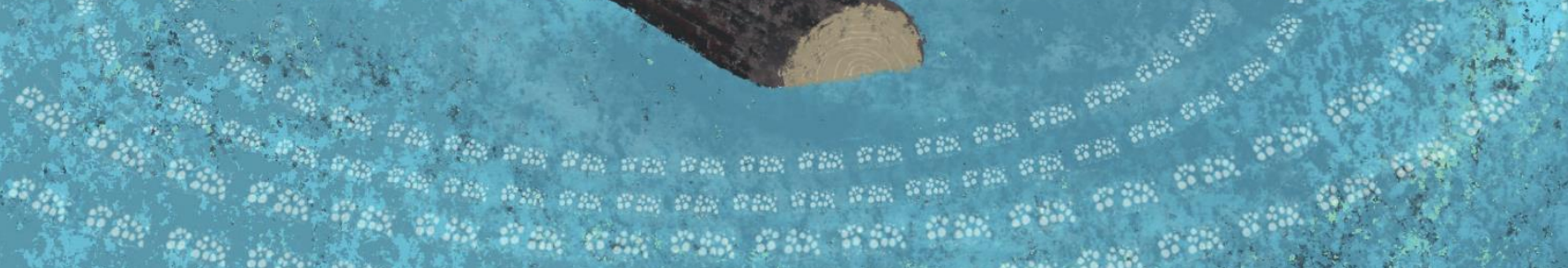

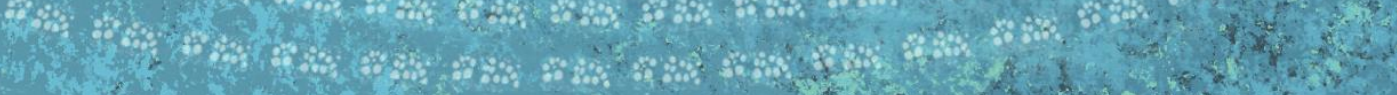

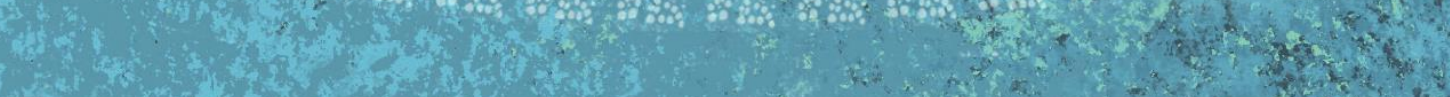

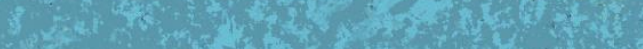




\section{Propositions:}

1. Combination of several wood characteristics enhances precision of dendroprovenancing.

(this thesis)

2. Archaeological research on a molecular level provides new insights on past human - environment interaction.

(this thesis)

3. Multidisciplinary projects yield mono-disciplinary results.

4. Common sense should overrule statistical significance.

5. Research as a commercial enterprise decreases trustworthiness of science.

6. Economic development in one place of a planet enhances decay in another.

7. Insecurity level throughout the $\mathrm{PhD}$ has a cosine pattern.

Propositions belonging to this thesis, entitled:

New tools for timber provenancing

Linar Akhmetzyanov

Wageningen, 25 November 2019 
New tools for timber provenancing

Linar Akhmetzyanov 


\section{Thesis committee}

\section{Promotors:}

Prof. Dr GMJ Mohren

Personal chair Forest Ecology and Forest Management

Wageningen University \& Research

\section{Prof. Dr I. García-González}

Professor of Departamento de Botánica, Escola Politécnica Superior de Enxeñaría

Universidade de Santiago de Compostela

\section{Co-promotors:}

Dr UGW Sass-Klaassen

Associate Professor, Forest Ecology and Forest Management Group

Wageningen University \& Research

Dr J. den Ouden

Assistant Professor, Forest Ecology and Forest Management Group

Wageningen University \& Research

\section{Other members}

Prof. Dr J Wallinga, Wageningen University \& Research

Prof. Dr K. Čufar, University of Ljubljana, Slovenia

Dr P. Fonti, Swiss Federal Research Institute,WSL, Birmensdorf, Switzerland

Dr H. Beeckman, Royal Museum for Central Africa, Tervuren, Belgium

This research was conducted under the auspices of the C.T. de Wit Graduate School for Production Ecology and Resource Conservation 


\title{
New tools for timber provenancing
}

\author{
Linar Akhmetzyanov
}

Thesis

submitted in fulfilment of the requirements for the degree of doctor at Wageningen University

by the authority of the Rector Magnificus

Prof. Dr A. P.J. Mol, in the presence of the

Thesis Committee appointed by the Academic Board

to be defended in public

on Monday 25 November 2019

at 4:00 p.m. in the Aula. 
Linar Akhmetzyanov

New tools for timber provenancing, 160 pages.

$\mathrm{PhD}$ thesis, Wageningen University, Wageningen, the Netherlands (2019) With references, with summary in English

ISBN: 978-94-6395-122-7

DOI: https://doi.org/10.18174/500106 


\section{Table of Contents}

\section{Chapter 1}

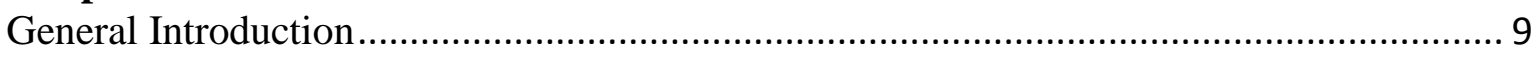

\section{Chapter 2}

Multi-variable approach pinpoints origin of oak wood with higher precision

\section{Chapter 3}

Towards a new approach for dendroprovenancing in the Mediterranean

\section{Chapter 4}

DNA of centuries-old timber reveals its origin

\section{Chapter 5}

General discussion

References

Summary

Acknowledgements

Short biography

List of publications

Affiliations of co-authors.

PE\&RC training and Education Statement 


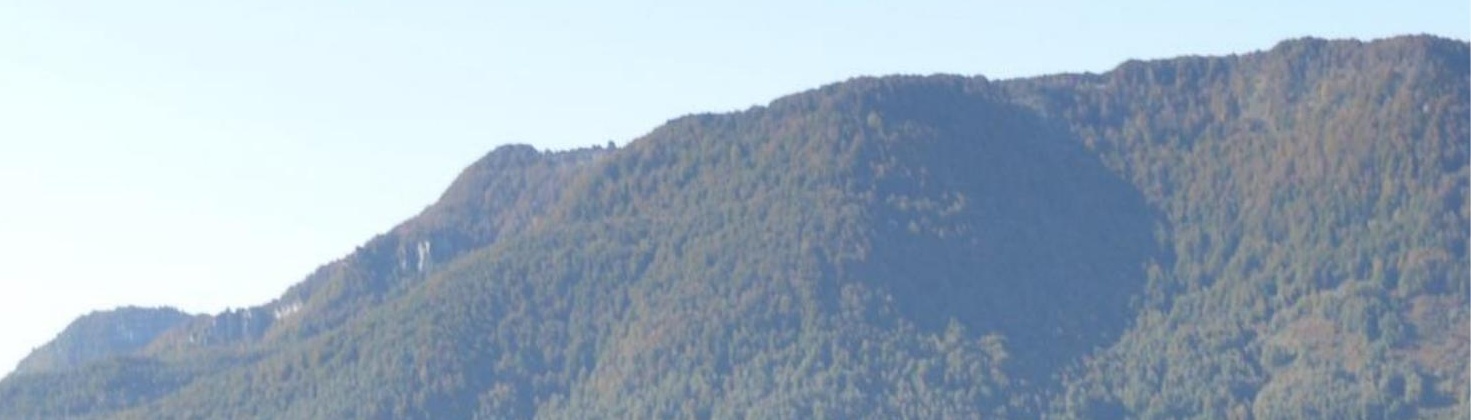

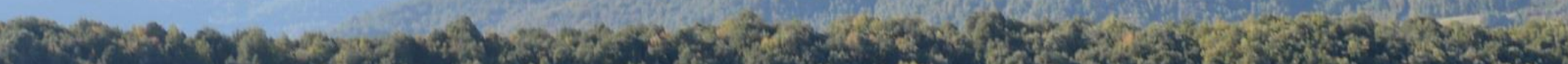

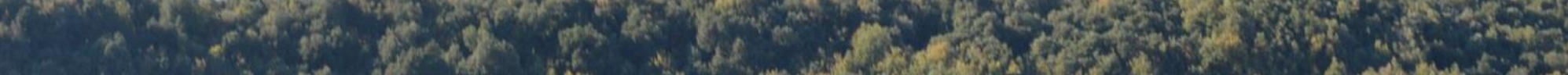

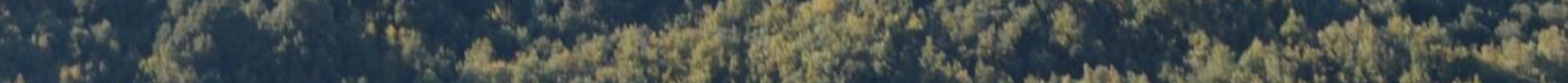

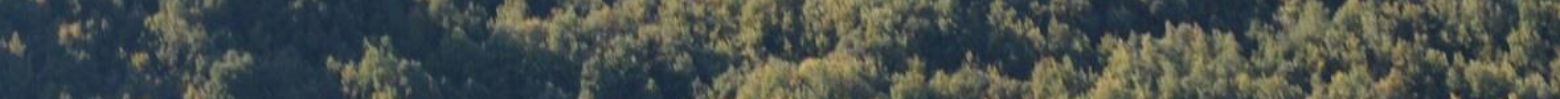

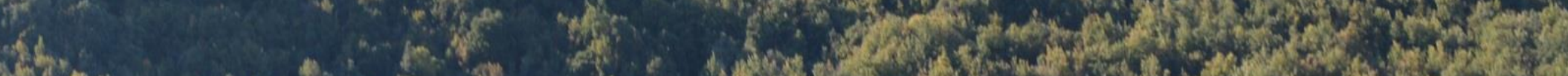

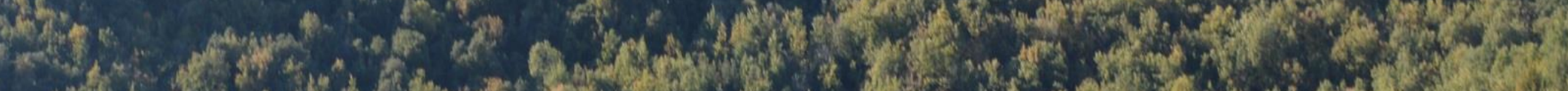

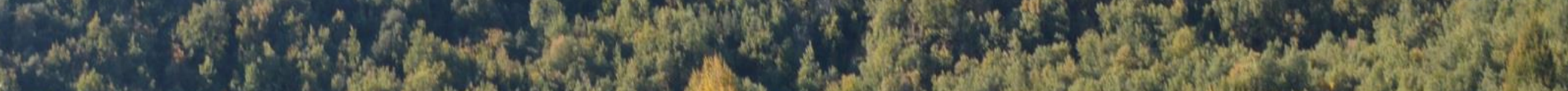

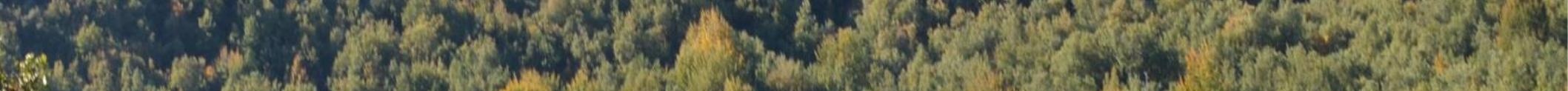

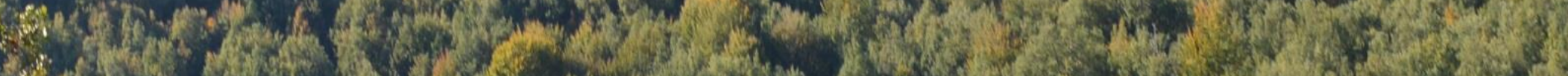
pata

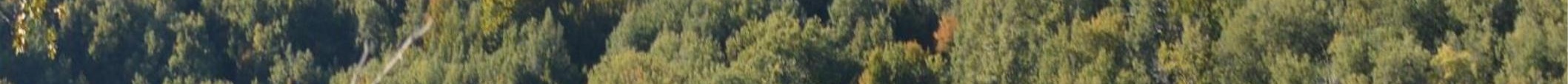

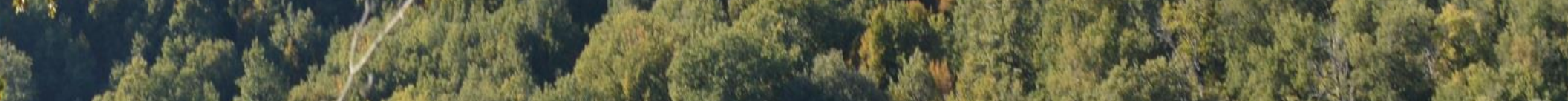
1.7.

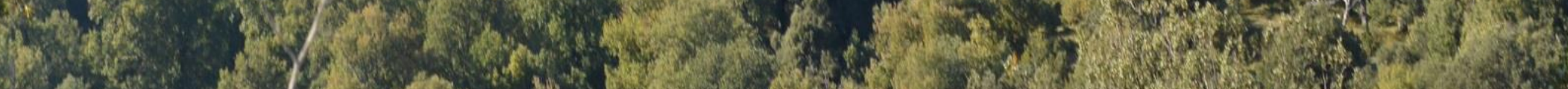

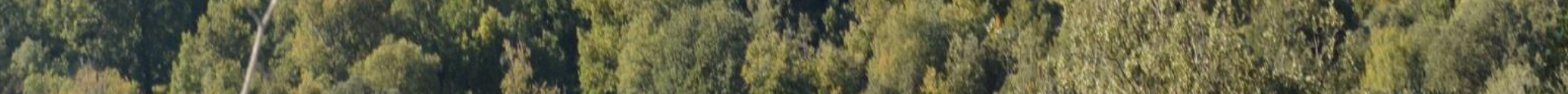
W.

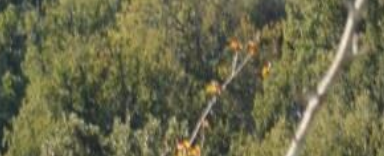

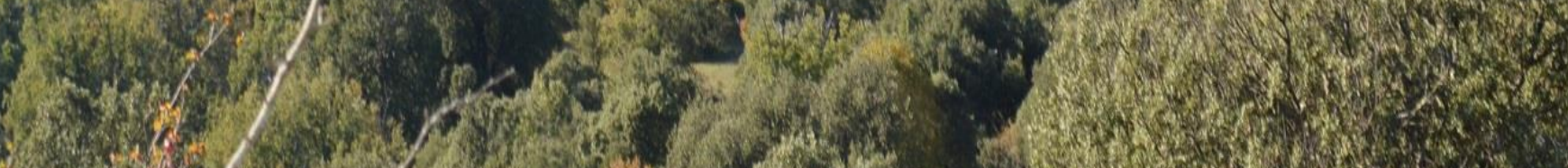

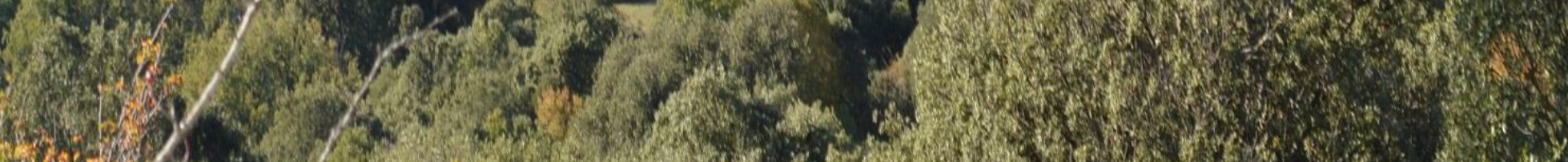

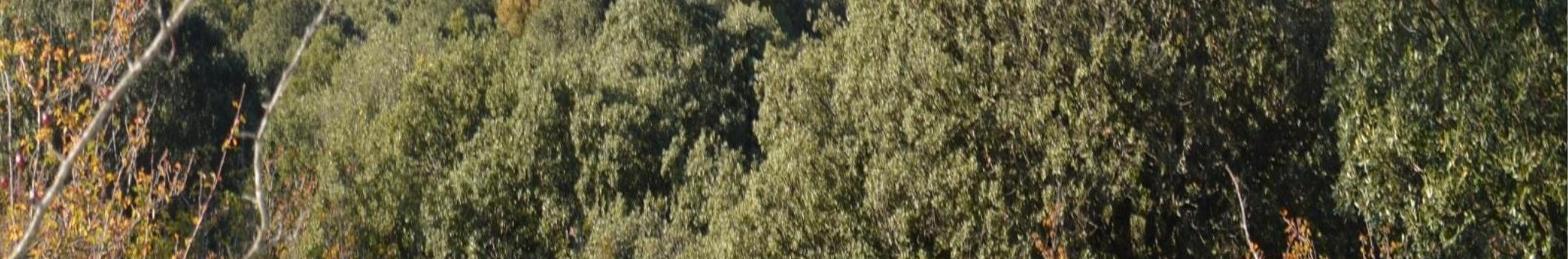




\section{Chapter 1}

General Introduction 


\section{Trees and environment}

Trees grow on every continent on Earth but Antarctica. The distribution of trees is limited by a set of abiotic and biotic factors with a spatial and temporal variation. Climatic conditions, together with altitude and soil properties, are amongst the most critical factors determining species distribution (Walthert \& Meier, 2017) and consequently biogeographic regions. Regional and site-specific conditions are reflected in the morphology and growth of trees and affect their strategy to deal with resources by, for instance, producing cheap or expensive (in terms of carbon) leaves (Reich, 2014), or forming light vs. dense wood (Wright et al., 2010). Moreover, specific environmental conditions also determine annual growth variation and are imprinted in the xylem structure of trees. This information can be used for the characterization of a given species growing under certain climate conditions (Fonti et al., 2010; Poorter et al., 2010; Babst et al., 2013; Holz et al., 2018).

Ecologically relevant long-term information on tree growth can be retrieved from trees by means of dendrochronology (Schweingruber, 1996). Trees form rings as a result of climate seasonality. During the growing season, prevailing environmental factors allow the cambium to be active and produce wood and bark. In the dormant season, when conditions restrict resource acquisition by the tree, cambial activity ceases. In higher latitudes and elevations, tree rings are formed as a result of temperature variation, whereas in many tropical areas precipitation variability, i.e. changes between dry and wet season, is the main factor triggering tree-ring formation (Bormann et al., 1981; Baas \& Vetter, 1989). The growth rate of trees or tree species largely depends on resource availability (water, light, nutrients) at a given site; tree-ring width, on the other hand, is related to climate conditions during or before the year when a ring is formed (Speer, 2010).

Trees growing under similar climate conditions share a common signal in the variation of their tree-ring width and, usually, this signal is related to the most robust growth limiting or enhancing climatic factor (Fritts, 1976). In areas with water shortage, e.g. under dry Mediterranean climate, trees were found to form narrower rings as a reaction to the reduction of photosynthetic rate under drought (de Luis et al., 2011; Olano et al., 2014). At higher latitudes and elevations, the temperature has been found to be the main factor limiting tree growth and thus recorded in the tree rings (Körner \& Paulsen, 2004; Grudd, 2008). Under conditions without extreme hot or cold periods, e.g. in lowlands or in areas with an Atlantic climate, trees have more complex relationships with the environment, and therefore multiple 
climatic signals are archived in their xylem structure (Gričar et al., 2005; Souto-Herrero et $a l ., 2018 b$ ). Information captured by tree rings has distinct advantages: it can be used as an archive of growing conditions in the past, and thus for climate reconstructions (Čufar et al., 2008; Rydval et al., 2017) as well as to assess the stationarity in tree growth and climate relationship (Holz et al., 2018). Thus, tree rings are used for studies across the time axis: the past, the present, and the future. As the trees' response to the current climate change is also stored in their ring-width series, this is also widely used for studies on species ecology (e.g. Pérez-de-Lis et al., 2016; Guada et al., 2018), and for the development of future species distribution models (Gutiérrez et al., 2016; van der Maaten et al., 2017).

\section{Tree rings and wood anatomy}

The field of quantitative wood anatomy has actively developed in recent years due to the improvements of measurement equipment and preparation techniques (Gärtner \& Nievergelt, 2010), which allows measuring wood-anatomical features with high precision and efficiency (Scholz et al., 2013; von Arx \& Carrer, 2014). Studies of xylem features, e.g. vessels or tracheids dimensions, and wood formation of conifers and broadleaves revealed new insights on tree ecology (e.g. Guada et al., 2016; Pérez-de-Lis et al., 2017; Guada et al., 2018) and tree physiology (Cuny et al., 2015; Steppe et al., 2015). Moreover, other xylem features were found to record either complementary information to tree-ring width (GarcíaGonzález \& Fonti, 2006; Fonti et al., 2007; Fonti \& García-González, 2008; Gea-Izquierdo et al., 2012) or to contain a stronger environmental signal than ring width (Wilson \& Hopfmueller, 2001; Wilson et al., 2014). The different signals in xylem features in comparison to ring width are related to various aspects and depend on tree species and their associated wood types, e.g. conifers versus broadleaved species, ring-porous versus diffuseporous as well as the specific growing conditions. Tree-ring width is complexly affected by multiple factors influencing the tree physiology before and during the growing season. Xylem features or variables, such as vessel size or latewood density, are often directly influenced by the weather conditions prevailing during and shortly before their formation, i.e. during spring (earlywood vessels) or summer (latewood density) and hence integrate other aspects of the climate conditions than ring width (Fonti \& García-González, 2008; Fonti et al., 2010). Fonti and García-González (2004) also pointed out that the different nature of environmental signals in xylem features made them worthy of consideration and could provide a better picture of trees' growth. 


\section{Dendroarchaeology \& provenancing}

Archaeological timber contains various information on the past: based on tool marks, insight can be gained on ancient methods of wood processing (Billamboz, 2003); ring-width patterns can reflect past forest management practices, i.e. coppice versus high forest systems (Haneca et al., 2006) and also its geographical origin (Bridge, 2012). Identification of the latter is traditionally done by statistical comparison of the ring-width series of a given timber to a network of regional and local chronologies from the same species (Eckstein, 2007). Furthermore, the chronology yielding the highest statistical match, e.g. $t$-test or the coefficient of parallel synchronous variation ("Gleichläufigkeit”, sensu (Eckstein, 1969)) at a specific position serves as an indicator of the cutting date and the geographical origin of the tree from which the timber originates (Bridge, 2012). This method has been successfully applied in many studies across Europe (Haneca et al., 2005; Haneca \& Debonne, 2012; Domínguez-Delmás et al., 2014), as well as in other areas across the world (Hoshino et al., 2008; Kim et al., 2013). Nevertheless, this method has clear limitations, for instance, when strong teleconnections are found between tree-ring series originating from forests located hundreds of kilometres away from each other (e.g. Domínguez-Delmás et al., 2013) and thus restricting high-precision provenancing in the area. Another problem is the limited number of tree rings, as sometimes found in historical timber (e.g. Pearson et al., 2012), which does not allow obtaining statistically significant matches with reference chronologies, although Sass-Klaassen et al. (2008) were able to provenance foundation piles of Dutch houses containing less than 50 rings. In addition, provenancing of oak timber originating from maritime regions of Europe often failed, probably due to the lack of a strong climate signal in the time series of oak growing under favourable conditions (Bridge, 2000). Most of these challenges can be overcome by broadening of the classical approach and improving wood provenancing by making use of recent advances in the fields of wood anatomy and chemistry, as well as the insights gained from the application of tree-ring research in forest ecology.

\section{Advancing provenancing}

Using more tree-ring based variables in combination with the knowledge on biogeographic species distribution are tools to enhance provenancing precision. Information on species ecology and their interaction with climatic factors is a prerequisite for advancing identification of the geographical origin of timber. Knowledge gained from dendroecological 
studies, e.g. distributions and responses to specific environmental factors (e.g. GeaIzquierdo et al., 2012; Lévesque et al., 2014) allows predefining potential timber source areas before the actual measurements of tree-ring variables. The benefit of using additional xylem features for provenancing depends on the complementarity of the signal captured by these features to the one archived by traditionally used ring width. If different climatic signals are captured by the features, e.g. due to the timing of formation, a multi-variable approach is undoubtedly beneficial. Few studies tested the added value of additional treering based chemical and anatomical variables for provenancing. The first attempts to use stable isotopes together with ring-width series showed promising results to more precisely pinpoint the origin of pinyon pines from the south-western United States (Kagawa \& Leavitt, 2010), to check source of larch wood (Horacek et al., 2009), and to identify origin of archaeological cedar timber (Rich et al., 2016b). Using latewood density has also significantly increased the chances of dating conifer timber in the UK (Wilson et al., 2017) compared to tree-ring width. Interestingly, the time-series of vessel variables have not yet been tested for improving provenancing of historical and archaeological oak timber, despite oak species have been widely used for construction (Haneca et al., 2009). Moreover, studies on earlywood vessels of oak in different areas of Europe proved the complementary of climate signal of earlywood-vessel chronologies to ring-width chronologies (GarcíaGonzález \& Eckstein, 2003; González-González et al., 2013; González-González et al., 2014; González-González et al., 2015). One reason why time series of xylem anatomical features, and here especially vessel features, were hitherto largely ignored, is likely due to the time-consuming and labour intensive data acquisition in comparison to ring-width measurements, despite recent approaches in image-analyses based technology (Gärtner \& Nievergelt, 2010; von Arx \& Carrer, 2014). In addition, measuring vessels from archaeological material is another challenge, as such material is often fragile, and its proper preparation for precise anatomical measurements is complicated. But the fact that wood xylem features record complementary to tree-rings site-specific signals indicates considerable potential for use in historical or archaeological studies.

DNA extraction for phylogenetic or taxonomic studies is traditionally done from the leaves or buds of trees rather than from xylem tissue. Extraction of DNA from wood is in its initial phase and has been mainly tested on living trees to tackle the problem of illegal logging (Vlam et al., 2018; Paredes-Villanueva et al., 2019). Tests on archaeological timber are still lacking, as the extraction of sufficient amount of DNA is complicated due to the degradation 
processes (Pääbo et al., 2004) and due to the presence of phenolic compounds of the lignin metabolism in the wood that are inhibiting amplification (Deguilloux et al., 2002; Liepelt et al., 2006; Swetha et al., 2014). Studies on archaeological DNA (aDNA) from old timber showed varying successful extraction rates (Dumolin-Lapegue et al., 1999; Deguilloux et $a l ., 2006)$ though promising results were found on extraction genetic material from sub-fossil sapwood (Wagner et al., 2018).

\section{ForSEAdiscovery}

This thesis was written in the context of the ForSEAdiscovery (Forest Resources for Iberian Empires: Ecology and Globalization in the Age of Discovery) project, an interdisciplinary Marie Curie ITN project where scientists from the Humanities (historiography and nautical archaeology) and Life Sciences (dendrochronology, wood anatomy, and geo/dendrochemistry) collaborated to address the broad question of the timber supply for Iberian Empires in the period known as the Age of Discovery (16th to 18th century) in European history. The quest for the Life Sciences group was to advance methods for provenancing, i.e. the identification of the geographical origin of the growth of oak and pine ship timbers derived from trees grown in the Iberian Peninsula. We approached this issue by testing the potential of different techniques, starting with the living trees in selected forest areas in the Iberian Peninsula known to be used for shipbuilding, as reported in historical documents (e.g. Aranda, 1990; Aragón Ruano, 2009) and paintings (Figure 1.1). Within the project, we aimed at delivering proof of the substantial potential of alternative techniques for oak and pine provenancing and in creating a reference dataset of tree-ring width (TRW), vessel size and blue intensity (BI) variables in Spain. The next step will be the application of these methods on more complicated historical and sub-fossil wood. 


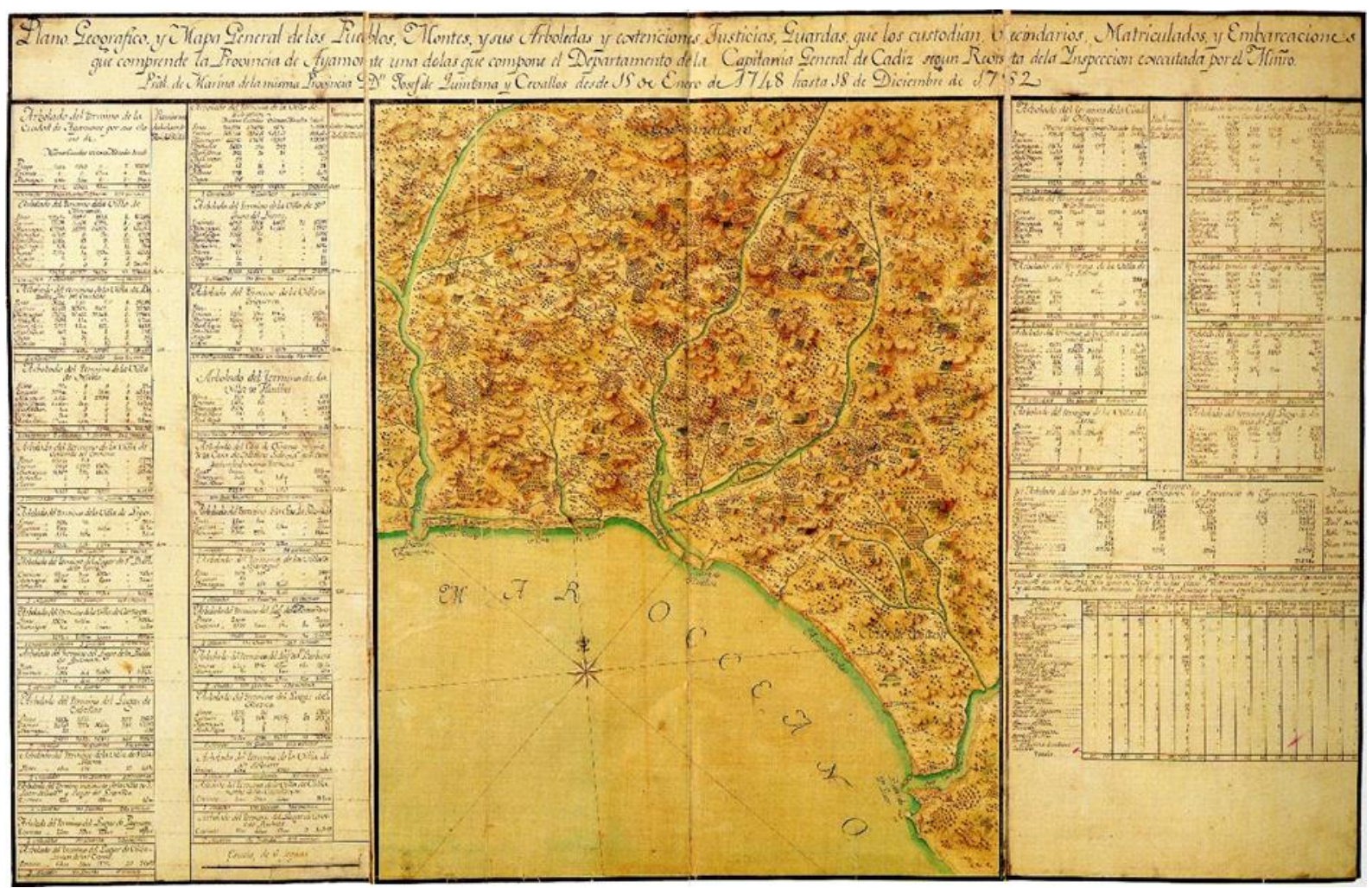

Figure 1.1. Example of a historical painting with information on timber trade in the $18^{\text {th }}$ century in Spain (Mapa o Carta Corographica que comprehende todas las provincias de Marina, que componen el departamento de Cadiz; reducido de las que en escala mayor se han formado, con Real Orden, por Dn. Joseph Antonio Espelius Capitan del Real Cuerpo de Yngenieros. Año de 1765).

\section{Objectives and hypothesis}

The overall aim of this project was to test the potential of tree-ring based xylem variables and DNA methods for high-precision dendroprovenancing. The focus was on oak and pine, two species widely used for shipbuilding in Spain in the Age of Discovery. The specific research objectives of the project were:

1. To assess the potential of oak earlywood vessels for the identification of the geographical origin of historical/archaeological oak timber;

2. To evaluate the effectiveness of blue intensity (BI) as an indicator for latewood density, for tracing the exact origin of pine species;

3. To assess whether and how much DNA can be extracted from degraded oak timber and how this can be used for origin tracing. 
These objectives are addressed in the three core chapters of this thesis:

Chapter 2: In this chapter, we explored and tested the possibility of applying a multi-variable approach on ring-porous oak species from Spain. We investigated whether using oak earlywood vessel variables and latewood width can improve the precision of ring-width based dendroprovenancing and, if so, what climatic variables are driving the differentiation of provenance areas based on vessels and tree rings. We expected to enhance the precision of oak timber dendroprovenancing due to the complementarity of climatic signals archived by tree rings and vessels (García-González et al., 2016; Souto-Herrero et al., 2018a; SoutoHerrero et al., 2018b). We expected that vessel size reflects the climatic conditions prevailing during vessel formation, i.e. in early spring, whereas latewood width is related to summer conditions. The fact that both climate factors show directional trends across bioclimatic regions suggests that their effect on both tree-ring variables varies, which would allow pinpointing of the origin of oak populations.

Chapter 3. This chapter covers the evaluation of the effectiveness of BI for pine timber provenancing. Research questions are: (1) how can BI variables assist in pinpointing pine timber origin in drought-limited areas?, and (2) what climatic factors determine variation differences in BI and tree-ring width time series along an elevational gradient and between regions in drought limited areas? We expected to find a stronger summer temperature signal in BI times series than in TRW, as BI variables were found to contain a more "pure" climatic (summer temperature) signal (Rydval et al., 2014; Wilson et al., 2014), whereas ring width is complexly influenced by climatic and non-climatic conditions prevailing during the entire growing season (Cook, 1985). Therefore, it was expected to be possible to discriminate between sites with pronounced differences in summer conditions based on the BI variables. Ring widths, on the other hand, were expected to separate sites based on climatic variations during other periods, and in combination with the BI results, would assist in pinpointing timber source origin on finer scale.

Chapter 4. In this chapter, we evaluated the potential of using DNA extracted from wood for oak timber provenancing. The research questions in this chapter are: (1) can we extract DNA from old, degraded oak timber?, and (2) can we use this extracted DNA to identify potential source area of the timber? We hypothesized that it is possible to extract DNA of sufficient quality from archaeological oak timber after adjustments of extraction protocols previously developed and used for fresh timber (Rachmayanti et al., 2006; Vlam et al., 
2018). This DNA will further be used to identify the haplotypes of degraded material. We expected to identify potential timber source areas of the historical timber by matching the identified haplotypes with the existing oak haplotypes distribution database (Petit et al., 2002a). The latter is possible due to the observed strong phylogenetic structure of oak haplotypes distribution in Europe (Petit et al., 2002b).

\section{Study species}

In this project, six tree species from two genera-Quercus and Pinus originating or growing in Spain were studied. All four Quercus spp. are deciduous and have a ring-porous anatomical structure with large earlywood vessels forming at the beginning of the growing season (e.g. Pérez-de-Lis et al., 2016; Guada et al., 2018). Quercus robur L. and Quercus petraea (Matt.) Liebl. - widely occur in Europe and extend from northern Europe until the boundary of the Mediterranean region, where they are progressively replaced by more drought-tolerant species. They are sympatric in many parts of their distribution and prefer fertile and moist soils, though they have a large ecological amplitude (Ellenberg, 1988). Quercus pyrenaica Willd. and Quercus faginea Lam. - are more drought-tolerant, marcescent oaks, mainly distributed over the Iberian Peninsula (IP) (Blanco Castro, 2005), with Q. pyrenaica reaching South-Western France and Northern Morocco (Nieto Quintano, 2016). Q. pyrenaica prefers siliceous mountains and sometimes is found limestone and dolomite bedrock, i.e. more acidic soils, covering wide elevation range of 0-2,100 m.a.s.1 (Nieto Quintano, 2016), but usually not reaching low elevation within the Mediterranean region, while $Q$. faginea subsp. faginea grows on more basic soils (Jiménez Sancho, 1998) and has a narrower altitudinal distribution - 600-1200 m.a.s.l. (Blanco Castro, 2005).

Two Pinus species - Pinus sylvestris L. and Pinus nigra J.F. Arnold - are softwood, conifer evergreen species. P. sylvestris is the most widespread species in the Pinus genus and occupies areas from Spain in the west to the far east in Russia in a wide range of elevations: up to 2,600 m.a.s.1. in the Caucasus (Houston Durrant, 2016). P. nigra, on the other hand, is considered as a more drought (Isajev et al., 2004) and shade (Trasobares \& Pukkala, 2004) tolerant species and can grow in both extremely dry and humid habitats (Nikolić \& Tucić, 1983). The distribution of $P$. nigra has a fragmented pattern extending from North-Western Africa through southern Europe to Asia Minor and in general restricted to basic soil areas (Nikolić \& Tucić, 1983). 


\section{Study sites and samples}

This study was carried out at nine oak stands from Northern Spain and six pine forests from the Central System and Andalusia (Figure 1.2). Oak study sites were located along the eastwest direction creating two study regions, with a gradient in continentality in the eastern group of sites. This continentality was also reflected by the gradual change of vegetation from Euro-Siberian (close to the coast) to more Mediterranean vegetation towards the South. Elevation also varied across the study area: from $80 \mathrm{~m}$ a.s.l at the coastal sites up to 1,200 $\mathrm{m}$ a.s.l at more inland sites.

Pine samples were collected in two regions - the mountains of the Central System massif and the Cazorla mountains (Andalusia) - located ca. $500 \mathrm{~km}$ distance between each other (Figure 1.1). Both regions are characterized by a Mediterranean climate with continental influence: dry summers and cool winters. Pine trees from the Andalusian sites suffer from more severe summer drought events, while Central System forests experience colder winters. In both areas sampling was carried along an elevation gradient, varying from 1,400 $\mathrm{m}$ a.s.l to $1,900 \mathrm{~m}$ a.s.1 in Central System and from 1,200 to 1,600 in Andalusia.

Samples for genetic analyses were collected from historical objects from Denmark, Latvia, and Spain. Samples varied in their age - from 240 years old up to 750 years old - and also in their degradation level. 


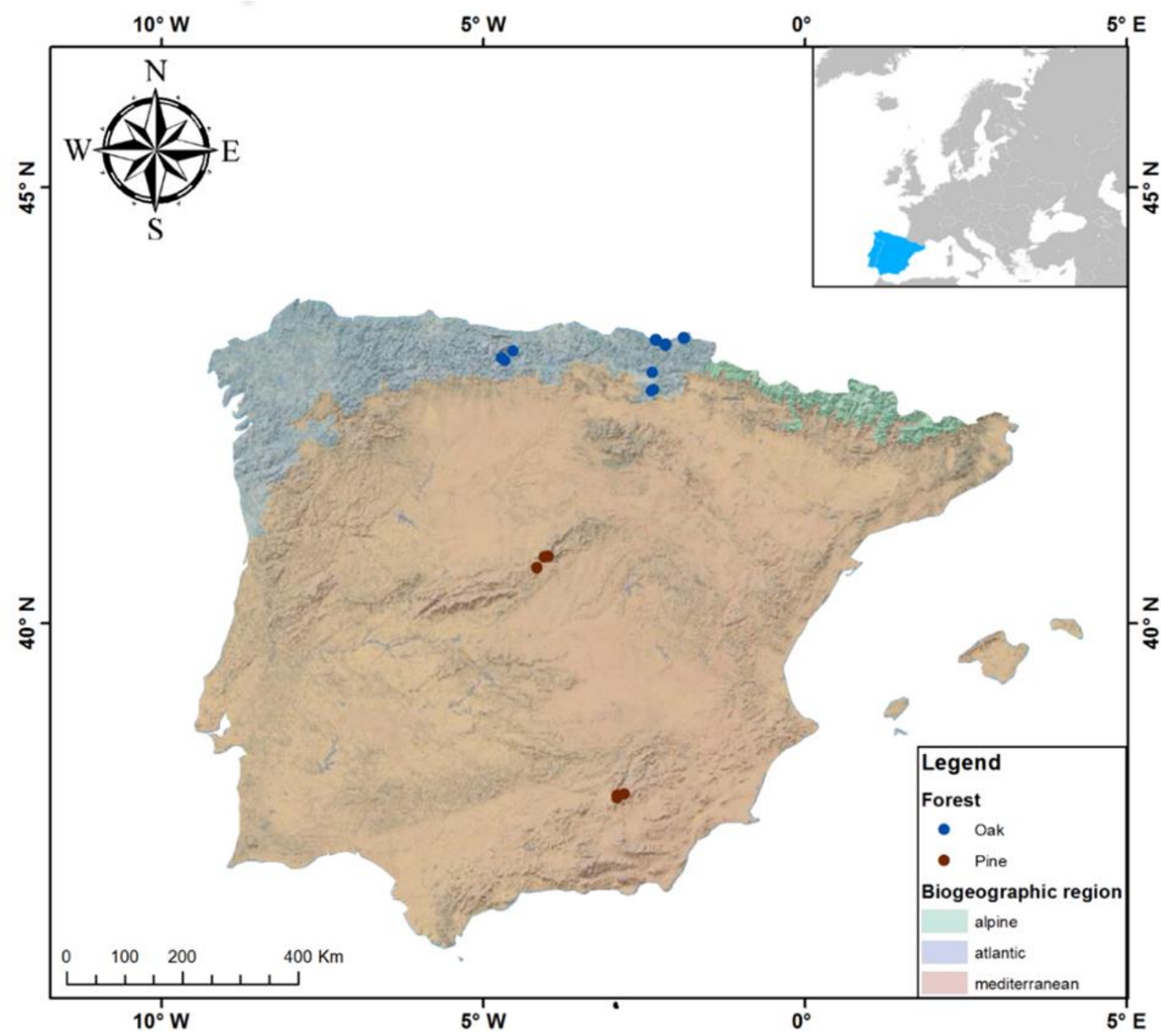

Figure 1.2. Study area and sampling sites in the Iberian Peninsula. In blue and red circle - oak and pine study sites, respectively. In transparent green, blue and orange - Alpine, Atlantic and Mediterranean biogeographic region, respectively (https://www.eea.europa.eu/). Layer Credits: Source: Esri

\section{Thesis outline}

This research comprises a General Introduction (Chapter 1), three core chapters (Chapters 2 to 4) and the General Discussion (Chapter 5). In three research chapters, we assess the potential of three new variables for timber provenancing in Spain. In Chapter 2, we analyse whether including oak earlywood vessels chronologies into provenancing research would yield better precision and how specific biogeographic responses to climate reflect in oak xylem structure could be used for pinpointing oak timber origin. In Chapter 3, we assess the potential of using Blue intensity variables for provenancing of pine timber in growth drought limited areas. In Chapter 4, we test the possibility of extracting DNA from degraded 
oak timber with further use of the DNA for haplotyping and indicating potential source area. Finally, in Chapter 5, I discuss the advantages of combining different but complementary approaches, limitations of each method, and added value of including ecological information revealed by modern trees for historical/cultural studies. 
Chapter 1. Introduction 


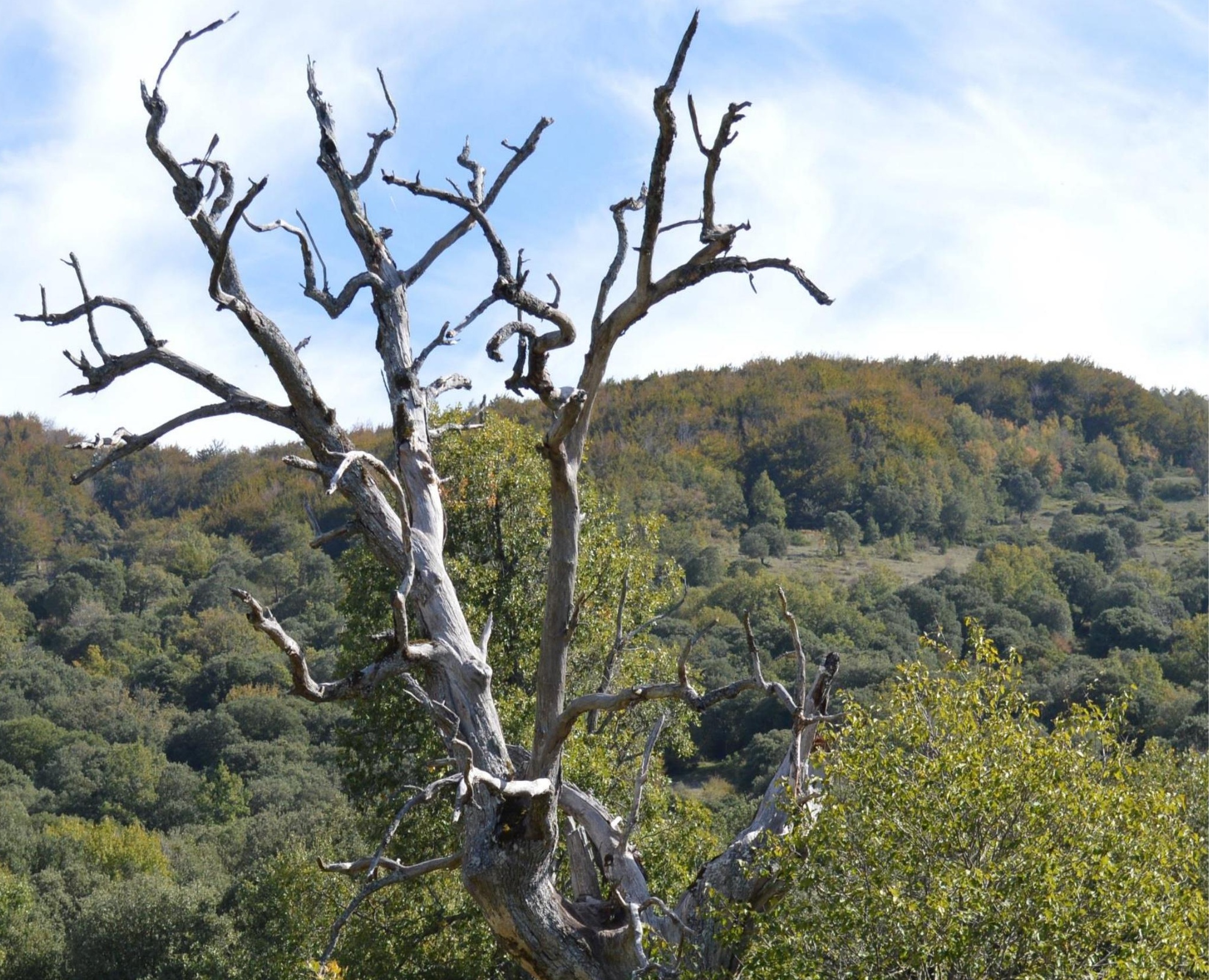

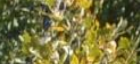
(x)

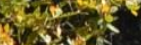

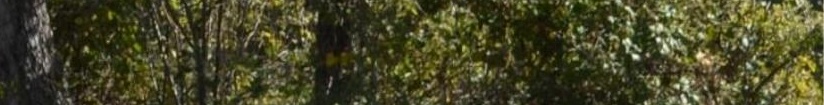
1.6.

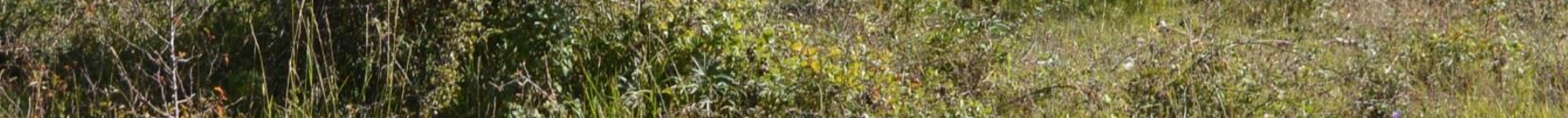




\section{Chapter 2}

\section{Multi-variable approach pinpoints origin of oak wood with higher precision}

Linar Akhmetzyanov, Allan Buras, Ute Sass-Klaassen, Jan den Ouden, Frits

Mohren, Peter Groenendijk, Ignacio García-González

Published in Journal of Biogeography 2019 46:1163-1177 


\begin{abstract}
Spatial variations of environmental conditions translate into biogeographic patterns of tree growth. This fact is used to identify the origin of timber by means of dendroprovenancing. Hitherto, dendroprovenancing attempts are commonly based only on ring-width measurements, and largely neglect additional tree-ring variables. In this study, we explore the potential of using wood-anatomy as a dendroprovenancing tool and investigate whether it increases the precision of identifying the origin of oak wood. Since different tree-ring variables hold different information on environmental conditions prevailing at specific times of the growing season - which vary between source regions - we hypothesize that their inclusion allows more precise dendroprovenancing. We found that a combination of latewood width and earlywood vessel size allows pinpointing the origin of oak wood with higher precision than ring width or latewood width only. Variation in latewood width pinpointed the wood to east and west areas, whereas variation in vessels assigned wood to locations along a latitudinal/topographic gradient. Performed leave-one-out analyses confirmed the strong potential of oak earlywood vessels for use in oak timber provenancing studies.
\end{abstract}

\title{
Keywords
}

Dendroprovenancing, earlywood vessels, latewood width, multi-variable approach, regionspecific growth patterns, Quercus spp., wood anatomy 


\subsection{Introduction}

Trees are affected by a set of spatially and/or temporarily varying environmental factors, such as precipitation, temperature, competition, soil type and many others. The combined effect of these local environmental factors on tree growth is reflected in the width and structure of the tree rings, and can be used to characterize a given species growing under specific site conditions (Babst et al., 2013; Vicente-Serrano et al., 2014; Martin-Benito \& Pederson, 2015; Holz et al., 2018). In dry Mediterranean areas, where trees have limited access to groundwater, drought-induced water shortage was observed as the main growthlimiting factor (de Luis et al., 2011; Martin-Benito et al., 2013; Olano et al., 2014). Under increased vapor-pressure deficit trees transpire more, which leads to a faster depletion of plant-available soil moisture. A decreasing soil-water potential initiates stomatal closure in the leaves to prevent drought-induced mortality (McDowell et al., 2008). The associated reduction of photosynthesis limits tree growth and leads to the formation of narrow tree rings (Bréda et al., 2006). In contrast, at higher latitudes and elevations, the temperature has been found as the main factor limiting tree growth (Körner \& Paulsen, 2004; Grudd, 2008; McCarroll et al., 2013; Yang et al., 2013). Low temperatures limit the trees' photosynthetic rate, which leads to reduced growth rates (Petit et al., 2011). Trees growing under moderate conditions, e.g. in Central European lowlands or in Atlantic regions, exhibit more complex relationships between environment and growth with often multiple growth-limiting factors (Gričar et al., 2013; Souto-Herrero et al., 2018b) but their growth patterns are still indicative for the specific environment-growth interactions at a given site through time.

Environmental information on growing conditions as stored in tree rings is widely used to predict growth responses of trees to climate change (Williams et al., 2010; Holz et al., 2018), to model potential future species distribution (Gutiérrez et al., 2016; van der Maaten et al., 2017), to quantify forest resistance to drought events (Gazol et al., 2017), and to reconstruct growth-limiting climate factors during the pre-instrumental period (Čufar et al., 2008; Schofield et al., 2016; Rydval et al., 2017). Information on spatial variation of climatic signals in tree rings is also important for archaeological and historical studies, as it serves as a basis for dating and determining the geographical origin of historical timbers (“dendroprovenancing") (Speer, 2010). This can be used to identify source areas of wood, as well as for reconstructing wood-trade networks (Domínguez-Delmás et al., 2015). Nowadays, dendroprovenancing is becoming more and more important also in terms of 
detection of illegal logging (Kagawa \& Leavitt, 2010; Vlam et al., 2018). Moreover, ancient timber contains information about past forest-management practices (Haneca et al., 2006), and reflects technological choices, such as selection of species for particular elements of ships or buildings, and also types of tools used for wood processing (Billamboz, 2003; Castro, 2008; Tegel et al., 2012). Dendroprovenancing was successfully applied to identify the origin of foundation piles under historical buildings in The Netherlands (Sass-Klaassen et al., 2008) or wood from shipwrecks (Bridge, 2011; Domínguez-Delmás et al., 2013), and to unravel the Baltic wood trade (Ważny, 2002). Dendroprovenancing of wood from shipwrecks is considered as the most challenging, since boats and ships may be found far away from the construction place (Bridge, 2012), which is not necessarily related to the timber source areas and, single shipwrecks may contain wood from different origins (Haneca et al., 2009).

Until now, dendroprovenancing is almost exclusively based on correlation analyses between ring-width series and a set of reference ring-width chronologies. A statistically significant match leads to dating and provenancing of a given ring-width sequence (indicated by the area covered by the reference chronology) (Fowler \& Bridge, 2017). In some specific areas, stable isotopic ratios have also shown great potential to be used in provenancing studies (Bridge, 2012). In combination with dendrochronological methods, carbon, oxygen and sulphur isotopes have been used to improve the spatial resolution of provenancing (e.g. Kagawa \& Leavitt, 2010; Horacek, 2012), discriminate between species (Horacek et al., 2009), and to identify wood origin (Gori et al., 2015). Strontium stable isotopes have also demonstrated good potential for provenancing cedar ship timber (Rich et al., 2016b). However, the isotopic composition of wood can be influenced by biological and physicochemical processes not related to geographical/climatic factors (Hajj et al., 2017) and for archaeological wood further care is needed as processes such as diagenesis in soils can modify wood composition (Hajj et al., 2017). Extending dendroprovenancing with techniques that use geographically and climatically bound proxies has the potential to strongly improve its accuracy.

Recently, the potential of using additional wood-anatomical variables besides ring width has also been investigated. Esteban et al. (2012) found that variation of wood biometry of a pine species was higher and more pronounced among provenances than within populations. A first attempt to include annual changes in maximum latewood density of a tree ring showed 
that the probability of successfully dating historical samples could be significantly increased (Wilson et al., 2017). The recent development of new techniques (Gärtner \& Nievergelt, 2010), and improvements in image analyses (von Arx \& Carrer, 2014) opened new perspectives for using more quantitative wood-anatomical variables for dendroprovenancing studies (Haneca et al., 2009).

In this study, we explored and tested the possibility to use a multi-variable approach on ringporous oak, a species group that is widely used in historic constructions. In the context of the multidisciplinary project ForSEAdiscovery (htttp://forseadiscovery.eu), we investigated whether using oak earlywood vessel properties and latewood width can improve the precision of ring-width based dendroprovenancing and, if so, what anatomical variables drive the improvement in such a multi-variable approach. We hypothesize that integrating earlywood vessels and latewood width leads to a more precise determination of the source area of a given oak timber, because both variables contain different and complementary climate signals which designate the wood to specific areas where combinations of these climate signals prevail. 


\subsection{Materials and methods}

\subsubsection{Study sites and species}

Samples were collected from nine oak forest stands in the Basque Country (six sites) and Cantabria (three sites) in Northern Spain (Figure 2.1). These forests were selected because they served as wood-source areas for shipbuilding in the $16^{\text {th }}$ to $18^{\text {th }}$ centuries (Martínez Ruiz, 1999). We sampled trees in the Basque country (eastern sites) and in Cantabria province (western sites) (Figure 2.1) with an elevational gradient in the Basque country (from 80 to 1,181 m a.s.1.). The eastern sites (AZK, UZK, OIR, GOR/GOY, OTE and SVA) are located along a phytogeographic gradient (Table 2.1), with a gradual change of vegetation from Euro-Siberian in the North to more Mediterranean towards the South, and a gradient in elevation ranging from $80 \mathrm{~m}$ a.s.l close to the coast to $954 \mathrm{~m}$ a.s.l. further inland (Table 2.1). The northeastern sites (AZK, UZK and OIR) have typical Euro-Siberian vegetation dominated by $Q$. robur. AZK and UZK were intensively used for charcoal production in the past but are not managed nowadays. OIR is a private-owned forest patch in the village of Oiartzun, with trees scarcely distributed on pasture land. The central eastern site (GOR/GOY) is located in the transitional zone between Euro-Siberian and Mediterranean vegetation and $Q$. pyrenaica is the dominant tree species with some inclusions of $Q$. petraea. This site was heavily managed (coppiced) until the mid-20 $0^{\text {th }}$ century but was not managed since. Whereas the southeastern sites OTE and SVA consist of Mediterranean forests dominated by $Q$. faginea, with OTE on steep hills and were not used/managed in the past, SVA mostly consists of old trees in flat pastureland (called dehesa in Spanish). All western sites (BRR/BRY, ONQ, and ORT; Figure 2.1) feature a typical transitional vegetation between Atlantic and Mediterranean phytogeographical regions, with the dominance of $Q$. pyrenaica in ORT and $Q$. petraea in ONQ. These sites share a similar mild climate, without a pronounced summer drought, and an altitudinal range from 1,037 to 1,181 $\mathrm{m}$ a.s.1. In our analyses we separate eastern from western sites (as categorical variables), and further separate eastern sites in northern, central, and southern categories (NE, CE and SE, respectively). 


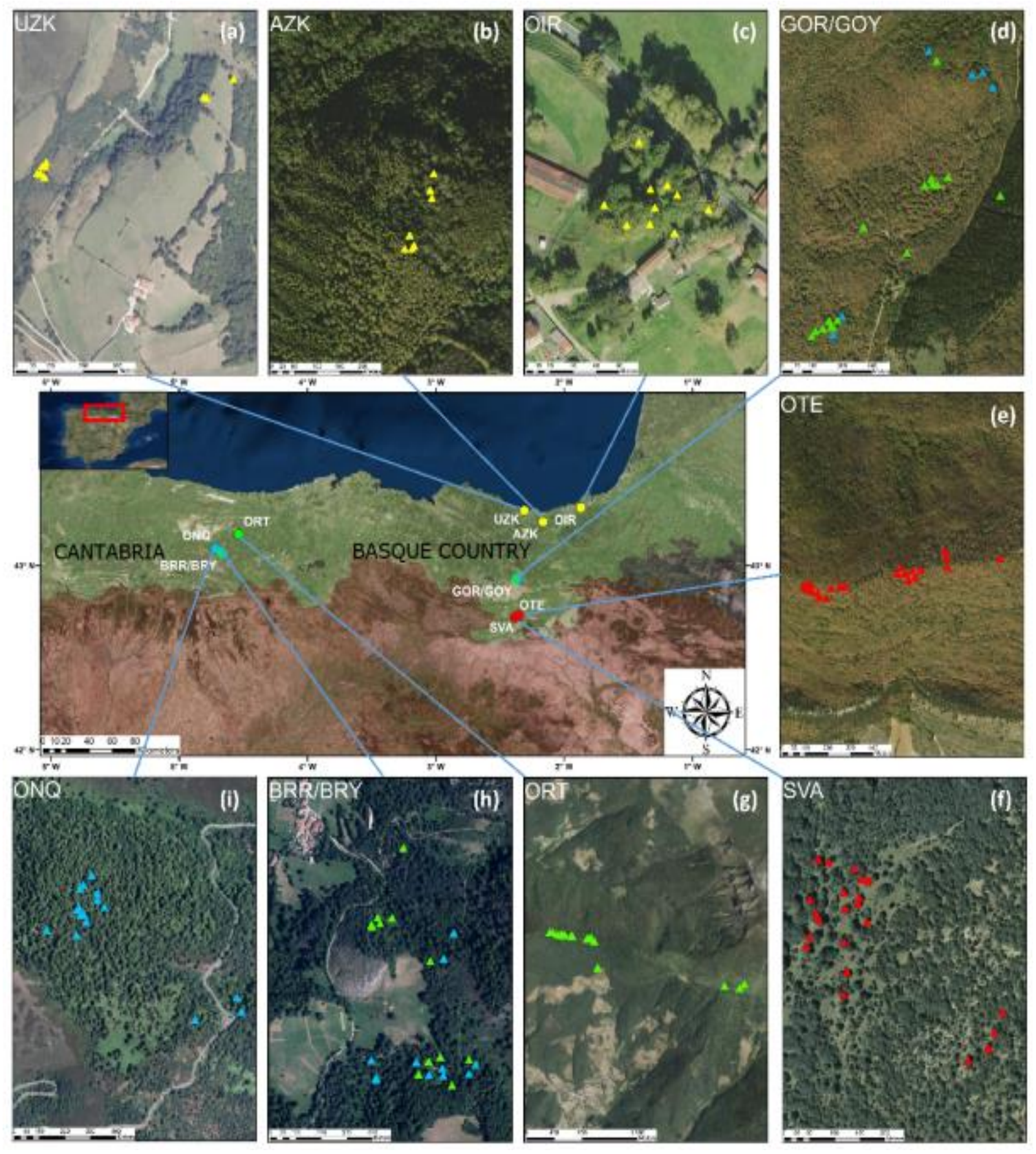

Figure 2.1. Location of study sites and the distribution of sampled trees at each site (a-i). Dots represent selected forest stands (see Table 2.1 for an explanation of the abbreviations of site names), triangles represent selected tree individuals, $Q$. robur - in yellow, $Q$. pyrenaica - in blue, $Q$. petraea - in green and $Q$. faginea - in red, respectively. Sites with double names indicate the collection of two different species from the same forest stand. Transparent red, transparent green and transparent purple refer to the Mediterranean, Atlantic, and Alpine biogeographical regions, respectively (https://www.eea.europa.eu/). Layer Credits: Source: Esri. 
Table 2.1. Overview on study-site characteristics and sampling design

\begin{tabular}{|c|c|c|c|c|c|c|c|c|c|c|c|}
\hline Forest & Code & Coord. & $\begin{array}{l}\text { Phyto- } \\
\text { geogr. } \\
\text { region }\end{array}$ & $\begin{array}{l}\text { Samp. } \\
\text { region }\end{array}$ & $\begin{array}{l}\text { Bed } \\
\text { rock }\end{array}$ & $\begin{array}{l}\text { Tavg } \\
\left({ }^{\circ} \mathrm{C}\right)\end{array}$ & $\begin{array}{l}\text { Prec } \\
(\mathbf{m m})\end{array}$ & $\begin{array}{c}\text { Elevation } \\
\text { (m a.s.l.) }\end{array}$ & Species & $\begin{array}{c}\text { Trees } \\
\text { TR }\end{array}$ & $\begin{array}{l}\text { Trees } \\
\text { VESS }\end{array}$ \\
\hline Azkorte & AZK & $43^{\circ} 14^{\prime} \mathrm{N} 2^{\circ} 09^{\prime} \mathrm{W}$ & $\mathrm{E}$ & $\mathrm{NE}$ & SL & 12 & 1101 & 523 & Q. robur & 7 & 6 \\
\hline Oiartzun & OIR & $43^{\circ} 18^{\prime} \mathrm{N} 1^{\circ} 51^{\prime} \mathrm{W}$ & $\mathrm{E}$ & $\mathrm{NE}$ & SS & 11.8 & 1189 & 115 & Q. robur & 10 & 9 \\
\hline Uzkanga & UZK & $43^{\circ} 17^{\prime} \mathrm{N} 2^{\circ} 18^{\prime} \mathrm{W}$ & $\mathrm{E}$ & $\mathrm{NE}$ & SL & 12.8 & 1199 & 80 & Q. robur & 9 & 9 \\
\hline Gordoa & GOR & $42^{\circ} 55^{\prime} \mathrm{N} 2^{\circ} 22^{\prime} \mathrm{W}$ & $\mathrm{T}$ & $\mathrm{CE}$ & SS & 9.7 & 878 & 1129 & Q. petraea & 6 & 6 \\
\hline Gordoa & GOY & $42^{\circ} 55^{\prime} \mathrm{N} 2^{\circ} 22^{\prime} \mathrm{W}$ & $\mathrm{T}$ & $\mathrm{CE}$ & SS & 9.7 & 878 & 1129 & Q. pyrenaica & 16 & 7 \\
\hline Oteo & OTE & $42^{\circ} 43^{\prime} \mathrm{N} 2^{\circ} 23^{\prime} \mathrm{W}$ & M & SE & SL & 10.4 & 653 & 829 & Q. faginea & 24 & 6 \\
\hline San Vicente de Arana & SVA & $42^{\circ} 43^{\prime} \mathrm{N} 2^{\circ} 21^{\prime} \mathrm{W}$ & M & SE & SL & 10.4 & 653 & 954 & Q. faginea & 25 & 7 \\
\hline Barrio & BRR & $43^{\circ} 04^{\prime} \mathrm{N} 4^{\circ} 39^{\prime} \mathrm{W}$ & $\mathrm{T}$ & $\mathrm{W}$ & SS & 11.2 & 963 & 1037 & Q. petraea & 11 & 10 \\
\hline Barrio & BRY & $43^{\circ} 04^{\prime} \mathrm{N} 4^{\circ} 39^{\prime} \mathrm{W}$ & $\mathrm{T}$ & $\mathrm{W}$ & SS & 11.2 & 963 & 1037 & Q. pyrenaica & 12 & 9 \\
\hline On Quemada & ONQ & $43^{\circ} 05^{\prime} \mathrm{N} 4^{\circ} 42^{\prime} \mathrm{W}$ & $\mathrm{T}$ & $\mathrm{W}$ & SS & 11.2 & 963 & 1118 & Q. petraea & 16 & 10 \\
\hline Orticeo & ORT & $43^{\circ} 10^{\prime} \mathrm{N} 4^{\circ} 32^{\prime} \mathrm{W}$ & $\mathrm{T}$ & $\mathrm{W}$ & SS & 11.2 & 963 & 1181 & Q. pyrenaica & 18 & 10 \\
\hline
\end{tabular}

Coord. - coordinates of the study site,

Phytogeogr. region - phytogeographical region: E is Euro-Siberian, M - Mediterranean and T - the transition from E to M,

Samp. region - sampling region: NE, CE, SE and $\mathrm{W}$ - northeastern, central eastern, southeastern and western sampling regions ,

Bedrock: SS - sedimentary silicate and SL - sedimentary limestone,

Tavg - yearly average temperature $\left({ }^{\circ} \mathrm{C}\right)$ of the corresponding study site, Prec - annual precipitation of the corresponding study site $(\mathrm{mm})$, (climate data taken from CRU TS 4.01 (Harris et al., 2014),

TreesTR - number of trees used for ring width, earlywood width and latewood width measurements,

TreesVESS - number of trees used for earlywood vessel measurements. 
Selected oak species vary in their habitat and ecology and hence show specific distribution patterns. $Q$. robur and $Q$. petraea are widely distributed in Europe whereas $Q$. faginea and $Q$. pyrenaica are largely restricted to the Iberian Peninsula (Table 2.2).

Table 2.2. Overview on study species characteristics, distribution and ecology

\begin{tabular}{|c|c|c|c|}
\hline Species & Distribution & Elevation & Bedrock/Soil \\
\hline Q. robur & Europe, (Eaton, 2016) & $\begin{array}{l}0 \text { to } 1300 \mathrm{~m} \text { a.s.l. } \\
\text { (Eaton, 2016) }\end{array}$ & $\begin{array}{l}\text { Fertile, moist soils (Eaton } \\
\text { 2016) }\end{array}$ \\
\hline Q. petraea & Europe, (Eaton, 2016) & $\begin{array}{l}0 \text { to } 2000 \mathrm{~m} \text { a.s.1 } \\
\text { (Eaton, 2016) }\end{array}$ & $\begin{array}{l}\text { Fertile, moist soils (Eaton } \\
\text { 2016) }\end{array}$ \\
\hline Q.pyrenaica & $\begin{array}{l}\text { Morocco, Iberian Peninsula and South- } \\
\text { Western France (Nieto Quintano, 2016) }\end{array}$ & $\begin{array}{l}0 \text { to } 2100 \mathrm{~m} \text { a.s.l. } \\
\text { (Nieto Quintano, } \\
2016 \text { ) }\end{array}$ & $\begin{array}{l}\text { Siliceous mountains, rarely } \\
\text { limestone and dolomites (Nietc } \\
\text { Quintano, 2016) }\end{array}$ \\
\hline $\begin{array}{l}\text { Q. faginea } \\
\text { (subsp. } \\
\text { faginea) }\end{array}$ & Iberian Peninsula (Blanco Castro, 2005) & $\begin{array}{l}600 \text { to } 1200 \text { m a.s.l. } \\
\text { (Blanco Castro, } \\
2005 \text { ) }\end{array}$ & $\begin{array}{l}\text { Basic soils (Jiménez Sancho } \\
\text { 1998) }\end{array}$ \\
\hline
\end{tabular}

\subsubsection{Acquisition of ring-width and vessel-size time series}

Sampling was performed in May/October 2015 and in October 2016. Between seven and 25 trees were sampled per site (Table 2.1). The variation of sample size per study site was caused by the different number of suitable trees at each site. Although oak species are prone to hybridize and many taxa were described for the Iberian Peninsula (Amaral Franco, 1990), we are confident of our species identification as we carefully identified each tree sampled at stands with coexisting oak species. The largest and apparently oldest oak trees with no visible damage to crowns or stems were selected, and two to four 5-mm cores were extracted from each tree.

Samples were air dried, glued onto wooden holders, cut using a sliding microtome (Gärtner $\&$ Nievergelt, 2010), and sanded with progressively finer sandpaper (grain sizes from P180 to P1200, FEPA Abrasives). Tyloses (parenchyma outgrowths into vessels) and wood dust were removed using a high-pressure water blast, after which each core was stained using black ink. Chalk was rubbed on the samples to fill earlywood vessels, thus achieving better contrast of the vessels for image analyses.

Total ring width (TRW), earlywood (EW) and latewood widths (LW) were measured using a Velmex measuring table (Velmex TA Unislide, Velmex Inc., Bloomfield NY, USA) coupled with a stereo-microscope (Olympus SZ60). Crossdating was done in two steps: first visually and then statistically. Visual crossdating was done by first matching the ring-width 
patterns of individual trees, and then different trees from the same site. Statistical crossdating was done using COFECHA ver. 6.02P (Grissino-Mayer, 2001). Crossdating is considered as the most important principle of dendrochronology (Fritts, 1976), as it allows linking each tree ring to the exact calendar year of its formation.

For measurement of the earlywood vessel area, a sequence of overlapping images with a resolution of 13,780 dpi was taken from the wood surface using a digital camera (Canon EOS 600D) coupled to the stereo-microscope (Figure 2.2). The images were stitched using PTGui ver. 9.2.0 (New House Internet Services B.V., Rotterdam, The Netherlands). We measured vessels on a subset of trees and cores showing the highest inter-correlation (Table 2.1) as vessel measurements are labour intensive, and thus can be conducted on a limited number of trees only. Moreover, some cores were broken or had cracks, which made them less suitable for wood-anatomical analyses.
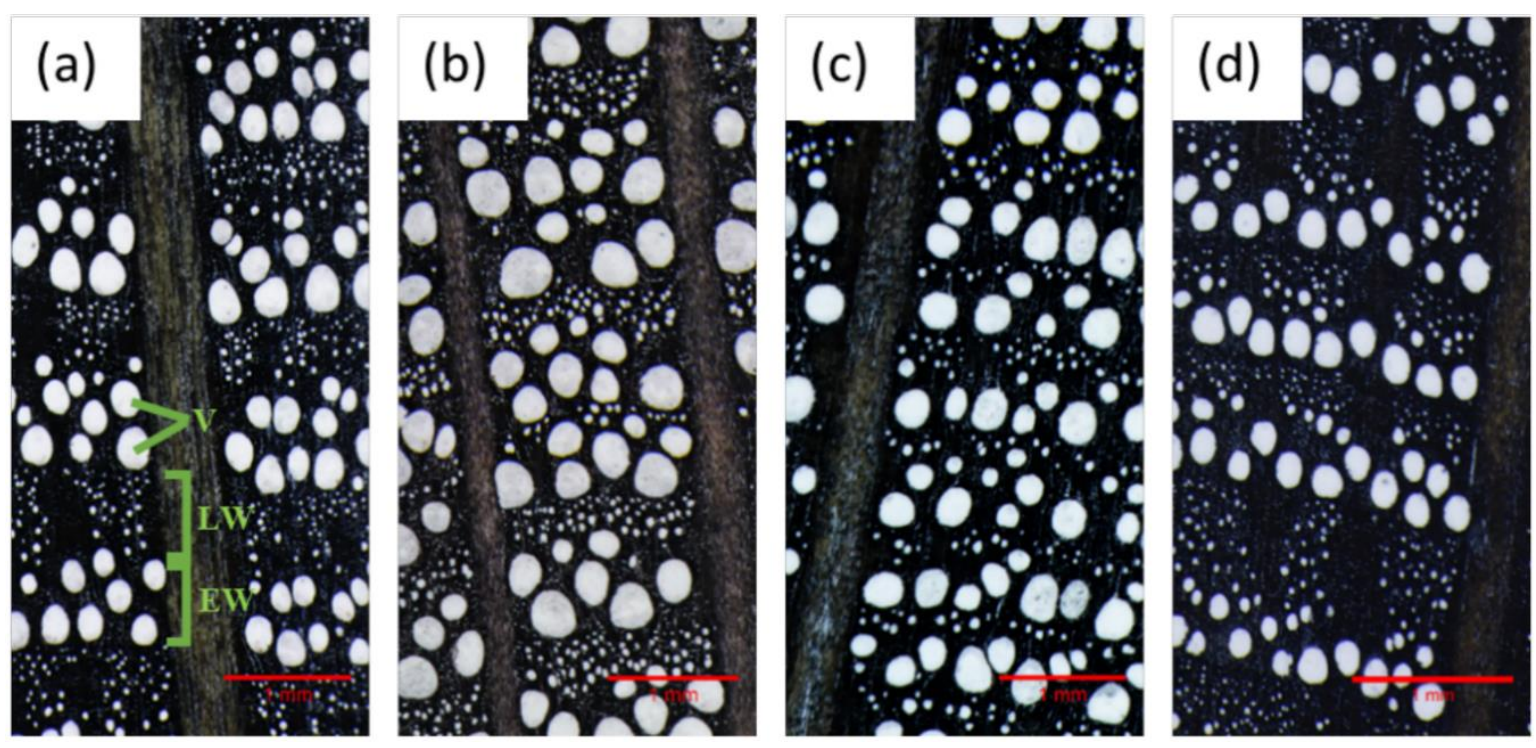

Figure 2.2. Wood surface images of a) Quercus robur, b) Quercus petraea, c) Quercus pyrenaica and d) Quercus faginea. EW, LW and V indicate earlywood, latewood and vessels, respectively.

Earlywood vessels were measured semi-automatically in ImageJ ver. 1.8.0 (Schneider et al., 2012) using the VesselJ plugin (García-González, unpubl.) and following the steps described in Souto-Herrero et al. (2018a). This plugin allows for efficient discrimination of the bright chalk-filled vessel-lumen area from the dark-stained background (the remaining wood structures). After scanning and stitching, images were converted to 8-bit black-and-white and vessels were distinguished from the background using gray-scale thresholds. To ensure that undesired objects were excluded, additional filters were applied removing elliptical 
objects (less than twice as long as wide) and objects smaller than $10,000 \mu \mathrm{m}^{2}$. This particular size threshold was taken from Fonti and García-González (2004) and Fonti et al. (2007) to exclude the smaller vessels formed later in the season, which may blur the climatic signal (García-González \& Fonti, 2006), and also because most of the signal is recorded by the largest vessels, usually located in the first row (González-González et al., 2014; GarcíaGonzález et al., 2016). The images with the detected vessels were then checked for detection errors and manual image corrections were performed where needed.

To assign each vessel to the corresponding dated tree ring, and to identify vessels belonging to the first-formed row at the beginning of the tree ring, we used the software package Autovasos (García-González, unpubl.), again following Souto-Herrero et al. (2018a). From the earlywood-vessel measurements, 11 variables related to size, position, and waterconducting capacity were derived from each tree ring: hydraulically-weighted vessel diameter $\left(D_{h}\right)$, mean vessels area, maximum vessel size, number of vessels (NV), total vessels area, mean area of the first row vessels, hydraulic diameter of vessels not belonging to the first row, mean area of vessels not belonging to the first row, maximum size of vessels not belonging to the first row, number of vessels not belonging to the first row, and total area of vessels not belonging to the first row. $D_{h}$ was calculated according to the equation:

$$
D_{h}=\frac{\sum_{n=1}^{N} D_{n}^{5}}{\sum_{n=1}^{N} D_{n}^{4}},
$$

where $D_{n}$ (in $\mu \mathrm{m}$ ) is the diameter of the vessel $n$ (Sperry et al., 1994). $D_{h}$ has been shown to be related to prevailing environmental conditions and to maximize the climatic signal (Pérezde-Lis et al., 2016; Souto-Herrero et al., 2017).

Before further processing, the individual time series of each variable were detrended to remove trends related to age and forest dynamics, using a cubic smoothing spline (Cook et $a l ., 1992$ ) with a frequency response of $50 \%$ at a wavelength of 32 years. We subsequently used individual time series to compute site and regional chronologies. Site chronologies included only trees of each site $\times$ species combinations, while regional chronologies included trees from the predefined geographical regions, namely west, east as well as NE, CE and SE (in the east) regions of the study area (see Figures S2.1, S2.2 and Table S2.1 for the detailed information on site TRW and $D_{h}$ chronologies). 


\subsubsection{Acquisition of a complementary set of variables}

Many of the 14 measured or derived variables (3 ring-width and 11 vessel-related variables) are correlated and carry redundant information (García-González et al., 2016). To reduce the number of variables to a subset of different, statistically meaningful variables, we used Principal Component Analysis (Varimax-rotated PCA) using the site chronologies calculated from the detrended individual time series. The selection was based on the ordination of variables according to the first two principal components. The resulting set of complementary variables, that contained different patterns of variation likely related to sitespecific and climate-related signals, were included in subsequent analyses.

\subsubsection{Geographic patterns of time-series variability}

Discrimination between patterns of annual variation in the selected variables was done based on the detrended individual time series of the trees from the nine study sites. Principal Component Gradient Analyses (PCGA) (Buras et al., 2016) was performed in a time interval covered by most study trees (1888-2014). PCGA is based on loadings on the first two principal components (PCs) obtained from an ordinary principal component analysis (PCA), defining a gradient among time series based on their polar coordinates - in particular the angle - of the loadings (Buras et al., 2016). PCGA was used to test whether our pre-defined biogeographical gradients were reflected in the loadings which represent single trees on the first two PCs. To obtain statistical confidence in the observed patterns, we tested whether the polar angles representative of the loadings differed between source regions using the Wilcoxon rank sum test. This individual tree approach, i.e. using time series of individual trees instead of site chronologies, was chosen since one of the aims was to investigate whether individual series of the selected variables express site- and/or region-specific patterns. If so, this would indicate that their origin can be correctly identified. For application as a provenancing tool, this is especially relevant as often only time series of a single or a few trees are available for dendroprovenancing.

\subsubsection{Climate effect on PCGA gradient}

The gradient obtained from the PCGA was further used to explore mechanisms possibly driving it. To do this, we focused on climate correlations of single tree-ring series, instead of calculating conventional climate-growth relationships based on site chronologies (Chen et al., 2015; Dorado-Liñán et al., 2017). We downloaded gridded CRU TS 4.01 temperature 
and precipitation data over the period 1901 to 2016 (Harris et al., 2014) from the KNMI climate explorer (https://climexp.knmi.nl/start.cgi) and correlated these climate data with each single ring-width and vessel series. To account for non-normally distributed data, we used Spearman's rank correlation in these analyses. Afterwards, we investigated whether these correlations varied significantly along the determined PCGA gradient using Spearman's rank correlation. In this analysis a strong correlation would indicate a directional variation of climate correlations along the PCGA gradient.

Moreover, to test the effect of the geographic origin on climate correlations, we also compared the individual climate correlations between the geographical categories using Wilcoxon rank sum test (for the comparison between east and west), as well as KruskalWallis test (for the north-, central and southeastern sites). Finally, we computed so-called regional chronologies, i.e. the average over all individual time series representative of each geographic category and performed the corresponding climate correlations. This was done to support the results from the single tree climate correlations.

\subsubsection{Species effect on PCGA gradient}

In addition to testing the resemblance of geographic categories in the PCGA-loadings, we also explored whether the variation of PCGA-loadings was related to species. That is, we tested - in a similar manner as for the geographic categories - whether the PCGA-loadings differed between the species. This was done, on the one hand, on all time-series per parameter (i.e. latewood-width and vessels). On the other hand, we also did this analysis on the basis of data considering only those sites where two of the study species ( $Q$. petraea and Q. pyrenaica) were co-existing (BRR/BRY and GOR/GOY).

\subsubsection{Identifying the area of origin}

To test whether the origin of a randomly selected tree can be identified from PCGA, we performed a 'leave-one-out' approach. For this, we successively selected each tree from the data set to test whether its origin could be correctly identified by means of PCGA. In order to do so, we excluded the respective tree from the data pool, and performed a PCGA on the remaining data set as explained in section 2.2.4. This analysis was done separately for LW and vessel time-series. Afterwards, we correlated the left-out time-series with the scores of the first two principal components of the corresponding PCGA and transformed these correlation values into PC-loadings. From these loadings we computed Euclidean distances 
to the loadings of all the other trees (those which were kept in the data for the PCGA) and computed the categorical mean Euclidean distances referring to geographical origins. If the mean Euclidean distance of the left-out tree to the other trees from the same geographical origin was lower in comparison to trees from a different geographical origin, we defined this as a correct assignment. As a measure of success of this approach, the proportion of correct assignments was calculated.

All calculations were done in R version 3.4 (R Development Core Team, 2017) using the 'dplR' (Bunn, 2010), 'psych' (Revelle, 2017) and 'treeclim' (Zang \& Biondi, 2015) packages.

\subsection{Results}

\subsubsection{Selection of complementary variables}

Based on the similarity of loadings on the first two principal components of Varimax rotated PCA, the number of variables for further analyses was reduced from 14 to three, i.e. number of vessels (NV), hydraulic diameter $\left(D_{h}\right)$, and latewood width (LW), since they appeared to carry unique and complementary information for most of the study sites likely related to sitespecific environmental signals (Figure S2.3).

\subsubsection{PCGA}

The common overlap period for the PCGA of LW data was 127 years (1888-2014) and incorporated 64 individual trees representing all study sites and species. The PCGA demonstrated that LW time series were grouping according to geographical categories, i.e. there was a clear separation between the loadings representing trees of eastern and western origin (Figure 2.3) $(\mathrm{p}<0.01$, Wilcoxon test). Trees showed a similar grouping according to the loadings as derived from NV time series; however, there were more mismatches compared to LW (Figure S2.4). 


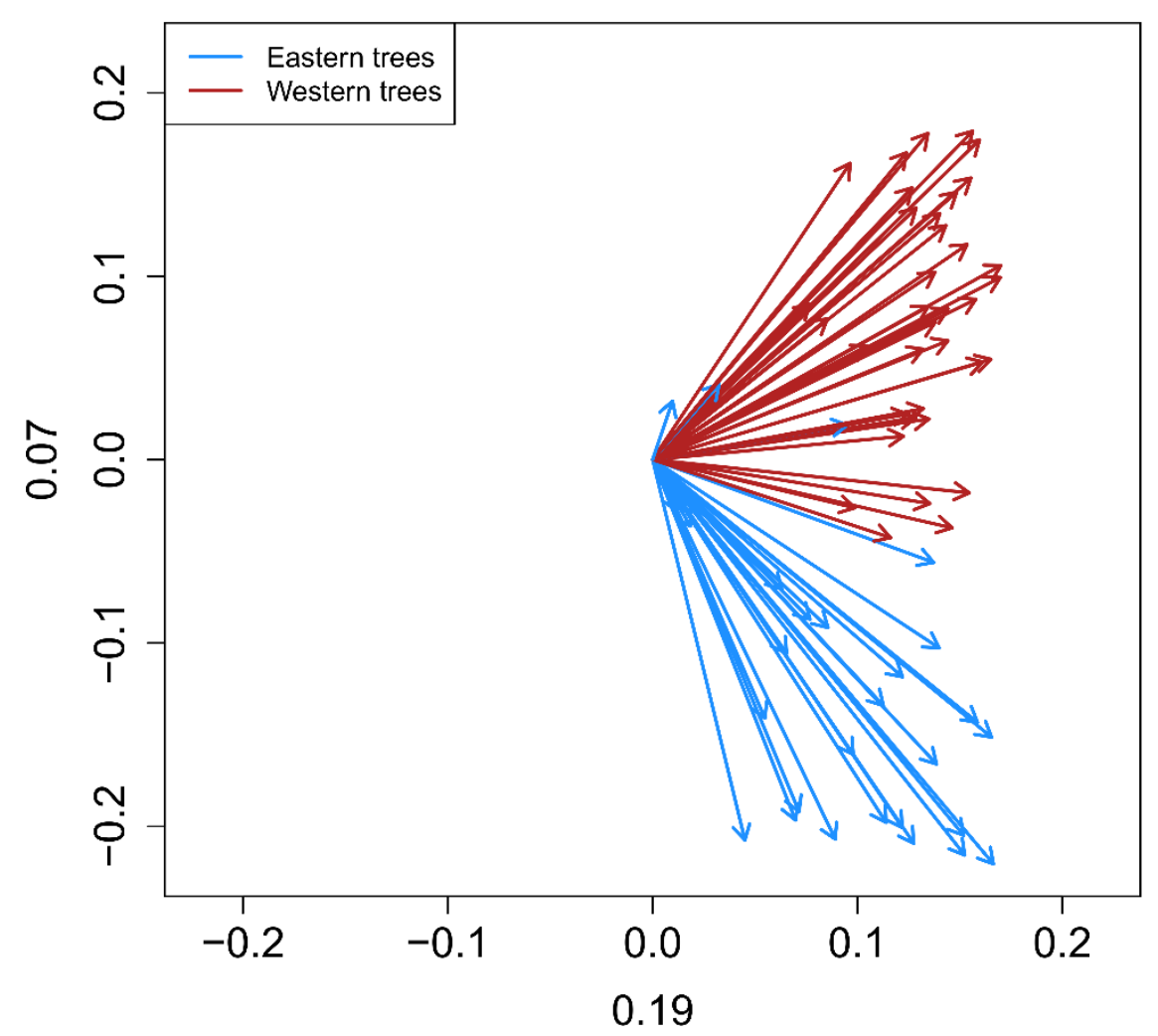

Figure 2.3. Loadings plot for the PCGA based on latewood width. Each arrow represents the loadings on the first two principal components from one tree. Value-labels on the $\mathrm{x}$ - and y-axes $(0.19$ and 0.07 ) represent the amount of explained variance by the respective component.

$D_{h}$ time series revealed no clear separation of loadings, neither across sites nor between the regions (Figure S2.5). Nevertheless, the application of PCGA only considering trees from the eastern sites, i.e. northeast - central east - southeast (NE - CE - SE), allowed grouping the trees according to the geographical categories based on $D_{h}$ (Figure 2.4). In this analysis, the common overlap period used for the PCGA was 102 years (1913-2014) involving 35 trees. A Kruskal-Wallis test indicated significant differences of loadings between trees from $\mathrm{NE}, \mathrm{CE}$ and $\mathrm{SE}(\mathrm{p}<0.01)$. At the same time, it was not possible to distinguish the CE trees from the other two sites on the basis of LW and NV (Figure S2.6). 


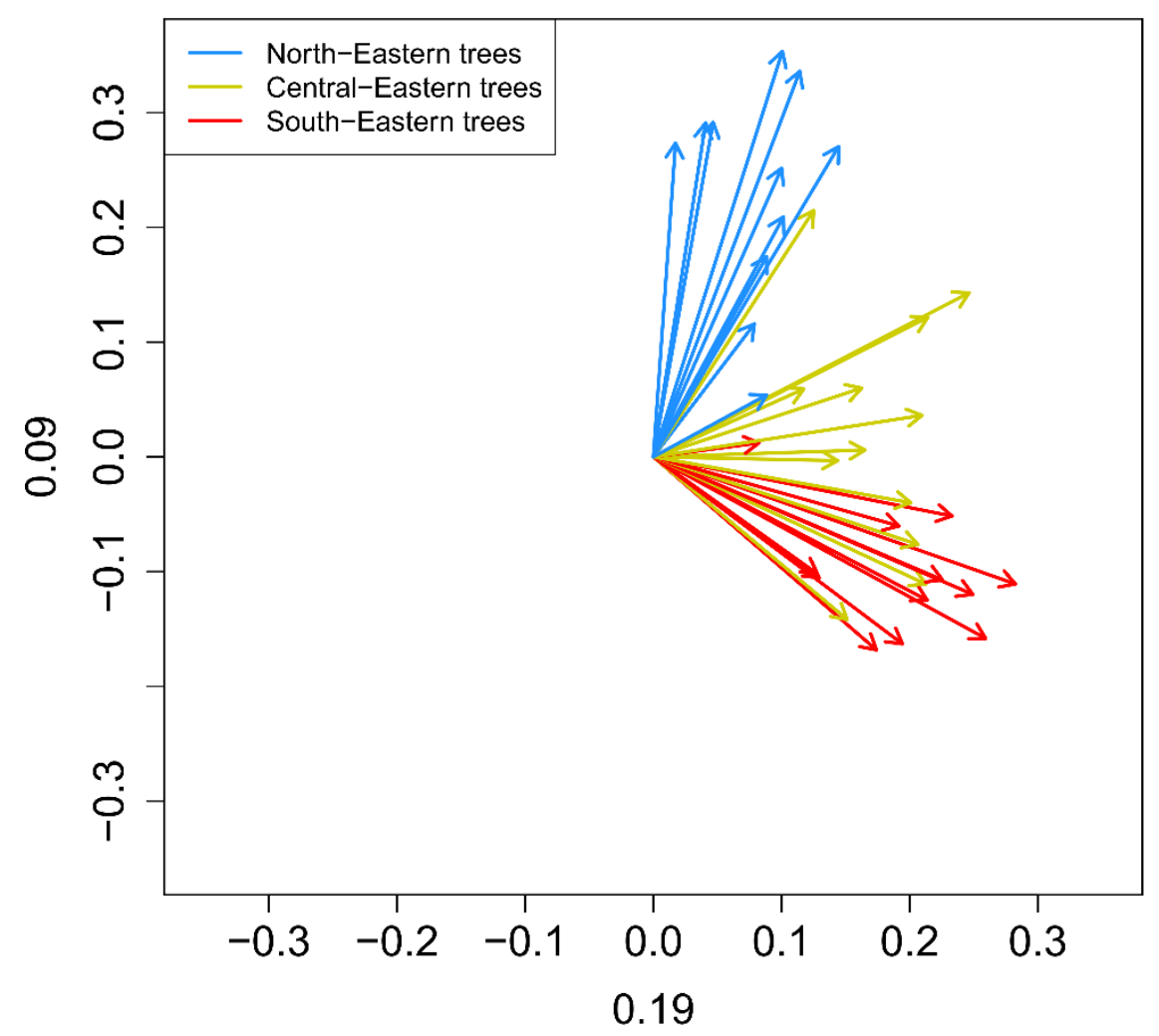

Figure 2.4. Loadings plot for the PCGA based on hydraulic diameter but only considering the eastern sites. Each arrow represents the loadings on the first two principal components from one tree. Valuelabels on the $\mathrm{x}$ - and $\mathrm{y}$-axes (0.19 and 0.09) represent the amount of explained variance by the respective component.

\subsubsection{Climate effect on PCGA gradient}

Correlation analyses between the gradient derived from the PCGA of LW time series and climate correlation scores indicate a strong effect for average June-July temperature on the PCGA gradient (Figure S2.7). Trees from the eastern sites were limited in LW formation by summer temperatures, whereas those from the western sites did not show any significant relationship between LW and early summer temperature (Figures 2.5a-b). 

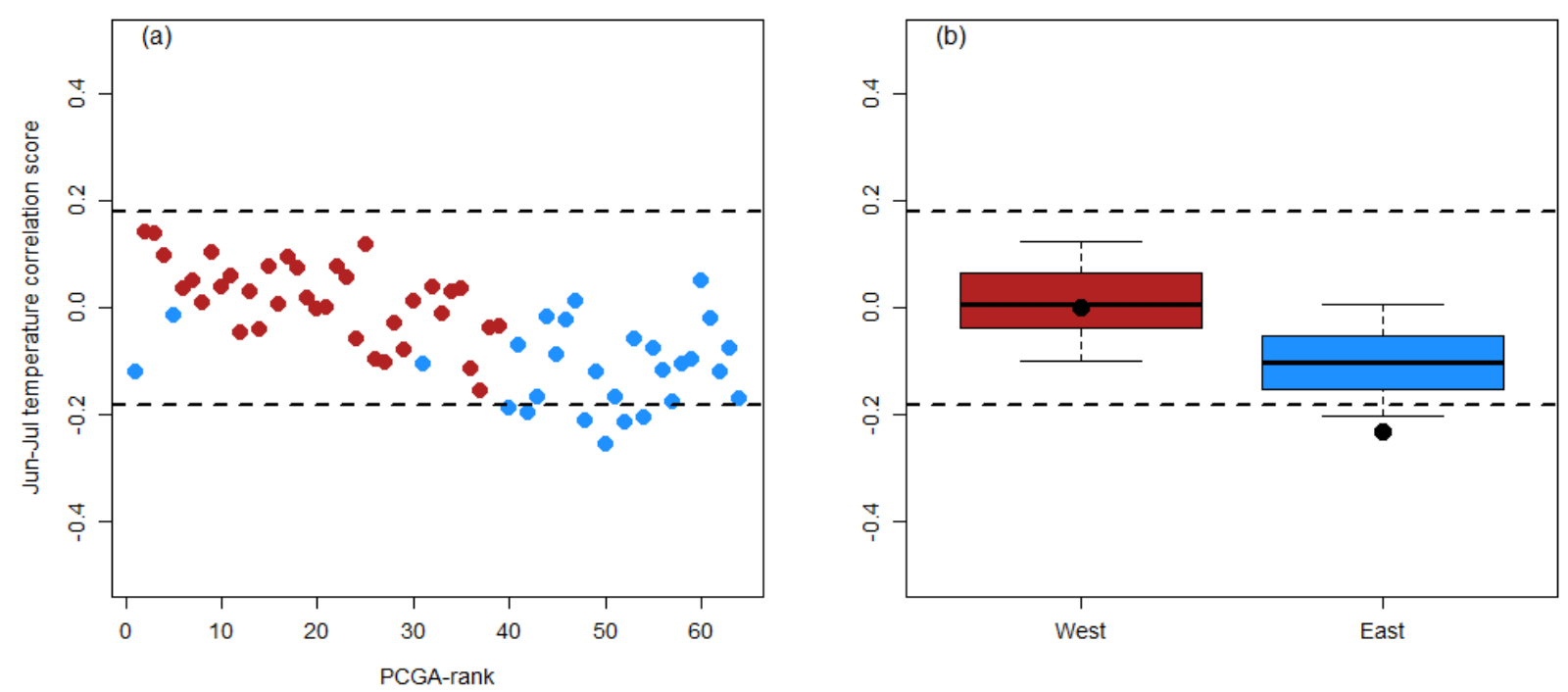

Figure 2.5. Relationships between climate correlations and the PCGA-rank derived from latewood time series. a) Correlations between latewood width time-series and average June-July temperatures for individual trees plotted against individual tree PCGA-ranks. PCGA-rank refers to the rank of a tree-ring series in the gradient defined by PCGA. b) Correlations of individual tree latewood width series with average June-July temperature, separated according to geographic origin. Black dots in b) represent the correlation coefficient of regional chronologies with average June-July temperature. Blue and red colors refer to eastern and western trees, respectively. Note that the y-axes span the interval from -0.5 to 0.5 .

The strength of the climate correlations also varied along the PCGA gradient as derived from $D_{h}$ (Figure S2.8). Vessel size $\left(D_{h}\right)$ of trees in NE, located at a lower elevation and closer to the sea was negatively correlated with February temperature, whereas for CE and SE correlations with February temperatures were weaker (Figure 2.6a-b). At the same time, $D_{h}$ of trees from SE, i.e. the higher and more southern sites was mostly positively correlated with average March-May temperature, while this relationship was not found for the other regions (Figure 2.6c-d). 

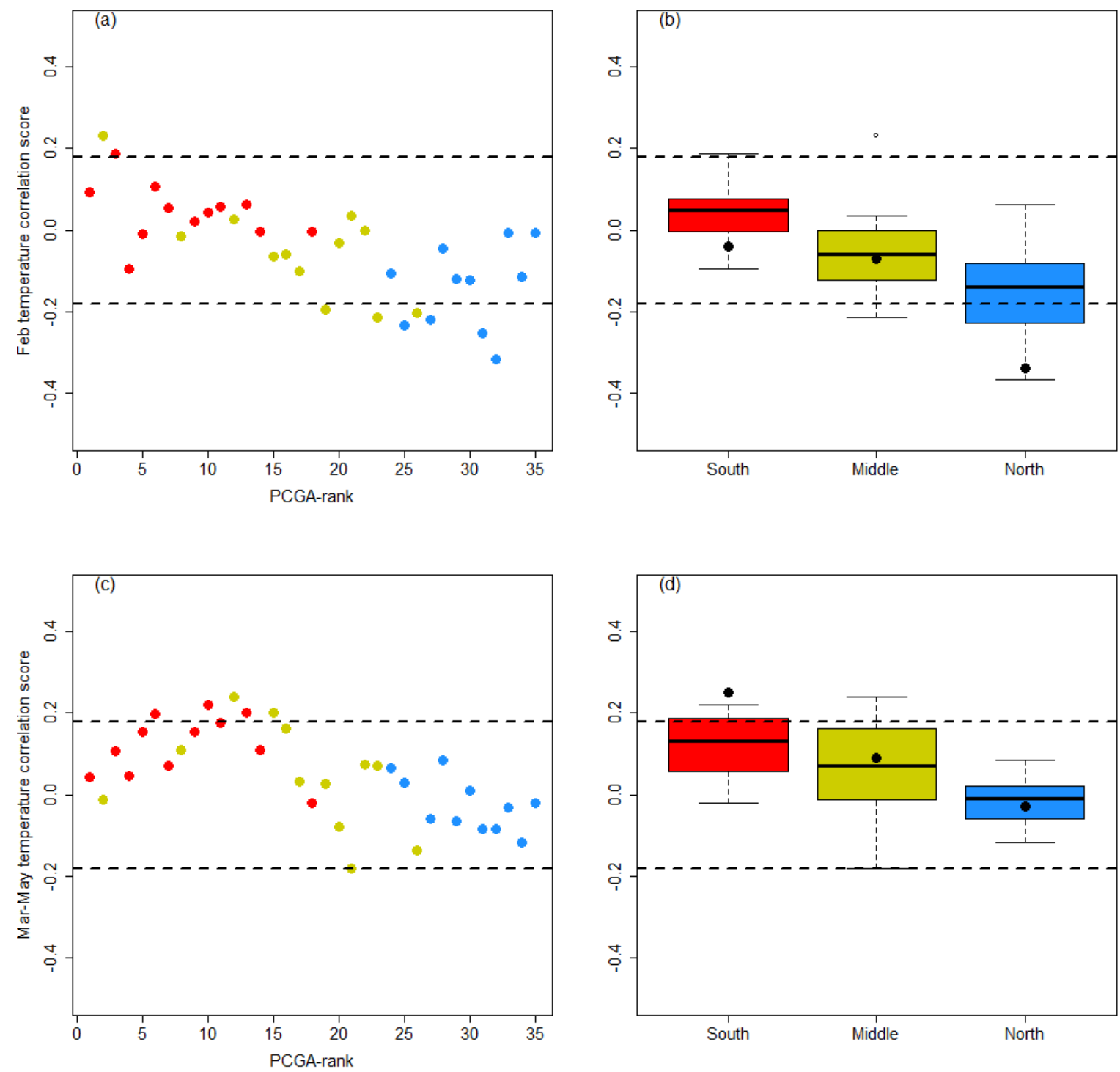

Figure 2.6. Relationships between climate correlations and the PCGA-rank derived from hydraulic diameter time series. a) Correlations between individual tree ranks (from the PCGA) with a correlation of individual tree hydraulic diameter series and mean February temperature. b) Correlations of individual tree hydraulic diameter series with February temperature, black dots represent the average correlation coefficient (after bootstrapping) of regional chronologies with February temperature. c) Correlations between individual tree ranks (from the PCGA) with a correlation of individual tree hydraulic diameter series and average March - May temperature. d) Correlations of individual tree hydraulic diameter series with average March - May temperature, with the black dot representing the average correlation coefficient (after bootstrapping) of regional chronologies with average March - May temperature. PCGA-rank in a) and c) refers to the rank of a hydraulic diameter series in the gradient defined by PCGA. Blue, gold and red colors refer to trees from northeastern, central eastern and southeastern sites, respectively. Dashed lines indicate 0.05 significance thresholds. Note that the y-axes span the interval from -0.5 to 0.5 .

PCGA indicated no species-specific effects on the observed gradient neither for LW nor for $D_{h}$ when involving all tree and oak species (Figure S2.9). This observation was supported 
when applying PCGA only to data from sites (GOR/GOY and BRR/BRY) where two species were co-existing (Figure S2.10).

\subsection{4. "Leave-one-out" analyses}

The "leave-one-out" analysis indicated that most trees were correctly assigned to their specific site of origin based on LW and $D_{h}$ (Table 2.3). That is, for LW $89 \%$ and $100 \%$ of eastern and western trees were assigned correctly, respectively. However, when analysing LW of only the eastern sites, no samples were assigned to the central east site. At the same time, $D_{h}$ chronologies successfully detected samples coming from the northeast (81\%), central east $(58 \%)$ or southeast $(91 \%)$.

Table 2.3. Rates of success for the leave one out approach. West, East indicate success rates of assigning trees to eastern and western sites, respectively. NE, CE and SE indicate success rates of assigning trees to north-, central and southeastern sites, respectively. For the latter, only trees from eastern sites were used.

\begin{tabular}{|l|c|r|r|r|r|}
\hline & West & East & \multicolumn{1}{c|}{ NE } & \multicolumn{1}{c|}{ CE } & \multicolumn{1}{c|}{ SE } \\
\hline LW & $100 \%$ & $89 \%$ & $81 \%$ & $0 \%$ & $100 \%$ \\
\hline $\boldsymbol{D}_{\boldsymbol{h}}$ & $61 \%$ & $35 \%$ & $81 \%$ & $58 \%$ & $91 \%$ \\
\hline
\end{tabular}

\subsection{Discussion}

\subsubsection{Added value of including complementary tree-ring variables into dendroprovenancing of oak}

Our results indicate that a higher precision of provenancing can be achieved for ring-porous oak wood when combining wood-anatomical variables such as LW and size of earlywoodvessels, rather than using TRW (or LW) alone, as is usually the case in dendroprovenancing (e.g. Haneca \& Debonne, 2012; Domínguez-Delmás et al., 2014). We found that annual variation patterns in LW and vessel $D_{h}$ of the study species were related to the biogeographic origin, especially for $D_{h}$. Both variables are probably reflecting different climatic signals (summer temperature for LW, winter and spring temperature for $D_{h}$ (Figures 2.5 and 2.6)), and therefore conditions during distinct periods of the year that largely determine the growth of oak in a specific area. LW allowed us to assign oaks to Basque (eastern) and Cantabrian (western) sites (Figure 2.3), whereas $D_{h}$ discriminated oak populations across a latitude and elevation gradient (NE-CE-SE in Figure 2.4), which also represented increasing continentality. Thus, combining LW and $D_{h}$ allows for resembling region-specific climate 
conditions over different parts of the growing season, which hence can be used to pinpoint the origin of the wood.

The proposed combined approach is also interesting for other areas, such as the maritime part of Central Europe, where classical dendroprovenancing of oak fails (Bridge, 2000), probably due to its complex signal in TRW (Bridge, 2012). Moreover, TRW and LW of $Q$. pyrenaica in northwestern Spain were found to be influenced by forest dynamics, which is hardly the case for earlywood vessels (Souto-Herrero et al., 2018a). This is especially interesting for archaeological studies, as wood used for (ship-) construction often comes from managed forests.

Wood-anatomical analyses can also be applied to waterlogged timber, whereas there still is a knowledge gap about the change of wood composition under waterlogged or buried conditions. Isotopic analyses do not necessarily improve wood provenancing precision of living trees as well (Vlam et al., 2018), therefore they need to be further tested for different species and regions. However, isotopes might contain site-specific signals complementary to wood-anatomical variables (e.g. maximum summer temperature and precipitation in $\delta^{13} \mathrm{C}$ and $\delta^{18} \mathrm{O}$ in temperate regions (Treydte et al., 2007), strontium - reflects the soil signature (Hajj et al., 2017)). A combined multi-proxy dendroprovenancing method thus is the most promising approach for future studies. And integration with other techniques recently tested for dendroprovenancing, e.g. Fourier transform infrared spectroscopy (Traore et al., 2018), seems to broaden this potential.

Our results also demonstrate that a tree-centered approach, i.e. using single trees as a main source of information to understand variability in growth responses, as proposed for ecological studies (Sass-Klaassen et al., 2016) allows pinpointing tree origin at both interand intra-regional scales. Such an approach also overcomes the problem that often only a few trees are available for dating and provenancing pieces of art (paintings, musical instruments, etc.).

\subsubsection{Spatial variation of climatic signal in different tree-ring variables}

\subsubsection{Climatic signal in latewood width}

Analyses of spatial variation of the climatic signal revealed that the main factor discriminating (based on LW time series) tree origin into Basque (eastern) and Cantabrian 
(western) sites was average June-July temperature (Figure 2.5a). The effect of average JuneJuly temperature on tree growth was changing from no significant in the west to significantly negative in the east (Figure 2.5b, Figure S2.11) with the signal mostly driven by the lowest and highest sites. In general, radial growth of deciduous oaks in the Mediterranean is negatively related to high temperature during summer (Tessier et al., 1994; Rozas, 2001, 2005; Souto-Herrero et al., 2018a), i.e. the period with maximum growth activity (Castagneri et al., 2017). High summer temperature increases drought stress due to elevated evapotranspiration, leading to reduction of photosynthesis, favouring reserve storage and consequently slowing of growth rates (Bréda et al., 2006; Sala et al., 2012). In contrast to oaks from Basque (eastern sites), trees from Cantabria (western sites) did not show any significant response to summer temperature (Figure 2.5b). The lack of summer signal was observed before in oaks growing in Northern Spain under an Atlantic climate, and was explained by forest dynamics, i.e. disturbances and management activities resulting in abrupt growth changes which probably masked the effect of climate (Souto-Herrero et al., 2018a; Souto-Herrero et al., 2018b). At the same time, LW of trees both from eastern and western regions showed positive correlations with summer precipitation (Figure S2.12), a common signal for the southeast of Central Europe (Čufar et al., 2014) and the Mediterranean region (Tessier et al., 1994; Nola, 1996).

\subsubsection{Climatic signal in earlywood vessels across a latitudinal/topographic gradient}

The grouping of the oaks growing in the Basque country (eastern sites) into a northern (NE), central (CE) and southern (SE) group was reflected in a varying response of $D_{h}$ to temperature in February and March-May (Figure 2.6). Although oak trees initiate cambial division in February/middle March (see Pérez-de-Lis et al. (2016) and González-González et al. (2013) for $Q$. robur and $Q$. pyrenaica), high winter temperatures are apparently related to the formation of smaller vessels. This effect was strongest in oaks from NE, and has been reported earlier for Castanea sativa Mill. in the Swiss Alps (Fonti \& García-González, 2004; Fonti et al., 2007) and for Q. petraea and Q. pyrenaica from Northern Iberia (GonzálezGonzález et al., 2014). A negative February temperature effect has been previously explained by the temperature sensitivity to the plant hormone auxin (Fonti et al., 2007), which controls the cambial activity and is involved in vascular differentiation (Fukuda, 2004; Kepinski, 2006). High winter temperature is assumed to increase cell sensitivity to auxin, 
resulting in an earlier and faster process of vessel differentiation, which leads to the formation of smaller vessels (Aloni \& Zimmermann, 1983). This temperature effect on vessel size can also be attributed to carbohydrate dynamics. Higher winter temperatures enhance respiration rates and thus can lead to the depletion of assimilates stored. As cambial resumption of ring-porous oaks starts before bud break (Kudo et al., 2014; Copini et al., 2016; Pérez-de-Lis et al., 2016), and vessel functionality occurs just before the leaf expansion (Kitin \& Funada, 2016; Guada et al., 2018) the formation of earlywood vessels relies on the amount of stored carbohydrates from the previous growing season. A shortage of carbohydrates as an effect of high winter temperatures can therefore be associated with the formation of smaller vessels (González-González et al., 2015). In contrast, high average temperatures during March-May have a positive effect on vessel size at the southeastern (the most inland) sites. During spring, warmer conditions are known to foster bud break, and thus produce new sources of auxin (Sorce et al., 2013) to be transported along the stem, so that cambial activity is initiated (Schrader et al., 2003) thereby favouring vessel expansion (Uggla et al., 1996).

\subsubsection{Species effect on variation of selected tree-ring variables}

The ring-porous oak species used in this study are very similar if not identical in their wood structure (Schweingruber \& Baas, 1990; Crivellaro et al., 2013) but differ in their ecology, and consequently in their geographical distribution. However, this difference was not reflected in the variation of their ring width and vessel size patterns as indicated by the PCGA (Figure S2.9a-b), which shows an overriding effect of site-specific conditions. It is evident that differences in species ecology determine their distribution in the study area, which is probably the reason why we did not find sites where all four species coexist. In fact, the two sub-Mediterranean oaks ( $Q$. pyrenaica and $Q$. faginea), apparently the most xeric species, could not be compared to each other because they have opposite soil requirements (acidic and basic, respectively). Therefore, we could only check for species-specific differences on two coexisting species ( $Q$. petraea and $Q$. pyrenaica) at two study sites.

Our results support the impression that both ring width and vessel size respond more to specific site conditions than to genetic background (Figure S2.10). Furthermore, at both sites where we could compare two species, one of them was $Q$. pyrenaica. This is a subMediterranean mountain species, with specific adaptations to these drier environments: xerophytic leaf habit, late flushing, and a more conservative wood formation strategy 
compared to nemoral oak species (Pérez-de-Lis et al., 2016). Despite these differences, its growth responses were similar to those of the other species occurring at the same sites. This is in contrast with previous works comparing nemoral and sub-Mediterranean oaks at the same site, where species-specific responses were observed (González-González et al., 2014). The inclusion of wood anatomical features and their directional and plausible climate responses across biogeographic gradients allow for more precise provenancing of oak wood in Northern Spain. These results are probably extendable to other areas, and a larger set of species and wood anatomical proxies (e.g., wood density (Wilson et al., 2017); parenchyma fractions (Morris et al., 2018)) should be explored. Moreover, as ring-porous oak species in Northern Spain exhibit specific biogeographical distributions, integration of DNA analyses for species identification or genome sequencing (Schroeder et al., 2016) could further supplement the tool-box for dendroprovenancing. We believe that with a multi-variable approach we achieve higher precision in dendroprovenancing and pinpoint the origin of timber on a finer scale.

\subsection{Conclusion \& outlook}

We showed that a novel approach - comprising multiple variables (latewood width and vessel area) and combining multivariate techniques (PCGA) with statistical validation procedures (leave-one-out) - can increase the precision of pinpointing the origin of oak timber. Further studies emphasizing on other regions, species (e.g. coniferous trees), and tree-ring variables (e.g. stable isotopes, wood density) are however needed to extend our knowledge on the ability of this approach to the refine dendroprovenancing. In addition, an individual tree-based approach may reveal more insights into spatial variations of climategrowth relationships, most likely depending on specific site conditions.

\section{Acknowledgements}

This research work is part of the ForSEAdiscovery project (Forest Resources for Iberian Empires: Ecology and Globalization in the Age of Discovery) and was funded by the Marie Curie Actions program of the European Union (PITN-2013-607545). This work was supported by a postdoc fellowship of the German Academic Exchange Service (DAAD). We thank Marta Domínguez Delmás, Fadi Hajj, and Mohamed Traoré for their great help in the field and in the lab. Also, many thanks to Manuel Souto-Herrero for introducing the wood preparation techniques and software for image analyses. 


\section{SUPPORTING INFORMATION}

AZK

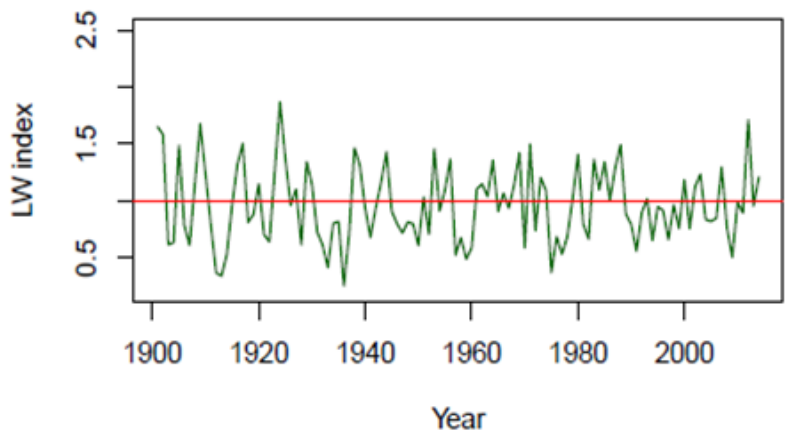

OIR

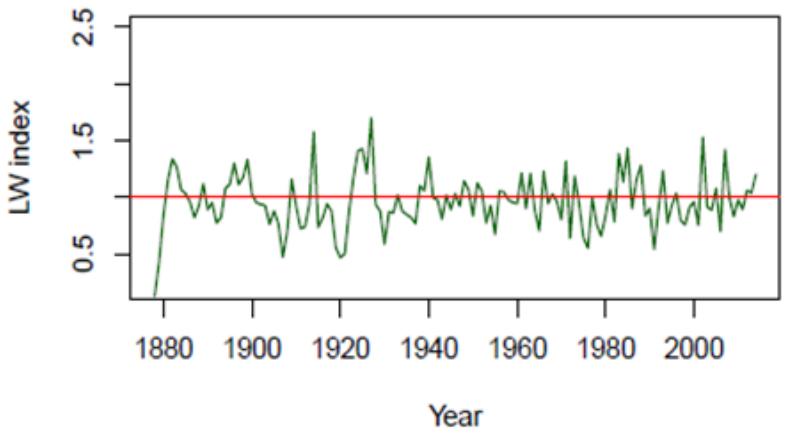

GOY

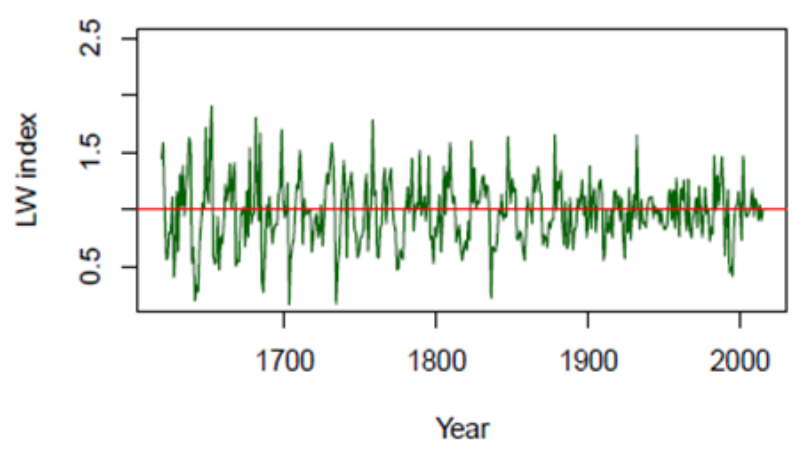

UZK

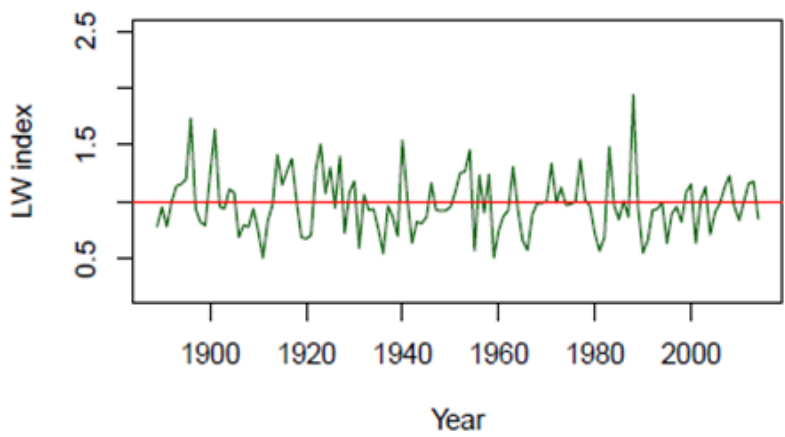

GOR

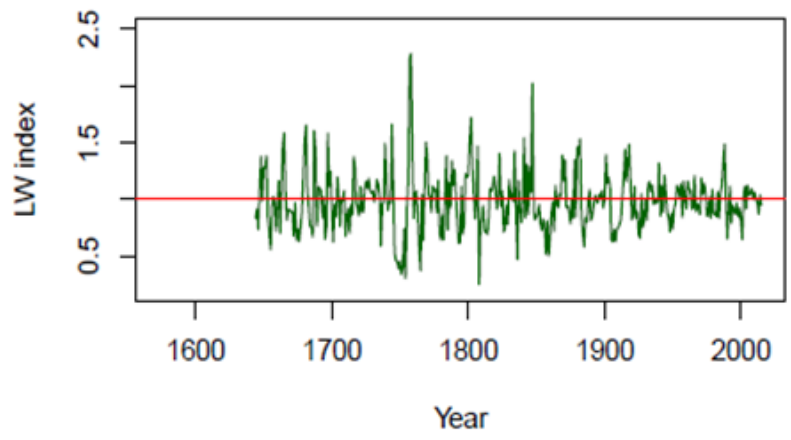

SVA

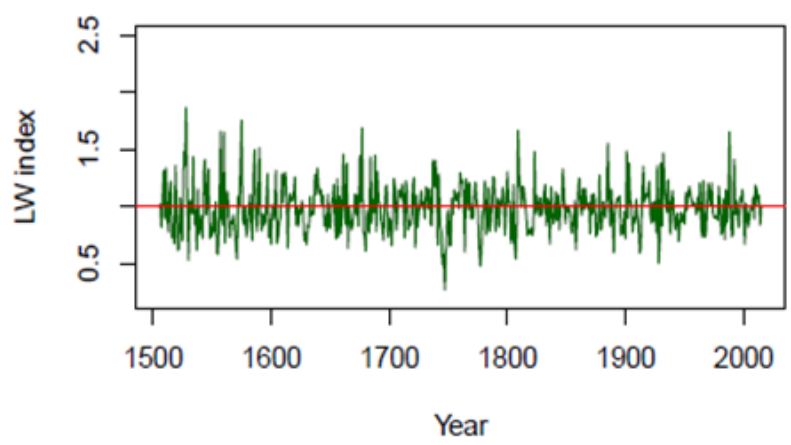


OTE

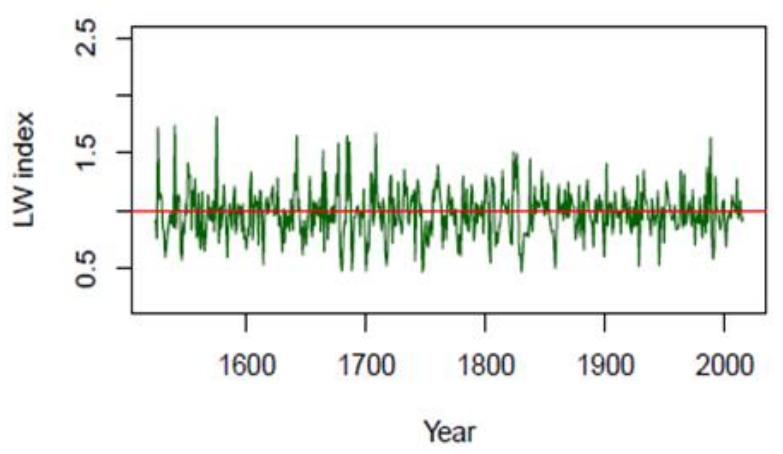

ORT

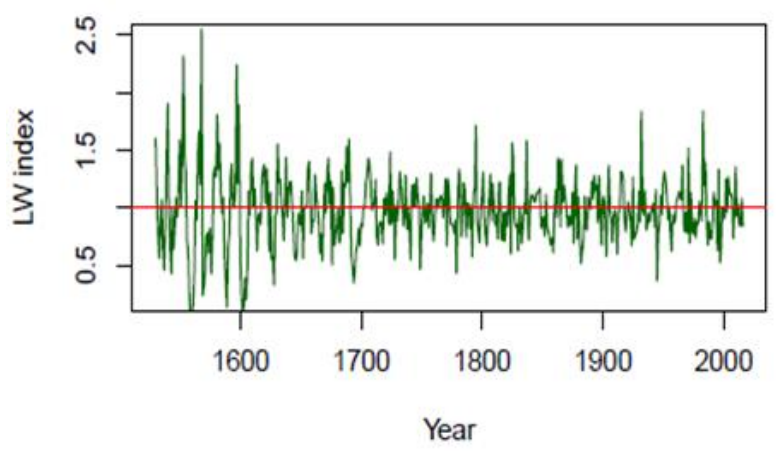

BRY

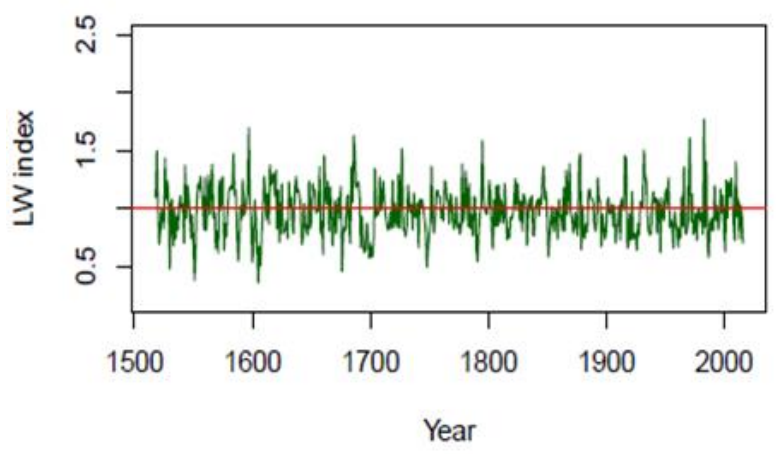

ONQ

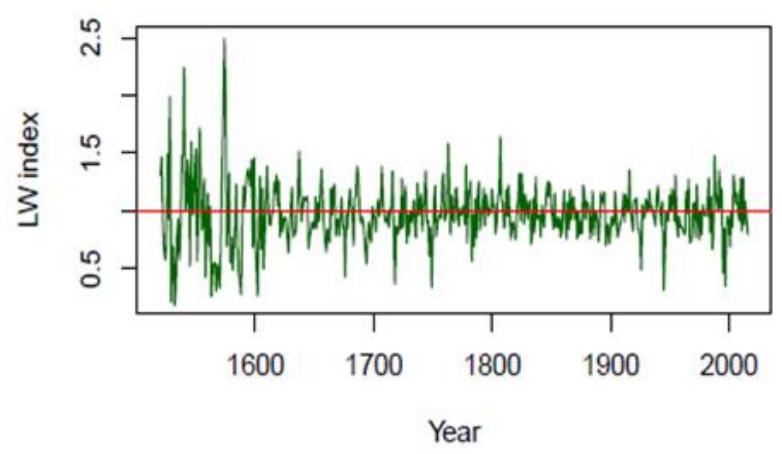

BRR

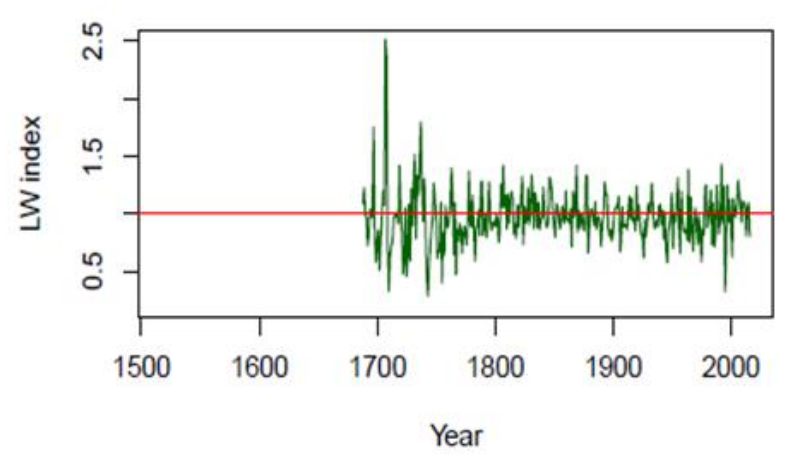

Figure S2.1. Standardized latewood width chronologies per study site. Green refers to latewood width chronology, red - reference line of a value 1 . Title of graph refers to the corresponding study site. For explanation of the abbreviations of sites' names see Table 2.1. 
AZK

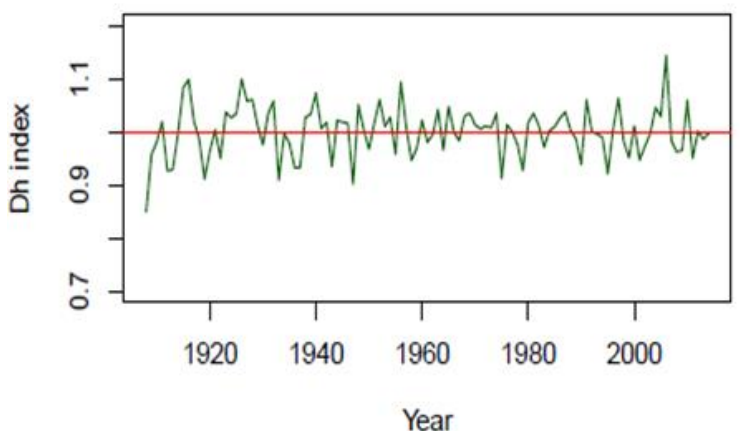

OIR

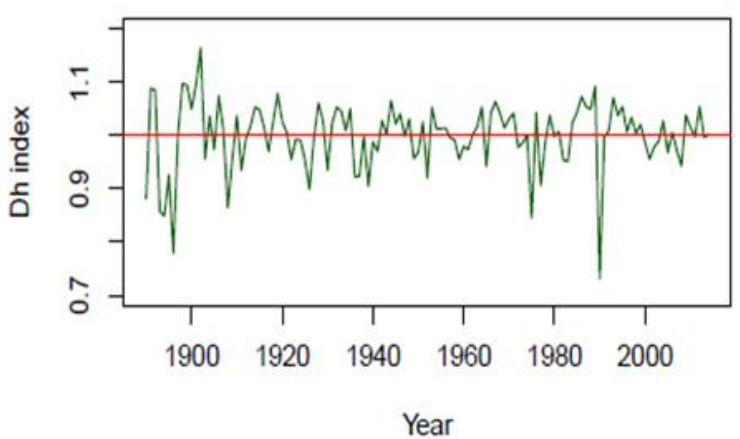

GOY

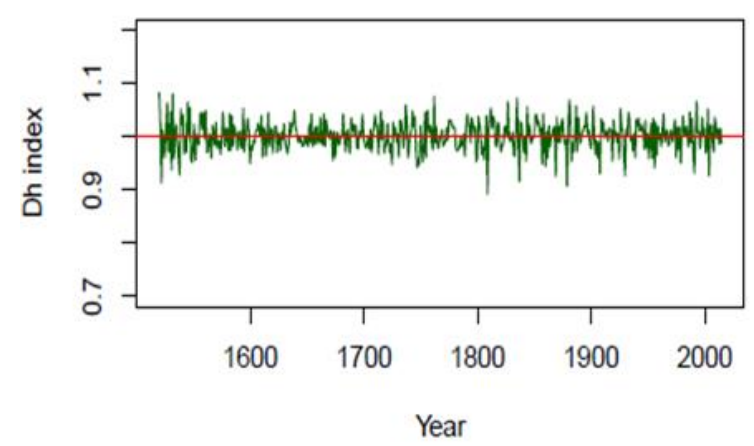

UZK

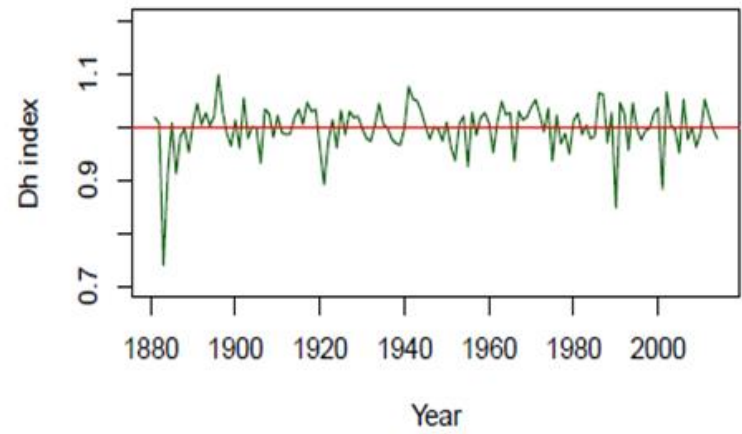

GOR

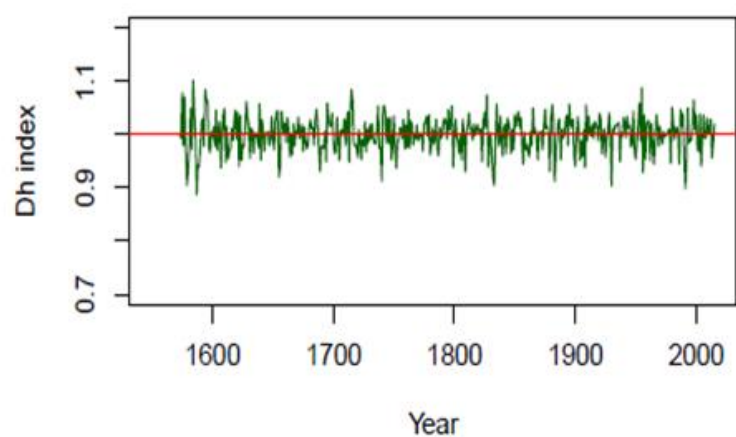

SVA

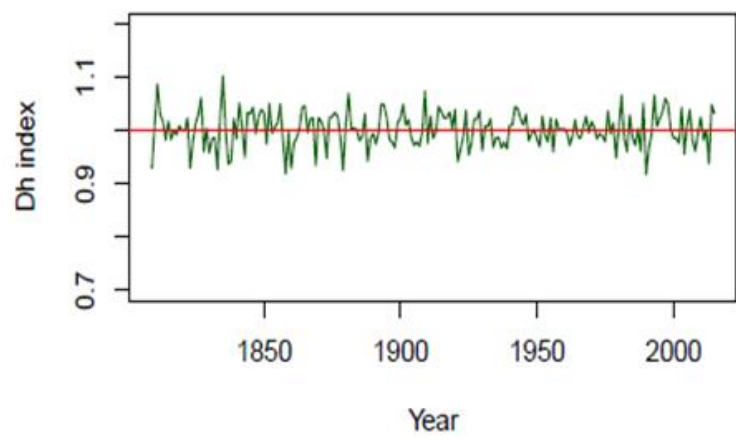


OTE

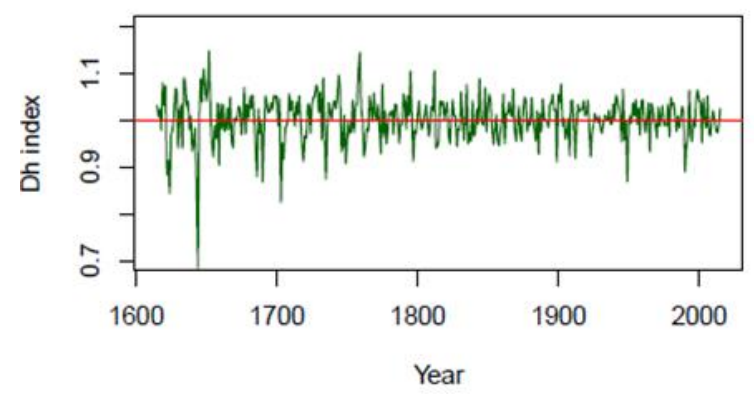

ORT

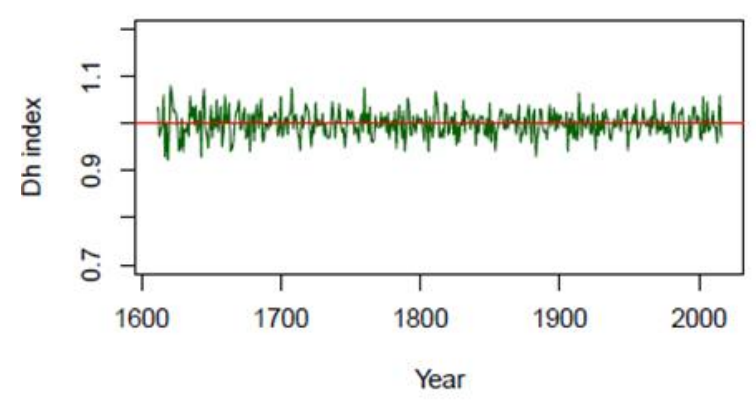

BRY

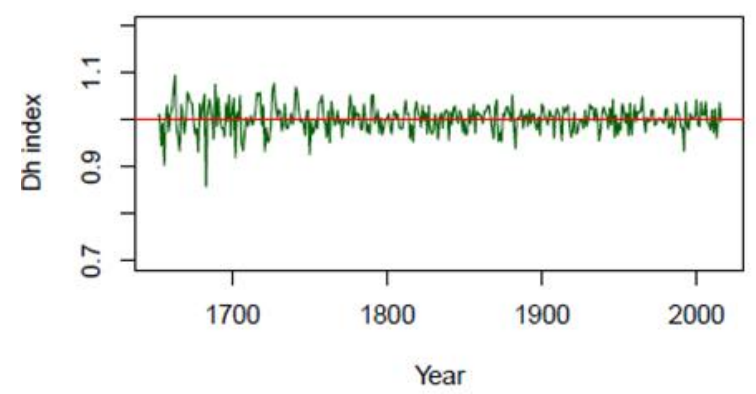

ONQ

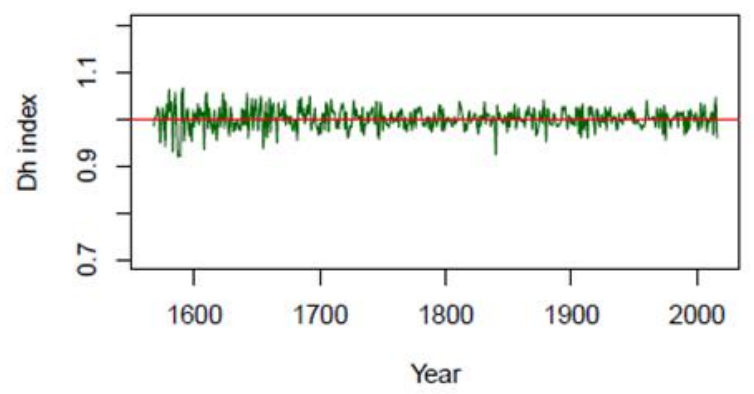

BRR

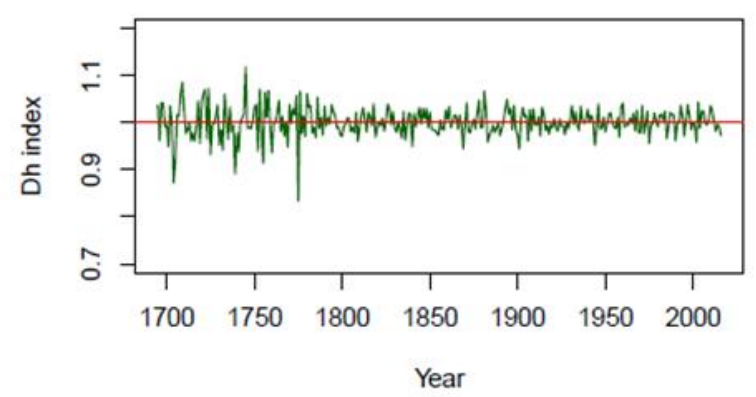

Figure S2.2. Standardized hydraulic diameter chronologies per study site. Green refers to hydraulic diameter chronology, red - reference line of a value 1. Title of graph refers to the corresponding study site. For explanation of the abbreviations of sites' names see Table 2.1. 
Table S2.1. Dendrochronological indicators of tree-ring width chronologies per study site

\begin{tabular}{l|cccccc} 
& $\begin{array}{l}\text { First } \\
\text { year }\end{array}$ & $\begin{array}{c}\text { Last } \\
\text { year }\end{array}$ & EPS & MS & Glk & rbar \\
\hline AZK & 1901 & 2014 & 0.8 & 0.34 & 0.69 & 0.35 \\
UZK & 1889 & 2014 & 0.76 & 0.32 & 0.61 & 0.27 \\
OIR & 1878 & 2014 & 0.75 & 0.25 & 0.62 & 0.27 \\
GOR & 1644 & 2015 & 0.73 & 0.22 & 0.61 & 0.31 \\
GOY & 1619 & 2015 & 0.88 & 0.19 & 0.65 & 0.32 \\
SVA & 1506 & 2015 & 0.91 & 0.17 & 0.63 & 0.31 \\
OTE & 1524 & 2015 & 0.92 & 0.17 & 0.61 & 0.36 \\
ONQ & 1520 & 2016 & 0.87 & 0.16 & 0.63 & 0.33 \\
ORT & 1530 & 2016 & 0.9 & 0.19 & 0.64 & 0.34 \\
BRR & 1688 & 2016 & 0.75 & 0.18 & 0.62 & 0.21 \\
BRY & 1518 & 2016 & 0.73 & 0.18 & 0.58 & 0.19
\end{tabular}

First year and Last year indicate the first and the last year of a chronology, respectively EPS - expressed population signal

MS - year-to-year variability in tree-ring width

Glk - similarity between two chronologies based on the first difference between successive tree rings

rbar - mean series inter-correlation 
AZK

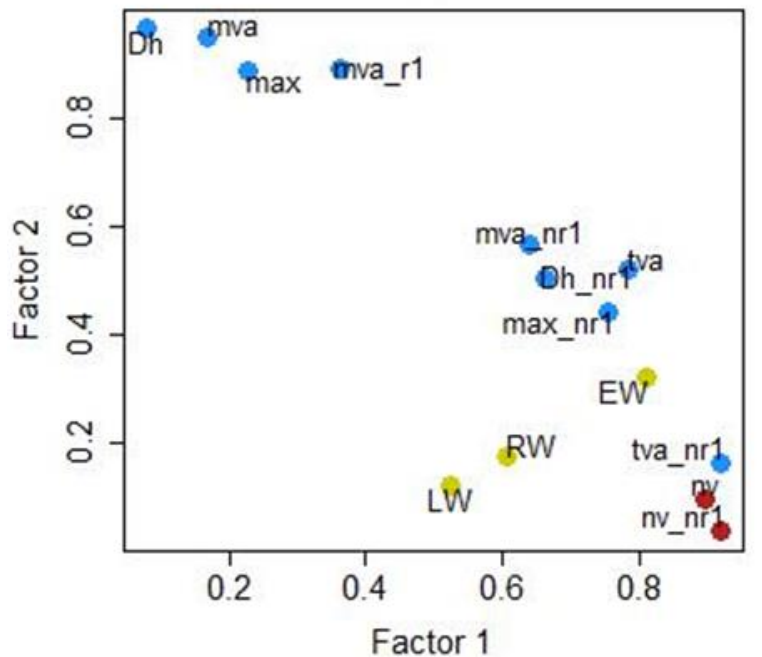

BRR

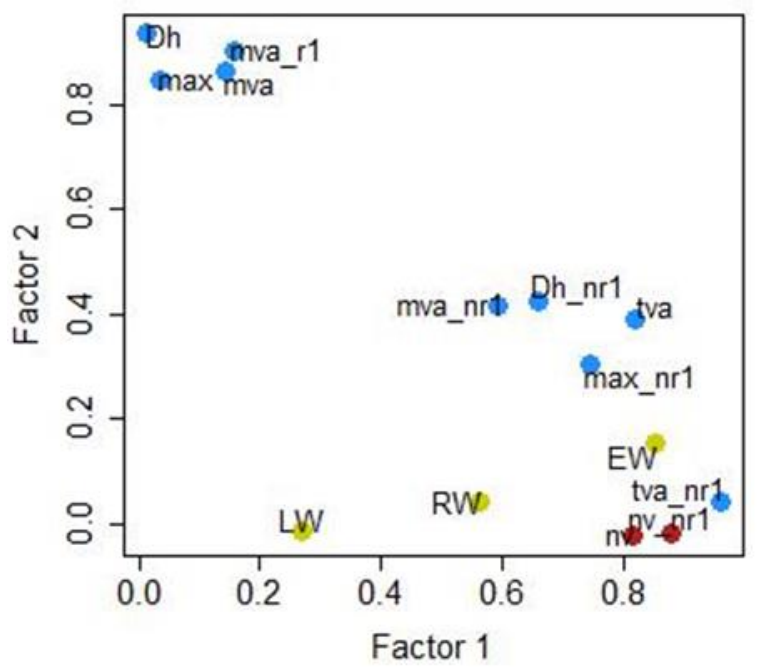

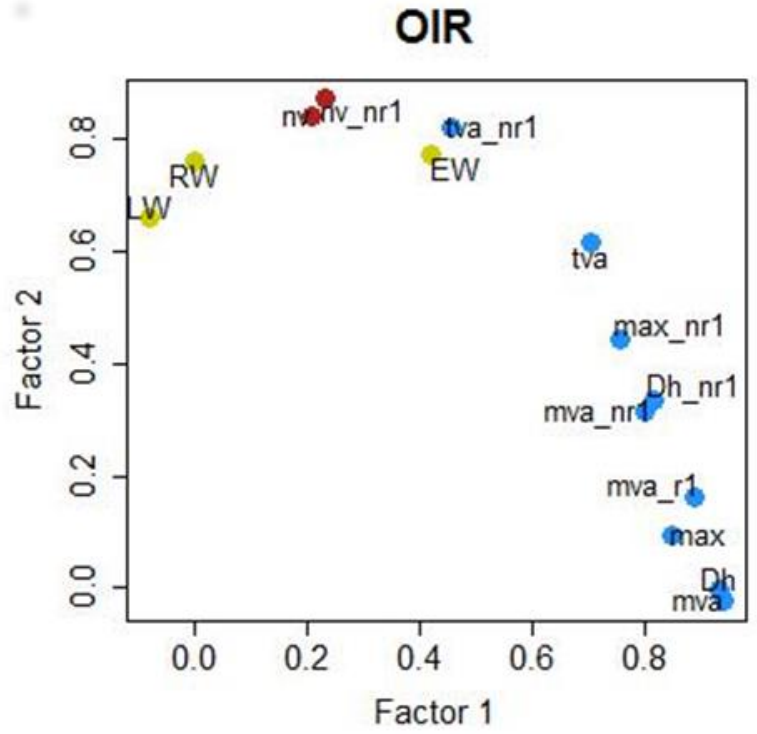

BRY

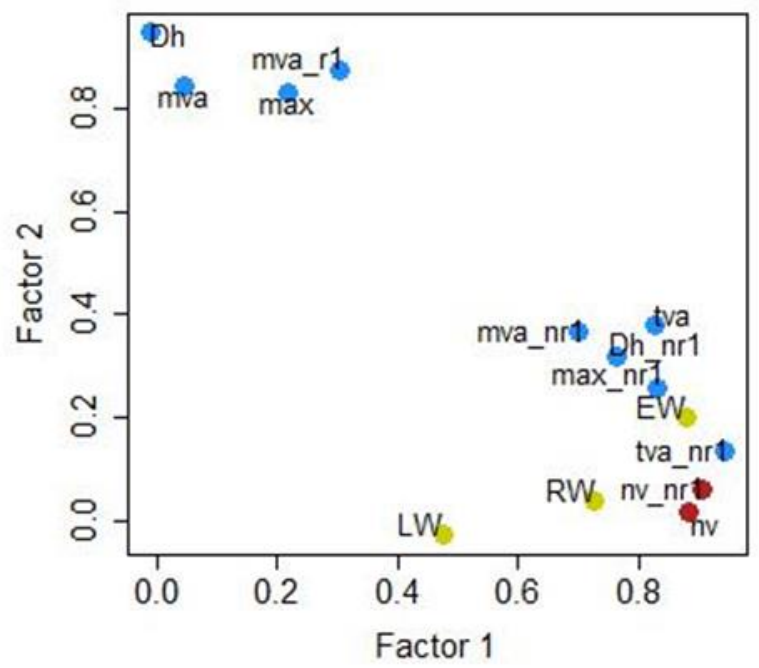


UZK

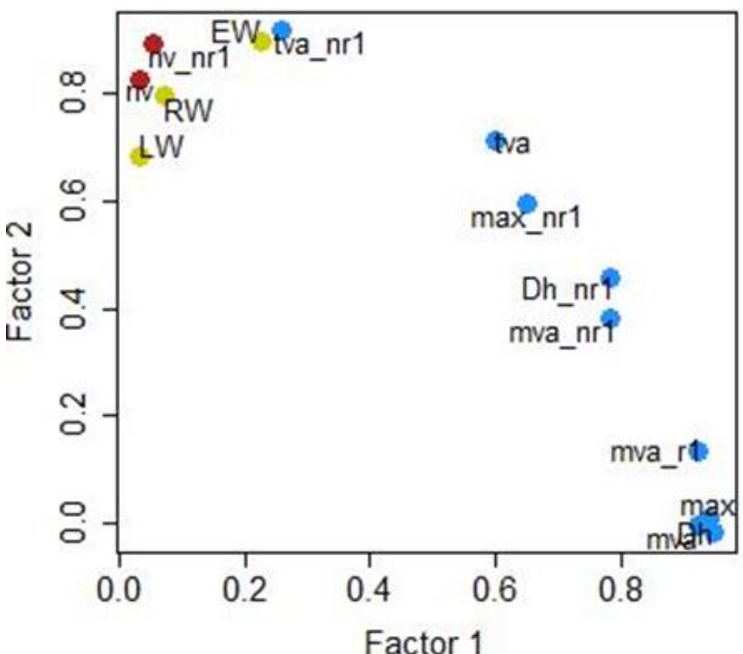

GOY

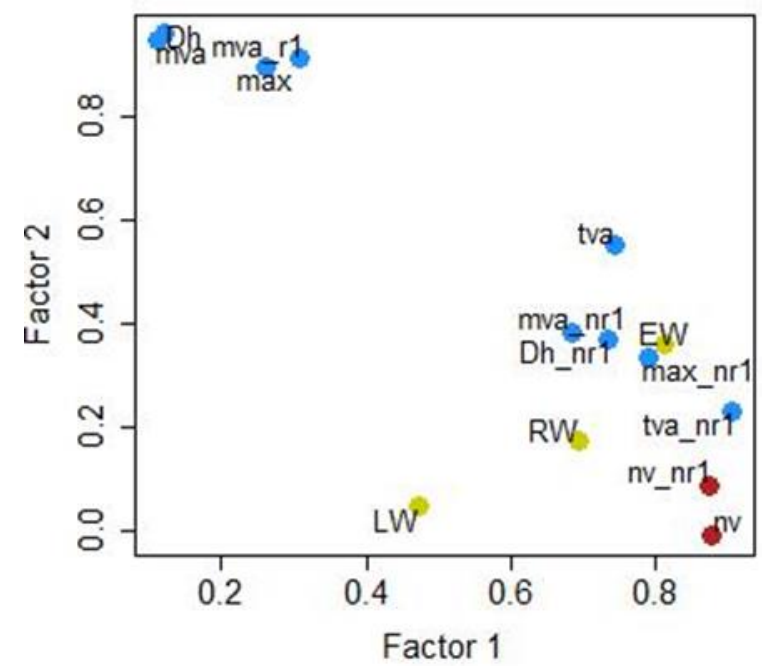

GOR

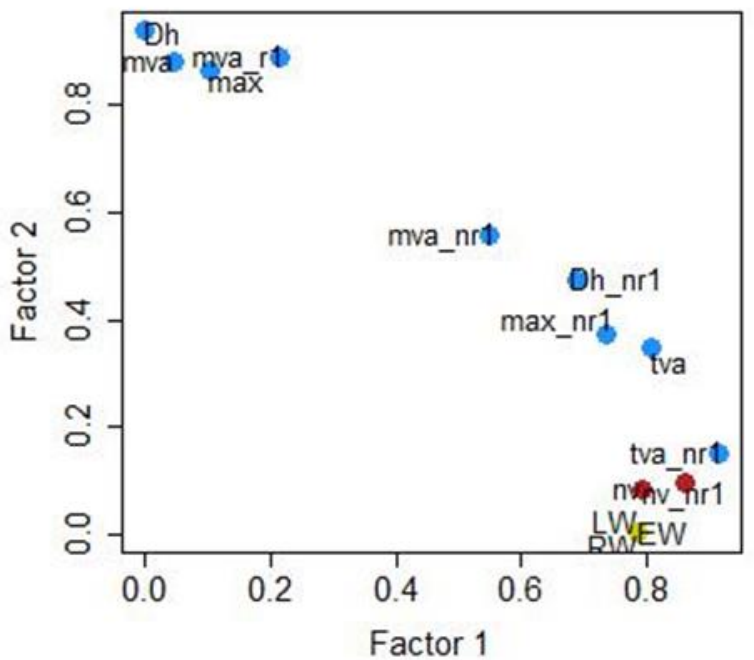

OTE

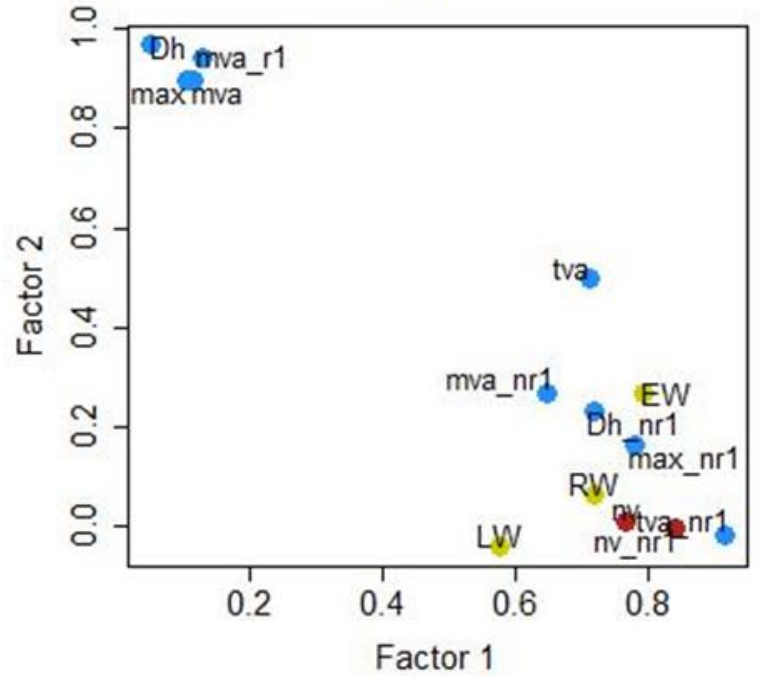


SVA

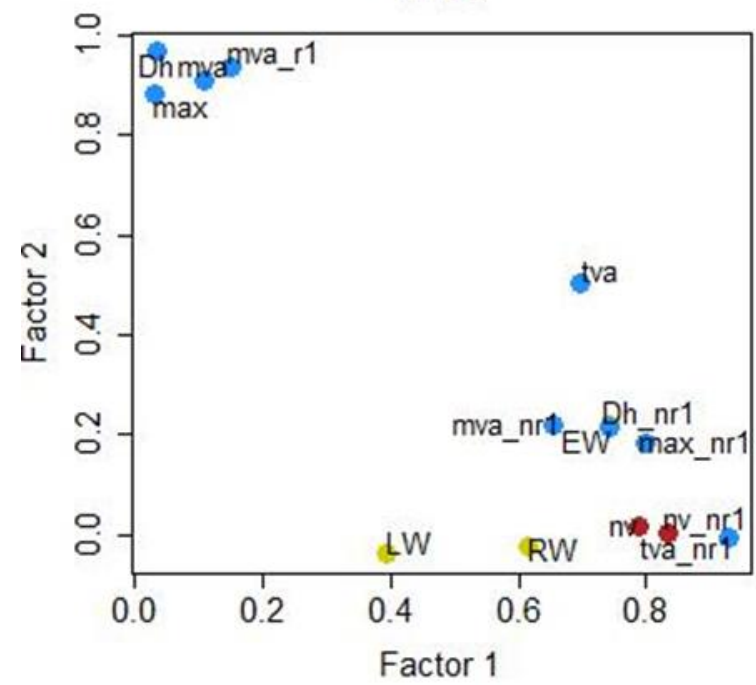

ORT

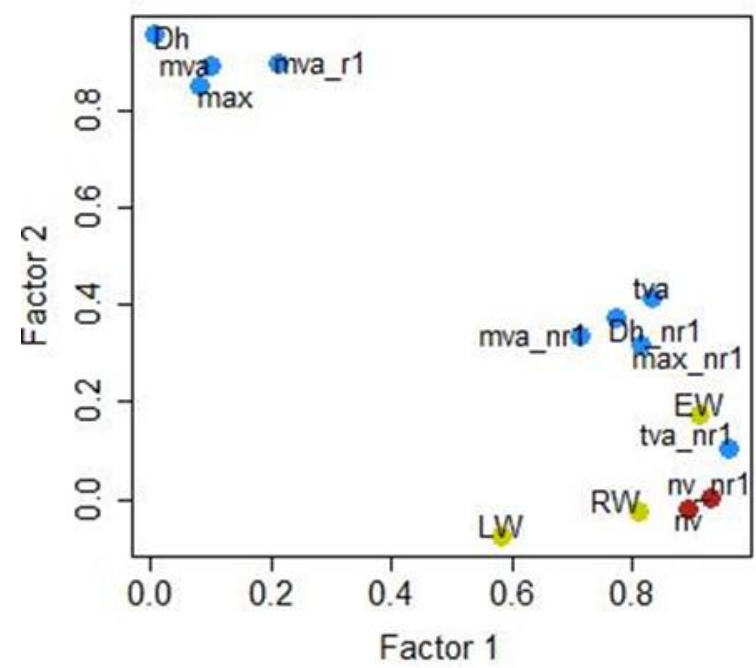

ONQ

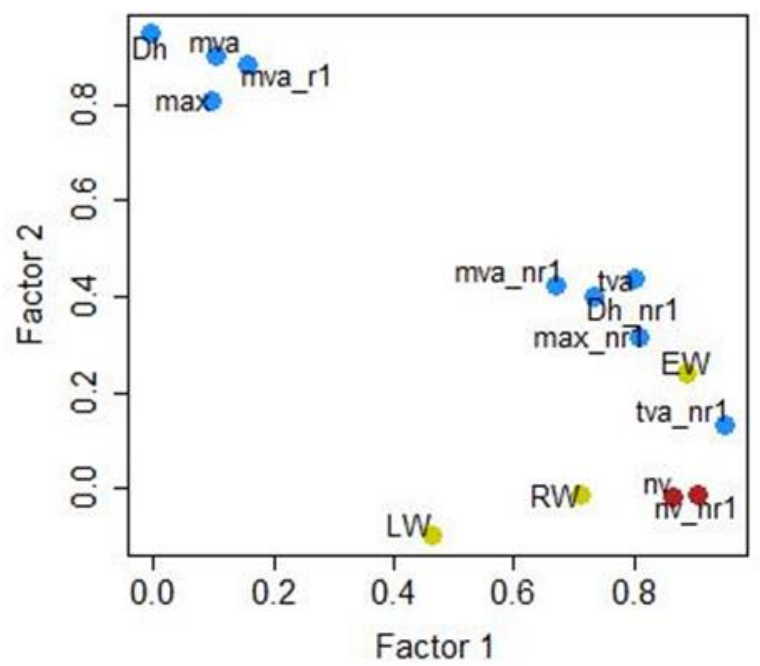

Figure S2.3. Loadings plot for the PCA of 14 tree-ring variables measured or calculated per each study site . $D_{h}$-hydraulic diameter, mva - mean vessels area, max- maximum vessel size, nv - number of vessels, tva - total vessels area, mva_r1 - mean vessels area of the first row vessels, $D_{h} \_$nr 1 - hydraulic diameter of vessels belonging not to the first row, mva_nr1 - mean vessels area of vessels belonging not to the first row, max_nr1 - maximum vessel size of vessels belonging not to the first row, nv_nr1 number of vessels belonging not to the first row, tva_nr1 - total vessels area of vessels belonging not to the first row, RW - ring width, EW - earlywood width, LW - latewood width. Blue, red and yellow colours indicate belonging of the variable to the groups related to vessels size, number of vessels and tree-ring widths, respectively. Title of graph refers to the corresponding study site. For explanation of the abbreviations of sites' names see Table 1. 


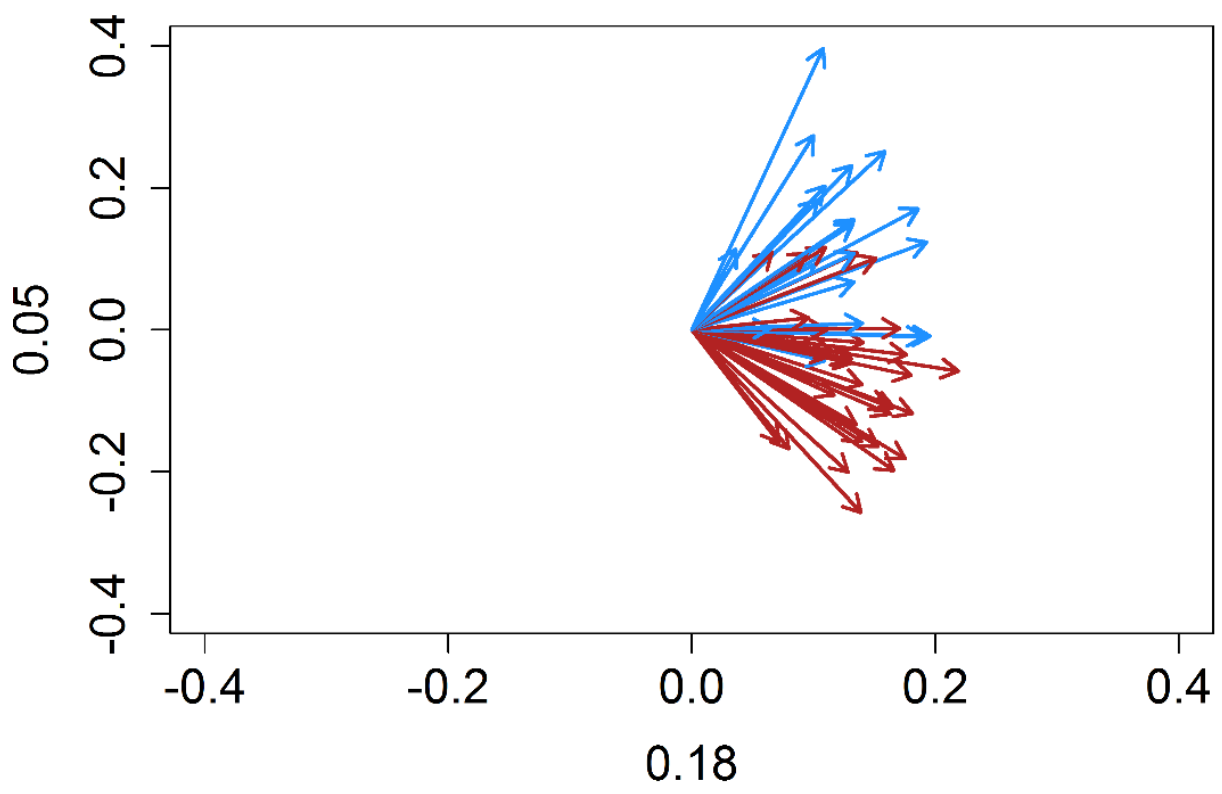

Figure S2.4. Loadings plot for the PCGA based on number of vessels. Each arrow represents the loadings on the first two principal components from one tree. Values on the $\mathrm{x}$ - and $\mathrm{y}$-axes represent the amount of explained variance by the respective component. Blue and red arrows refer to Eastern and Western trees, respectively.

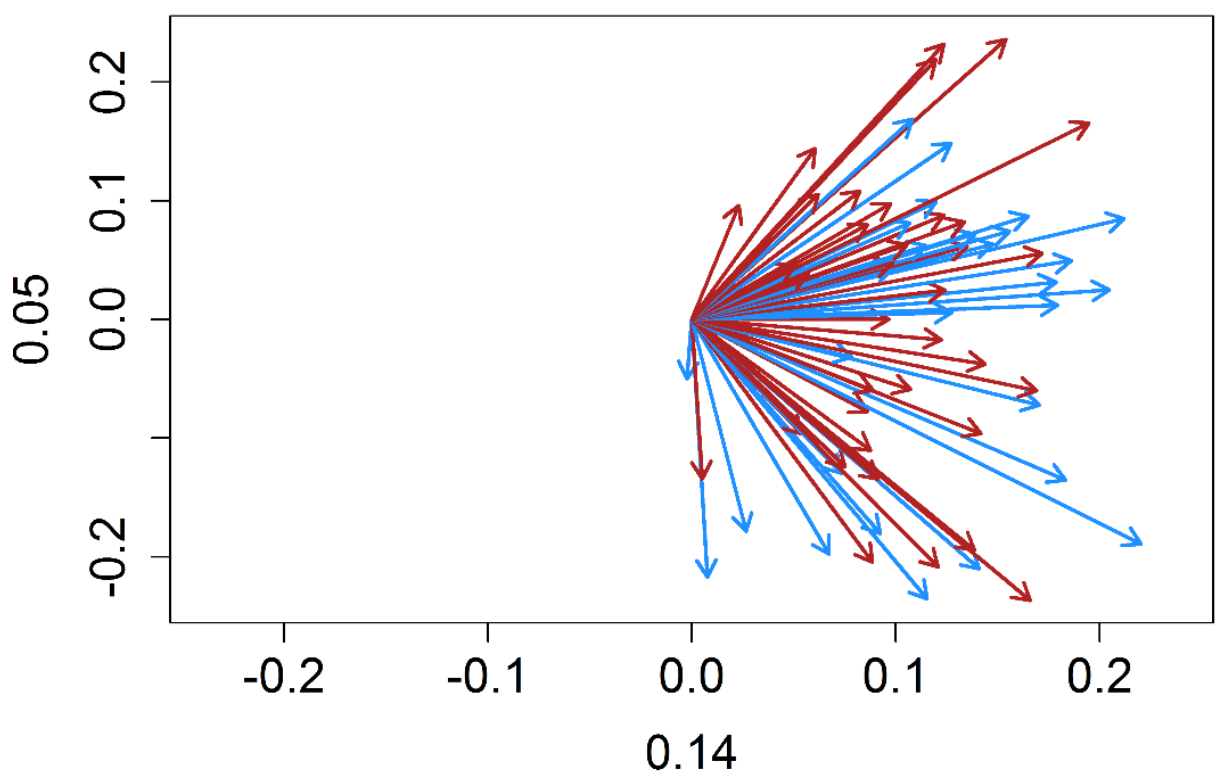

Figure S2.5. Loadings plot for the PCGA based on hydraulic diameter. Each arrow represents the loadings on the first two principal components from one tree. Values on the $\mathrm{x}$ - and $\mathrm{y}$-axes represent the amount of explained variance by the respective component. Blue and red arrows refer to Eastern and Western trees, respectively. 

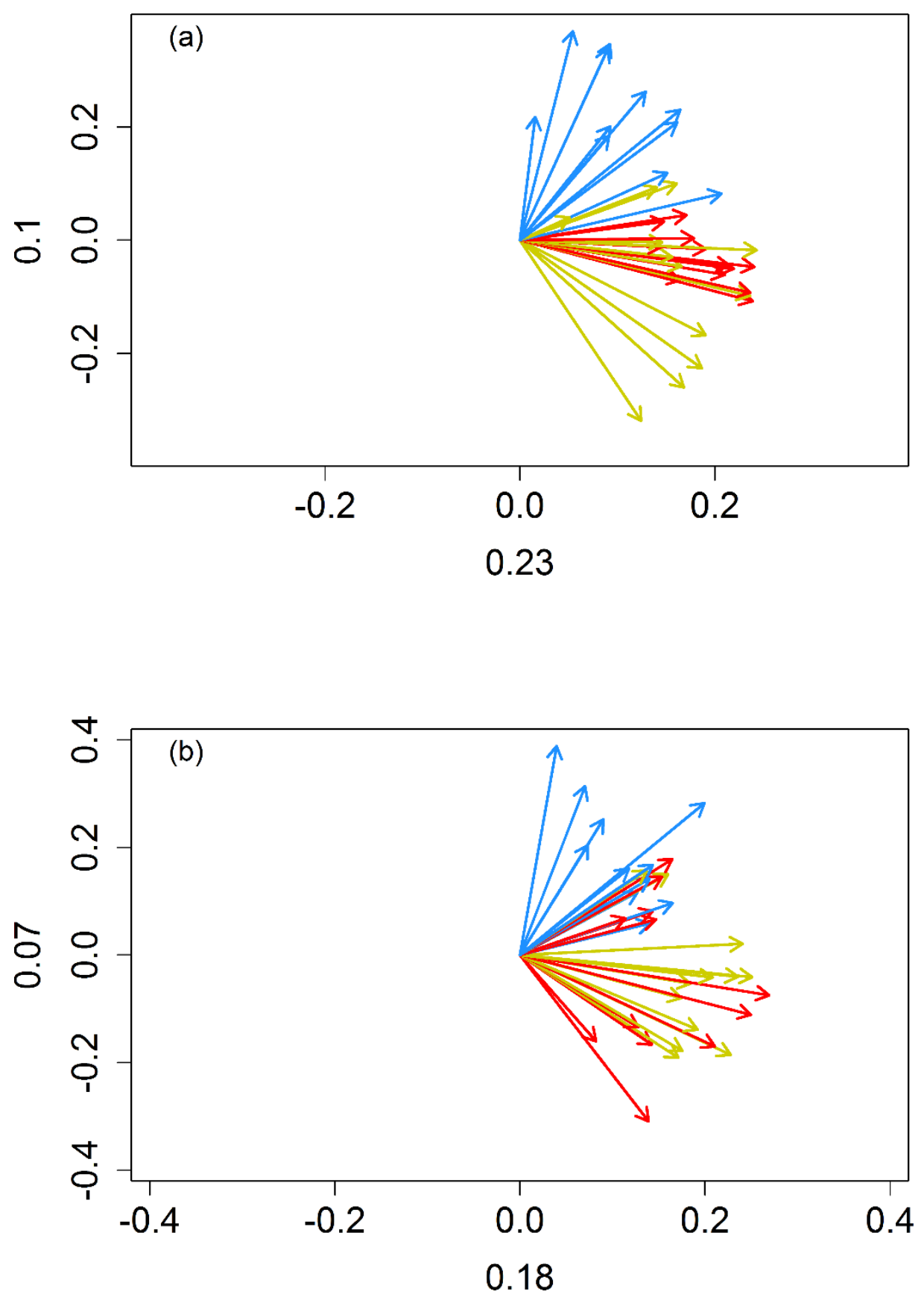

Figure S2.6. Loadings plot for the PCGA based on a) latewood width time series and b) time series of number of vessels. Each arrow represents the loadings on the first two principal components from one tree. Values on the $\mathrm{x}$ - and $\mathrm{y}$-axes represent the amount of explained variance by the respective component. Blue, gold and red loadings refer to North-Eastern, Central-Eastern and South-Eastern sites, respectively. 


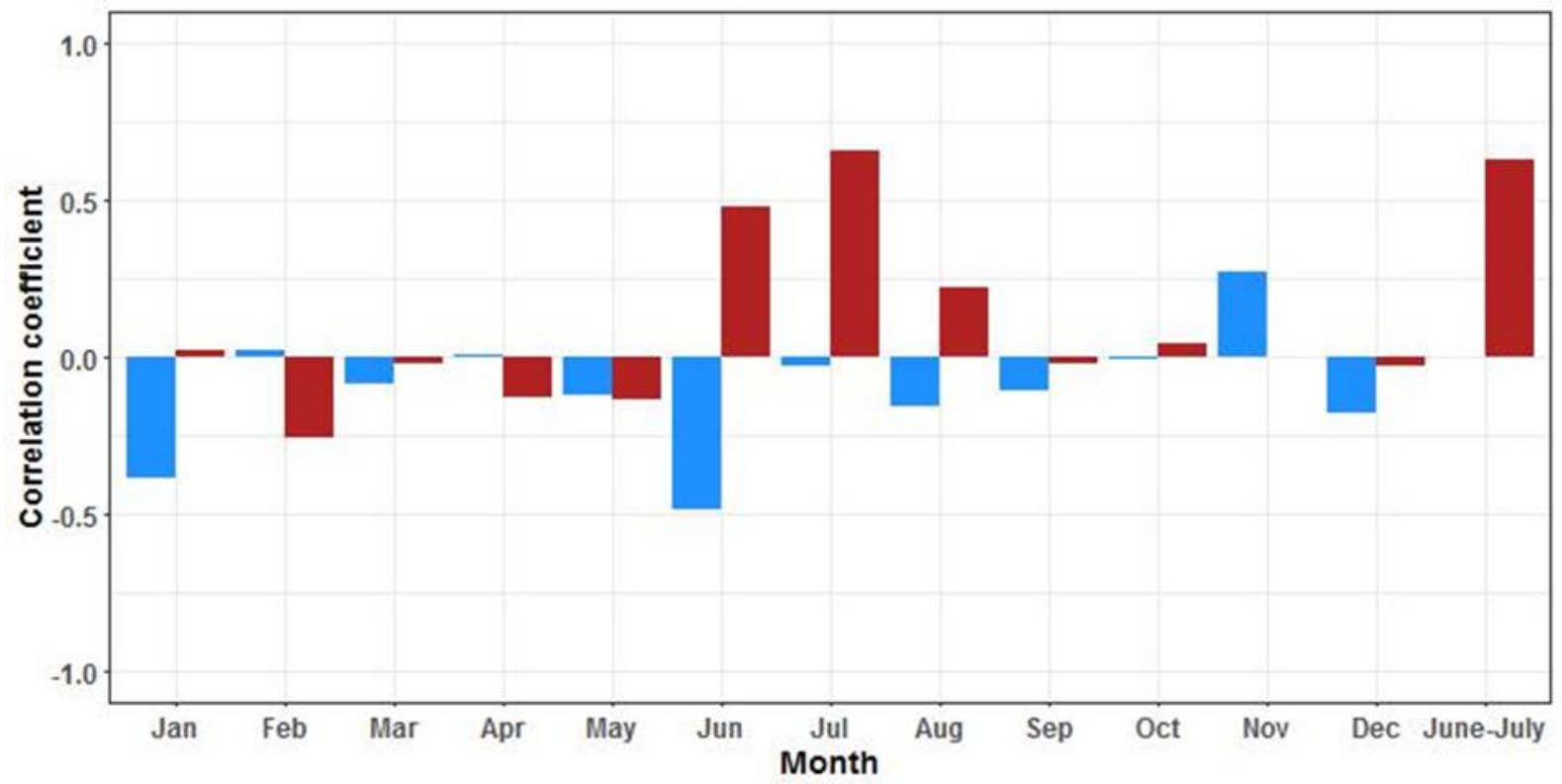

Figure S2.7. Correlations between individual tree ranks (from the PCGA) with correlation of individual tree latewood width time series and mean monthly temperatures and precipitation. Red and blue bars refer to correlations with temperature and precipitation, respectively.

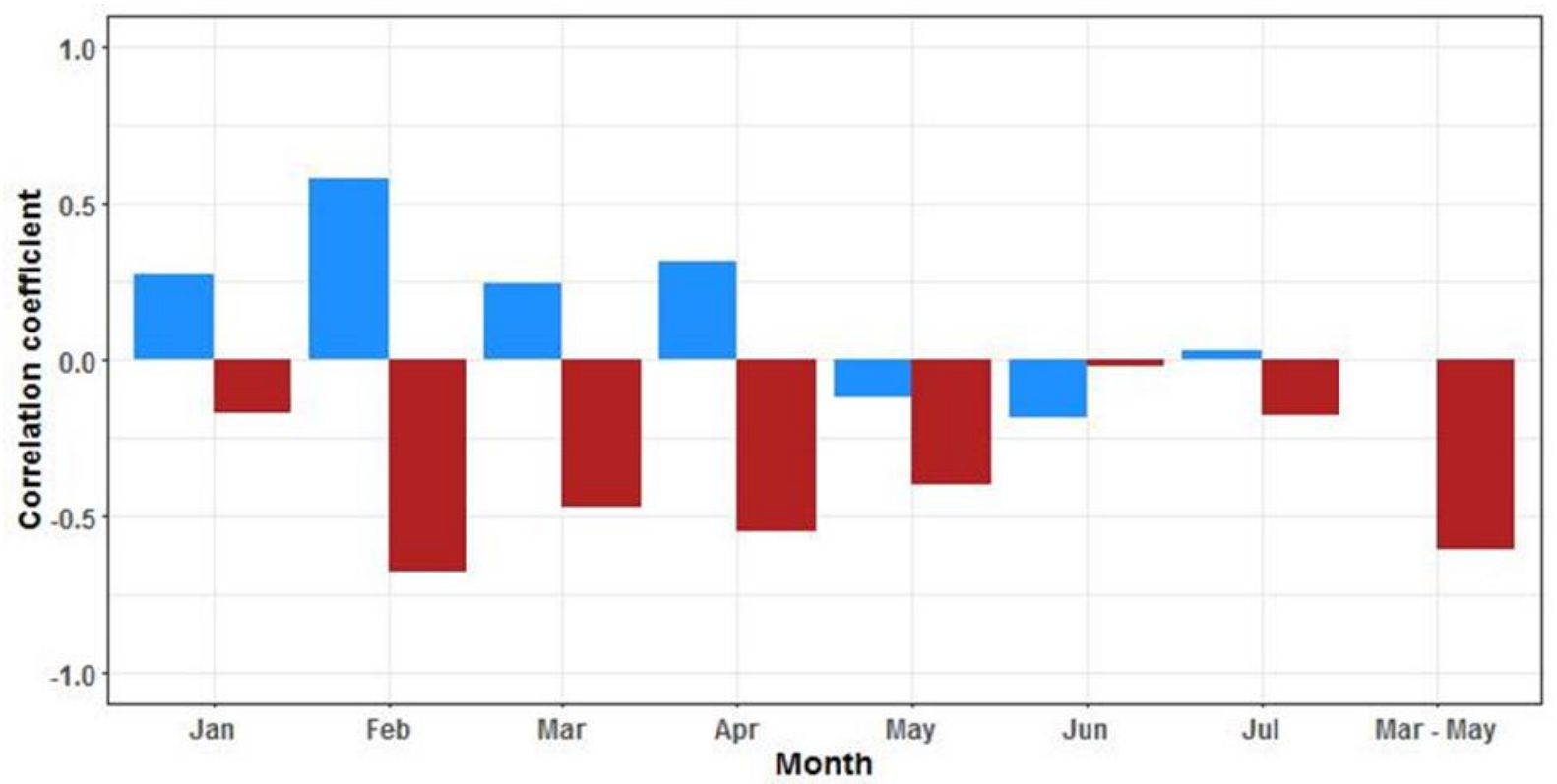

Figure S2.8. Correlations between individual tree ranks (from the PCGA) with correlation of individual tree hydraulic diameter series and mean monthly temperatures and precipitation. Red and blue bars refer to correlations with temperature and precipitation, respectively. 

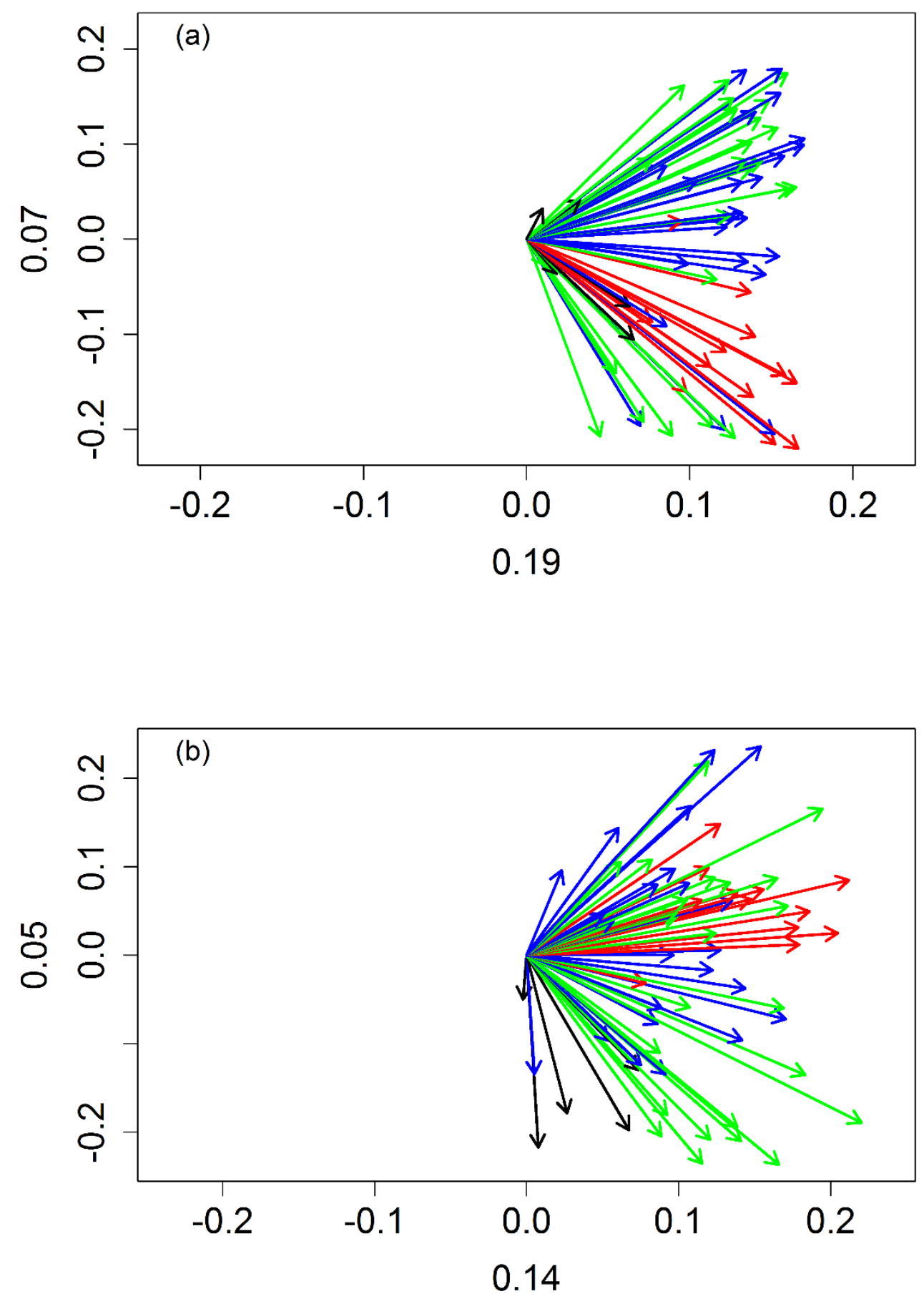

Figure S2.9. Loadings plot for the PCGA based on a) latewood width time series and b) hydraulic diameter time series. Each arrow represents the loadings on the first two principal components from one tree. Values on the $\mathrm{x}$ - and $\mathrm{y}$-axes represent the amount of explained variance by the respective component. Red, blue, green and black loadings refer to Quercus faginea, Quercus petraea, Quercus pyrenaica and Quercus robur respectively. 

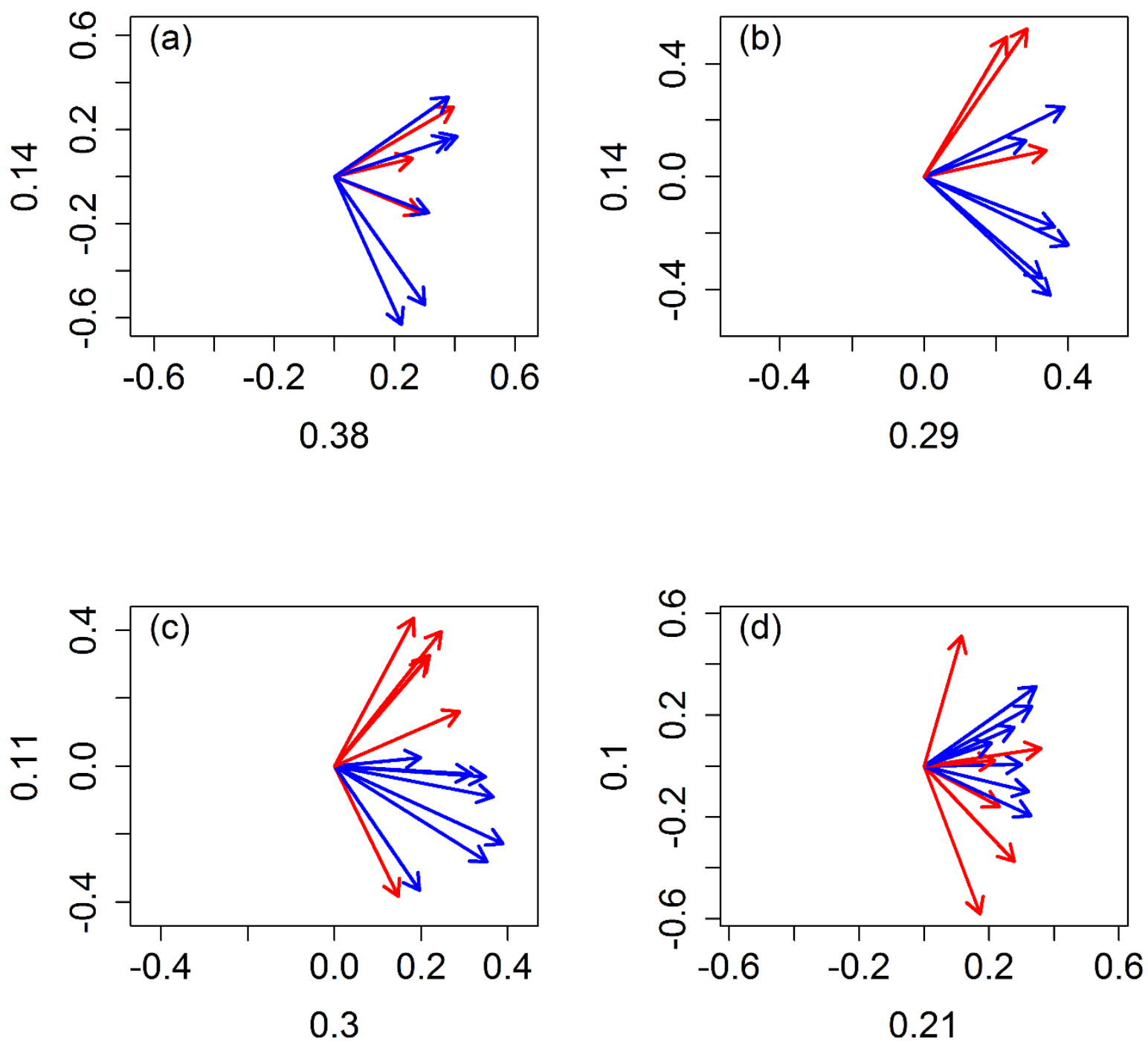

Figure S2.10. Loadings plot for the PCGA based on a) latewood width time series of GOR/GOY study site, b) hydraulic diameter time series of GOR/GOY study site, c) latewood width time series of BRR/BRY study site and d) hydraulic diameter time series of BRR/BRY study site. Each arrow represents the loadings on the first two principal components from one tree. Values on the $\mathrm{x}$ - and $\mathrm{y}$ axes represent the amount of explained variance by the respective component. Red and blue loadings refer to Quercus petraea and Quercus pyrenaica respectively. 

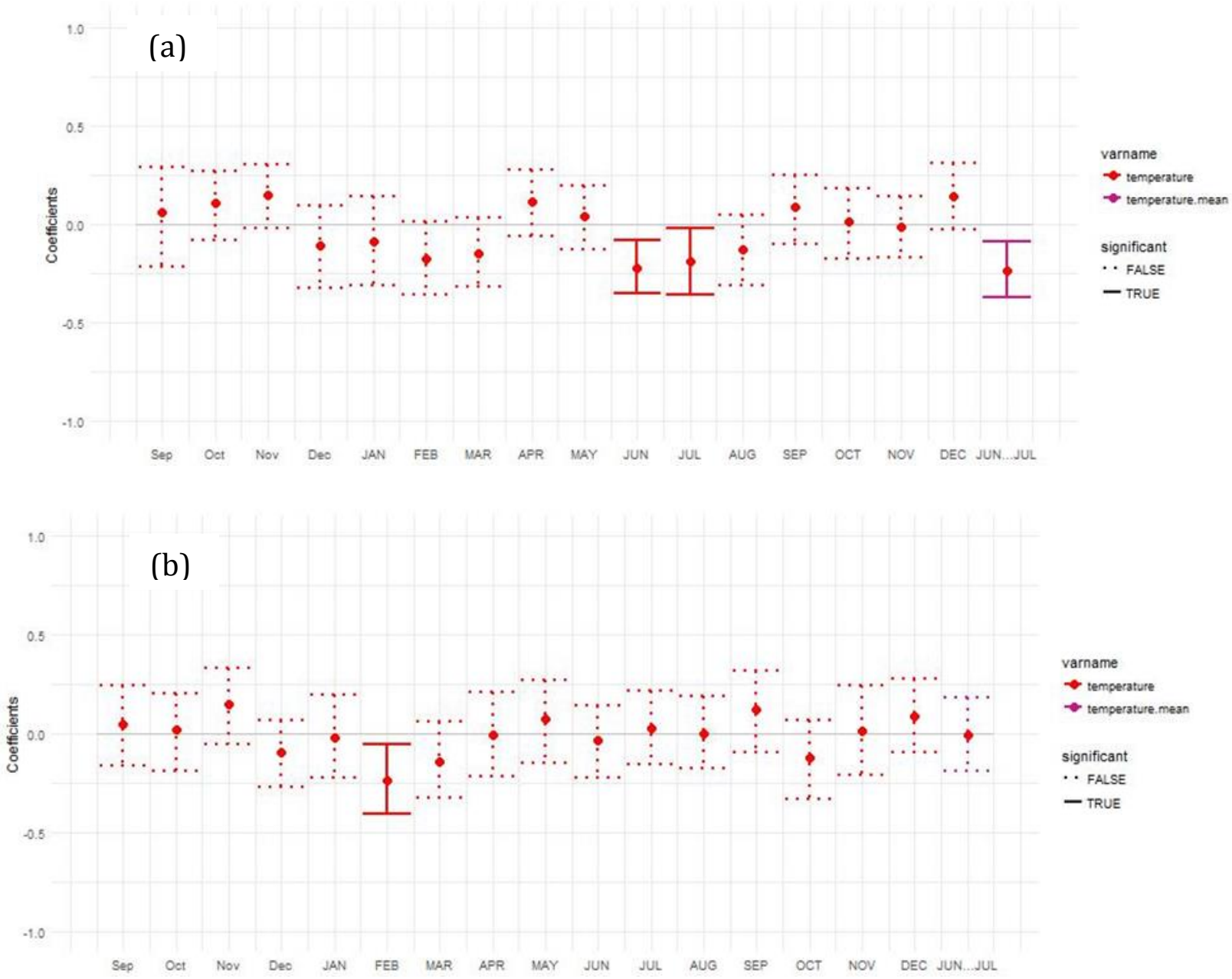

Figure S2.11. Bootstrapped correlations between monthly temperature and a) eastern regional latewood width chronology; b) western regional latewood width chronology . In lower case - months of the previous growing season, in upper case - months of the current growing season. JUN..JUL indicates average June-July temperature 

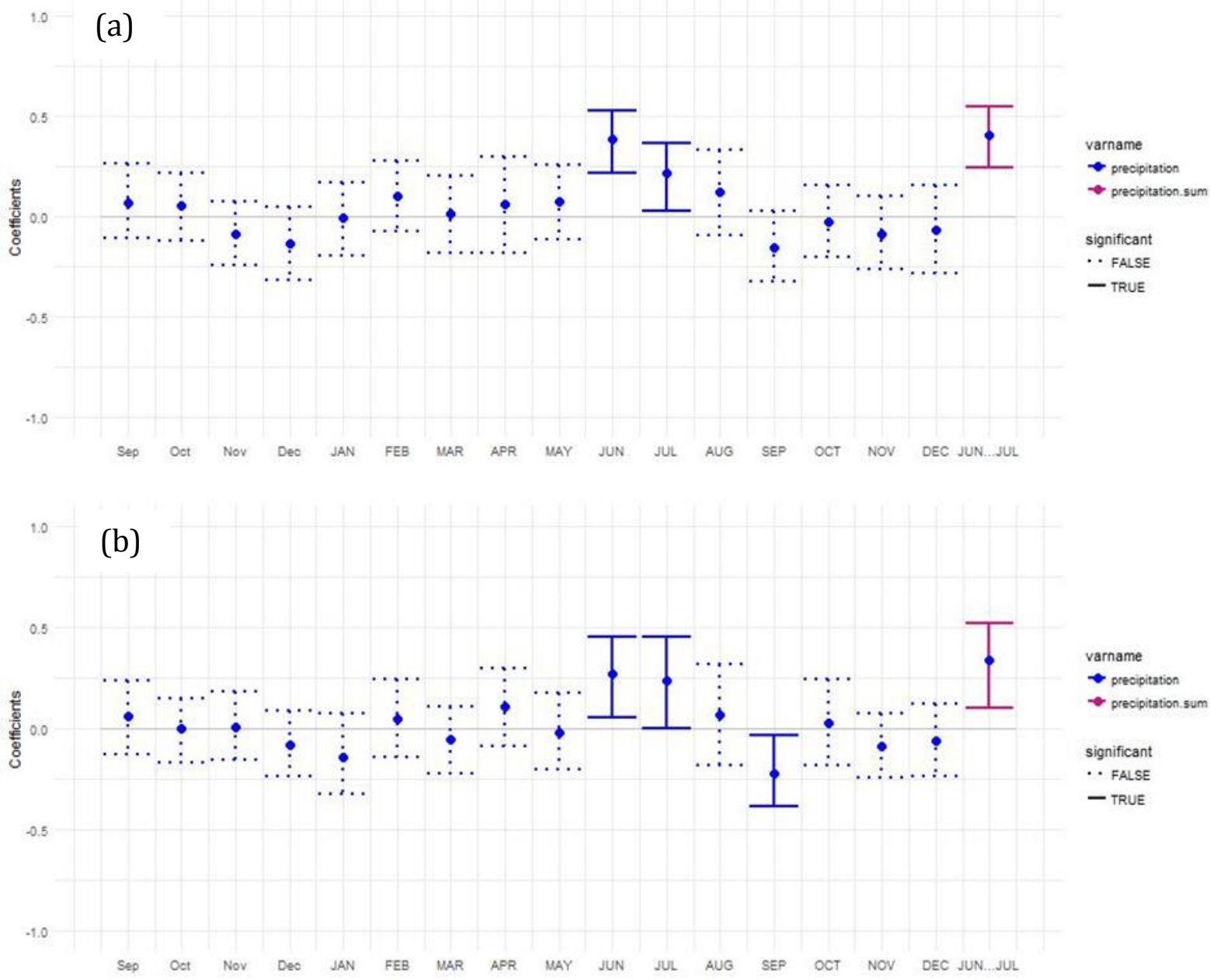

Figure S2.12. Bootstrapped correlations between monthly precipitation and a) eastern regional latewood chronology; b) western regional latewood chronology. In lower case - months of the previous growing season, in upper case - months of the current growing season. JUN..JUL indicates total June-Jule precipitation 
Chapter 2. Oaks 







\section{Chapter 3}

\section{Towards a new approach for dendroprovenancing in the Mediterranean}

Linar Akhmetzyanov, Raúl Sánchez-Salguero, Ignacio García-González, Allan Buras, Marta Domínguez-Delmás, Frits Mohren, Jan den Ouden, Ute SassKlaassen 


\begin{abstract}
Dendroprovenancing studies frequently use individual site chronologies to identify the origin of archaeological and historical timber. However, radial growth (tree-ring width, TRW) of tree species is influenced by both local (elevation) and regional climate scales. Here we investigate how the use of annually-resolved Blue Intensity (BI) measurements can enhance dendroprovenancing precision of black pine (Pinus nigra Arn.) and Scots pine ( $P$. sylvestris L.) in the Iberian Peninsula. Principal Component Gradient Analyses (PCGA) was used to assess geographical patterns of annual variation in TRW and different BI variables of pine trees from two mountain ranges in the Central System and Andalusia in Spain. Local climate-growth relationships were quantified to identify underlying causes of identified groups with diverse growth patterns. Two distinct elevation groups were observed when performing PCGA of latewood BI time series with the response to summer drought as the main factor causing the differences between the groups. Both P. nigra and P. sylvestris BI time series were found to be more related to summer drought at low-elevation sites showing an increase in sensitivity at lower latitudes. PCGA of TRW time series allowed to discriminate between trees from Andalusia and Central System within the elevation groups. Winter and October temperatures were found to be the main climatic factors causing the differences in TRW time series among the high-elevation sites, whereas for low-elevation trees previous November and late summer/early autumn weather conditions determined grouping according to the geographical origin. A subsequent leave-one-out analyses confirmed that including latewood BI time series improves the precision of dendroprovenancing of pine wood in the Iberian Peninsula.
\end{abstract}

Key words: Blue intensity, drought, Elevational gradient, Pinus nigra, Pinus sylvestris, SPEI 


\subsection{Introduction}

Identifying the geographical origin of timber using dendroprovenancing methods has provided insights into the use of local and foreign wood resources in a specific time and place, allowing inferences about the organisation of timber trade networks during past centuries (Bridge, 2012). Dendroprovenancing of wood from a given species is traditionally done by comparing tree-ring width (TRW) time series derived from archaeological wood with a set of available TRW reference chronologies of known origin from living trees (Eckstein, 2007). The source area is then detected by a maximum match (e.g. using Student's $t$-value or correlation coefficient), but this method has strong pitfalls (Bridge, 2012), particularly when strong teleconnections are found between forests located far away from each other (e.g. Domínguez-Delmás et al., 2013). Seeking to improve the accuracy of dendroprovenancing, other methods based on more site-dependent variables have shown promising results, such as the use of vessel-size oak chronologies in Spain (Akhmetzyanov et al., 2019), and stable carbon isotopes of pine species in SW USA (Kagawa \& Leavitt, 2010). Moreover, tree-ring based variables can be combined with other timber tracing techniques based on mass spectrometry to assess the composition of species-specific and site-specific organic (Traore et al., 2018) and inorganic wood substances (Hajj et al., 2017; Paredes-Villanueva et al., 2018), or on DNA analyses (Vlam et al., 2018; ParedesVillanueva et al., 2019) to link a piece of timber to a specific tree population.

It is noteworthy that maximum latewood density of conifers (MXD) has been proven to be a better variable than TRW for temperature reconstructions in cool temperate climates (Grudd, 2008; McCarroll et al., 2013). MXD series show a stronger correlation with growing season temperature, at least in northern mid- and high latitudes (Anchukaitis et al., 2013; Wilson et al., 2016), lower autocorrelation and lag effects (Briffa et al., 2002), and are also less disturbed by other ecological signals than climate (Rydval et al., 2015). These characteristics make them a very promising tool for provenancing historical timbers of conifer species. However, the costs for generating MXD data are high, both time-wise and financially (Campbell et al., 2007), which results in a restricted number of studies that use this method for provenancing purposes.

However, the improvements of digital image analyses have evolved an easier and cheaper alternative to MXD, the blue intensity (BI), i.e. the intensity of the blue channel of light reflected from the wood surface, c.f. McCarroll et al. (2002). Minimum latewood blue 
intensity (LWBI), which can easily be measured from scans of tree cores, shows high similarities to MXD (Björklund et al., 2014; Rydval et al., 2014) because it reflects similar wood characteristics as MXD, such as combined lignin, cellulose and hemicellulose content in the cell walls of latewood tracheids (Björklund et al., 2014; Wilson et al., 2014; Wilson et al., 2017). The BI method has been used largely to extract climatic signals from tree rings and to build multi-century temperature reconstructions in cool temperate environments (e.g. Wilson et al., 2014; Fuentes et al., 2018), and recently was also applied in tropical forests also (Buckley et al., 2018). Pioneer work exploring the use of LWBI data to date wood of historical buildings in Scotland showed great potential (Wilson et al., 2017), whereas the possibilities of using EWBI for historical studies yet have to be tested. However, we yet lack a comprehensive assessment of LWBI-suitability for dendroprovenancing in water-limited environments like in the Iberian Peninsula (IP), where trees endure double climatic stress of cold winters and summer droughts (Mitrakos, 1980). Thus, it would be of interest to assess how BI can help dendroprovenancing techniques in areas with drought limitations, with a historically strategic position in trade routes, and the abundance of interesting cultural heritage suitable for dendroarchaeological research.

Pines have been intensively logged and used as a building material for centuries in the IP (Domínguez-Delmás et al., 2015; Domínguez-Delmás et al., 2018). Understanding timbertrade since at least the Middle Ages is particularly relevant in this area to understand the interactions between humans and their natural environment on past societies (Büntgen et al., 2011). By applying classical TRW for provenancing, wood structures of Scots pine and black pine (respectively Pinus sylvestris and P. nigra) of different historic buildings have been dated, and their origin identified (Richter \& Eckstein, 1986; Richter \& Rodriguez Trobajo, 1986; Domínguez-Delmás et al., 2017; Domínguez-Delmás et al., 2018). However, provenancing of black pine in the IP is restricted by the fact that TRW site chronologies show stronger correlations with chronologies of similar-elevation sites located hundreds of kilometres away, rather than with chronologies from neighbouring areas at different elevations (Domínguez-Delmás et al., 2013). In Bavaria (Germany), Norway spruce (Picea abies) chronologies originating from sites located in close vicinity but at different elevations also showed a low mutual correlation with each other (Wilson \& Hopfmueller, 2001). Elevation was also found to be the main driver of variation in TRW for three pine species in the Eastern Mediterranean region (Touchan et al., 2016). This large-scale elevation-based similarity in growth patterns has advantages for dendrochronological dating, as it allows for 
the creation of so-called "regional chronologies" covering large areas at similar elevations, however hampers dendroprovenancing precision. Yet, the additional small-scale network of chronologies using a combination of wood features may improve timber provenancing studies (Akhmetzyanov et al., 2019).

Here, we assess whether variables obtained through BI-based measurements can improve the dendroprovenancing accuracy of Scots pine and black pine timber in the IP. Our objectives are (a) to evaluate whether BI can improve the precision of previous RW-only dendroprovenances at different elevations and (b) to test whether BI is a suitable proxy under dry Mediterranean conditions to more precisely identify the geographical origin of these pine species in the Iberian Peninsula. We hypothesize that BI-based time series contain a different and stronger climatic signal than TRW, which will allow for pinpointing the elevation and geographic origin of timber at higher precision, thereby overcoming the above-mentioned limitations of TRW series.

\subsection{Materials and Methods}

\subsubsection{Study areas and species}

The study was carried out along an elevational gradient located on the north-facing slopes of the Spanish Central System (CS) (Sierra de Guadarrama National Park) and the Cazorla, Segura and Las Villas Natural Park in Andalusia, southern Spain (AND), two mountain woodlands dominated by Scots pine (Pinus sylvestris L.) in CS and black pine (P. nigra subsp. salzmannii Arn.) in AND above 1,000 m. a.s.l. Historical evidence and dendrochronological studies show that these forests were intensively managed since ancient times up to the mid-20 $0^{\text {th }}$ century for the exploitation of construction timber (Trobajo, 2008). As a result, wood from these forests can nowadays be found in historic buildings of different periods.

Both sites are characterized by a Mediterranean climate with marked continental influence, characterized by dry summers and cool winters (Sánchez-Salguero et al., 2015). The total annual rainfall is $1,266 \mathrm{~mm}$ for $\mathrm{CS}$ and 1,100 for AND, and the mean annual temperature is $6.5^{\circ} \mathrm{C}$ and $11.7^{\circ} \mathrm{C}$ for CS and AND, respectively. The bedrock is mainly formed by granite and gneiss in CS and by limestone and dolomites in AND. 


\subsubsection{Sample collection and data acquisition}

Between 2014 and 2016, as part of the ForSeaDiscovery project (http://forseadiscovery.eu/), field samplings were carried out in three pine stands for each region. Two PISY stands in CS were sampled at high-elevation (ARF and FFR) and one stand with PISY and PINI individuals at low elevation (JRS/JRN) (Table 3.1). In the case of Andalusia (AND) two sampled PINI stands were located at high elevation (PMB and NAV), and one PINI stand at low-elevation (LIN; Table 3.1). The largest and apparently oldest pine trees with no visible damage to crowns or stems were selected for sampling two to four 5-mm tree-ring cores from each tree at breast height. Sample sizes varied between study site due to the different number of suitable trees at each stand (see Figure S3.1 for the detailed information on sampling area).

Due to the varying quality of collected samples, cores were divided into two groups: a) for tree-ring width (TRW) measurements, and b) for the blue intensity (BI), TRW, earlywood width (EW) and latewood width (LW) measurements. For the latter, increment cores with no obvious cracks or wood discolorations were selected. Samples selected for the TRW analyses were air dried, glued onto wooden holders, and cut using a sliding microtome (Gärtner \& Nievergelt, 2010). TRW was measured using a Velmex measuring table (Velmex Inc., Bloomfield NY, USA) coupled to a stereo-microscope (Olympus SZ60). Crossdating was first performed on a visual basis, i.e. comparing the annual fluctuations of ring-width among samples and eventually checked statistically using COFECHA (Holmes, 1983; Grissino-Mayer, 2001). Identified missing rings were inserted with a width value of 0.01 $\mathrm{mm}$.

Prior to the BI measurements, the specifically selected tree cores underwent a treatment to remove organic extractives, i.e. resins, which may cause a bias in the measurements (Buckley et al., 2018). Samples were first surfaced with a sliding microtome and then immersed in acetone. After $24 \mathrm{~h}$, acetone was renewed to prevent saturation by extractives, as some cores were very resinous. Samples were kept immersed in acetone at room temperature for 72 hours in total, as this time interval was found to be sufficient to remove all the extractives (Rydval et al., 2014). Afterwards, the cores were scanned at a resolution of 2,400 dpi with an Epson Expression 10000XL scanner. To ensure comparability of the generated data among different laboratories, an IT8 Calibration Target (IT8.7/2) was used to calibrate the scanner using the SilverFast Auto8 calibration procedure integrated into the 
SilverFast Ai (v.6.6) professional scan software. In order to minimize any influence of ambient light, the scanning surface was isolated from its surroundings by placing a box, fitted to the shape of the scanner.

BI measurements were carried out using CooRecorder 9.0.1 (Larsson, 2018). Two different BI variables were measured, namely minimum latewood blue intensity (LWBI), and maximum earlywood blue intensity (EWBI). The raw BI data are essentially inversely related to density (Campbell et al., 2007); therefore, in order to facilitate the interpretation, LWBI data were inverted first by multiplying each value by -1 , and then adding the constant 2.56 (related to light intensity scale 0 to 255 ) to remove any negative values. Since colour differences between sap- and heartwood of conifer trees can cause a bias in the BI measurements, $\triangle \mathrm{BI}$ was also calculated as a difference between EWBI and raw LWBI (Björklund et al., 2014). CooRecorder measures BI values by placing a window around each tree-ring point, and the mean BI value of the window is then calculated. The window parameters are adjustable, and were selected as follows: width -100 pixels, offset -3 pixels, depth -200 pixels. For details of BI measurements and window parameters, we refer to the Cybis website (Cybus, 2018). The option "Not available" was selected for the BI values of missing rings.

Before further processing, individual time series of each variable were averaged per tree and then, in order to remove age-related trends, averaged series were detrended using a smoothing cubic spline (Cook et al., 1992) with a frequency response of 50\% at a wavelength of 32 years to remove low-frequency variations and emphasize high-frequency variations; for this we used the $d p l R$ package (Bunn, 2010) in R 3.4 (R Development Core Team, 2017). Individual time series were subsequently used to compute site chronologies. Statistics to assess the quality and characteristics of the tree-ring series were calculated for the period 1900-2014 (Table S3.1), notably first-order autocorrelation of raw width data (AC), mean sensitivity (MS) of indexed TRW or BI values, mean correlation between trees (rbt), variance accounted for by the first principal component (PC1), and expressed population signal (EPS), which measures the statistical quality of the mean site chronology compared with a theoretical, infinitely replicated chronology (Wigley et al., 1984). 


\subsubsection{Spatial grouping of time series}

Assessment of geographical patterns of annual variation in the measured/calculated variables was done using Principal Component Gradient Analysis (PCGA) (Buras et al., 2016). PCGA allows for identifying clusters of shared growth patterns at individual tree scale and visualizing whether these clusters are related to available (categoric) explanatory variables such as site or elevation. PCGA was performed on all measured variables (TRW, EW, LW, EWBI, LWBI, and $\triangle \mathrm{BI}$ ) over a common interval, including the maximum number of trees and years, to investigate whether differences in trees origin, i.e., CS or AND, were reflected in the identified clusters of the respective selected variables. In order to test whether elevation is a prevailing factor causing differences in the measured variables and climategrowth responses, trees were also classified into two groups for each species: from high elevation (> 1,500 $\mathrm{m}$ a.s.l.) and low elevations (< 1,500 $\mathrm{m}$ a.s.l.). PCGA loadings were coloured according to the corresponding categoric explanatory variable (i.e. either CS vs. AND or high vs. low elevation). Thus, the observation of clustered colours indicates that the chosen proxy clearly differs between the chosen category (see e.g. Rehschuh et al., 2017; Buras et al., 2018).

\subsubsection{Gradient analyses}

Individual tree ranks obtained from the PCGA were used to identify the main climatic factors driving the grouping of the measured variables. That is, we computed single tree climate correlations (Spearman's rank correlation to account for non-normal distribution of data) with available climate data and tested for a systematic variation of correlation scores along the PCGA rank using Spearman's rank correlation. Gridded CRU TS 4.01 climate data were downloaded over the period 1901 to 2015 (Harris et al., 2014) from the KNMI climate explorer (https://climexp.knmi.nl/start.cgi) with a $0.5^{\circ}$ grid cell. In addition, Standardized Potential Evapotranspiration Index (SPEI) integrated over 1-24 months was calculated for each study site (Vicente-Serrano et al., 2010), and used for climate correlation analysis. The SPEI is useful to identify time-dependent contrasting geographical and elevational growth responses to drought (see Pasho et al., 2011a). Afterwards, we investigated whether these correlations varied significantly along the determined PCGA gradient using Spearman's rank 
correlation. In this analysis, a strong correlation would indicate a directional variation of climate correlations along the PCGA gradient.

Table 3.1. Characteristics of the study sites and sampling strategies.

\begin{tabular}{|c|c|c|c|c|c|c|c|c|c|c|}
\hline $\begin{array}{l}\text { Mountain } \\
\text { range }\end{array}$ & Forest & Code & Coord. & Spec. & $\begin{array}{l}\text { Bed } \\
\text { rock }\end{array}$ & $\begin{array}{c}\text { Elevation } \\
\text { (m a.s.l) }\end{array}$ & $\begin{array}{l}\text { Trees } \\
\text { TRW }\end{array}$ & $\begin{array}{c}\text { Trees } \\
\text { BI }\end{array}$ & $\begin{array}{l}\text { Dbh } \\
(\mathbf{c m})\end{array}$ & $\begin{array}{l}\text { Mean } \\
\text { TRW } \\
\text { series } \\
\text { length } \\
\text { (years) }\end{array}$ \\
\hline \multirow{4}{*}{$\begin{array}{c}\text { Sierra de } \\
\text { Guadarra } \\
\text { ma }\end{array}$} & $\begin{array}{l}\text { Arroyo } \\
\text { Frío }\end{array}$ & ARF & $\begin{array}{l}40^{\circ} 47^{\prime} \mathrm{N} \\
3^{\circ} 59^{\prime} \mathrm{W}\end{array}$ & PISY & MG & 1917 & 83 & 13 & 58 & $146 \pm 42$ \\
\hline & Fuenfría & FFR & $\begin{array}{c}40^{\circ} 47^{\prime} \mathrm{N} \\
4^{\circ} 2^{\prime} \mathrm{W}\end{array}$ & PISY & MG & 1900 & 30 & 11 & 93 & $357 \pm 90$ \\
\hline & La Jarosa & JRS & $\begin{array}{c}40^{\circ} 39^{\prime} \mathrm{N} \\
4^{\circ} 9^{\prime} \mathrm{W}\end{array}$ & PISY & MG & 1421 & 14 & 11 & 61 & $169 \pm 49$ \\
\hline & La Jarosa & JRN & $\begin{array}{c}40^{\circ} 39^{\prime} \mathrm{N} \\
4^{\circ} 9^{\prime} \mathrm{W}\end{array}$ & PINI & MG & 1421 & 27 & 11 & 58 & $386 \pm 100$ \\
\hline \multirow{3}{*}{$\begin{array}{l}\text { Sierra de } \\
\text { Cazorla }\end{array}$} & Linarejos & LIN & $\begin{array}{l}37^{\circ} 55^{\prime} \mathrm{N} \\
2^{\circ} 54^{\prime} \mathrm{W}\end{array}$ & PINI & SL & 1191 & 64 & 14 & 49 & $160 \pm 32$ \\
\hline & $\begin{array}{l}\text { Navanogu } \\
\text { era }\end{array}$ & NAV & $\begin{array}{l}37^{\circ} 55^{\prime} \mathrm{N} \\
2^{\circ} 48^{\prime} \mathrm{W}\end{array}$ & PINI & SL & 1585 & 63 & 12 & 59 & $150 \pm 88$ \\
\hline & $\begin{array}{l}\text { Poyos de la } \\
\text { Mesa }\end{array}$ & PMB & $\begin{array}{l}37^{\circ} 53^{\prime} \mathrm{N} \\
2^{\circ} 54^{\prime} \mathrm{W}\end{array}$ & PINI & SL & 1596 & 17 & 10 & 86 & $331 \pm 121$ \\
\hline
\end{tabular}

Code - abbreviation used for the study forest,

Coord. - coordinates of the study site,

Spec. - species,

PISY and PINI - Pinus sylvestris and Pinus nigra, respectively,

MG and SL - magmatic granite and sedimentary limestone, respectively,

Trees TRW - the number of trees used for ring width, earlywood width, and latewood width measurements,

Trees BI- the number of trees used for blue intensity measurements,

Dbh - average diameter at breast height,

TRW - tree-ring width.

To test for significance in differences of the polar coordinates of the different categories derived from the PCGA, the Wilcoxon rank sum test was performed. A non-parametric test was chosen due to the non-normal data distribution. Finally, we computed regional chronologies, i.e. the average of all individual time series representative of each geographic and elevational category. These regional chronologies were again correlated with monthly temperature and precipitation using a 15-month window, from August in the prior growing season to October in the current growing season, and with 1-24 months SPEI. Correlation analysis with climatic factors was done to assess whether the climatic effects behind the gradients' analyses were also the main factors limiting/enhancing tree growth in the study areas. 


\subsubsection{Leave-one-out analyses}

To test if incorporation of BI time series improves the performance of wood provenances, a leave-one-out analysis (LOOA) was performed following the steps described by Akhmetzyanov et al. (2019). LOOA was first performed on all trees using only BI time series to see the 'correct' elevation group identification, and then on TRW time series of subgroups derived from the BI PCGA. The latter was performed to understand if including more variables would lead to a more accurate provenancing of the collected material.

\subsection{Results}

\subsubsection{Characteristics of chronologies}

The average length of derived TRW time series varied both between and within areas (Table 3.1). Among the sites from CS, the longest series were derived from trees at JRN and FFR whereas JRS and ARF series were considerably shorter. Trees of comparable age to the latter were found at LIN and, whereas trees from PMB had an age close to trees from JRN and FFR (Table 3.1).

The mean TRW values varied across sites as well, with the largest values in ARF, JRS and NAV and smallest in JRN (Figure 3.1a). A similar pattern was observed for the EW, but not for the LW, where the largest mean value was found in LIN (Table S3.1). As for the BI variables, the largest mean LWBI values were found in JRN and LIN, while ARF trees had the smallest average LWBI (Figure 3.1b). All sites showed similar mean $\triangle \mathrm{BI}$, but at LIN the value was considerably higher, probably due to the low EWBI value (Table S3.1). 

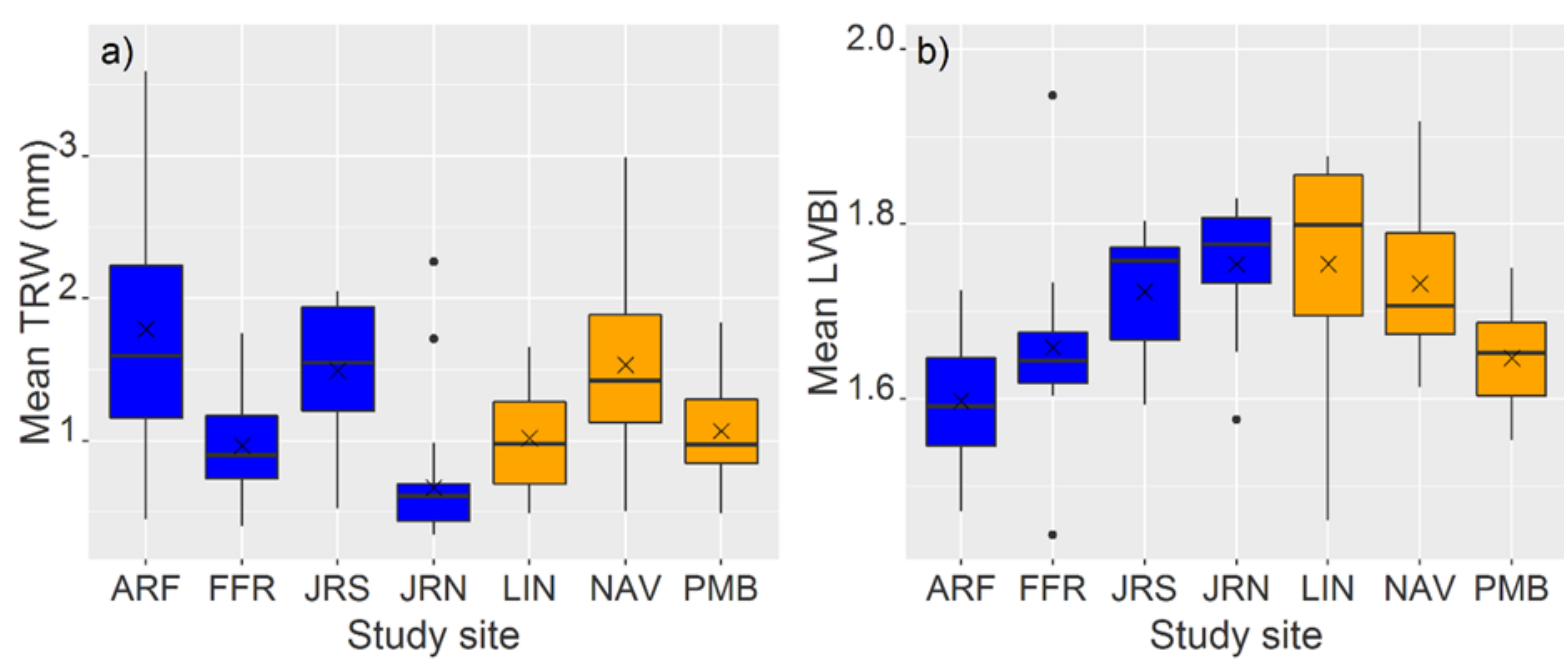

\section{Area}

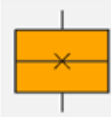

Andalusia

Central System

Figure 3.1. Mean TRW (a) and LWBI (b) of series from the Central System (blue) and Andalusia (orange). Black crosses indicate average time series length per study site (abbreviations for study sites as in Table 3.1). Lower and upper box boundaries 25th and 75th percentiles, respectively, line inside box median, lower and upper error lines 10th and 90th percentiles, respectively, filled circles data falling outside 10th and 90th percentiles.

The correlation between TRW series (rbt) within each stand varied from 0.69 (NAV from AND) to 0.57 (FRR from CS) (Table S3.1), confirming a high growth coherency among trees from the same provenance. Some tree-ring variables were highly correlated for all sites, i.e. TRW and EW/LW (Table 3.2). BI variables were also correlated among each other and with ring-width variables, but EWBI showed considerably lower and largely insignificant correlations with other variables. 
Table 3.2. Spearman correlations calculated between tree-ring variables (RW ring width, EW earlywood width; LW latewood width; $\triangle \mathrm{BI}$, delta blue intensity, EWBI, earlywood blue intensity, LWBI, latewood blue intensity) for each site. The correlation was computed over the 1900-2014 period. Bold and grey characters show significance at $p<0.01$ and $p<0.05$ level.

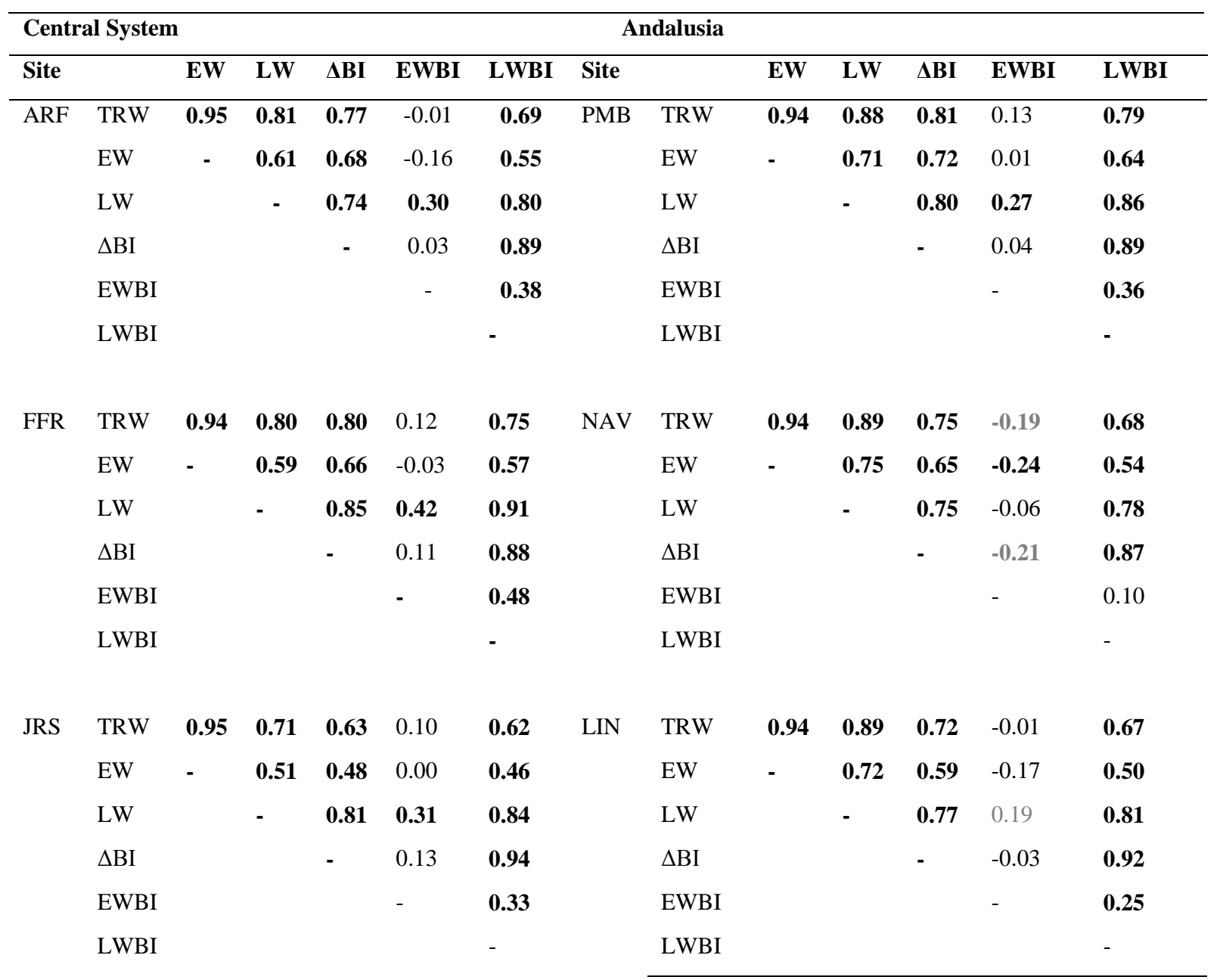

$\begin{array}{lllllll}\text { JRN } & \text { TRW } & \mathbf{0 . 9 7} & \mathbf{0 . 8 5} & \mathbf{0 . 8 5} & \mathbf{- 0 . 2 7} & \mathbf{0 . 7 6} \\ \text { EW } & - & \mathbf{0 . 7 3} & \mathbf{0 . 7 7} & \mathbf{- 0 . 3 3} & \mathbf{0 . 6 6} \\ \text { LW } & & - & \mathbf{0 . 9 0} & -0.04 & \mathbf{0 . 9 0} \\ & & & - & -0.14 & \mathbf{0 . 9 2} \\ \text { EWI } & & & - & - & 0.15 \\ \text { EWBI } & & & & - & \end{array}$




\subsubsection{Spatial grouping of time series}

\subsubsection{PCGA of geographical provenances}

The common interval for the PCGA performed for all 196 TRW time series comprised the common period from 1863 to 2014. The analyses failed to group the TRW series according to their geographical origin, as a set of trees from the CS (from low elevation) grouped with AND trees (Figure 3.2a). The cluster of incorrectly assigned trees composed of both P. nigra and P. sylvestris from JRS/JRN (CS low-elevation group). PCGA of LW and LWBI time series per study region didn't reveal any clear grouping according to geographical provenance (Figure 3.2b-c). At the same time, the PCGA of LW time series (common interval 1902-2014, 78 series) yielded separation between trees from high and low elevations but also featured nine inconsistently assigned series (Figure 3.2e). The PCGA of LWBI (common interval 1902-2014, 61 series) however, showed a clear grouping of trees according to their elevation origin with only one incorrectly assigned series (Figure 3.2f) (p $<0.01$, Wilcoxon test). PCGA of EW showed similar results to TRW analyses (Figure S3.2a), while PCGA of $\triangle \mathrm{BI}$ revealed comparable results to LWBI (Figure S3.2-c), but having more outliers. PCGA of EWBI did not result in any meaningful grouping of time series (Figure S3.2b). No meaningful grouping of time series per study species was found (Figure S3.3). 

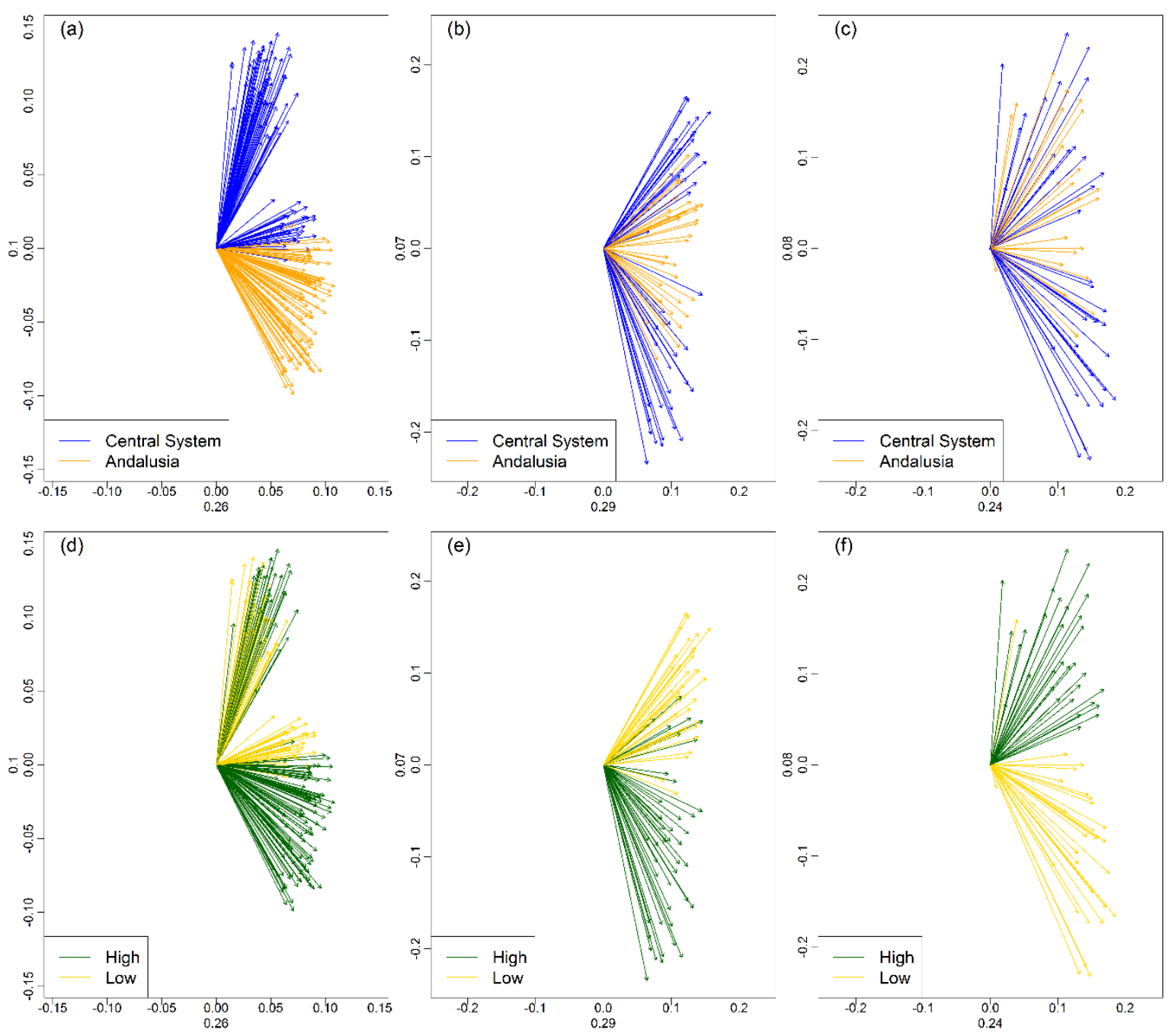

Figure 3.2. Loadings plots for PCGA for study regions (upper panels) and for elevation subgroups (lower panels), for time series of tree-ring width index (a and d), latewood width (b and e), and latewood blue intensity ( $c$ and f). Low-elevation sites included LIN, JRS and JRN; high-elevation sites are PMB, NAV, ARF and FFR. Each arrow represents the loadings on the first two principal components from one tree. Values in parenthesis represent number of trees in the respective category. Values on the $x$ - and $y$-axes represent the amount of explained variance by the respective component.

\subsubsection{PCGA of elevation groups}

PCGA based on TRW of elevation groups as identified by the PCGA using LWBI showed a clear distinction between CS and AND trees both within high and low elevational subgroups (Figure 3.3a and Figure 3.3b, respectively) ( $p<0.01$, Wilcoxon test). The common interval of PCGA of trees coming from lower elevations was 1894-2014 (121 years) and involved $28 \mathrm{TRW}$ time-series, whereas for the trees from higher elevations it was 1888-2014 (127 years) and involved 31 trees. The CS low-elevation group comprised of both $P$. nigra (9 individuals) and $P$. sylvestris (10 individuals). However, the difference between the species was not reflected in PCGA of the respective elevational group (Figure 
S3.4b). PCGA of other selected variables also showed a similar grouping of trees according to their geographical origin within the elevational groups, especially EW and LW time-series (Figure S3.5).
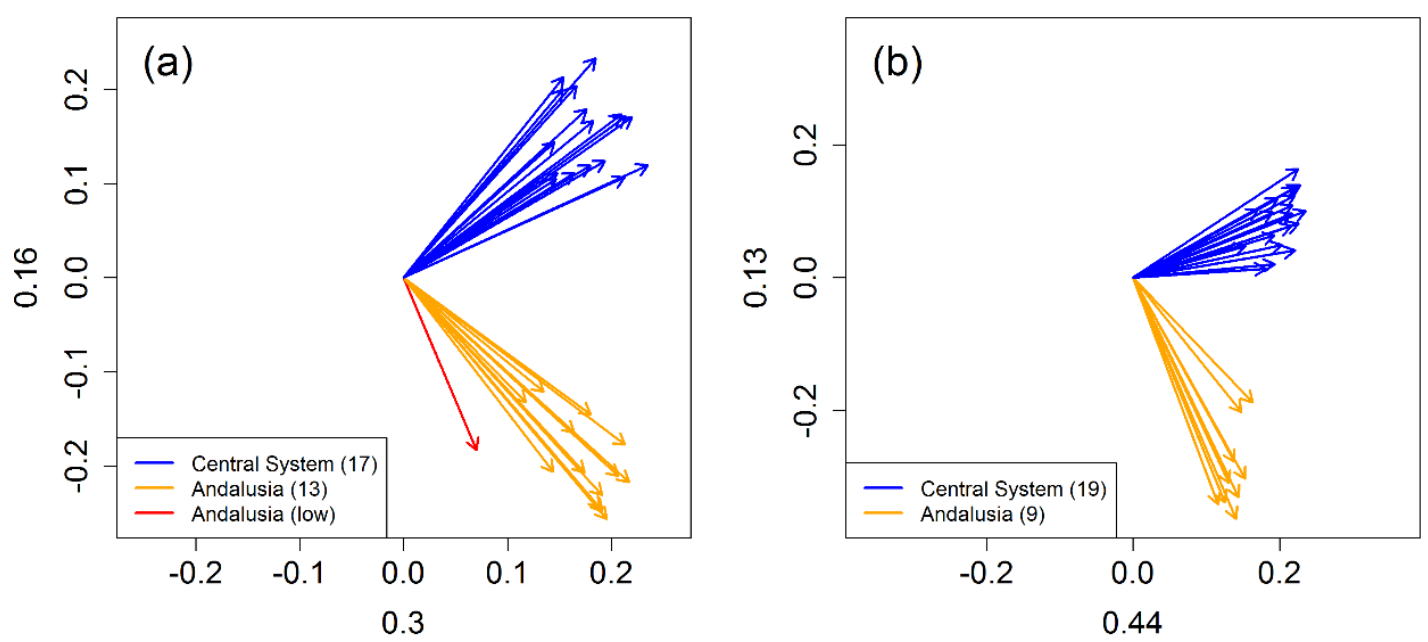

Figure 3.3. Loadings plot for the PCGA based on tree-ring width index of a) trees from high elevations (ARF/FFR from CS, and NAV/PMB from AND), one "Andalusia (low)" red arrow represents the outlier from the LWBI PCGA; b) trees from low elevations (JRS/JRN from CS, and LIN from AND). Each arrow represents the loadings on the first two principal components from one tree. Values in parenthesis represent number of trees in the respective category. Values on the $x$ - and $y$-axes represent the amount of explained variance by the respective component.

\subsubsection{LWBI and TRW climate-growth relationships}

\subsubsection{Drought sensitivity of the selected variables}

The correlation analysis between TRW and SPEI showed a significant positive association between growth and drought index, but these associations were found to be increasing if using LWBI chronologies (Figure 3.4). A positive and significant relationship between summer SPEI and low-elevations trees' LWBI chronologies was recorded at 3-4 months long scales, while correlations with TRW were considerably weaker. High-elevation trees did not show any significant relationship with drought, neither in TRW nor in LWBI chronologies. 


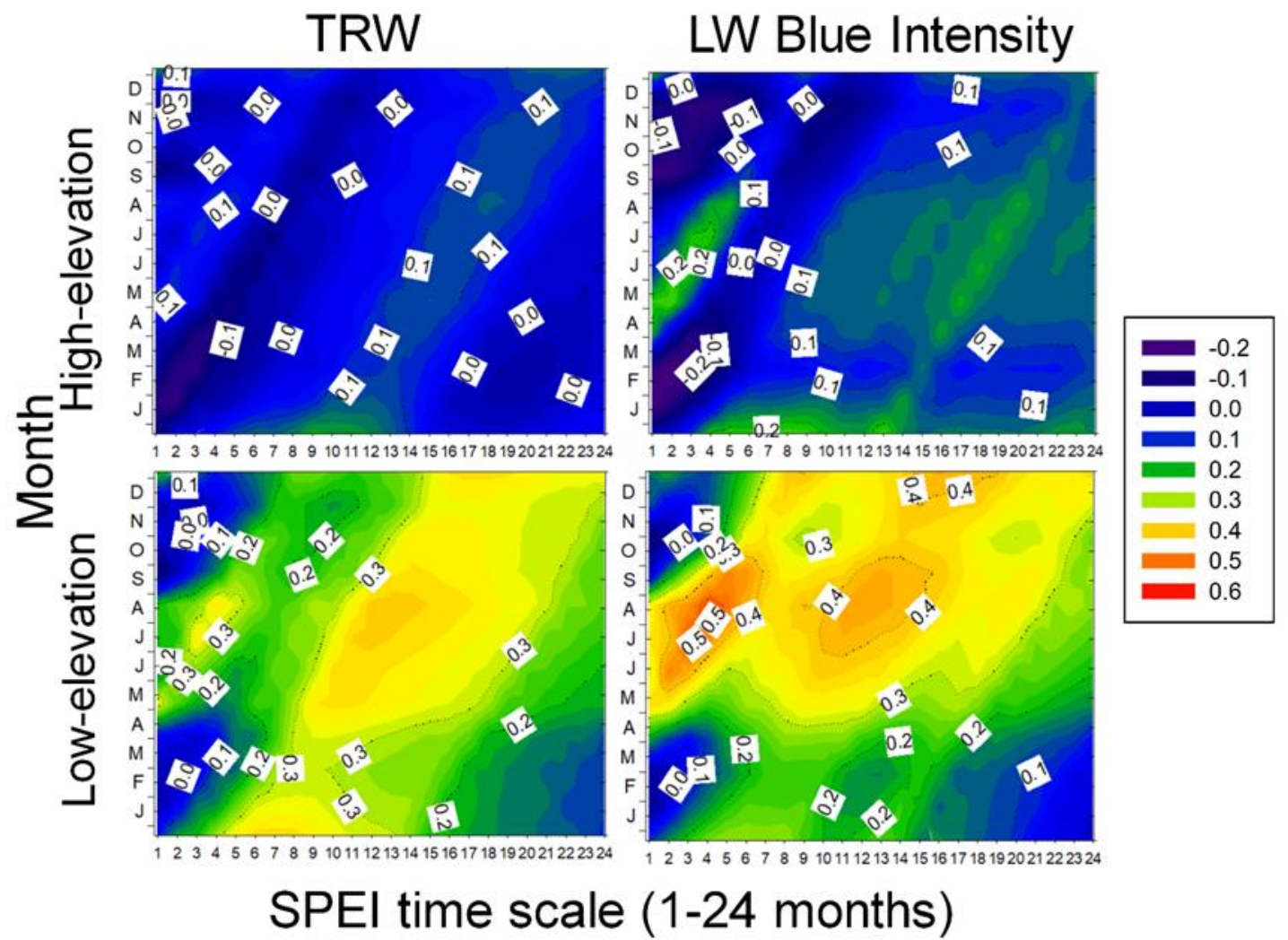

Figure 3.4. Drought associations of the regional chronologies by elevations assessed by relating ringwidth indices (TRW) and latewood blue intensity (LWBI) to the Standardized PrecipitationEvapotranspiration Index (SPEI) considering up to 24-month long scales ( $x$-axes). Correlations were calculated for the common and best-replicated period 1900-2014 and considering the months of the current growth year ( $y$-axes). Correlation values above +0.20 and below -0.20 are significant at $p<0$ .05 level.

\subsubsection{TRW and BI responses to climate within elevational groups}

Assessment of climate growth-relationships between regional TRW and LWBI chronologies within the elevation subgroups and climatic factors revealed a strong negative effect of temperature of the previous autumn and positive effect of current winter temperature on TRW of high-elevation trees from Andalusia (AND), whereas such strong effects were not observed for trees from the Central System (CS) of the same elevation group (Figure 3.5). On the other hand, the trees from CS at high-elevation were negatively affected by average October 


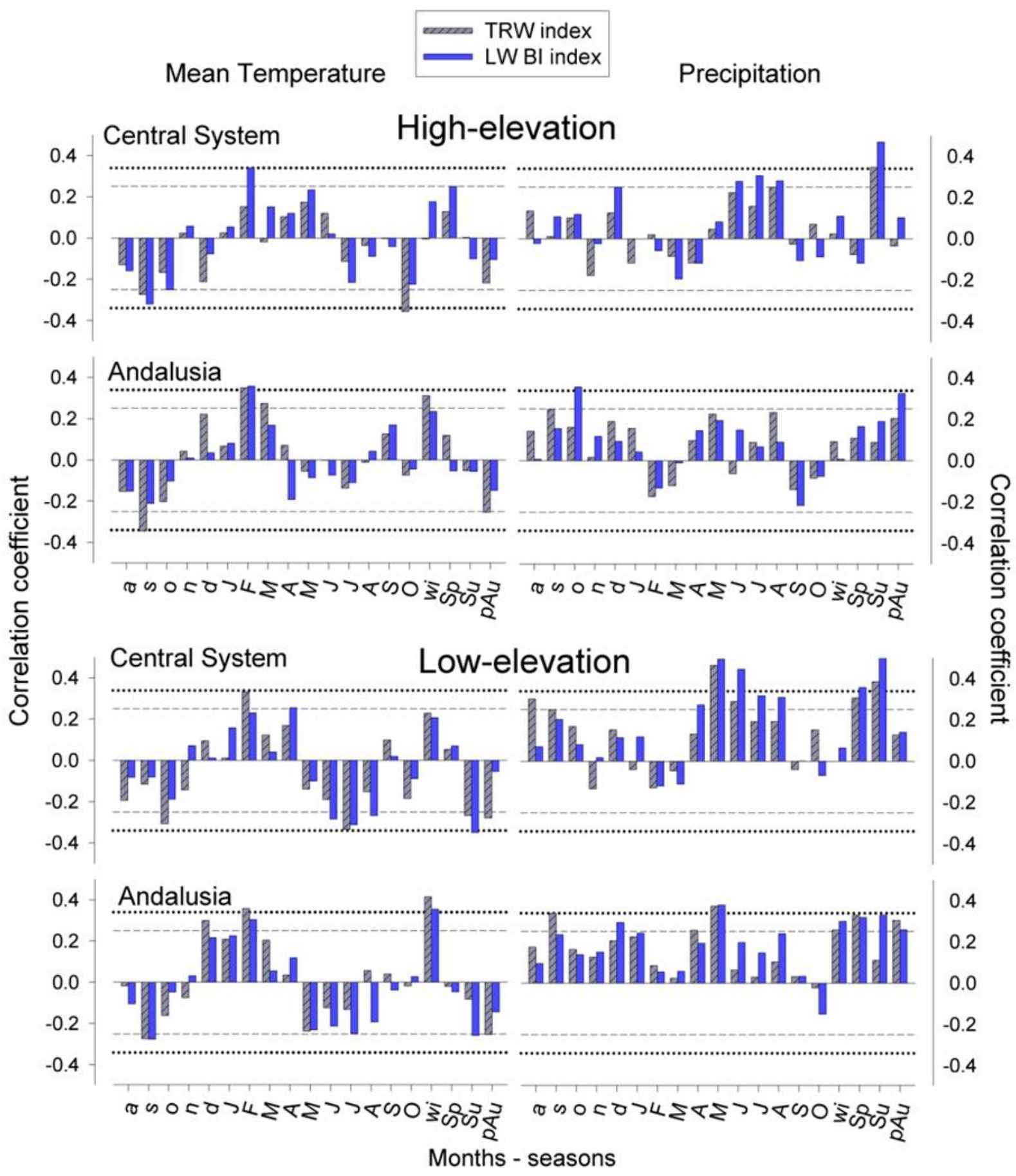

Figure 3.5. Bootstrapped correlation coefficients between tree growth variables-climate associations for the studied sites assessed by relating ring-width indices (TRW) and latewood blue intensity (LWBI) to seasonal and monthly climatic variables (mean temperature and precipitation). The temporal window of analyses includes from previous August up to current October. Previous-year months are abbreviated by lowercase letters; wi, $\mathrm{Sp}, \mathrm{Su}$ and $\mathrm{pAu}$ indicate winter, spring, summer and previous autumn seasons, respectively. Significance levels are shown with dashed $(\mathrm{P}<0.05)$ or dotted $(\mathrm{P}<0.01)$ lines.

temperature, while this signal was very weak in Andalusian trees. A strong positive effect of summer precipitation was found in LWBI for low-elevation sites, with a stronger correlation 
at CS (Figure 3.5). Furthermore, the average winter temperature was found to be the main factor driving the growth of trees in Andalusia for both elevations, while only February temperature showed significant correlations with the Central System low elevation TRW chronology (Figure 3.5).

\subsubsection{Variations of climate-growth relationships along the PCGA gradient}

Climate correlations varied significantly along the PCGA-gradient for several parameters and months as indicated by spearman's rank correlation (Figure 3.6). The gradient derived from the PCGA based on LWBI time series (Figure 3.2f) reflects the strong correlation between LWBI time series of individual trees with summer temperature and precipitation, but the strongest correlations were found with the summer SPEI-3 (Figure 3.6).

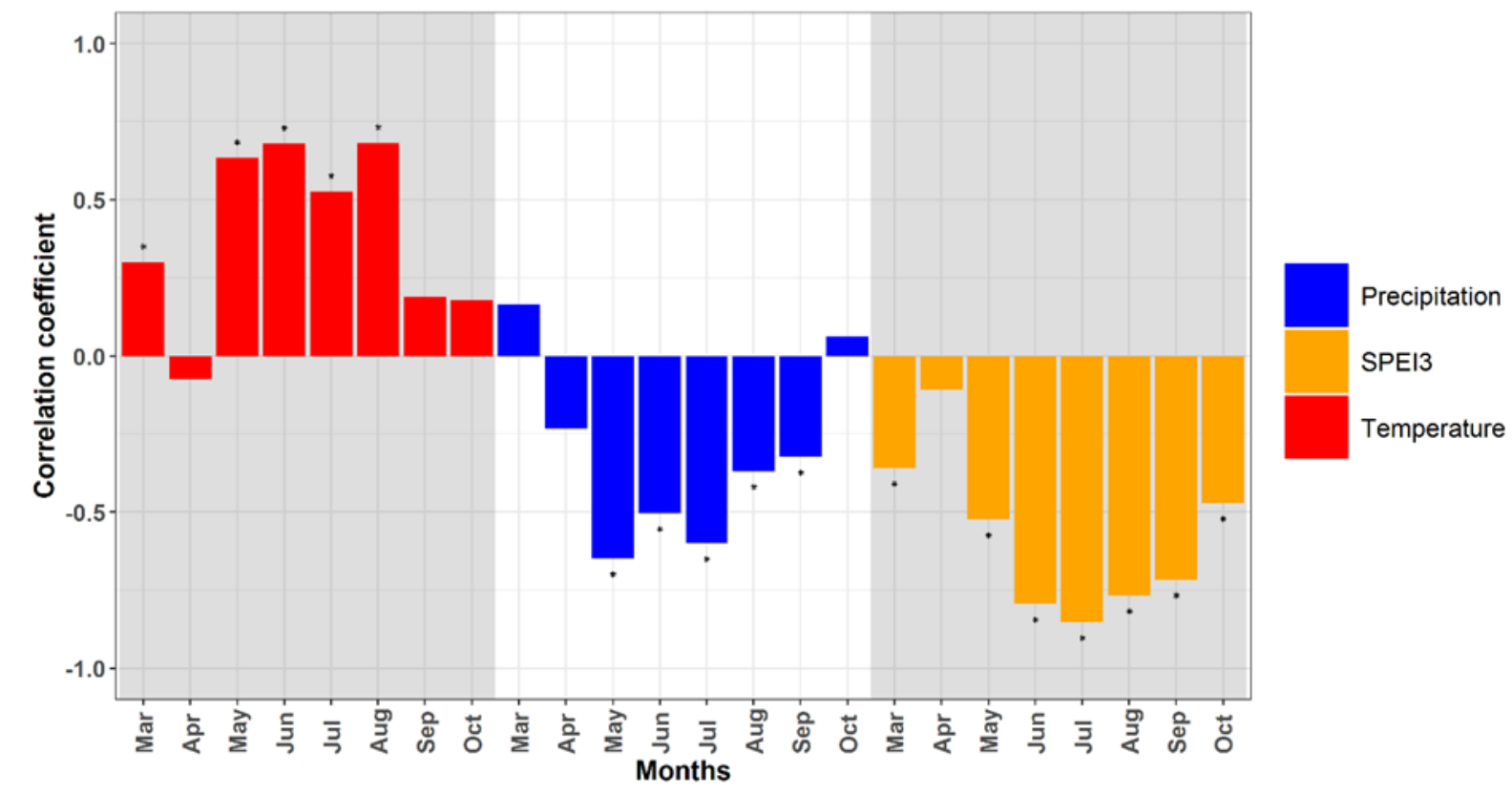

Figure 3.6. Correlation between ranks of all trees derived from LWBI PCGA, with the correlation between individual LW BI time series and average temperature (red), precipitation (blue) and 3months-long scale Standardized Precipitation Evapotranspiration Index - SPEI (orange). Asterisks indicate significant correlations ( $p$ adj. $<0.01)$

Also, the ranking of the PCGA using TRW on elevational subgroups revealed the significant variation of climate correlations along the corresponding gradient. That is, high elevation gradients revealed a significant variation in response to temperature and precipitation before the start of the growing season and current October (Figure 3.7a), whereas low elevation gradients revealed a signification variation of correlations with the late summer/early autumn and previous November growing conditions (Figure 3.7b). 

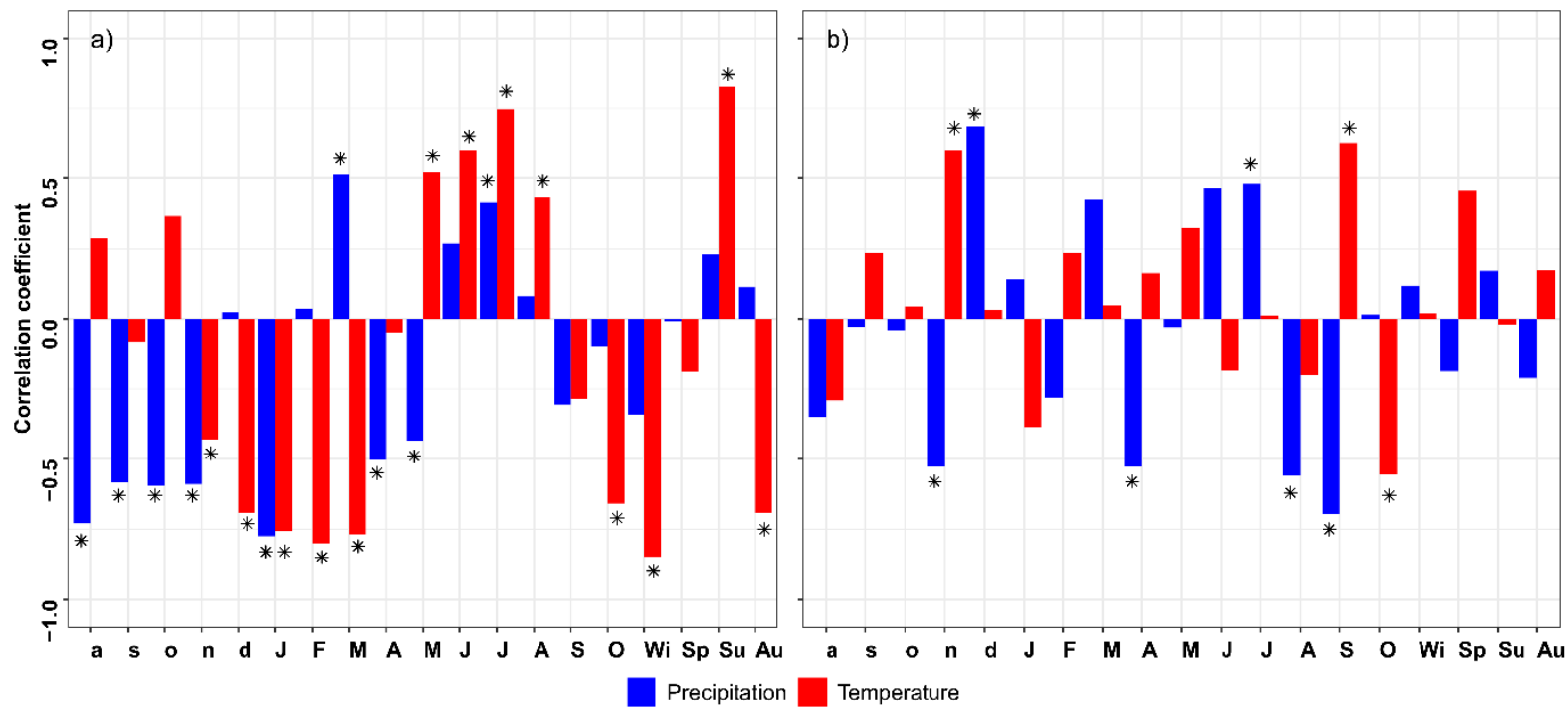

Figure 3.7. Correlation between individual tree PCGA ranks with the correlation between individual tree-ring width time series of a) high elevation trees and climatic factors and b) low elevation trees and climatic factors. The temporal window of analyses includes from previous August up to current October. Previous-year months are abbreviated by lowercase letters; wi, Sp, Su and Au indicate winter, spring, summer and autumn seasons, respectively. Asterisks indicate significant correlation (p adj. $<0.01)$

\subsubsection{Leave-one-out analyses}

The leave-one-out analyses demonstrated a highly correct assignment of trees to the elevation groups based on LWBI (100\% and 93\% to high and low elevations, accordingly), whereas for TRW and $\triangle \mathrm{BI}$ the percentages were lower (Table 3.3). Performing a similar analysis within the elevation groups as defined by PCGA on LWBI, TRW performed best, i.e. $100 \%$ of series were correctly assigned to their geographical origin for both elevation subgroups. The same analyses for LWBI and $\Delta \mathrm{BI}$ showed lower percentages (Table 3.3). 
Table 3.3. Rates of success for the leave-one-out approach. High, Low - success rates of assigning trees to sites, from high and low elevations, respectively. Central System (CS) and Andalusia (AND) indicate success rates of assigning trees to each region. For the latter, trees from predefined by the PCGA of latewood blue intensity time series from each elevational group, i.e., high elevation and low elevation, were analysed separately. In grey - the highest success rate values.

\begin{tabular}{lrrrccc} 
& \multirow{2}{*}{ High } & \multirow{2}{*}{ Low } & \multicolumn{2}{c}{ High elevation } & \multicolumn{2}{c}{ Low elevation } \\
\cline { 5 - 7 } & & & CS & AND & CS & AND \\
\cline { 2 - 7 } LWBI & $100 \%$ & $93 \%$ & $100 \%$ & $88 \%$ & $100 \%$ & $66 \%$ \\
TRW & $52 \%$ & $96 \%$ & $100 \%$ & $100 \%$ & $100 \%$ & $100 \%$ \\
$\Delta$ BI & $76 \%$ & $96 \%$ & $100 \%$ & $100 \%$ & $88 \%$ & $100 \%$ \\
\hline
\end{tabular}

CS, AND - Central System and Andalusia, respectively,

LWBI, TRW and $\triangle \mathrm{BI}$ - latewood blue intensity, tree-ring width and delta blue intensity, respectively

\subsection{Discussion}

\subsubsection{The added value of latewood blue intensity for pine timber provenancing}

Application of multivariate techniques on individual time series of pine trees from the Mediterranean area revealed that a combination of ring-width and blue intensity enhances the precision of dendroprovenancing (Table 3.3). By combining time series of LWBI with the commonly used TRW in a two-step procedure we were able to overcome the frequently observed elevation effect (e.g. Domínguez-Delmás et al., 2013) (Figures 3.2f and 3.3). In the first step, LWBI allows assigning time series to their elevation category (Figure 3.2f), while further analyses of TRW series within these elevation categories allowed the identification of trees' geographic origin with high precision (Table 3.3). This was possible due to the observed differences in the climate signal captured by the two selected variables, i.e. a summer drought signal in the LWBI and temperature and precipitation before and at the end of the growing season for TRW series (Figures 3.4 and 3.5). The difference in summer drought signal strength among elevation groups is triggered by the difference in average summer temperature between low and high elevation sites, i.e. sites from higher elevations experience less drought compared to lower elevations sites (e.g. SánchezSalguero et al., 2015). BI values were also found to express stronger relationships with climate than TRW in areas with temperature as the main growth limiting factor i.e. at high latitudes (Campbell et al., 2007; McCarroll et al., 2013; Fuentes et al., 2018), as well as in regions with no dominant climate signal in TRW series , e.g. in Caucasus (Dolgova, 2016), 
or Pyrenees (Büntgen et al., 2008; Wilson et al., 2017). This is explained by the fact that TRW chronologies contain aggregated information on conditions throughout the whole growing season, which also includes factors not related to climate (Cook, 1985), while LWBI, as a surrogate of maximum latewood density (MXD), specifically reflects summer conditions hence contains a stronger climatic signal (Björklund et al., 2014; Wilson et al., 2014). These factors likely explain why the combined LWBI and TRW approach can be used to identify the geographical origin of conifer wood in Mediterranean areas with higher precision than with TRW alone.

High provenancing precision can also be achieved by creating a dense reference network of chronologies (Domínguez-Delmás et al., 2015). However, creating long TRW chronologies from lower elevations is sometimes hampered by intensive logging in the past (DomínguezDelmás et al., 2013). In those areas, developing chronologies using proxies with a complementary or stronger climate signal, such as BI, may serve to overcome the lack of long-lived trees at low-elevation. Additional studies involving historic timber are needed to test this hypothesis.

\subsubsection{TRW and BI climate-growth relationships}

To our knowledge, this is the first study examining the potential of BI together with TRW for dendroprovenancing in dry areas, where trees experience a severe lack of soil water. Most of the studies involving BI were done at higher latitudes where trees' secondary growth as well as BI is positively affected by summer temperatures (e.g. Björklund et al., 2014; Wilson et al., 2014). But, due to the strong similarity between the BI and MXD variables (Campbell et al., 2007), BI-climate associations can be interpreted as MXD-climate one. In this sense, at several sites MXD was found to be strongly and directly dependent on conditions prevailing during late summer and early autumn, i.e. when the latewood is formed (Briffa et al., 1998). This strong association between latewood density and climate conditions at the end of the growing season are related to cell-wall lignification of the latest formed tracheids, which may take place long after the cells division (Gričar et al., 2005).

Under drought stress, conifer trees were found to produce smaller tracheids with thicker cell walls (Bouriaud et al., 2005; Park \& Spiecker, 2005), leading to the production of denser wood thus allowing tracheids to endure high xylem tension resulting from low water potential (Hacke et al., 2001). In our study, however, we observed a positive association between BI chronologies from low elevation trees and drought index (Figure 3.4). Similar 
positive correlations between summer SPEI and MXD were found for Pinus uncinata trees from the Pyrenees, which has been explained by the enhancement of carbohydrate production and tracheid lignification during wet summers (Galván et al., 2015). Presumably, similar processes may lead to the observed correlations with LWBI in our study. The positive correlation with 12-month scale SPEI (Figure 3.4) reflects that wood density in our study trees depends on the amount of available water during the entire year preceding the current growing season (c.f. Camarero et al., 2013). Such a long-term influence of previous-season conditions on latewood production/MXD was also found for $P$. halepensis in eastern Spain (Pasho et al., 2011b), P. pinaster (Caminero et al., 2018); P. nigra (Camarero et al., 2013), and for P. uncinata from the Pyrenees, but only for the second half of the twentieth century (Galván et al., 2015). This signal can be explained by benefits the tree has from carbohydrate synthesis and storage under favourable conditions in the previous year (Galván et al., 2015).

The observed negative effect of previous autumn temperature on TRW chronologies from Andalusia (Figure 3.5) together with positive precipitation was also found for P. nigra chronologies growing in the same region (Domínguez-Delmás et al., 2013), and for P. nigra, $P$.sylvestris and P. uncinata chronologies from other regions of Spain (Andreu et al., 2007). Positive previous autumn precipitation on TRW was also found for $P$. canariensis from the Canary Islands (Rozas et al., 2013). These results can be explained by the extension of the growing season due to the warmer autumn temperatures and hence consumption of carbohydrates and lower reserves formation for the next growing season, which eventually leads to the formation of narrower tree rings (Andreu et al., 2007). These results were also confirmed by Camarero et al. (1998). A strong positive effect of winter temperature on Andalusian TRW chronologies may also be related to the change of the vegetation period: colder winters may postpone growth resumption in the following springs and consequently depress ring formation (Domínguez-Delmás et al., 2013) and, vice versa, warmer winters might induce an earlier start of physiological activity in the tree and thus extend the length of the growing season (Lebourgeois, 2000). TRW chronologies from the Central System did not exhibit such a strong correlation with winter temperature. Instead, low elevation TRW chronologies were negatively/positively affected by summer temperature/precipitation, whereas high elevation chronologies were found to be negatively associated with late autumn temperature and positively with summer precipitation (Figure 3.5). The strong positive summer precipitation effect found in our study is in line with other studies on pines in the Mediterranean area (Sánchez-Salguero et al., 2015), as well as in dry areas in central 
Europe (Lebourgeois, 2000; Eilmann et al., 2010; Eilmann et al., 2011), where pine trees suffer from a lack of water which results in the reduction of secondary growth. The negative influence of October temperature found for high-elevation TRW chronology was also observed in mid- and low-elevation trees from the Central System (Sánchez-Salguero et al., 2015), where trees still have high photosynthetic rates while high temperatures inhibit secondary growth.

It is important to stress that our study is representative for two coniferous species in the Iberian Peninsula. For this dataset, the presented approach succeeded in dendroprovenancing timber from regions and elevations. Whether this approach is applicable to other species and/or regions remains to be tested in future studies.

\subsection{Conclusion}

Our study suggests that a stepwise, multivariate (PCGA) approach combining latewood blue intensity (LWBI) with tree-ring width enhances the precision of dendroprovenancing. Therefore, our study provides a meaningful contribution to increasing the reliability of identifying the origin of historical and/or sub-fossil timber in the Mediterranean area. Consequently, applying this approach at larger scales and to additional tree species may help to deepen our knowledge about past trade routes and the socio-economic development of the Iberian Peninsula.

\section{Acknowledgments}

This research work is part of the ForSEAdiscovery project (Forest Resources for Iberian Empires: Ecology and Globalization in the Age of Discovery) and was funded by the Marie Curie Actions program of the European Union (PITN-2013-607545). RSS is grateful to the project LESENS (RTI2018-096884-B-C33, Ministry of Science, Innovation and Universities, Spain). AB was supported by a postdoc fellowship of the German Academic Exchange Service (DAAD). We thank Fadi Hajj, Mohamed Traoré and Manuel SoutoHerrero for their great help in the field and in the lab. 


\section{SUPPORTING INFORMATION}

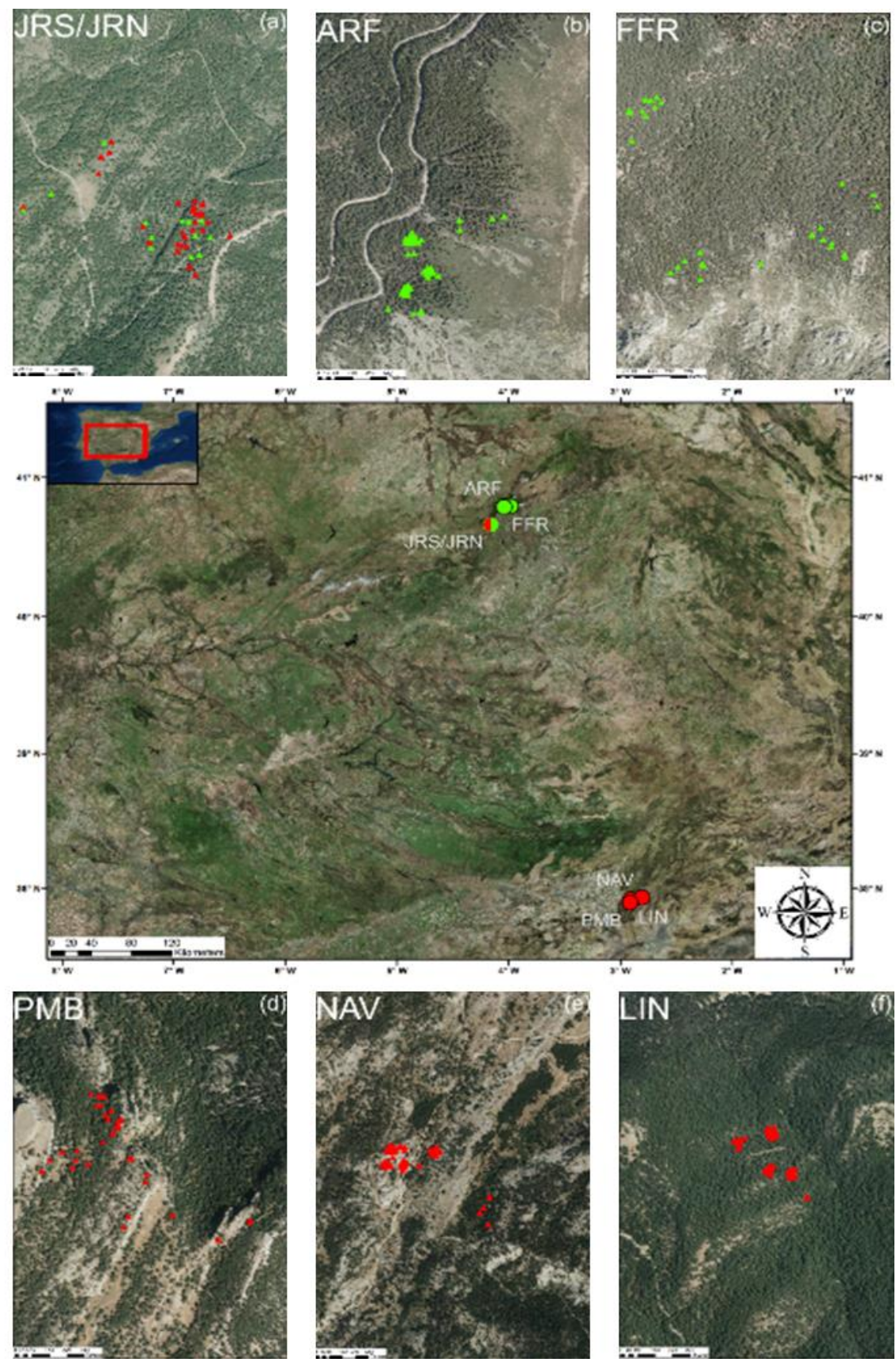

Figure S3.1. Location of the study sites and the distribution of sampled trees at each site (a-f). Green and red dots represent selected forest stands (see Table 3.1 for an explanation of the abbreviations of site names). Sites with double names indicate the collection of two different species from the same forest stand. Green and red colours refer to PISY and PINI, respectively. Layer credits: Source: ESRI 
Table S3.1. Comparison of the dendrochronological statistics calculated for each site and species. The statistics and mean ring-width values (SD for standard deviation were calculated for the common period 1900-2014 considering six variables (TRW ring width; EW earlywood width; LW latewood width; BI, delta blue intensity; EWBI, earlywood blue intensity, LWBI, latewood blue intensity), PC1 was calculated over the common interval varying per study site. All dendrochronological statistics were calculated for index chronologies, excepting Mean which was obtained from raw data.

\begin{tabular}{|c|c|c|c|c|c|c|c|c|c|c|c|c|c|c|c|c|c|c|}
\hline & & & & \multicolumn{5}{|l|}{ RW } & \multicolumn{5}{|l|}{ EW } & \multicolumn{5}{|l|}{ LW } \\
\hline Species & Region & Code & $\begin{array}{l}\text { Time } \\
\text { span }\end{array}$ & $\begin{array}{l}\text { Mean } \\
(\mathrm{mm})\end{array}$ & rbt & $\mathbf{A C}$ & MS & PC1 & Mean & rbt & $\mathbf{A C}$ & MS & PC1 & Mean & rbt & $\mathbf{A C}$ & MS & PC1 \\
\hline \multirow[t]{3}{*}{ PISY } & CS & ARF & $\begin{array}{l}1648- \\
2015\end{array}$ & 1.61 & 0.58 & 0.35 & 0.23 & $40 \%$ & 0.92 & 0.62 & 0.41 & 0.22 & $49 \%$ & 0.31 & 0.63 & 0.12 & 0.38 & $50 \%$ \\
\hline & CS & FFR & $\begin{array}{l}1515- \\
2015\end{array}$ & 0.60 & 0.57 & 0.27 & 0.25 & $37 \%$ & 0.54 & 0.50 & 0.34 & 0.23 & $38 \%$ & 0.15 & 0.54 & 0.04 & 0.42 & $39 \%$ \\
\hline & CS & JRS & $\begin{array}{l}1745- \\
2015\end{array}$ & 1.29 & 0.61 & 0.26 & 0.23 & $49 \%$ & 0.97 & 0.60 & 0.29 & 0.22 & $51 \%$ & 0.24 & 0.60 & 0.02 & 0.44 & $52 \%$ \\
\hline \multirow[t]{6}{*}{ PINI } & $\widetilde{\mathrm{CS}}$ & JRN & 1488- & 0.51 & 0.66 & 0.28 & 0.29 & $48 \%$ & 0.37 & 0.72 & 0.32 & 0.29 & $59 \%$ & 0.11 & 0.62 & 0.12 & 0.42 & $52 \%$ \\
\hline & AND & NAV & $\begin{array}{l}1501- \\
2014\end{array}$ & 1.25 & 0.69 & 0.31 & 0.29 & $49 \%$ & 0.66 & 0.58 & 0.31 & 0.24 & $45 \%$ & 0.34 & 0.56 & 0.13 & 0.44 & $46 \%$ \\
\hline & AND & PMB & $\begin{array}{l}1498- \\
2014\end{array}$ & 0.66 & 0.67 & 0.29 & 0.38 & $52 \%$ & 0.59 & 0.54 & 0.26 & 0.32 & $44 \%$ & 0.27 & 0.51 & 0.21 & 0.52 & $43 \%$ \\
\hline & AND & LIN & $\begin{array}{l}1795- \\
2014\end{array}$ & 0.85 & 0.62 & 0.25 & 0.32 & $41 \%$ & 0.67 & 0.58 & 0.24 & 0.29 & $46 \%$ & 0.34 & 0.63 & 0.14 & 0.46 & $52 \%$ \\
\hline & & & & \multicolumn{5}{|l|}{$\Delta \mathrm{BI}$} & \multicolumn{5}{|l|}{ EWBI } & \multicolumn{5}{|l|}{ LWBI } \\
\hline & & & & Mean & rbt & $\mathbf{A C}$ & MS & PC1 & Mean & rbt & $\mathbf{A C}$ & MS & PC1 & Mean & rbt & $\mathbf{A C}$ & MS & PC1 \\
\hline \multirow[t]{3}{*}{ PISY } & CS & ARF & $\begin{array}{l}1676- \\
2015\end{array}$ & 0.27 & 0.42 & 0.09 & 0.27 & $40 \%$ & 1.22 & 0.21 & 0.26 & 0.02 & $17 \%$ & 1.51 & 0.47 & 0.11 & 0.04 & $38 \%$ \\
\hline & CS & FFR & $\begin{array}{l}1609- \\
2015\end{array}$ & 0.23 & 0.45 & 0.06 & 0.32 & $37 \%$ & 1.27 & 0.28 & 0.31 & 0.02 & $23 \%$ & 1.50 & 0.52 & 0.08 & 0.04 & $40 \%$ \\
\hline & CS & JRS & $\begin{array}{l}1814- \\
2015\end{array}$ & 0.29 & 0.58 & 0 & 0.28 & $49 \%$ & 1.38 & 0.19 & 0.31 & 0.02 & $20 \%$ & 1.67 & 0.54 & 0.11 & 0.04 & $47 \%$ \\
\hline \multirow[t]{4}{*}{ PINI } & CS & JRN & $\begin{array}{l}1503- \\
2015\end{array}$ & 0.21 & 0.62 & 0.09 & 0.35 & $44 \%$ & 1.38 & 0.32 & 0.22 & 0.02 & $21 \%$ & 1.60 & 0.59 & 0.18 & 0.04 & $42 \%$ \\
\hline & AND & NAV & $\begin{array}{l}1708- \\
2014\end{array}$ & 0.26 & 0.38 & 0.26 & 0.28 & $31 \%$ & 1.35 & 0.16 & 0.24 & 0.02 & $29 \%$ & 1.64 & 0.40 & 0.14 & 0.03 & $39 \%$ \\
\hline & AND & PMB & $\begin{array}{l}1640- \\
2014\end{array}$ & 0.27 & 0.34 & 0.06 & 0.40 & $33 \%$ & 1.38 & 0.14 & 0.19 & 0.03 & $23 \%$ & 1.65 & 0.41 & 0.17 & 0.05 & $32 \%$ \\
\hline & AND & LIN & $\begin{array}{l}1795- \\
2014\end{array}$ & 0.47 & 0.41 & 0.06 & 0.28 & $33 \%$ & 1.15 & 0.30 & 0.21 & 0.03 & $18 \%$ & 1.62 & 0.45 & 0.07 & 0.06 & $33 \%$ \\
\hline
\end{tabular}




\section{Chapter 3. Pines}
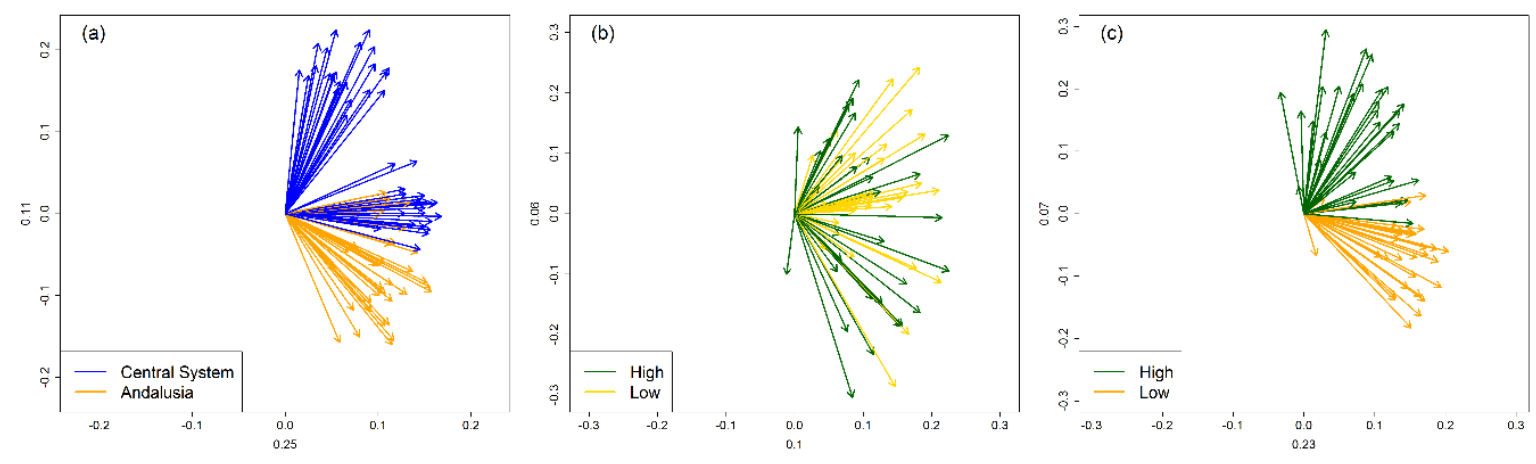

Figure S3.2. PCGA loadings plots for a) EW b) EWBI and c) $\Delta B I$. Each arrow represents the loadings on the first two principal components from one tree. Values on the $x$ - and $y$-axes represent the amount of explained variance by the respective component.
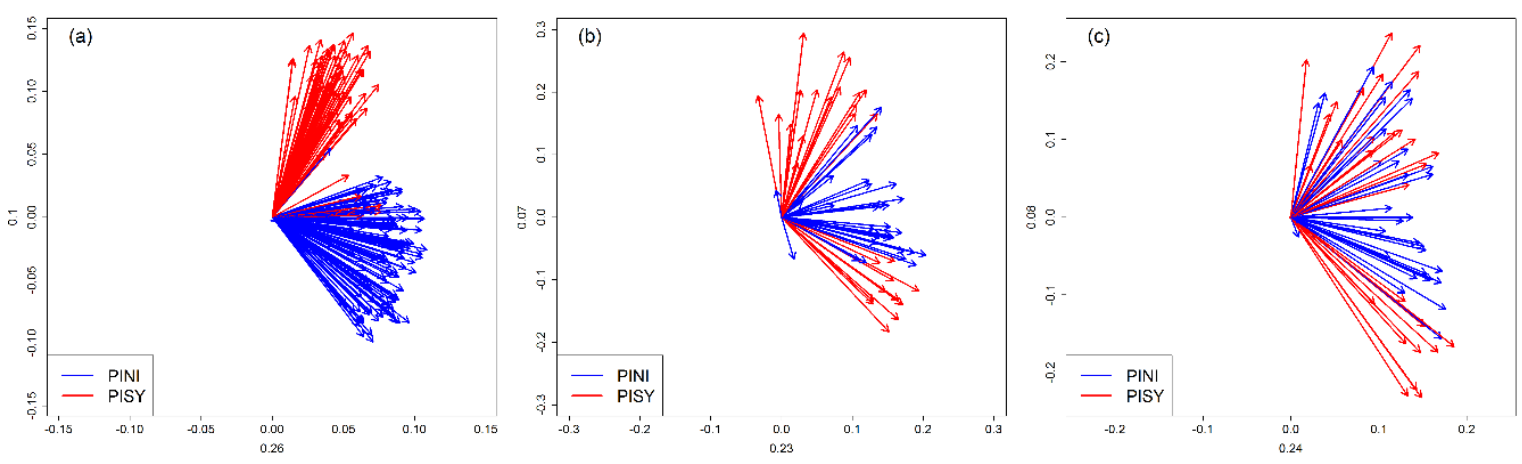

Figure S3.3. PCGA loadings plots for a) TRW b) LW and c) LWBI. Each arrow represents the loadings on the first two principal components from one tree. Values on the $x$ - and $y$-axes represent the amount of explained variance by the respective component. 

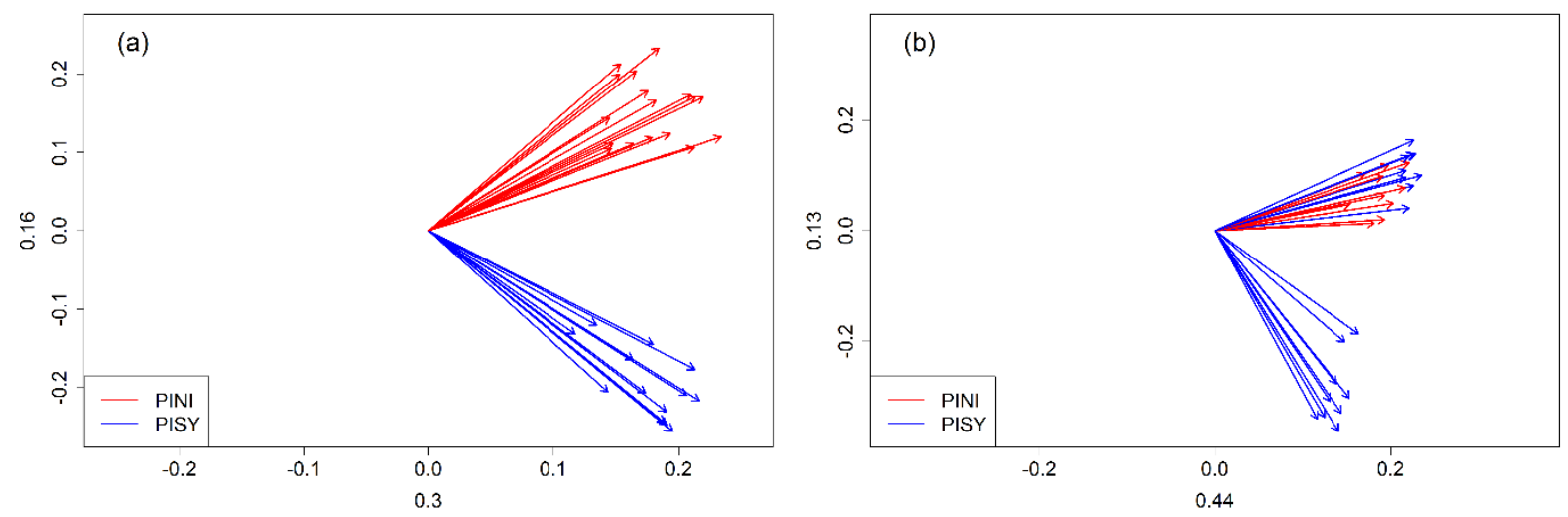

Figure S3.4. PCGA loadings plots based on tree-ring width index of a) trees from high elevations and b) trees from low elevation. Each arrow represents the loadings on the first two principal components from one tree. Values on the $x$ - and $y$-axes represent the amount of explained variance by the respective component. 

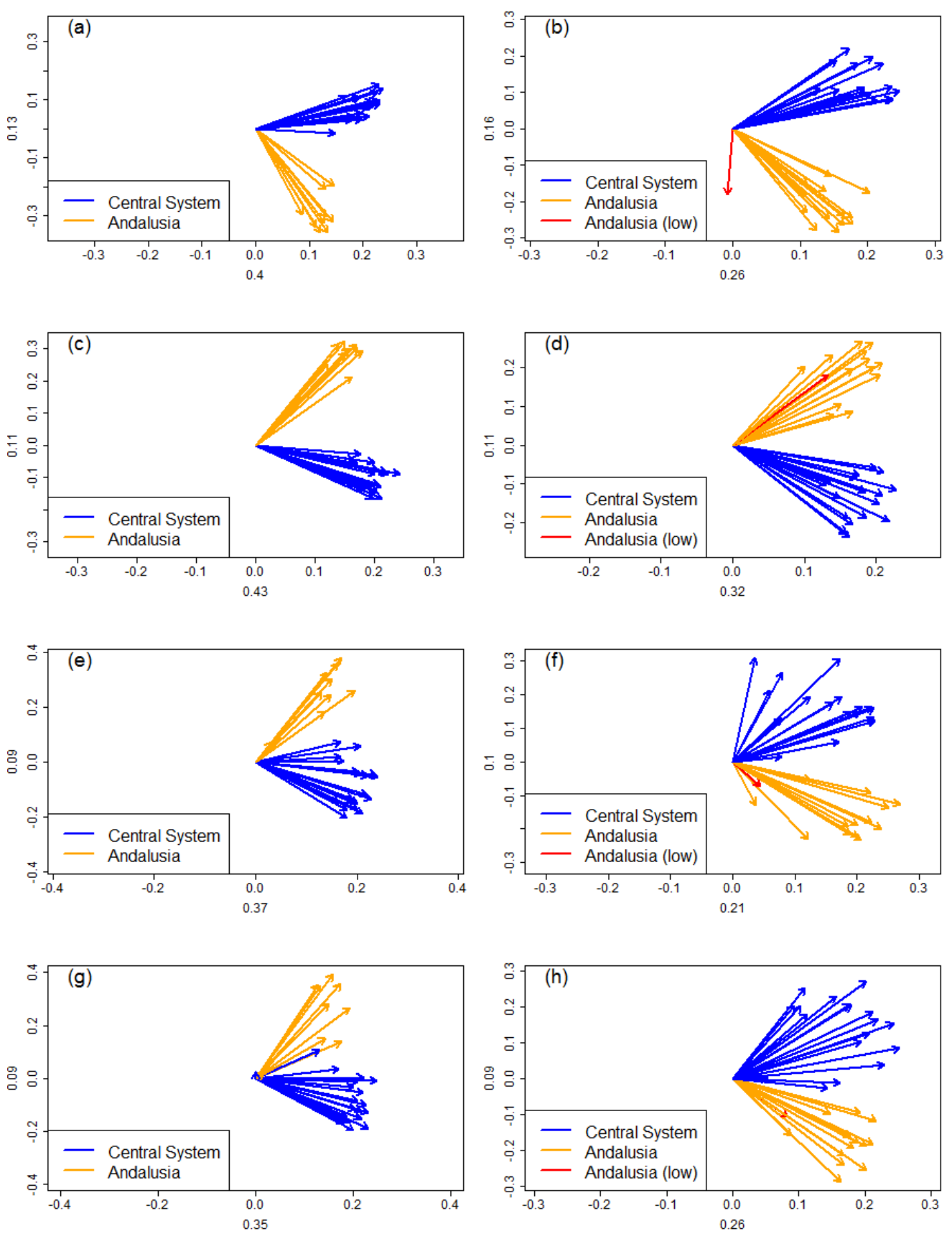

Figure S3.5. Loadings plot for the PCGA based on a) EW of trees from low elevations, b) EW of trees from high elevations, c) LW of trees from low elevations, d) LW of trees from high elevations, e) $\triangle \mathrm{BI}$ of trees from low elevations, $\mathrm{f}) \Delta \mathrm{BI}$ of trees from high elevations, g) LWBI of trees from low elevations, f) LWBI of trees from high elevations. One "Andalusia (low)" red arrow on plots of trees from high elevations $(b, d, f, h)$ represents the outlier from the LWBI PCGA Each arrow represents the loadings on the first two principal components from one tree. Values on the $x$ - and $y$-axes represent the amount of explained variance by the respective component. 
Chapter 3. Pines 
(1)

(2)
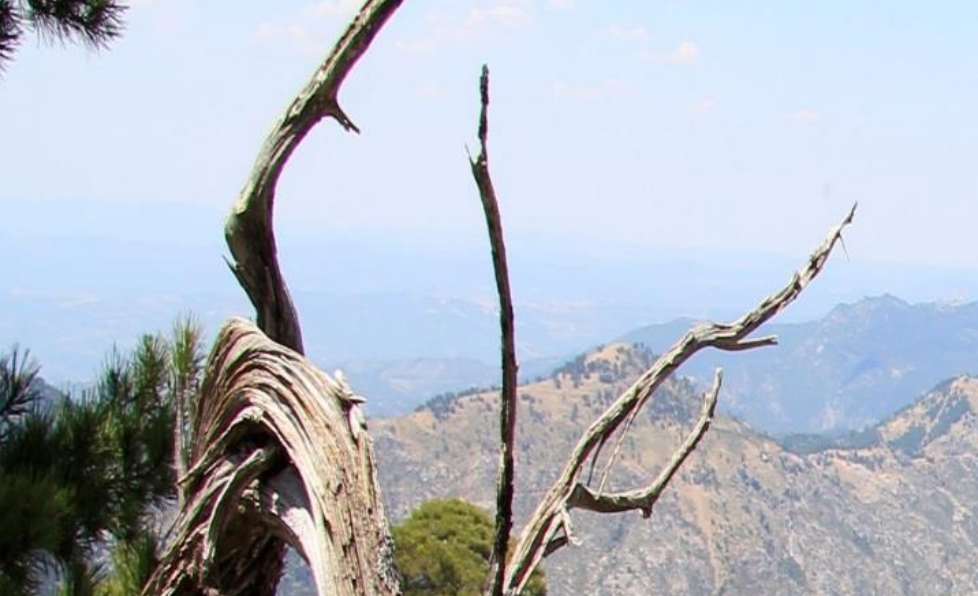

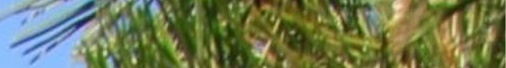

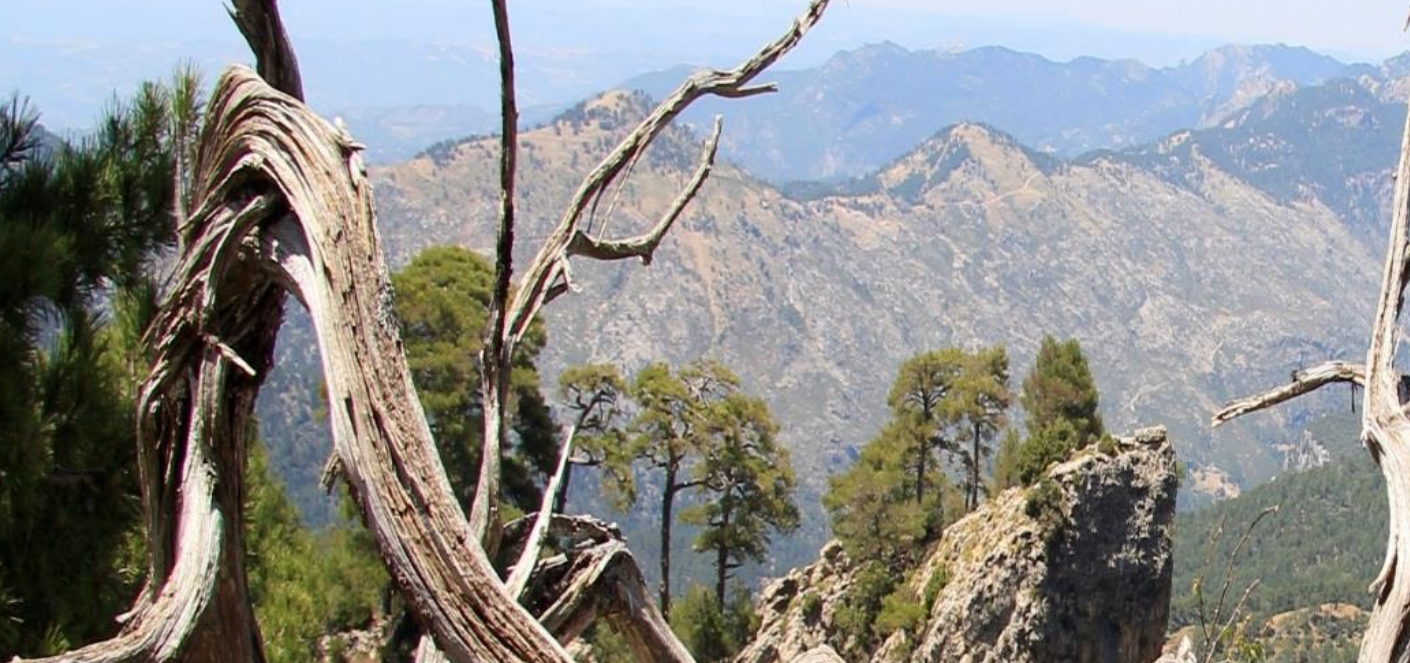

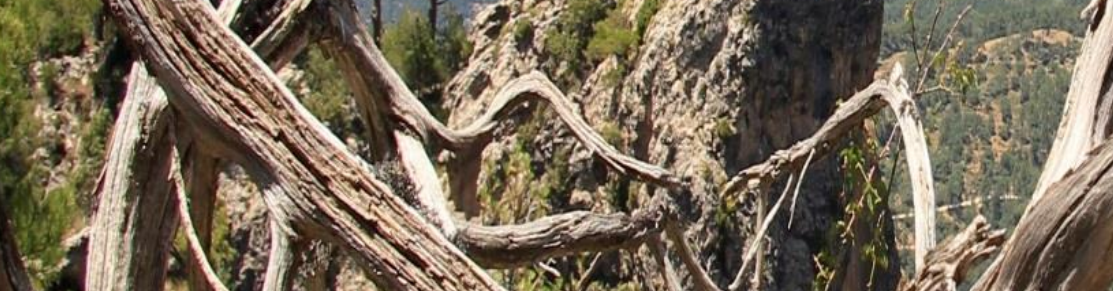

1)
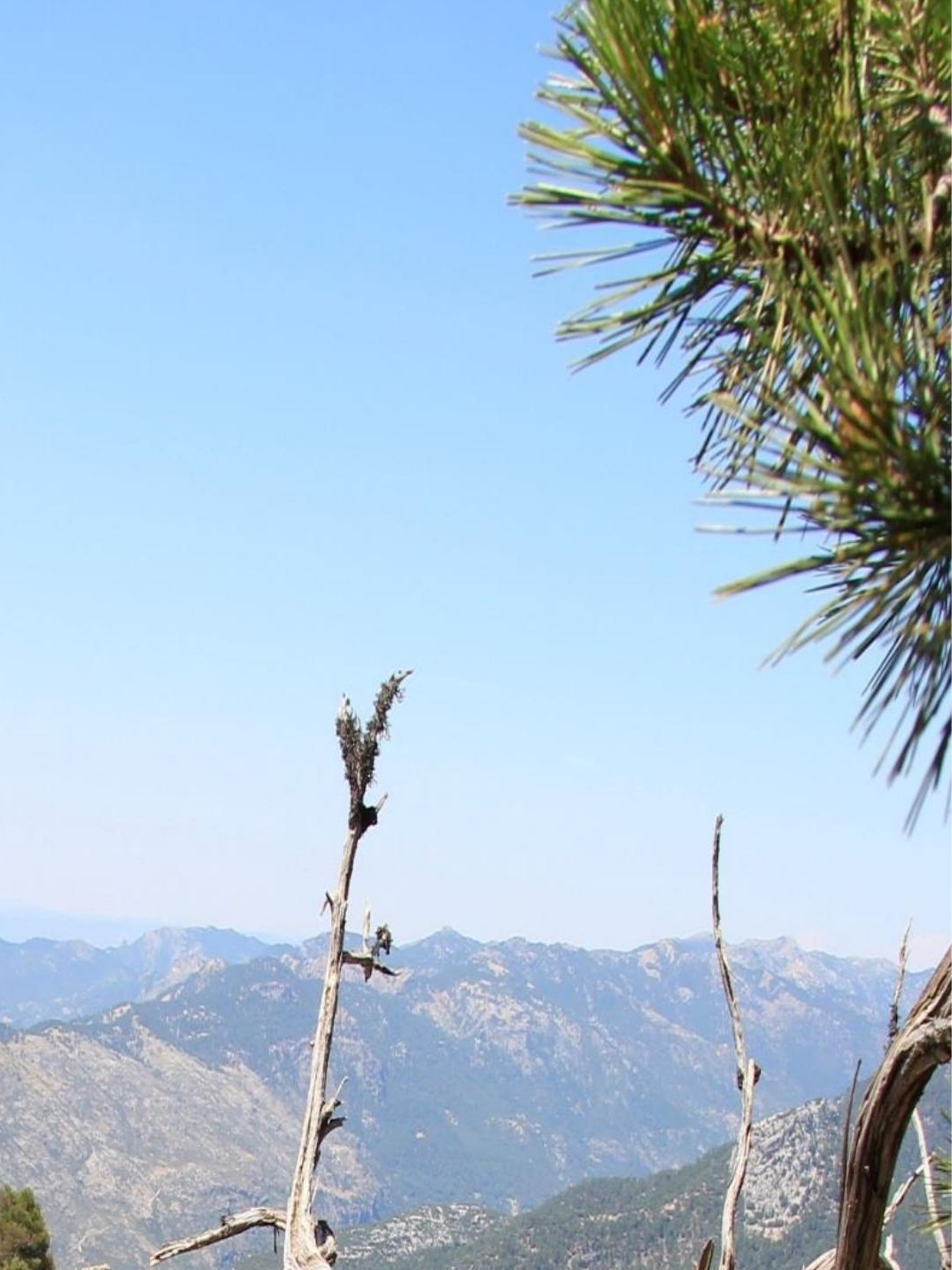

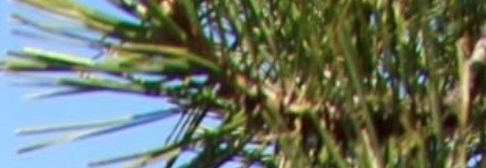

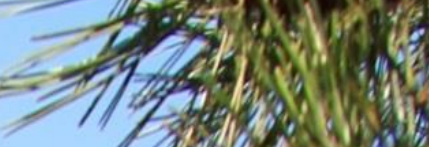

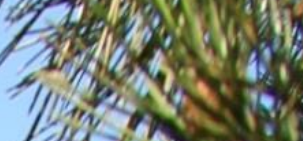

th
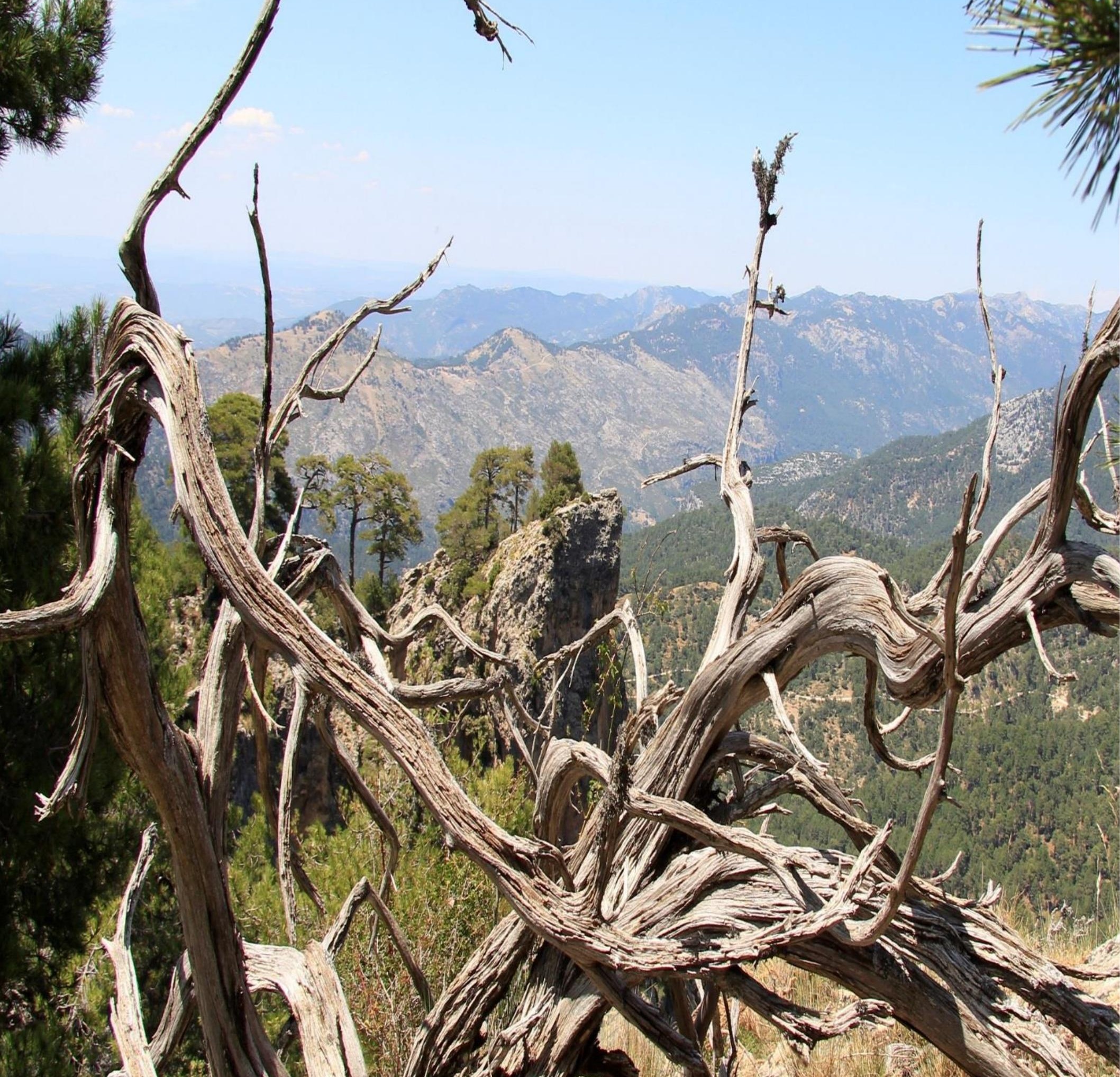
1. 12 -

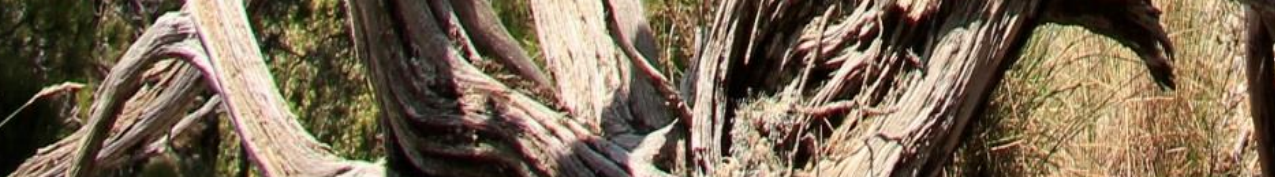
- 4 ars.

a. $12 \times$

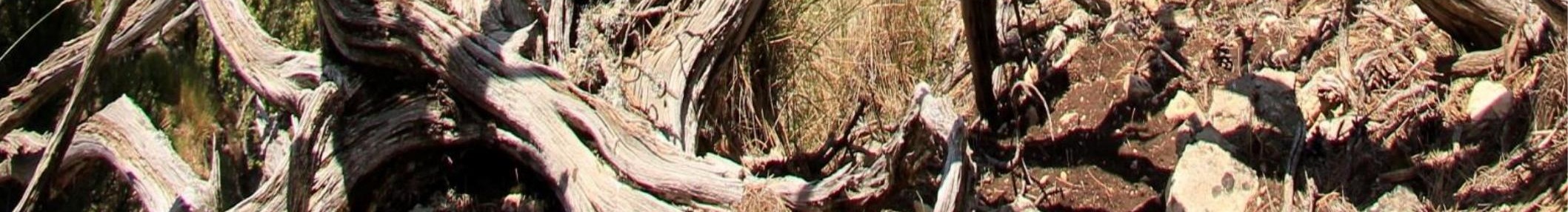
I) 


\section{Chapter 4}

\section{DNA of centuries-old timber reveals its origin}

Akhmetzyanov L., Copini P., Schroeder H., de Groot G.A., Daly, A., SassKlaassen U. 


\begin{abstract}
Ring-porous oak species were highly appreciated and widely used for ship and buildings construction in the past. With the rapid economic development and demographic evolution, the local forest could hardly sustain increased demand in high-quality timber. Therefore, vast amounts of (oak) timber were imported from elsewhere, mainly from Baltic states. Origin of archaeological or historical timber is usually identified by means of dendroprovenancing, i.e. statistical match of tree-ring width series of timber with unknown origin with available reference dataset. However, in recent decades potential of other techniques to enhance the precision of dendroprovenancing has been widely studied. Here we investigate potential of extraction of a sufficient amount of DNA from old, degraded oak timber derived from historical objects from Denmark, Latvia, and Spain. DNA extraction from the wood is challenging, as it mainly consists of dead cells and contains extractives inhibiting DNA amplification. Archaeological timber is even more challenging material as it has been subjected to environmental exposure and is often decomposed. Despite this, from $60 \%$ of samples (including heartwood samples), DNA was successfully amplified at least for one marker per type of analyses. An existing haplotype distribution map was used to identify the potential source area of material from two study cases from Latvia and Denmark. The results suggest that genetic analyses have a strong potential for pinpointing timber origin, though until now only in combination with the TRW based method. However, improvements in DNA extraction from degraded wood and amplification protocols are essential for future applications in dendroprovenancing studies.
\end{abstract}




\subsection{Introduction}

Demographic evolution during the Middle Ages in Northern Europe and during the Age of Discovery in the Iberian peninsula (Bauer, 1980) resulted in an increased need for construction timber which in turn resulted in a radical change of forest cover in certain areas (Haneca et al., 2005). Local forests could hardly sustain the increased demand in primarily high-quality timber for shipbuilding and construction of monumental buildings, e.g. cathedrals (Haneca \& Debonne, 2012). Therefore, vast amounts of wood had to be imported from elsewhere, mainly by rafting via the rivers or by shipping (Rackham, 1982; Aranda, 1990) also from other continents (Bauer, 1980).

Ring-porous oak wood (Quercus spp.) was highly appreciated for its mechanical properties and its durable heartwood (Haneca et al., 2009), which makes that oak timbers of different dimensions are commonly found as archaeological remains (e.g. Haneca \& Beeckman, 2005; Haneca et al., 2006). Identification of the origin of archaeological timber allows understanding of the organization of timber-trade networks and transportation of timber in the past (e.g. Ważny 2001; Ważny, 2002; Daly, 2007a; Domínguez-Delmás et al., 2014). The date and origin of such a timber can be identified using dendroprovenancing, i.e. matching tree-ring width (TRW) series of the timber with reference TRW chronologies existing for the species (Speer, 2010). Until now, this TRW-based method was the most common approach to pinpoint the origin of timber (e.g. Daly, 2007b; Sass-Klaassen et al., 2008; Domínguez-Delmás et al., 2013). Tests on using other tree-ring related wood-anatomical (Akhmetzyanov et al., 2019) or wood chemical (Kagawa \& Leavitt, 2010) time series as well as wood-chemical profiles (Traore et $a l ., 2018$ ) have also been carried out and revealed the power and weakness of each method, but also the potential of integrating different approaches (Akhmetzyanov et al., 2019). The first trial on exploring DNA analyses for oak timber provenancing has also indicated the large potential but also the need for improvements (Deguilloux et al., 2004).

The genetics of ring-porous European oaks have been intensively studied, and a detailed genetic reference dataset was created during the last decades based on samples from 2613 populations by a consortium of 16 laboratories. Together, they distinguished 32 distinct genotypes, referred to as haplotypes (Petit et al., 2002b). The availability of such an extensive data on oak haplotype distribution across Europe would allow pinpointing wood origins from regional up to countrylevel within the continent, as a strong phylogeographic structure was observed among these 32 oak cpDNA variants (Petit et al., 2002b). Moreover, Schroeder et al. (2016) developed a set of DNA markers for the identification of oak timber origin on a continental level. These markers 
can be used as a first step to identify the continental source (Europe, Asia or North America) of archaeological oak timber. Thus, using markers first for continental provenancing and then using chloroplast single sequence repeat (cpSSRs) markers (microsatellites) developed explicitly for haplotype identification of white European oaks (Deguilloux et al., 2003a) would, in theory, allow pinpointing potential source areas. Finally, species identification of oak trees could serve as an additional tool to scale down provenancing precision, as distribution areas of species do not always overlap (e.g. Ellenberg, 1988; Blanco Castro, 2005), e.g. identification of endemic Iberian oak species would indicate Iberia as the origin of studied oak timber.

Although reference data sets are to some extent available, application of DNA-based provenancing methods is still hampered by the quality of DNA which can be extracted from old and partially degraded wood samples. Methods to extract the required amounts of DNA of sufficient quality from wood are still under development even if dealing with contemporary timber samples, and here specifically if it concerns heartwood. Sapwood contains living (parenchyma) cells, whereas all heartwood cells, although mostly still intact, are already dead for many years (Bamber \& Fukazawa, 1985), meaning that the DNA is also partly degraded. Moreover, heartwood contains extractives, which increase the resistance of cell walls to degradation but may inhibit DNA amplification (Deguilloux et al., 2002). DNA extraction from historical timber is even more challenging, as old timber has been subjected to environmental abiotic (UV radiation, changes in moisture content resulting in shrinkage and swelling) and biotic (fungi, insects) exposure for long periods and its cells are often partly mechanically affected or decomposed. The few studies done on DNA extraction from the heartwood of archaeological timber showed limited success expressed in low amplification rates (DumolinLapegue et al., 1999; Deguilloux et al., 2006) whereas a recent study based on the sapwood of archaeological timber showed promising results (Wagner et al., 2018). However, finding a sufficient amount of sapwood remained in historical or even archaeological ship timber is a challenge, as often either only the more durable heartwood was used for construction purposes or sapwood that remained attached has been decomposed.

In this study, we explore the potential of extracting and analysing DNA from oak timber from historical objects in Spain, Denmark, and Latvia to identify the geographical origin of the timber. We hypothesize that DNA can be extracted from sapwood and in smaller quantity and quality also from heartwood. This DNA can then be used for provenancing oak timber a) on the continental level and b) on regional/country level. Finally, we use two case studies to illustrate 
the added value of integrating DNA into provenancing and the relevance for applied archaeological investigations.

\subsection{Materials and Methods}

\subsubsection{Sample collection}

A total of 13 sapwood and 17 heartwood samples (Quercus spp.) were collected from 17 historical objects (Table 4.1). The number of objects ranged from five in Northern Spain and Denmark to seven in Latvia. All these samples were previously dendrochronologically dated, and ages ranged from the $13^{\text {th }}$ to $17^{\mathrm{h}}$ century (Table 4.1). Based on the anatomy and chronologies used for dating, all objects were identified as deciduous oak species.

We also included sapwood and heartwood from contemporary trees as a reference (respectively five Quercus petraea, $Q$. faginea and $Q$. pyrenaica, and three $Q$. robur trees). All contemporary oaks are growing in forests located in the Basque Country, Northern Spain $\left(42^{\circ} 43^{\prime}-42^{\circ} 56^{\prime} \mathrm{N}\right.$; $\left.2^{\circ} 48^{\prime}-2^{\circ} 51^{\prime} \mathrm{W}\right)$ where trees were intensively logged in the past for ship construction. In October 2016, one wooden sample was taken from each tree by using a $40 \mathrm{~cm}$ long Haglöf increment borer. Obtained samples were put into zipped plastic bags with silica gel.

The samples from historical objects were sent to the Molecular Ecology Laboratory of Wageningen Environmental Research, Wageningen, The Netherlands and the Thünen Institute of Forest Genetics, Großhansdorf, Germany for DNA analyses. Historical and fresh samples were always treated completely separated, i.e. kept and analysed in different lab rooms to avoid contamination.

\subsubsection{DNA isolation}

The samples were first treated with UV light in the PCR cabinets for two hours per side. Then the outer layer of the sample was removed. The remaining sample was cut into pieces and 300 $\mathrm{mg}$ was incubated in liquid nitrogen for 2 minutes with a stainless steel bead ( $5 \mathrm{~mm}$; Qiagen, The Netherlands). The frozen sample was grounded using a mixer-mill apparatus Type MM 300 (Westburg) for $2 \mathrm{~min}$ at $20 \mathrm{~Hz}$ frequency. For the contemporary trees, we used $100 \mathrm{mg}$ of each sample, and samples were not UV treated. 
Table 4.1. List of historic objects used in DNA analyses with information on object, its age as derived from dendrochronological dating, the wood type and researcher responsible for sample collection.

\begin{tabular}{|c|c|c|c|c|c|}
\hline $\begin{array}{c}\text { Object } \\
\text { code }\end{array}$ & Location of object & Object & Dated to & $\begin{array}{c}\text { Wood } \\
\text { type }\end{array}$ & Collector \\
\hline JMT011 & Jugo, Spain & staircase & 1777 & SW/HW & $\begin{array}{l}\text { M. Domínguez- } \\
\text { Delmás }\end{array}$ \\
\hline JMT031 & Jugo, Spain & staircase & 1779 & SW/HW & $\begin{array}{l}\text { M. Domínguez- } \\
\text { Delmás }\end{array}$ \\
\hline ARR031 & Arriola, Spain & roof beam & 1762 & SW/HW & $\begin{array}{l}\text { M. Domínguez- } \\
\text { Delmás }\end{array}$ \\
\hline SVT031 & $\begin{array}{c}\text { San Vicente de Arana, } \\
\text { Spain }\end{array}$ & roof beam & 1548 & SW/HW & $\begin{array}{l}\text { M. Domínguez- } \\
\text { Delmás }\end{array}$ \\
\hline SVT061 & $\begin{array}{c}\text { San Vicente de Arana, } \\
\text { Spain }\end{array}$ & roof beam & 1548 & SW/HW & $\begin{array}{l}\text { M. Domínguez- } \\
\text { Delmás }\end{array}$ \\
\hline H011001 & Aalborg, Denmark & beam & $1564-79$ & SW/HW & A .Daly \\
\hline H011005 & Aalborg, Denmark & beam & $1560-75$ & HW & A. Daly \\
\hline F042003 & Horsens, Denmark & beam & $1614-22$ & SW/HW & A. Daly \\
\hline F042010 & Horsens, Denmark & beam & $1608-23$ & SW/HW & A. Daly \\
\hline F042011 & Horsens, Denmark & beam & $1621-22$ & SW/HW & A. Daly \\
\hline JK-I & Riga, Latvia & beam & $\sim 1514(=1493)$ & HW & M. Zunde \\
\hline JK-B & Riga, Latvia & beam & 1678(?) & HW & M. Zunde \\
\hline $\mathrm{JKd} 2$ & Riga, Latvia & door & $\sim 1479(=1477)$ & SW/HW & M. Zunde \\
\hline CesDt2 & Cesis, Latvia & arquebus & $\sim 1538$ & SW/HW & M. Zunde \\
\hline CesDt3 & Cesis, Latvia & arquebus & $\sim 1538$ & SW/HW & M. Zunde \\
\hline CesDt5 & Cesis, Latvia & arquebus & $\sim 1538$ & HW & M. Zunde \\
\hline CRL32 & Cesis, Latvia & beam & $\sim 1278$ & SW/HW & M. Zunde \\
\hline
\end{tabular}

Dated to - an estimated cutting date based on sapwood statistics.

SW/HW - sapwood and heartwood, respectively

Next, we used two different DNA extraction protocols on all samples from historical objects.

Protocol 1: DNA extraction was done using the DNeasy Plant Mini Kit (Qiagen, The Netherlands) following Rachmayanti et al. (2006), adding $2.6 \%$ of polyvinylpyrrolidone (PVP), into the AP1 lysis buffer of the DNeasy Plant Mini Kit and treating with $0.1 \mathrm{M} \mathrm{N}$ Phenacylthiazolium bromide (PTB), $20 \mathrm{mg} / \mathrm{ml}$ of proteinase $\mathrm{K}$ and $1 \mathrm{M}$ solution of DTT before lysis incubation.

Protocol 2: DNA extraction was done using a previously developed and patented protocol based on the CTAB method (Lowe et al., 2015) in combination with the innuPREP Plant DNA Kit from Analytik Jena (Germany) which was used for the last purification step.

DNA from contemporary trees was extracted following Protocol 1 only. 


\subsubsection{Determining continental origin}

To determine the continental origin, we used the chloroplast marker set developed and published by Schroeder et al. (2016). First, we used DNA from the contemporary trees to test whether continental provenancing also worked for $Q$. pyrenaica and $Q$. faginea - two species that were not included in the study of Schroeder et al. (2016) but were commonly used in construction (Domínguez-Delmás et al., 2014). Next, DNA from the historical objects extracted by both extraction protocols was amplified according to Schroeder et al. (2016). Due to the small amount of total DNA extracted from the historic objects, the DNA quantity was not determined and a standard dilution of 1:10 and 1:20 (DNA:water) was used for all PCR reactions.

\subsubsection{Determining haplotypes}

The same DNA extracts and dilutions were used for haplotype identifications of the historical objects. For the latter, again, two different methods were used: an approach based on microsatellites located on the chloroplast genome (cpSSR) and a restriction fragment length polymorphism (RFLP) approach. For microsatellite analyses, we used a total of six markers. Five were previously developed by Deguilloux et al. (2003a) ( $\mu d t 1, \mu c d 5, \mu k k 4, \mu d t 4$, and $\mu d t 3$ ). A newly identified, sixth marker ( $T F-I v o$ ) was used for discrimination between haplotypes 10 and 11 (see Table S4.1 in Supplementary Material for primers sequences). Primers were designed from sequencing the whole TF fragment of non-coding DNA, following Taberlet et al. (1991).

The used set of markers allows differentiating between haplotypes 1, 7, 10,11, and 12, five common oak haplotypes in Europe. Amplification was done in multiplex PCR using $10 \mu \mathrm{PCR}$ reactions, containing $2 \mu \mathrm{l}$ template DNA, $1.9 \mu \mathrm{l} \mathrm{H}_{2} \mathrm{O}, 5 \mu \mathrm{l}$ Qiagen Multiplex Buffer (Qiagen

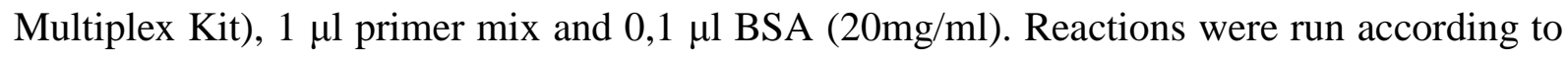
the following protocol: $15 \mathrm{~min}$ at $95^{\circ} \mathrm{C}$, then 45 cycles of $15 \mathrm{sec}$ at $94^{\circ} \mathrm{C}, 180 \mathrm{sec}$ at $53^{\circ} \mathrm{C}, 60$ sec at $72^{\circ} \mathrm{C}$, and finally $30 \mathrm{~min}$ at $60^{\circ} \mathrm{C}$. PCR products were diluted 100 times before fragment length analyses.

For the RFLP analyses, primers developed in Thünen Institute were used (see Table 4.2 for details). This set of markers allows identification haplotypes $4 / 5 y$ and $5 x / 6$ in addition to the cpSSR method. Amplification was done using $15 \mu \mathrm{l}$ PCR reactions, containing $5 \mu \mathrm{l}$ template DNA, $1.5 \mu \mathrm{l}$ AmpliTaq Gold 360 Buffer, $1.5 \mu \mathrm{l} \mathrm{MgCl} 2,0.3 \mu \mathrm{l}$ dNTPs, $0.08 \mu \mathrm{l}$ AmpliTaq Gold DNA polymerase (ThermoFisher Scientific, Darmstadt, Germany), $0.3 \mu 1360$ GC Enhancer, 
and $0.15 \mu \mathrm{l}$ of each primer per marker. PCRs were run according to the following protocol: $94^{\circ} \mathrm{C}$ for $10 \mathrm{~min}$, followed by 45 cycles of $94^{\circ} \mathrm{C}$ for $45 \mathrm{sec}, 52^{\circ} \mathrm{C}\left(54^{\circ} \mathrm{C}\right.$ for QT8F_QT5R) for $45 \mathrm{sec}$ and $72^{\circ} \mathrm{C}$ for $45 \mathrm{sec}$, and a final elongation at $72^{\circ} \mathrm{C}$ for $10 \mathrm{~min}$.

For all markers, restriction enzymes were used (Table 4.2). The restriction digestion reaction contained $10 \mu \mathrm{l}$ PCR product, $2.2 \mu \mathrm{l} \mathrm{CutSmart}{ }^{\circledR}$ buffer, and $0.6 \mu l$ enzyme in a final volume of $20 \mu \mathrm{l}$. The reaction lasted $60 \mathrm{~min}\left(20 \mathrm{~min}\right.$ for QT8F_QT5R) at $37^{\circ} \mathrm{C}$ followed by an inactivation at $65^{\circ} \mathrm{C}\left(80^{\circ} \mathrm{C}\right.$ for QT8F_QT5R) for $20 \mathrm{~min}$. Digestion products were diluted five times before further analyses.

Analyses of all diluted PCR and digestion products was done using an automated ABI Prism ${ }^{\circledR}$ Genetic Analyzer (Applied Biosystems) coupled to 3730 Series Data Collection Software 4. Fragment sizes (alleles) were scored using GeneMarker® v.2.6.7 (Softgenetics, State College, PA, USA) software.

Table 4.2. List of primers for the amplification and resequencing of the markers. Fluorescence-labelling of the primers is given in column "sequence": VIC = green.

\begin{tabular}{cccc}
$\begin{array}{c}\text { Marker } \\
\text { name }\end{array}$ & Primer & Sequence 5`-3‘ & Restriction enzyme \\
\hline \multirow{2}{*}{ QT8F_QT5R } & QT8F & to be published & MluCI \\
& QT5R & & \\
Dt72F_QT5R & Dt72F & GCG TTG CTA TTT AGT AAA TCC & MseI \\
& QT5R & GTC ATT CGC CAC TAT GAG TC_VIC & \\
QT7F_R & QT7F & to be published & HpyCH4V \\
\hline
\end{tabular}

To control for (cross) contamination, each DNA extraction included two to four negative controls, and each PCR run one negative control. They were treated in the same way as the normal samples except that no DNA was added.

To see if the marker size effects effectiveness of the DNA amplification, Spearman correlation was computed between the amplification success rate (per marker) and the mean PCR product size (in bp) expected from the respective marker. Moreover, to test the significance of the marker length effect on DNA amplification success, bootstrapped linear modelling resembling rows of the original data was applied. 


\subsubsection{Results}

For 18 samples from historical objects (60\% of the total amount of samples) allele scores were obtained for at least one of the provenancing methods tested, although rarely scores were obtained for all markers of a method (Table 4.3). Success percentages differed between different combinations of extraction and provenancing methods (Figure 4.1a). Both the highest and lowest success percentages were observed for the cpSSR haplotyping method, depending on the extraction protocol used. Among these 18 samples, nine were heartwood and nine sapwood samples (Table 4.3) with ages varying between 237 and 478 years. More sapwood than heartwood samples showed successful allele scores for the cpSSR haplotyping method and $\mathrm{CP}$, while the opposite was found for the RFLP (Figure 4.1b). Wherever multiple results for the same object were obtained (e.g. from two extraction methods or both for heartwood and sapwood), the results were always confirming each other (as can be seen in Table 4.3).

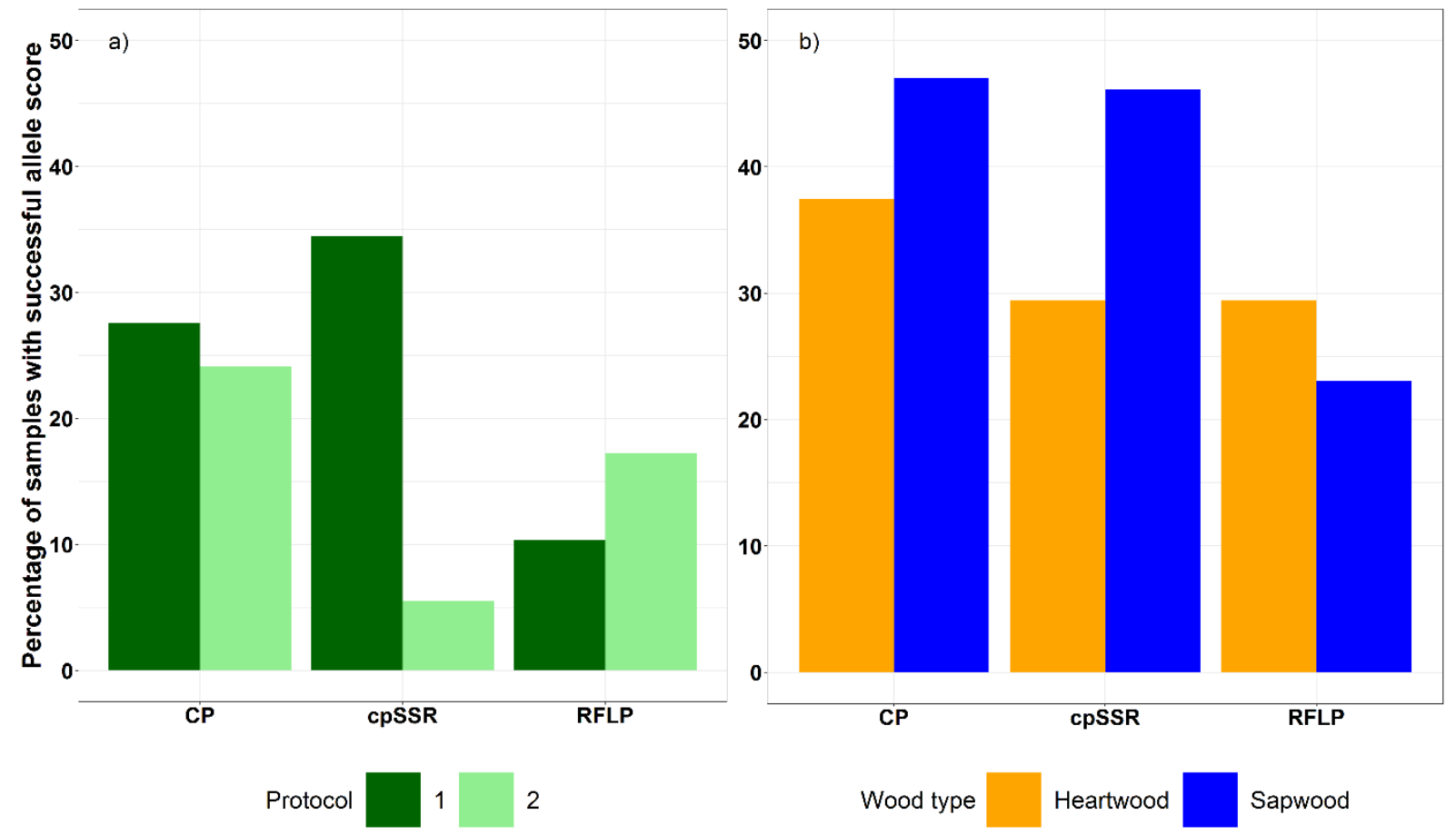

Figure 4.1. Percentages of samples with successful allele scores per extraction protocol (a) and per wood type (b). CP, cpSSR and RFLP refer to continental provenancing, microsatellites and restricted length polymorphism analyses, respectively. Samples with at least one marker scored per provenancing method are considered as successful. 


\subsubsection{Continental provenancing}

Using the contemporary trees, we found that the same alleles and their combination of $Q$. pyrenaica and $Q$. faginea from Spain were the same as of other European oak species, such as $Q$. robur and $Q$. petraea (Table S4.2). In total, DNA of $72.3 \%$ of samples was successfully amplified, and fragment sizes were scored. From this subset, all samples showed fragment lengths indicating European origin.

Among the historical set of samples with at least one allele scored, three samples were identified as "European oak" and 10 samples were identified as having either Eurasian or European/North American origin (Table 4.3). Out of these 13 samples, eight were sapwood and five heartwood type (Figure 4.1b).

A comparable success percentage between extraction protocols was achieved for the $\mathrm{CP}$ analyses: $27.6 \%$ and 24.1\% per Protocol 1 and Protocol 2, respectively (Figure 4.1a).

\subsubsection{Haplotype determination}

For the cpSSR analyses, amplification percentage depended strongly on the extraction method used, with DNA extracted using Protocol 1 showing considerably higher success than DNA extracted via Protocol 2 (34.5\% versus 5.6\% respectively, Figure 4.1a and Table S4.3). At the same time, RFLP analyses were more successful for DNA extracted via Protocol 2 (17.2\%, versus $10.3 \%$ for Protocol 1) (Figure 4.1a and Table S4.3).

Based on cpSSR analyses, at least one allele was scored in 11 (5 heartwood and 6 sapwood) samples (Figure 4.1b and Table 4.3). Haplotypes of three Danish samples were identified as haplotypes 12 (x2) and 7. With the RFLP analyses, at least one allele of eight samples (5 heartwood and 3 sapwood) were scored for at least one marker, and two samples were identified as having haplotype 1 and haplotype 7.

\subsubsection{Marker fragment length effect on amplification rate}

No significant correlation was found between the mean PCR fragment length and the DNA amplification success rate $(\mathrm{r}=-0.36, \mathrm{p}>0.05)$, as also obvious from Figure 4.2. However, correlation between the mean PCR fragment size and the DNA amplification success rate within the type of analyses (CP, cpSSR or RFLP) showed strong negative correlations, especially for cpSSR ( $r=-0.69)$ and RFLP ( $r=-0.74)$, though again, related to low sample size, not significant $(\mathrm{p}>0.05)$. 


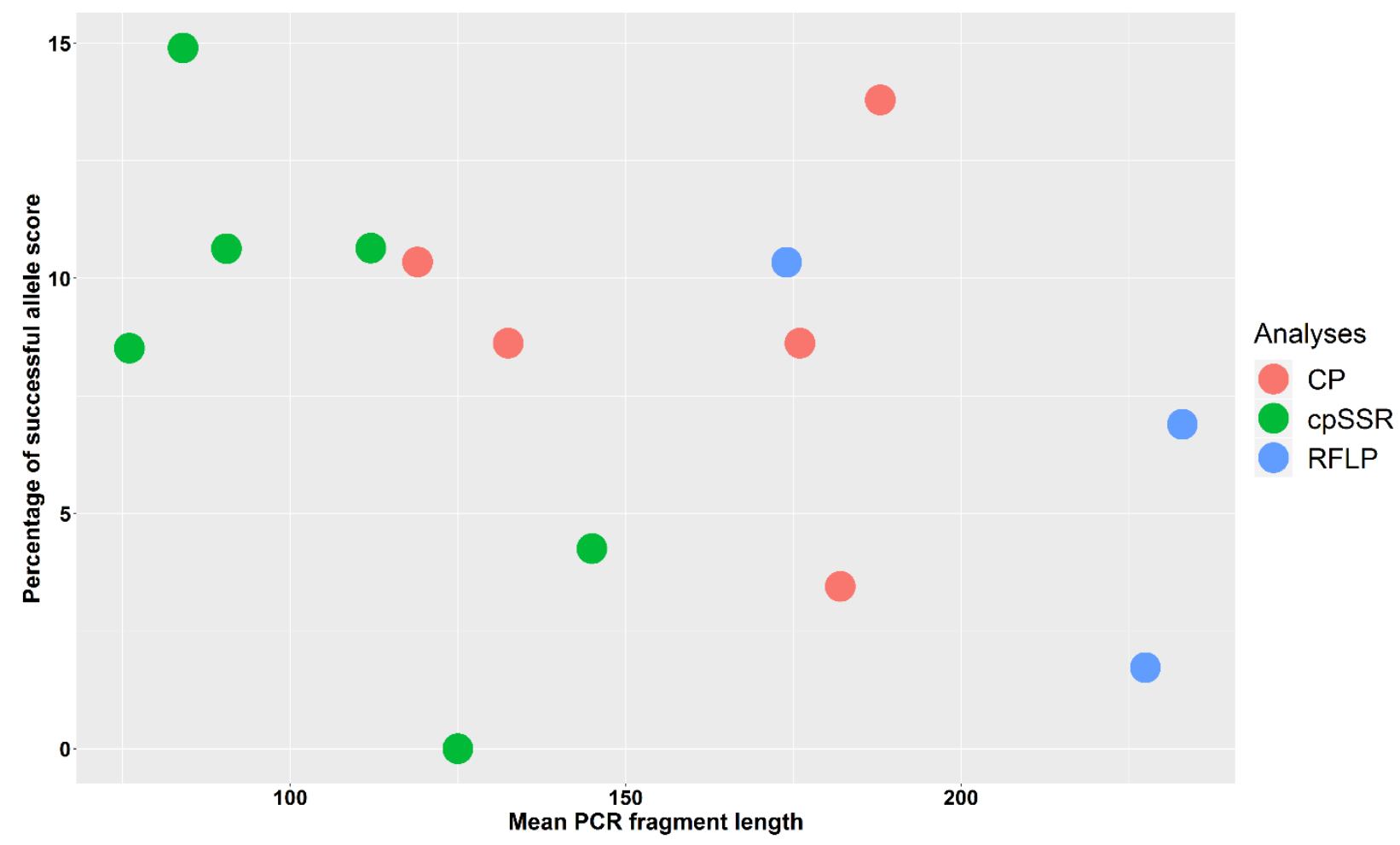

Figure 4.2. Amplification success rate related to the mean amplified fragment length (in base pairs) per type of analyses.

From the bootstrapped linear modelling, no significant effect of marker length on amplification success was found (data not shown).

\subsubsection{Case studies}

\section{Denmark}

Three samples, F042003, F042010, and F042011 were collected from a $17^{\text {th }}$ century historical building located at Nørregade 12, Horsens, Denmark. The houses in this main street of the city are of large architectural and historical value (Callesen, 2019). According to dendrochronological dating results, the samples are dated to 1614-1622, 1608-1623, and 16211622, respectively (Daly, 2019). Haplotype analyses revealed that samples F042003 (heartwood) and F042011 (heartwood) (based on CpSSR analyses) belong to haplotype 12, whereas both cpSSR and RFLP analyses showed that sample F042010 (heartwood) belongs to haplotype 7 (Table 4.3). Both haplotypes identified (2xH12 and 1xH7) are matching haplotypes distribution as expected for the region; i.e. NE Denmark. H7 has a Balkan refugial origin and is mainly found in eastern Denmark, not reaching Sweden, the same as H12, which was found 
only in planted forests in Eastern Denmark (but considered as autochthonous stands) (Jensen et al., 2002).

\section{Latvia}

The sample JKd2_SW consists of sapwood from an old door of the Saint Jacob church (or St. James's Cathedral, or the Cathedral Basilica of St. James), which is in Riga's Old town, Latvia. It was dated to $\sim 1479$ by using the well-known Baltic 1 and Baltic 3 regional TRW chronologies (Zunde, pers. comm.). Based on the cpSSR analyses, the samples were identified as belonging to either haplotype 10 or 12. Both haplotypes belong to lineage B (Petit et al., 2002b) and are the most common haplotypes of this lineage (see Petit et al. (2002a) for the detailed information on haplotypes distribution). 
Table 4.3. Overview on allele scores per extraction method and per analyses. Only samples with at least one allele scored are presented.

\begin{tabular}{|c|c|c|c|c|c|c|c|c|c|c|c|c|c|c|c|c|c|c|c|}
\hline \multirow{2}{*}{ Object } & \multirow{2}{*}{$\begin{array}{l}\text { Wood } \\
\text { type }\end{array}$} & \multirow{2}{*}{$\begin{array}{l}\text { Extraction } \\
\text { protocol }\end{array}$} & \multicolumn{5}{|c|}{ CP markers Continental provenancing } & \multirow[b]{2}{*}{ Origin } & \multicolumn{6}{|c|}{ cpSSR markers Haplotypes } & \multirow[b]{2}{*}{ HT_cpSSR } & \multicolumn{3}{|c|}{ RFLP markers Haplotypes } & \multirow[b]{2}{*}{ HT_RFLP } \\
\hline & & & $\operatorname{trnCD}$ & $\begin{array}{l}\text { psal- } \\
\text { ycf4 }\end{array}$ & $\begin{array}{l}\text { psbE- } \\
\text { petL }\end{array}$ & $\operatorname{trnDT}$ & $\operatorname{trnLF}$ & & $\mu \mathrm{dt} 1$ & $\mu \mathrm{cd} 5$ & $\mu \mathrm{kk} 4$ & $\mu \mathrm{dt} 4$ & $\begin{array}{l}\text { TF- } \\
\text { Ivo }\end{array}$ & $\mu \mathrm{dt} 3$ & & QT8_QT5 & dt72_QT5 & QT7 & \\
\hline JМT011 & HW & 2 & 123 & 178 & 0 & 0 & 0 & Eu & NA & NA & NA & NA & NA & NA & & 0 & 0 & 100 & Not HT7 \\
\hline JMT011 & SW & 1 & 0 & 0 & 0 & 86 & 0 & $\mathrm{Eu} / \mathrm{As}$ & 0 & 0 & 0 & 143 & 0 & 0 & $10,11,12$ & 0 & 0 & 0 & \\
\hline JMT031 & HW & 2 & 123 & 178 & 0 & 86 & 135 & $\mathrm{Eu}$ & NA & NA & NA & NA & NA & NA & & 0 & 0 & 100 & Not H7 \\
\hline ARR031 & HW & 2 & 0 & 0 & 0 & 0 & 0 & & NA & NA & NA & NA & NA & NA & & 28 & 0 & 100 & $\mathrm{H} 1$ \\
\hline SVT031 & SW & 2 & 0 & 0 & 0 & 0 & 0 & & 0 & 0 & 0 & 0 & 0 & 0 & & 0 & 0 & 100 & Not H7 \\
\hline \multirow{2}{*}{ SVT061 } & \multirow{2}{*}{ HW } & 1 & 0 & 0 & 0 & 0 & 0 & & 83 & 0 & 0 & 0 & 0 & 0 & 10,11 & 0 & 0 & 0 & \\
\hline & & 2 & 123 & 0 & 0 & 0 & 135 & $\mathrm{Eu} / \mathrm{As}$ & NA & NA & NA & NA & NA & NA & & 0 & 0 & 0 & \\
\hline H011001 & SW & 1 & 123 & 0 & 0 & 86 & 0 & $\mathrm{Eu} / \mathrm{As}$ & 0 & 76 & 0 & 0 & 0 & 0 & $10,11,12$ & 91.5 & 0 & 0 & $5,6,7,10,11,12$ \\
\hline H011001 & HW & 1 & 0 & 0 & 0 & 0 & 0 & & 83 & 0 & 0 & 0 & 0 & 0 & 10,11 & 91.5 & 0 & 0 & $5,6,7,10,11,12$ \\
\hline F042003 & SW & 1 & 0 & 0 & 0 & 86 & 0 & $\mathrm{Eu} / \mathrm{As}$ & 0 & 0 & 0 & 0 & 0 & 0 & & 0 & 0 & 0 & \\
\hline F042003 & $\mathrm{HW}$ & 1 & 0 & 0 & 0 & 0 & 0 & & 0 & 0 & 110 & 0 & 84 & 0 & 12 & 0 & 0 & 0 & \\
\hline \multirow{2}{*}{ F042010 } & \multirow{2}{*}{ SW } & 1 & 0 & 0 & 0 & 0 & 0 & & 0 & 0 & 0 & 0 & 84 & 0 & & 0 & 0 & 0 & \\
\hline & & 2 & 0 & 178 & 185 & $86 / 101$ & 0 & $\mathrm{Eu}$ & 82 & 75 & 0 & 0 & 84 & 0 & 1,7 & 0 & 0 & 0 & \\
\hline F042010 & $\mathrm{HW}$ & 1 & 0 & 0 & 0 & 86 & 135 & $\mathrm{Eu} / \mathrm{As}$ & 82 & 75 & 110 & 0 & 0 & 0 & 7 & 91.5 & 203 & 174 & 7 \\
\hline F042011 & $\mathrm{HW}$ & 1 & 0 & 0 & 0 & 0 & 0 & & 84 & 76 & 110 & 0 & 0 & 0 & 12 & 0 & 0 & 0 & \\
\hline F042011 & SW & 2 & 0 & 0 & 0 & 0 & 135 & $\mathrm{Eu} / \mathrm{As}$ & 0 & 0 & 0 & 0 & 84 & 0 & & 0 & 0 & 100 & Not H7 \\
\hline \multirow{2}{*}{$J K-I$} & \multirow{2}{*}{ HW } & 1 & 0 & 0 & 0 & 0 & 135 & $\mathrm{Eu} / \mathrm{As}$ & 0 & 0 & 0 & 0 & 0 & 0 & & 0 & 0 & 0 & \\
\hline & & 2 & 0 & 178 & 0 & 0 & & $\mathrm{Eu} / \mathrm{N} \mathrm{Am}$ & 0 & 0 & 0 & 0 & 0 & 0 & & 0 & 0 & 0 & \\
\hline $\mathrm{JKd} 2$ & SW & 1 & 0 & 178 & 185 & 0 & 0 & $\mathrm{Eu} / \mathrm{N} \mathrm{Am}$ & 83 & 0 & 110 & 143 & 0 & 0 & 10,11 & 0 & 0 & 0 & \\
\hline CesDt2 & SW & 1 & 123 & 0 & 0 & 86 & 0 & $\mathrm{Eu} / \mathrm{As}$ & 82 & 0 & 0 & 0 & 84 & 0 & 1,7 & 0 & 0 & 0 & \\
\hline \multirow{2}{*}{ CesDt3 } & \multirow{2}{*}{ sW } & 1 & 0 & 0 & 0 & 86 & 0 & $\mathrm{Eu} / \mathrm{As}$ & 0 & 0 & 110 & 0 & 0 & 0 & $7,10,11,12$ & 0 & 0 & 0 & \\
\hline & & 2 & 123 & 0 & 0 & 0 & 0 & $\mathrm{Eu} / \mathrm{As}$ & NA & NA & NA & NA & NA & NA & & 0 & 0 & 0 & \\
\hline
\end{tabular}

1,2 - Extraction Protocol 1 and extraction Protocol 2, respectively,

Origin - identified continental origin of the sample based on continental provenancing analyses,

$\mathrm{CP}$, cpSSR and RFLP - continental provenancing, chloroplast simple sequence repeat and restricted fragment length analyses, respectively,

Origin, HT cpSSR and HT_RFLP - continental origin of sample based on continental provenancing analyses, sample haplotype based on cpSSR analyses and sample haplotype

based on RFLP analyses, respectively,

$\mathrm{Eu}$, As and $\mathrm{N}$ Am - Europe, Asia and North America, respectively,

HW, SW - heartwood and sapwood, respectively. 


\subsection{Discussion}

\subsubsection{DNA potential for timber provenancing}

Current dendroprovenancing methods based on TRW, isotopes, mass spectrometry or wood anatomy were successfully applied in many studies (e.g. Sass-Klaassen et al., 2008; ParedesVillanueva et al., 2018; Traore et al., 2018). However, each method has its own limitations and specific requirements for successful identification of timber origin, e.g. a sufficient number of rings, specific climatic gradients in the study area or distinct differences in bedrock material etc. Therefore, all additional information which can be extracted from wood, such as DNA, is valuable for enhancing the precision of provenancing. However, efficient use of DNA requires improvement of current DNA extraction and amplification protocols, especially if it comes to analysing old and partly degraded material.

In our study, we aimed to extract DNA from historical timber and use it for identification of the geographical origin of the timber. We could show that in $60 \%$ of all samples, allele scores were obtained for at least one marker per provenancing method, both from sapwood and heartwood. While our DNA results look still incomplete because in most of the cases only some markers for some combinations of DNA-based provenancing methods could be successfully amplified (Table 4.3), the results of the case studies reflect the enormous potential of using ancient DNA from white oaks for identification of timber origin. The results also illustrate the added value of combining DNA analyses with classical TRW based dendroprovenancing, as haplotypes have a wide distribution and initial regional identification of samples' origin it is essential for the fine-scale timber provenancing.

Often archaeological material, especially from the shipwrecks, is not datable with European chronologies at all (e.g. Guibal, 1996). This could be caused by the American origin of the timber, as local wood sources were used for repairing ships while being at American coast, among which Quercus macrocarpa or Quercus alba could also have been used. Moreover, American oak timber import for ships building to the Spanish Kingdom has also increased in the Age of Discovery (Aranda, 1990). Therefore, there is a high chance of finding timber having non-European origin in "European" shipwrecks. Since anatomically American white oak species are very similar to European oaks, i.e. ring-porous wood with wide uniseriate axial rays, it is not feasible to identify the continental origin of archaeological oak ship timber based on its xylem structure (Schroeder et al.). However, continental provenancing of such 
timber based on the DNA analyses and using previously developed markers (Schroeder et $a l ., 2016)$ specifically for this purpose seems to overcome this problem.

\subsubsection{DNA amplification from heartwood and sapwood}

Heartwood is considered as the most complicated timber material for molecular studies as even in the living tree all the cells in the heartwood are dead (Bamber \& Fukazawa, 1985; Nobuchi et al., 1987), but short fragments of DNA may have remained absorbed in the cell wells (Cano, 1996). This was confirmed in our study, where DNA from nine heartwood samples was successfully amplified and haplotype of four of them identified (Table 4.3). In previous studies, DNA from the heartwood was also amplified, but with considerably lower success rates (Deguilloux et al., 2003b) or only longer fragments were amplified (Deguilloux et al., 2002). Rachmayanti et al. (2009) have also found a gradual decrease in successful amplification rate along the wood regions from outer sapwood to inner heartwood, though together with the decrease of the content of PCR inhibiting substances.

\subsubsection{Marker length}

Previously it was shown that reducing marker size has a strong positive effect on DNA amplification (Deguilloux et al., 2002). Though, in Deguilloux et al. (2003b), this effect was found to be less pronounced. In the present study, the trend of having higher success rates while using shorter markers was also observed, but only for the cpSSR and only to some extent for the RFLP analyses (Figure 4.2). However, for the latter, only three markers were used. This result could be explained by the degradation of timber together with its genetic material. Hydrolytic and oxidative processes degrade and fragment the DNA after the death of a living organism, which results in preservation of only short fragments (Pääbo et al., 2004; Schlumbaum et al., 2008). Aging is another factor of DNA splitting, resulting in DNA degradation into fragments ranging from 50 to 500 bp in length (Deguilloux et al., 2002; Speirs et al., 2009; Jiao et al., 2014). This degradation has a gradual character, starting from the felling of the tree (Deguilloux et al., 2002) due to the limited DNA chemical stability (Lindahl, 1993). This was also confirmed by the test on DNA extraction from the wood of the living trees, where considerably higher successful amplification rates were obtained (Table S4.2) and also by the fact that from the oldest sample in the study collection - CRL32 ( 740 years old) - no DNA was amplified. However, short DNA fragments were also found to hold sufficient information for understanding material history and taxonomic identification (Jiao et al., 2015). Therefore concentration on analyses of shorter DNA 
fragments from degraded timber material might be beneficial. High-throughput sequencing has shown great potential on the sapwood of water-logged oak timber (Wagner et al., 2018), but more tests on heartwood material and degraded archaeological timber are needed.

\subsection{Conclusions and outlook}

Here, we show that successful DNA extraction and amplification from old, degraded timber is possible, though complicated due to DNA degradation and fragmentation. Both extraction and amplification phases show room for further methodological improvement. Our results also clearly illustrate that the combination of multiple methods may already yield new insights with practical applicability in historical and archaeological research. Testing additional innovative DNA-based techniques, e.g. shotgun sequencing, with emphasis on shorter DNA fragments, is recommended for further studies. Yet, the combination of wood genetics with more traditional dendroprovenancing approaches may already further enhance the precision in which a potential origin area can be pinpointed.

\section{Acknowledgements}

This research was funded by the PE\&RC graduate school projects "DEXTRO" and "Vessel to vessel". Financial support from the project TIMBER: Northern Europe's timber resource - chronology, origin and exploitation (ERC, grant agreement No. 677152) and from the ForSEAdiscovery project (Forest Resources for Iberian Empires: Ecology and Globalization in the Age of Discovery) Marie Curie Actions program of the European Union (PITN-2013607545) is acknowledged. Authors are grateful to Māris Zunde for providing samples from Latvia and to Frederik Callesen for sharing an unfinished manuscript with archaeological information on the Danish case study. 


\section{SUPPORTING INFORMATION}

Table S4.1. Primers sequence designed for discrimination between haplotypes 10 and 11

Primer

TF-Ivo_F

TF-Ivo_R_PIG
Sequence $5^{6}-3^{6}$

PET_TGACGACCCGAATCTTTATTTATTT

GTTTCTTGGATCGATTCACAACAACTCTTTC

Table S4.2. PCR products fragment length analyses for continental provenancing of material from living oak trees

\begin{tabular}{|c|c|c|c|c|c|}
\hline \multirow{2}{*}{ Sample ID } & \multicolumn{5}{|c|}{ Marker } \\
\cline { 2 - 6 } & trnDT & psbE-petL & psaI-ycf4 & trnLF & trnCD \\
\hline JUG020H & 0 & 0 & 0 & 0 & 0 \\
\hline JUG008H & 86 & 185 & 178 & 135 & 123 \\
\hline GOR005H & 86 & 185 & 178 & 135 & 123 \\
\hline GOR007H & 86 & 185 & 178 & 135 & 123 \\
\hline JUG009H & 86 & 0 & 178 & 135 & 123 \\
\hline SVA004H & 86 & 185 & 178 & 135 & 123 \\
\hline OTE002H & 86 & 185 & 178 & 135 & 123 \\
\hline SVA002H & 0 & 0 & 0 & 0 & 0 \\
\hline OTE001H & 86 & 185 & 178 & 135 & 123 \\
\hline SVA003H & 86 & 185 & 178 & 135 & 123 \\
\hline JUG016H & 0 & 0 & 0 & 0 & 0 \\
\hline JUG004H & 86 & 185 & 178 & 135 & 123 \\
\hline JUG006H & 0 & 0 & 0 & 0 & 0 \\
\hline JUG023H & 86 & 185 & 178 & 135 & 123 \\
\hline JUG007H & 86 & 185 & 178 & 135 & 123 \\
\hline GOR022H & 0 & 0 & 0 & 0 & 0 \\
\hline JUG024H & 0 & 0 & 0 & 0 & 0 \\
\hline GOR006H & 0 & 0 & 0 & 0 & 0 \\
\hline JUG020S & 86 & 185 & 178 & 135 & 123 \\
\hline JUG008S & 86 & 185 & 178 & 135 & 123 \\
\hline GOR005S & 86 & 185 & 178 & 135 & 123 \\
\hline GOR007S & 0 & 0 & 0 & 0 & 0 \\
\hline JUG009S & 86 & 185 & 178 & 135 & 123 \\
\hline SVA004S & 86 & 185 & 178 & 135 & 123 \\
\hline OTE002 & 86 & 185 & 178 & 135 & 123 \\
\hline SVA002 & 86 & 185 & 178 & 135 & 123 \\
\hline OTE001 & 86 & 185 & 178 & 135 & 123 \\
\hline SVA003 & 86 & 185 & 178 & 135 & 123 \\
\hline JUG016 & 86 & 185 & 178 & 135 & 123 \\
\hline JUG004 & 0 & 0 & 0 & 0 & 0 \\
\hline JUG006 & 86 & 185 & 178 & 135 & 123 \\
\hline JUG023 & 86 & 185 & 178 & 135 & 123 \\
\hline JUG007 & 86 & 185 & 178 & 135 & 123 \\
\hline GOR022 & 0 & 0 & 0 & 0 & 0 \\
\hline JUG024 & 86 & 185 & 178 & 135 & 123 \\
\hline GOR006 & 86 & 185 & 178 & 135 & 123 \\
\hline & & & & & \\
\hline & & 05 & & \\
\hline & 055 & & 0 & \\
\hline
\end{tabular}


Table S4.3. PCR products fragment length analyses from historical material, continental provenancing and haplotyping per extraction method

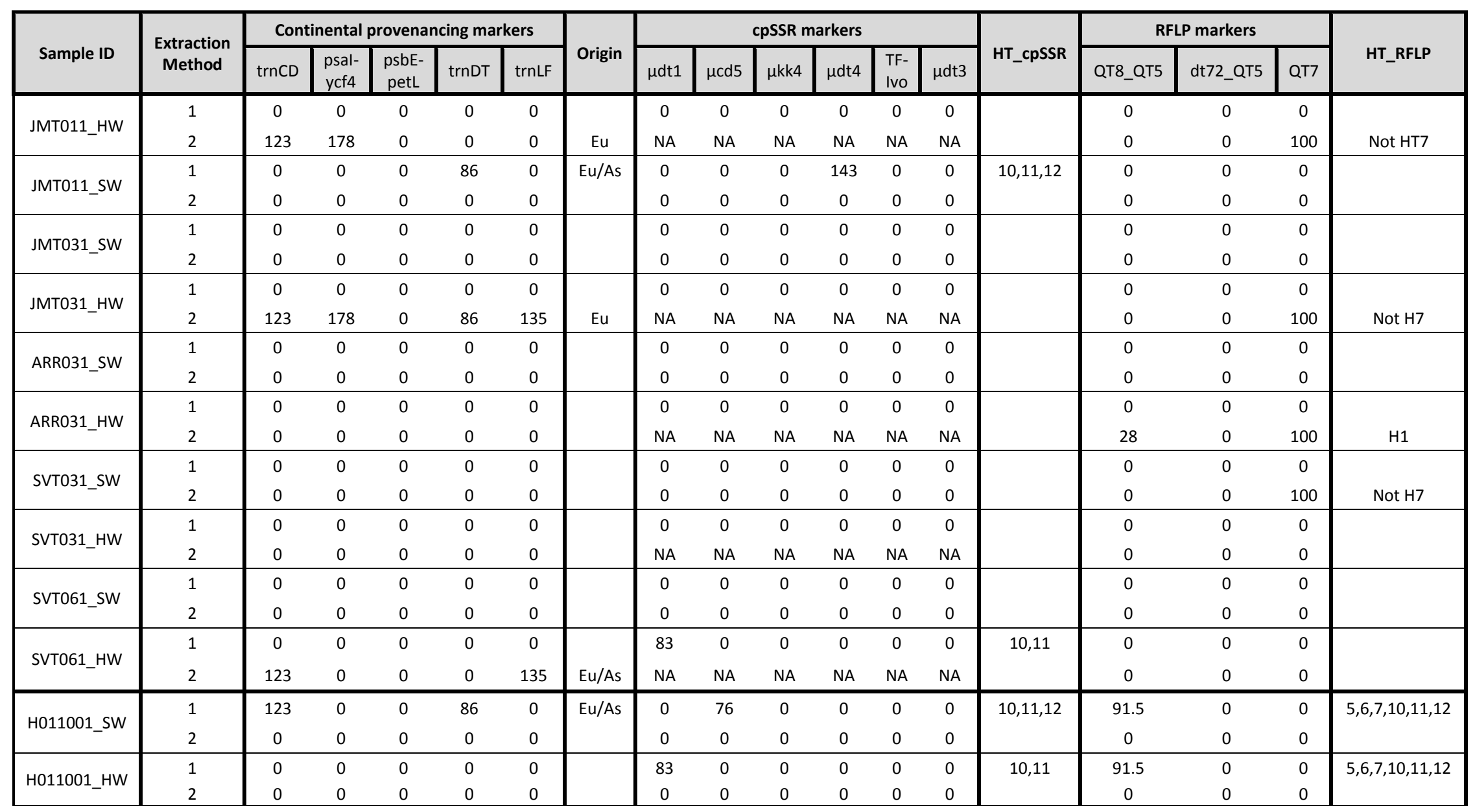


Table S4.3. Continuation

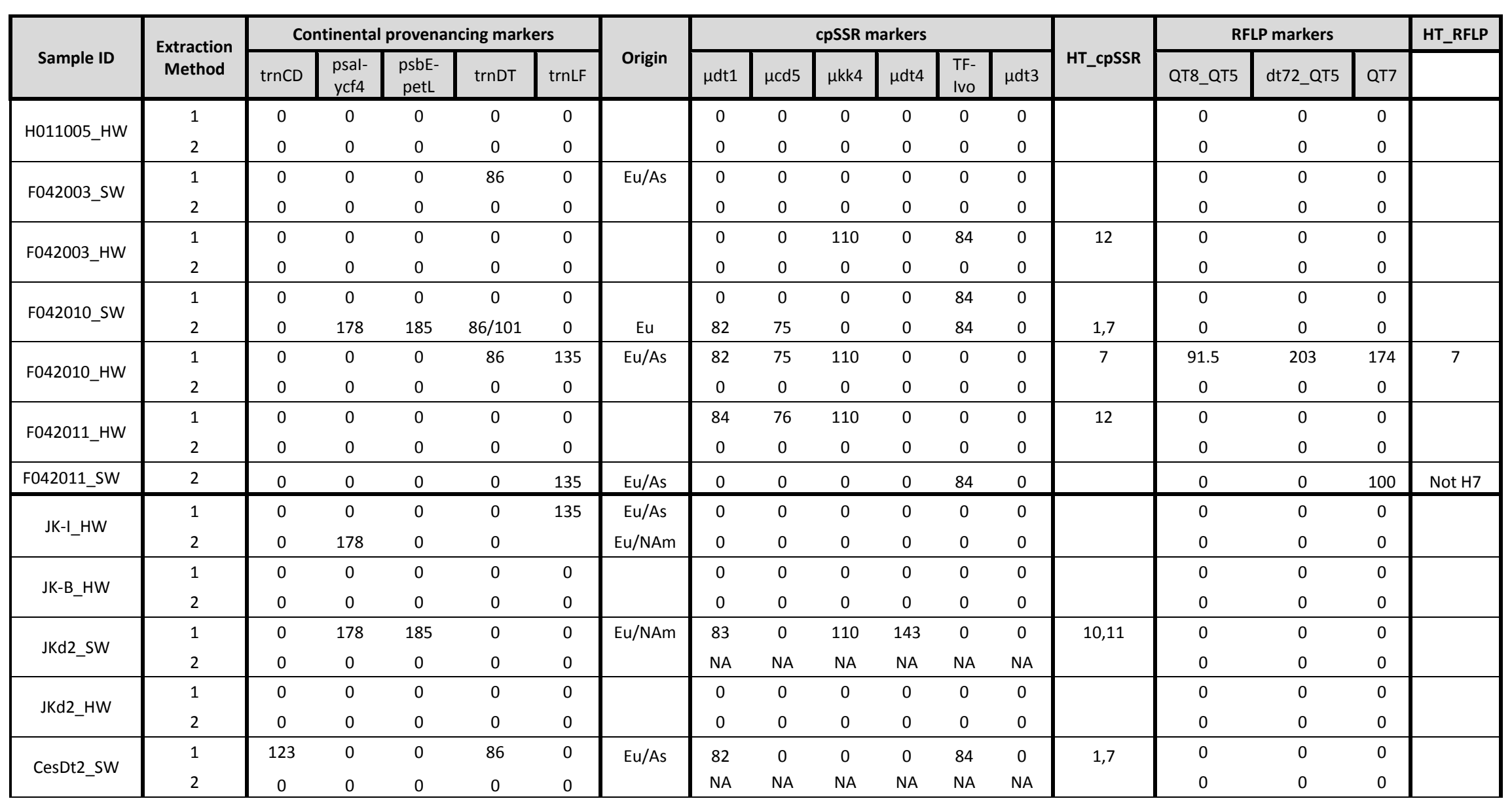


Table S4.3. Continuation

\begin{tabular}{|c|c|c|c|c|c|c|c|c|c|c|c|c|c|c|c|c|c|c|}
\hline \multirow[b]{2}{*}{ Sample ID } & \multirow{2}{*}{$\begin{array}{c}\text { Extraction } \\
\text { Method }\end{array}$} & \multicolumn{5}{|c|}{ Continental provenancing markers } & \multirow[b]{2}{*}{ Origin } & \multicolumn{6}{|c|}{ cpSSR markers } & \multirow[b]{2}{*}{ HT_cpSSR } & \multicolumn{3}{|c|}{ RFLP markers } & \multirow[b]{2}{*}{ HT_RFLP } \\
\hline & & $\operatorname{trnCD}$ & $\begin{array}{l}\text { psal- } \\
\text { ycf4 }\end{array}$ & $\begin{array}{l}\text { psbE- } \\
\text { petL }\end{array}$ & $\operatorname{trnDT}$ & $\operatorname{trnLF}$ & & $\mu \mathrm{dt} 1$ & $\mu \mathrm{cd} 5$ & $\mu \mathrm{kk} 4$ & $\mu \mathrm{dt} 4$ & $\begin{array}{l}\text { TF- } \\
\text { Ivo }\end{array}$ & $\mu \mathrm{dt} 3$ & & QT8_QT5 & dt72_QT5 & QT7 & \\
\hline \multirow{2}{*}{ CesDt2_HW1 } & 1 & 0 & 0 & 0 & 0 & 0 & & 0 & 0 & 0 & 0 & 0 & 0 & & 0 & 0 & 0 & \\
\hline & 2 & 0 & 0 & 0 & 0 & 0 & & NA & NA & NA & NA & NA & NA & & 0 & 0 & 0 & \\
\hline \multirow{2}{*}{ CesDt3_sw } & 1 & 0 & 0 & 0 & 86 & 0 & $\mathrm{Eu} / \mathrm{As}$ & 0 & 0 & 110 & 0 & 0 & 0 & $7,10,11,12$ & 0 & 0 & 0 & \\
\hline & 2 & 123 & 0 & 0 & 0 & 0 & $\mathrm{Eu} / \mathrm{As}$ & NA & NA & NA & NA & NA & NA & & 0 & 0 & 0 & \\
\hline CesDt3_HW & 1 & 0 & 0 & 0 & 0 & 0 & & 0 & 0 & 0 & 0 & 0 & 0 & & 0 & 0 & 0 & \\
\hline \multirow{2}{*}{ CesDt5_HW } & 1 & 0 & 0 & 0 & 0 & 0 & & 0 & 0 & 0 & 0 & 0 & 0 & & 0 & 0 & 0 & \\
\hline & 2 & 0 & 0 & 0 & 0 & 0 & & NA & NA & NA & NA & NA & NA & & 0 & 0 & 0 & \\
\hline \multirow{2}{*}{ CRL32_SW } & 1 & 0 & 0 & 0 & 0 & 0 & & 0 & 0 & 0 & 0 & 0 & 0 & & 0 & 0 & 0 & \\
\hline & 2 & 0 & 0 & 0 & 0 & 0 & & NA & $\mathrm{NA}$ & NA & NA & NA & NA & & 0 & 0 & 0 & \\
\hline \multirow{2}{*}{ CRL32_HW } & 1 & 0 & 0 & 0 & 0 & 0 & & 0 & 0 & 0 & 0 & 0 & 0 & & 0 & 0 & 0 & \\
\hline & 2 & 0 & 0 & 0 & 0 & 0 & & NA & NA & NA & NA & NA & NA & & 0 & 0 & 0 & \\
\hline
\end{tabular}

1, 2 - extraction Protocol 1 and extraction Protocol 2, respectively

Origin - identified continental origin of the sample based on continental provenancing analyses

CP, cpSSR and RFLP - continental provenancing, chloroplast simple sequence repeat and restricted fragment length analyses, respectively

Origin, HT_cpSSR and HT_RFLP - continental origin of sample based on continental provenancing analyses, sample haplotype based on cpSSR analyses and sample haplotype based on RFLP analyses, respectively

Eu, As and NAm - Europe, Asia and North America, respectively

HW, SW - heartwood and sapwood, respectively. Given in column "Sample ID”. 



\section{Chapter 5}

\section{General discussion}




\subsection{Introduction}

Trees react to their environment, and this is reflected in their xylem structure. The reaction of trees to their specific growing conditions over time can be studied by means of dendrochronology (Speer, 2010). The fact that tree rings archive site-specific environmental information makes tree-ring width (TRW) series from a tree in a respective area a unique fingerprint of nature. Such fingerprints, i.e. ring-width patterns, of trees growing at the same site are similar and can be averaged into TRW chronologies. Depending on the bioclimatic context of an area, regional chronologies can be build, which consist of several site chronologies and reflect the ring-width variation in a given species. Such networks of chronologies have been built for many species and regions across the world. Networks of long chronologies, with reasonable spatial coverage, are available for few species only. For Europe and parts of Asia, this concerns oak and pine, two species which have been historically used in constructions (e.g. Haneca et al., 2009).

Dendrochronological dating and provenancing are based on matching TRW series of oak and pine samples of unknown origin with the existing reference chronologies available for the two species (Eckstein, 2007; Haneca et al., 2009). However, this approach has multiple pitfalls (Bridge, 2012) related to (i) short TRW time series which do not yield significant matches with reference chronologies (Billamboz, 2003) or (ii) strong teleconnections between trees, which means that high Student's $t$-value or correlation coefficients can be obtained with chronologies from both nearby and far-away sites (e.g. Domínguez-Delmás et al., 2013), and finally (iii) presence of a complex environmental signal in TRW with lack of one, dominant growthlimiting climatic factor which allows discrimination between sites (Bridge, 2000). Moreover, chances of dating and provenancing are often limited due to the fact that only a few or even one single TRW sequence is available from a historical or archaeological object. Individual TRW series, in contrast to site chronologies constructed from multiple series from the same stand, contain more individual-tree and micro-site related variation (Rehschuh et al., 2017) which can make provenancing more difficult.

With a new approach adopted from ecological research, most of these issues can be resolved or strongly improved. TRW tells only part of the story of the interaction between tree growth and specific site conditions. By using the full potential of the tree-ring archive, i.e. a more detailed fingerprint, the precision of provenancing can be enhanced. Time series of wood-anatomical characteristics have been found to either store complementary environmental information in comparison to TRW or to reflect a stronger climate signal than TRW. In both cases, it is expected that a multi-variable approach will be beneficial for pinpointing (or fingerprinting) wood of unknown origin. 
This thesis aimed at exploring the potential of selected wood-anatomical variables for oak and pine, the two most intensively used and planted timber species in Europe across the past centuries. For oak earlywood-vessel size was studied and for pine latewood density was selected. Latewood density was measured by means of blue intensity variables, a measure for the combined lignin, cellulose and hemicellulose content in the cell walls of latewood tracheids (Björklund et al., 2014; Wilson et al., 2014; Wilson et al., 2017). In addition, the individual tree approach for better discrimination between tree populations from adjacent regions was tested.

To highlight the relevance of an interdisciplinary approach in wood provenancing - especially for historic and archaeological timber - the aDNA approach was integrated into the thesis. aDNA refers to the extraction and analyses of ancient DNA for provenancing of wood either to accomplish dendrochronology-based tracking methods or to replace them if dendrochronological methods are not applicable.

The embedding of this research into the ForSEAdiscovery project (Forest Resources for Iberian Empires: Ecology and Globalization in the Age of Discovery) explains the focus on Spain when it comes to testing the newly developed provenancing tools. This final chapter presents and discusses the full potential of a multivariable and multidisciplinary approach to enhance provenancing precision for oak and pine timber throughout Europe.

\subsection{Xylem variables for timber provenancing}

Including wood-anatomical variables and properties into the classical TRW-based method in combination with multivariate statistical analyses has shown to increase the spatial resolution of pine and oak timber provenancing (Chapters $2 \& 3$ ). For oak, earlywood vessel size acts as a complementary variable to TRW (Eckstein, 2004). Annual variation of oak vessel size in response to winter and spring temperatures enabled discrimination between sites in Northern Spain along a continentality gradient (Chapter 2). The signal reflected by oak vessels has a distinct spatial variability and depends on climatic conditions before or during vessels formation (e.g. García-González \& Eckstein, 2003; Copini et al., 2016; Pérez-de-Lis et al., 2017). Conditions in either one of these two time periods were found critical for vessel formation of ring-porous species also in other areas of the Iberian Peninsula (González-González et al., 2014; González-González et al., 2015) as well as in different regions of Europe (Fonti \& GarcíaGonzález, 2004; Fonti et al., 2007; Fonti \& García-González, 2008). In each case, this signal was found to be complementary to TRW. However, this might not be the case under all conditions. Research from Canada on ring-porous oak growing near the northern distribution 
limit has shown that vessels of white oak, Quercus alba L., and red oak, Q. rubra L., did not reveal any unique climatic signal and were intrinsically linked to ring width variables (Tardif $\&$ Conciatori, 2006). The latter indicates that use of earlywood vessels for dendroprovenancing should be based on the specific climatic conditions and biogeographic gradients within the region. Including vessel variables is especially relevant for areas with a complex maritime climate, as e.g. in the UK, where it was suggested as an explanation of statistical mismatch of TRW series from sites located within $100 \mathrm{~km}$ from each other (Bridge, 2012). Overall, areas known for intensive exploitation of oaks forests in the past, i.e. long logging history, and with a gradient in the distance to the sea are the most promising cases for including earlywood vessels area to obtain higher precision of oak-timber provenancing. Southern Sweden, Poland and the Baltic States are target regions where time series of earlywood vessels likely enhance the chance of precisely dendroprovenancing oak timber. However, the presence of a climatic gradient in winter or early spring, i.e. before or during the time of vessel formation, is considered as a sufficient criterion for including earlywood vessels chronologies into oak timber provenancing in the region. Moreover, as was stated in ecological analyses by Fonti and GarcíaGonzález (2008), including vessels may be of particular interest in mesic areas that lack a prevailing growth-limiting climatic factor.

For conifer species, especially pine, different considerations hold for the added value of wood density-related variables for provenancing. The interest for using wood-density based time series for provenancing has grown since the introduction of the blue intensity (BI) method, which allows relatively easy and cheap analysis of wood-density related variables from tree rings in a scanned wood samples (Campbell et al., 2007). Several dendroclimatological studies have shown that chronologies of wood-density variables reflect growth-limiting factors stronger than TRW itself, which makes them valuable e.g. for the reconstruction of past temperature in the Northern hemisphere (e.g. Hughes et al., 1984; Briffa et al., 1988; Briffa et $a l .$, 1992). For application in provenancing, this means that blue intensity (BI) variables work well for dendroprovenancing if a gradient in a growth-limiting climate factor exists over the study area. Our study showed that with BI variables pine stands can be discriminated based on their elevation in dry areas, although BI variables alone failed to assign individual trees to their geographical origin (Chapter 3). This is due to the more robust response of the BI variables to the primary growth-limiting climate factor compared to TRW series (e.g. Björklund et al., 2014; Rydval et al., 2017). In dry environments, growth limiting factors concern a gradient of drought, which has stronger elevational than spatial variation with decreasing intensity from low to high elevation (Mokhov \& Akperov, 2006). In other regions, elevation gradients are often defined 
by temperature-limited growth conditions, with lower growth due to lower temperatures at high elevations, caused by a shorter growing season (Grudd, 2008; McCarroll et al., 2013).

Our research indicates that BI variables can be used to enhance dendroprovenancing of pine species in regions with a pronounced elevation gradient, as in the case of North and Central Spain related to water availability (drought), although only in combination with TRW series. As for the areas with different main growth-limiting climatic factor, e.g. temperature in the UK, BI has also been shown to increase the probability of successful dating and provenancing because of the robustness of the archived climatic signal (Wilson et al., 2017). Moreover, in Western Siberia, also an area where tree growth is mainly limited by the temperature, BI variables were successfully used for dating historical timber, and allowed to discriminate between sites located along the river (Sidorova M., 2016, pers. communication). This means that BI variables have the potential to be used for dendroprovenancing throughout a wide range of areas starting from the Iberian Peninsula and Apennine Peninsula up to Scandinavia and eastern Russia. Moreover, the simplicity of obtaining wood-density related variables by the BI method (Campbell et al., 2007) makes BI variables a promising tool for dendroarchaeological research.

\subsection{Single tree approach in dendroprovenancing}

In this thesis, we avoided the usual approach of calculating mean site chronologies from individual tree time series of TRW and wood-anatomical variables (e.g. Haneca et al., 2006; Domínguez-Delmás et al., 2014; Domínguez-Delmás et al., 2018). Site chronologies are used for dendroprovenancing as it is assumed that they reflect the 'common signal' of all included individual in time series in their annual variation (Cook, 1985). Depending on the spatial distribution and number of sites and trees included, regional chronologies can vary in their value for dendroprovenancing. We have used an individual tree approach (Chapters $2 \& 3$ ) to test if single series express site or region-specific patterns. Such an individual tree approach allows preservation of microsite differences among the trees and can be used to identify ecological gradients behind these differences, an aspect which is eliminated when calculating mean chronologies (Buras et al., 2016). To test if by applying an individual tree approach we indeed obtain enhanced discrimination between the study regions, we performed additional analyses using regional mean chronologies. The test was done by consecutive exclusion of single tree latewood-width or vessel time series (using the same data as in Chapter 2) from the data pool, subsequent computation of regional chronologies, and calculation of $t$-values between the leftout tree time series and regional chronologies of the respective variable. Next, Wilcoxon rank sum test (for latewood-width series) and Kruskal-Wallis test (for vessel size series) were 
performed to check for significant differences between the $t$-values of different regions. The analysis revealed that based on latewood width, discrimination between an eastern and western group of sites would also have been possible (Figure 5.1a) as $t$-values of the "correct" regions were significantly higher (Wilcoxon, $\mathrm{p}<0.01$ ). However, mean $t$-values between the excluded trees and their respective regional chronologies were low (3.99 and 5.35 for eastern and western regions, respectively), indicating substantial individual variation in latewood-width time series, which may obscure dendroprovenancing based on the classical TRW based approach. Moreover, based on vessel size, no statistical difference between $t$-values of Central East and South East regions was revealed (Kruskal-Wallis, $p>0.05$, Figure 5.1b), contrary to the findings in Chapter 2, where 58\% of trees from the central eastern group were correctly assigned to their origin (Table 2.3). This suggests - at least for environmental settings as in our study areas - that an individual tree approach provides a higher precision for dendroprovenancing, but has to be wider tested in other areas to confirm its applicability for different species.
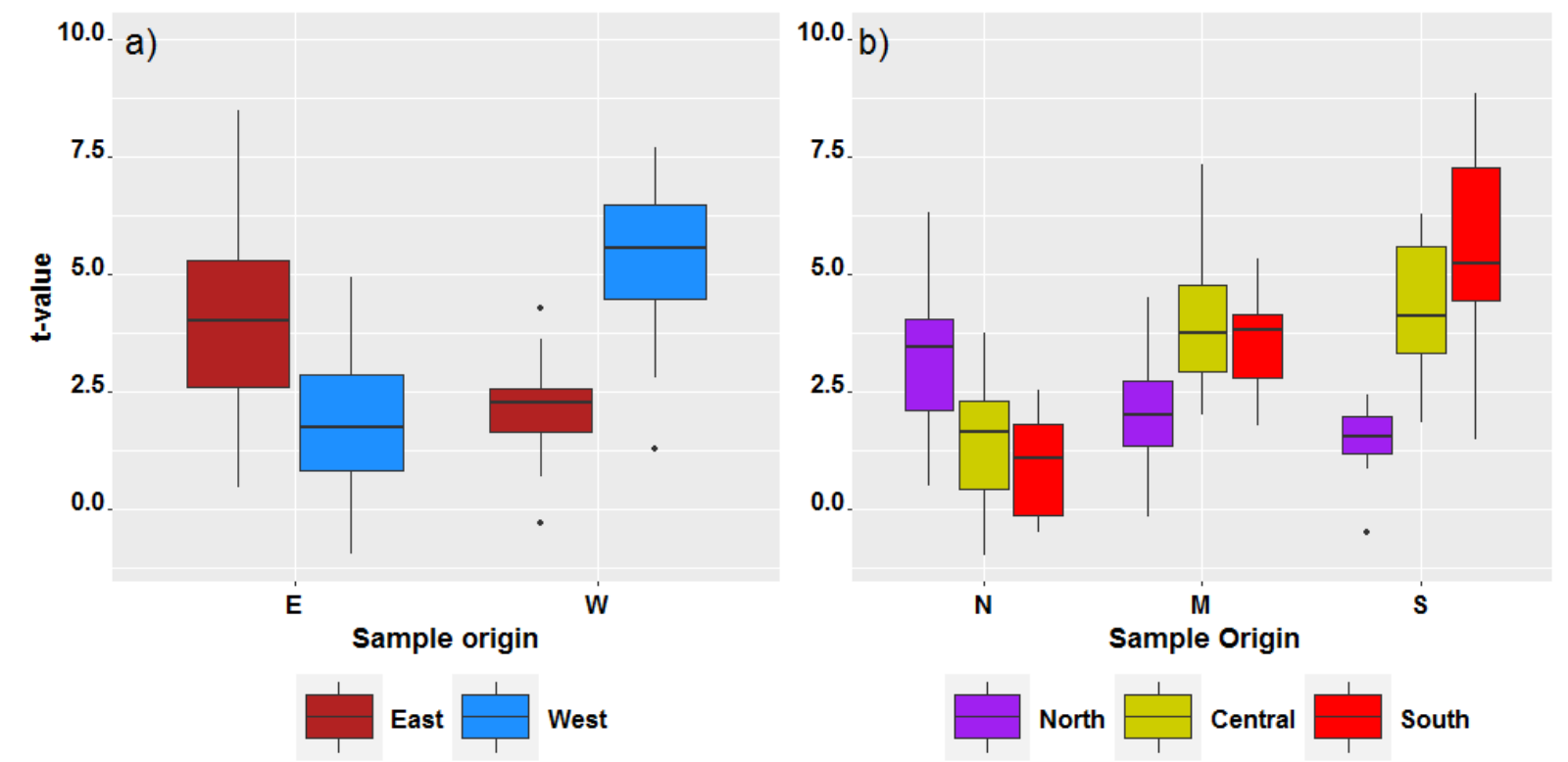

Figure 5.1. $t$-values between regional chronologies and the single excluded time series from latewood width (a) and vessel size (b); $x$-axes the geographical origin of the excluded sample, $y$-axes $t$-values with the regional chronologies. E, W, N, C, and S-eastern, western, north-eastern, central-eastern, and southeastern origin of the sample, respectively. Lower and upper box boundaries $25^{\text {th }}$ and $75^{\text {th }}$ percentiles, respectively, line inside box median, lower and upper error lines $10^{\text {th }}$ and $90^{\text {th }}$ percentiles, respectively, filled circles data falling outside $10^{\text {th }}$ and $90^{\text {th }}$ percentiles.

The individual tree approach is especially relevant to provenance single pieces of wood, as in the case of shipwrecks, where timber used for ship construction may come from different areas (Bridge, 2011). Moreover, studies trying to identify the origin of material from musical instruments based on $t$-values thresholds have failed for some individual TRW ring series 
(Bernabei et al., 2010). In these cases the approach proposed in this thesis may help in solving the problems.

\subsection{Potential of vessel time-series to solve actual dendro-puzzles}

\section{The Baltic challenge}

A massive trade of Baltic oak timber took place during the Middle Ages (Tossavainen, 1994), and during the last decades vast amounts of panel paintings and sculptures were dated using the dense network of oak chronologies from northern and central Poland (e.g. Eckstein et al., 1975; Bauch et al., 1978; Ważny, 2002; Läänelaid \& Nurkse, 2006). However, one of the remaining dendroarchaeological puzzles is the strong correlation among 15 available Polish TRW chronologies, which allows dating of historical or sub-fossil material, but which does not allow identification of oak-timber origin with higher precision than the country level. Four Polish TRW chronologies, calculated based on their geographical location rather than a statistical difference in their variation, allowed timber geographical provenance identification in only $12.9 \%$ of all cases (Haneca et al., 2005). Creating earlywood-vessel reference chronologies for this region may assist in the differentiation of sites based on their distance to the sea, which for Poland varies both in north-south and west-east directions. With the increase in distance to the sea, the correlation between earlywood vessel area time series and the temperature is expected to change from negative influence of winter temperature to a positive influence of spring temperature allowing discrimination of areas. Identification of sub-areas within Poland as well as within the entire Baltic area will comprise a large step forward for dendroarchaeological studies in the region, where broad-scale Baltic 1 and Baltic 2 (Hillam \& Tyers, 1995) TRW chronologies are commonly used for timber dating without exact knowledge of the geographic background of the included TRW time series.

\section{Added value of vessels for dendroprovenancing timber from managed oak forests}

Forest structure is reflected in patterns of TRW time series (Billamboz, 2003). This fact is used for reconstruction of past forest structure and forest management activities (e.g. Haneca \& Beeckman, 2005) and provides insights on the relation between human occupation and woodland development (Haneca et al., 2009). However, these strong human-induced disturbances can distort site-specific variation in TRW sequences and therefore hamper the potential of using them for dendroprovenancing. Discriminating variation caused by disturbances such as forest management from climate-based variations is especially relevant as 
timber from managed forests was often used for the construction of buildings and specific parts of ships (Castro, 2008). Recent research indicated that vessel time series are less susceptible to forest disturbances, such as forest management, than TRW series (Souto-Herrero et al., 2018a). This once more highlights the added value of vessel variables in provenancing. In combination with TRW, it allows studying past changes in forest dynamics, both related to human forest use but also in response to changes in climate conditions. The TRW and wood-anatomical records created in the context of this thesis for oak and pine forests in North, Central and Southern Spain reach back as far as 496 years for oak and 528 years for pine. A unique archive to gain valuable information on past forest dynamics and a chance to evaluate the future performance of Iberian forests under predicted climate change.

\subsection{DNA from historical oak timber as a tool to pinpoint its origin}

Dating and provenancing of oak timber may be obscured by the lack of reference TRW chronologies due to intensive deforestation in the past and short time series derived from subfossil or historical wood (e.g. Vitas \& Zunde, 2007). As DNA techniques are developing fast, extraction of DNA from wood can be instrumental to differentiate between tree populations at a very fine scale (Vlam et al., 2018). Major challenges are the extraction from DNA from wood, especially old wood, and the availability of a reference database for relevant wood species. In

Chapter 4, we have tested the potential of DNA extraction from old oak timber and the further use for identification of timber origin. Extraction of a sufficient amount of good quality DNA from degraded timber is challenging, as the DNA degrades over time and especially heartwood contains extractives inhibiting amplification (Deguilloux et al., 2002). However, compared to other studies (e.g. Deguilloux et al., 2002; Deguilloux et al., 2003b; Deguilloux et al., 2004) we were able to extract a reasonable amount of DNA. In $60 \%$ of samples, DNA was amplified at least for one primer pair, even from heartwood samples. This demonstrates the strong potential of the applied extraction methods for application in archaeological studies, although it remains challenging. The availability of reference datasets to assess white oak haplotype distribution remains a limitation (Petit et al., 2002b). Yet, haplotype analyses allow identifying possible oak timber origin on a rather coarse scale, which might involve several countries. A more dense network of reference data involving more microsatellites on non-coding chloroplast DNA regions will help to increase the spatial resolution of provenancing. This was previously demonstrated for Tali (Erythrophleum spp.) timber from Cameroon (Vlam et al., 2018) where $92 \%$ of correct timber assignment was achieved, whereas for Cedrela odorata in Bolivia the 
discrimination error was considerably higher, i.e. 33.7\% (Paredes-Villanueva et al., 2019). DNA analyses can also be used for species identification using barcoding techniques, but this requires sufficient quantity and quality of DNA (Yoshida, 2007), which at the moment remains challenging if it comes to extraction from historical and archaeological timber. However, identifying the haplotype of an oak timber would at least indicate a potential source area and open a window for application of other (dendro)provenancing methods, e.g. isotopic or massspectrometry analyses, in this region.

Continental provenancing of historical timber remains a valuable tool not only for tracing illegal wood (Schroeder et al., 2016) but also for archaeological studies, especially in nautical archaeology. The well-known Sparrow Hawk shipwreck found in Cape Cod, USA (Bradford, 1908), provides an excellent case to examine the continental origin of the timber used in its construction. This vessel is an example of one of the first tobacco trade vessels providing physical evidence of the state of English shipbuilding and early colonial experience. However, until now it remains uncertain whether or not this ship was an English trade vessel (Tucker, 2017). Given the importance of this vessel in modern archaeology, identification of its remains as well as being able to confirm European origin would be highly relevant. Identification of at least continental identity of wood from other shipwrecks with unknown origin will also be a important step in nautical archaeological studies.

\subsection{Limitations of dendroprovenancing and integration with other techniques}

In both Chapter 2 and Chapter 3, we could not conclude that vessel size of oak or wooddensity related variables of pine are superior to TRW for dendroprovenancing. Instead, the multivariable approach showed the best result in both applications, suggesting the importance of the combination of several variables. However, a specific biogeographic gradient, such as the difference in winter-spring temperature (for vessels) or summer drought (for the BI variables) between the study sites is required to achieve higher precision of provenancing with such a multivariable approach. Vessel chronologies alone did not reveal any differences, neither between Western and Eastern groups nor within the Western group of sites (Chapter 2), and the BI time series could not discriminate between Andalusian and Central System pine stands (Chapter 3) due to the absence of the climate gradients mentioned above. Therefore, for such regions, combination with other methods or techniques is essential for fine-scale provenancing. 
Wood chemical composition can be used for tuning down the scale of the potential timbersource area (e.g. Horacek et al., 2009; Kagawa \& Leavitt, 2010; Förstel et al., 2011; ParedesVillanueva et al., 2018), though this still has to be tested on a wide range of species and areas (Vlam et al., 2018). Strontium isotopic analyses have shown great potential for provenancing archaeological timber (Kagawa et al., 2002; Rich et al., 2016a). Applying such an analysis on the same areas and trees as in Chapter 2 and Chapter $\mathbf{3}$ revealed a clear separation between oak stands from tree population growing in NW Spain based on the ${ }^{87} \mathrm{Sr} /{ }^{86} \mathrm{Sr}$ isotope ratio which reflects differences in rock type (Hajj F., 2016, personal communication). However, based on this strontium isotope ratio, it was not possible to discriminate between stands from Andalusia and the Basque country, due to the fact that the bedrock material in these areas was identical. This suggests that also strontium analyses cannot be used as a stand-alone approach, but should be combined with other techniques to enhance provenancing precision, at least in this area.

Species identification could also assist in the identification of timber-source area as species differ in their geographical distribution. The four ring-porous oak species and two pine species studied in this project are very similar if not identical in their anatomical structure within the genus (Schweingruber \& Baas, 1990; Crivellaro et al., 2013). However, two of the oak species, Quercus pyrenaica, and Quercus faginea, are endemic to the Iberian Peninsula and North Africa (Blanco Castro, 2005; Nieto Quintano, 2016), meaning that species identification of historical or archaeological timber would link the timber to this specific distribution area. Variation in time series of TRW, earlywood vessels as well as BI variables did not show any species-specific patterns (Chapter 2 and Chapter 3). However, FTIR-ATR (Fourier transform infrared spectroscopy) analyses of the pine samples from northern and southern Spain, revealed a clear difference between Pinus nigra and Pinus sylvestris based on polysaccharide absorption bands (Traore et al., 2018). This suggests that integrating FTIR with BI and TRW results would further increase resolution, and may yield finer scale results for identifying the origin of pine timber in the Iberian Peninsula.

\subsection{Decision tree for pine and oak timber provenancing}

Based on the results derived from this thesis and other studies on the same samples within the ForSEAdiscovery project, a decision tree was created to illustrate possibilities of oak and pine timber provenancing (Figure 5.2). The decision tree includes all provenancing techniques as discussed before and aims at providing an idea on the potential and limitations of different techniques. 
The first essential step is assigning the timber to a genus and requires wood determination based on multiple wood anatomical features (Wheeler, 2011). Discrimination between pine and oak timber is straightforward: oak is a ring-porous broadleaved species with wide rays, and pine is a coniferous species with resin canals and window pits in cross-field tracheids and rays.

For oak (Quercus spp.) based on TRW chronologies, it has to be defined whether biogeographic or climate gradients are large enough to identify a potential source area. If this is not the case apply DNA analyses (Chapter 4), followed by strontium analyses for the bedrock material identification (Hajj F., 2016, personal communication) and consequently by FTIR-ATR analyses for species ID (Traore et al., 2018). If a clear biogeographic gradient is present vessel analyses should be performed to discriminate between sub-regions (Chapter 2), followed by strontium analyses for identification of bedrock material (Hajj F., 2016, personal communication).

For pine, BI analyses should be applied first to identify the elevation category of the studied timber (Chapter 3); then the geographical provenance has to be determined by using TRW time series. If both BI and TRW analyses provide results, i.e. elevation and the source region of timber are identified, strontium analyses can be as a final step to identify bedrock material (Hajj F., 2016, personal communication) and to achieve maximum precision. Alternatively, the application of FTIR-ATR (Traore et al., 2018) analyses for species ID followed by strontium analyses is recommended.

Additional methods, which were not tested in this project but demonstrated good potential in timber tracing, such as other stable isotopes (Kagawa \& Leavitt, 2010; Horacek, 2012), DARTTOFMS (Paredes-Villanueva et al., 2018) as well as multi-elemental analyses (Kagawa et al., 2007) may further enhance provenancing precision. However, these methods have to be thoroughly tested on archaeological timber, as the chemical composition of wood can be influenced by processes not related to geographical factors (Hajj et al., 2017). 


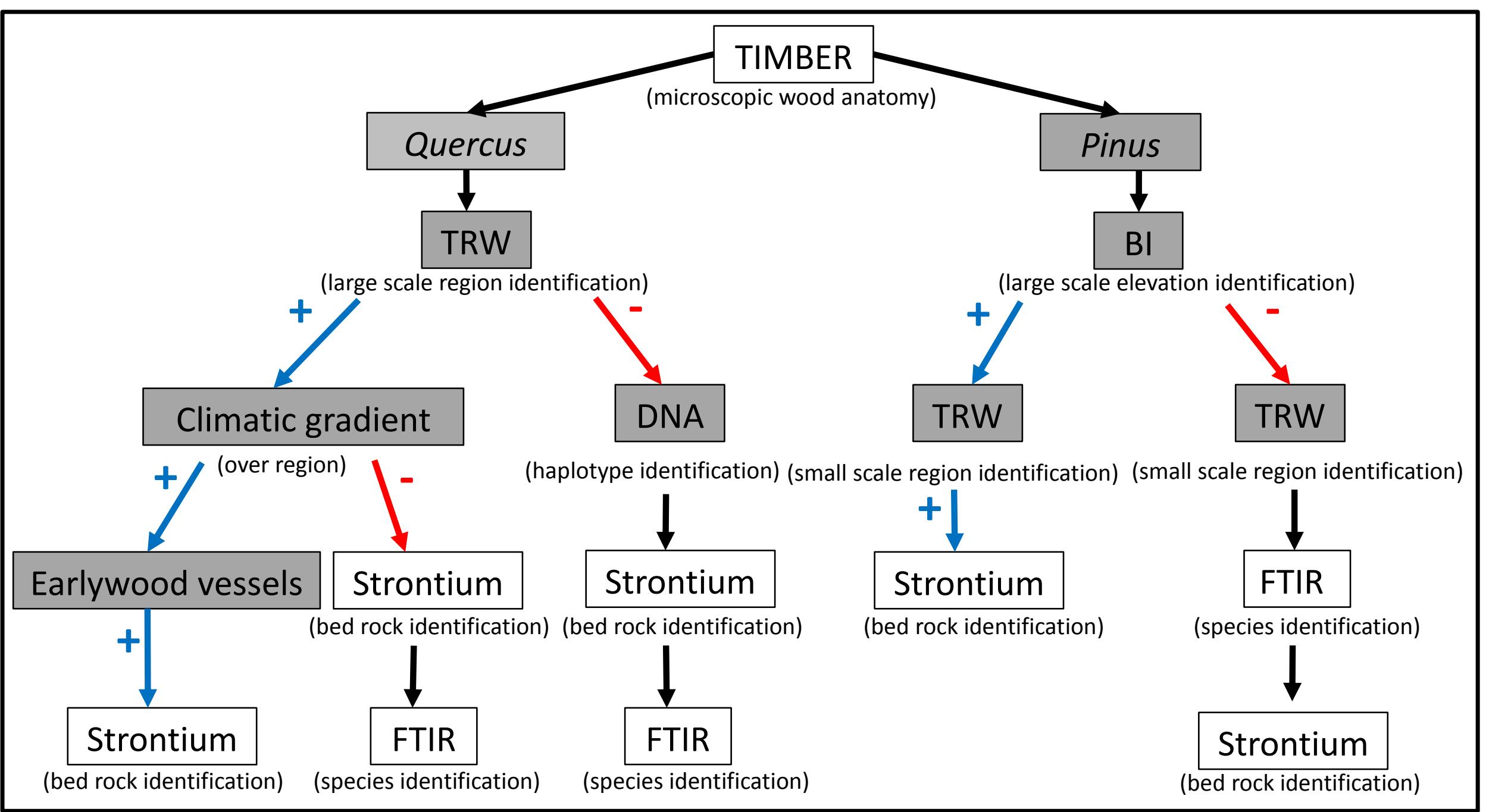

Figure 5.2. Decision tree for provenancing oak and pine timber in Europe. In blue and red - positive and negative result of the analyses, respectively. Shaded blocks - methods tested in this thesis. Non-shaded blocks - methods tested on the same samples as in this thesis. 
In this thesis, we used tree ecology as a key for pinpointing timber provenance. Pines and oaks were the centre of the study as in the past these two genera were extensively used and planted for use in all kinds of constructions. Application of the same approach on other species would certainly be interesting, though less relevant for provenancing historical and archaeological timber. Instead, effort should be focussed on extending TRW networks, complemented by networks of wood-anatomical variables and other tools. We have shown the added value of including anatomical variables for provenancing and using an individual tree approach for our study area in Spain. Mechanisms behind the success or limitation of applying our dendroprovenancing approach were discussed, and the potential for a successful application for other regions in Europe was critically evaluated. By going beyond a dendrochronology-based approach and including DNA as a provenancing tool, we not only extended the possibilities for provenancing non-datable timber but also highlighted the strength of a multi-disciplinary provenancing approach. Based on our results, we conclude that provenancing of timber is complex and largely depends on the available reference datasets, but has great potential when different methods are combined. The required reference datasets therefore should include multiple variables which reflect biogeographic gradients in a target region that have affected tree growth variation (TRW, wood-anatomical variables), species distribution patterns (DNA, FTIR), but also geological characteristics ( $\mathrm{Sr}$ isotopes). 


\section{References}


Akhmetzyanov, L., Buras, A., Sass-Klaassen, U., den Ouden, J., Mohren, F., Groenendijk, P. \& García-González, I. (2019) Multi-variable approach pinpoints origin of oak wood with higher precision. Journal of Biogeography, 46, 1163-1177.

Aloni, R. \& Zimmermann, M.H. (1983) The Control of Vessel Size and Density Along the Plant Axis - a New Hypothesis. Differentiation, 24, 203-208.

Amaral Franco, J. (1990) Quercus L. Flora Ibérica II (ed. by S. Castroviejo, Laínz, M., López González, G., Montserrat, P., Muñoz Garmendia, F., Paiva, J. \& Villar, L.), pp. 15-36. C.S.I.C, Madrid.

Anchukaitis, K.J., D’Arrigo, R.D., Andreu-Hayles, L., Frank, D., Verstege, A., Curtis, A., Buckley, B.M., Jacoby, G.C. \& Cook, E.R. (2013) Tree-ring-reconstructed summer temperatures from northwestern North America during the last nine centuries. Journal of Climate, 26, 3001-3012.

Andreu, L., Gutiérrez, E., Macias, M., Ribas, M., Bosch, O. \& Camarero, J.J. (2007) Climate increases regional tree-growth variability in Iberian pine forests. Global Change Biology, 13, 804-815.

Aragón Ruano, Á. (2009) Los robles trasmochos guiados o ipinabarros: una apuesta sostenible de futuro para una técnica forestal olvidada.

Aranda, G.d. (1990) Los bosques flotantes : historia de un roble del siglo XVIII. Instituto Nacional para la Conservación de la Naturaleza, Madrid.

Baas, P. \& Vetter, R.E. (1989) Growth rings in tropical trees. IAWA bull./Intern. assoc. of wood anatomists, 10, 2.

Babst, F., Poulter, B., Trouet, V., Tan, K., Neuwirth, B., Wilson, R., Carrer, M., Grabner, M., Tegel, W., Levanic, T., Panayotov, M., Urbinati, C., Bouriaud, O., Ciais, P. \& Frank, D. (2013) Site- and species-specific responses of forest growth to climate across the European continent. Global Ecology and Biogeography, 22, 706-717.

Bamber, R. \& Fukazawa, K. (1985) Sapwood and heartwood: a review. Forestry abstracts (ed by, pp. 567-580.

Bauch, J., Eckstein, D. \& Brauner, G. (1978) Dendrochronologische Untersuchungen an Eichenholztafeln von Rubens-Gemälden. Jahrbuch der Berliner Museen, 209221.

Bauer, E. (1980) Los montes España en la historia. Ministerio de Agricultura.

Bernabei, M., Bontadi, J. \& Rognoni, G.R. (2010) A dendrochronological investigation of stringed instruments from the collection of the Cherubini Conservatory in Florence, Italy. Journal of Archaeological Science, 37, 192-200.

Billamboz, A. (2003) Tree Rings and Wetland Occupation in Southwest Germany Between 2000 and 500 BC: Dendroarchaeology Beyond Dating in Tribute to F. H. Schweingruber. Tree-Ring Research, 59, 37-49.

Björklund, J.A., Gunnarson, B.E., Seftigen, K., Esper, J. \& Linderholm, H.W. (2014) Blue intensity and density from northern Fennoscandian tree rings, exploring the potential to improve summer temperature reconstructions with earlywood information. Climate of the Past, 10, 877-885.

Blanco Castro, E., Casado González, M.A., Costa Tenorio, M.,Escribano Bombín, R., Garcia Antón, M., Genova Fuster, M., Gómez Manzaneque, A., Gómez Manzaneque, F., Moreno Saiz, J.C., Morla Juaristi, C., Regato Pajares, P., Sainz Ollero, H (2005) Los bosques ibéricos. Una interpretación geobotánica.

Bormann, E., Herbert, F. \& Berlyn, E. (1981) Age and growth rate of tropical trees: new directions for research. 
Bouriaud, O., Leban, J.-M., Bert, D. \& Deleuze, C. (2005) Intra-annual variations in climate influence growth and wood density of Norway spruce. Tree physiology, 25, 651-660.

Bradford, W. (1908) Bradford's History of Plymouth Plantation, 1606-1646. C. Scribner's sons.

Bréda, N., Huc, R., Granier, A. \& Dreyer, E. (2006) Temperate forest trees and stands under severe drought: a review of ecophysiological responses, adaptation processes and long-term consequences. Annals of Forest Science, 63, 625-644.

Bridge, M. (2000) Can Dendrochronology be used to Indicate the Source of Oak Within Britain?

Bridge, M. (2011) Resource Exploitation and Wood Mobility in Northern European Oak: dendroprovenancing of individual timbers from the Mary Rose (1510/111545). International Journal of Nautical Archaeology, 40, 417-423.

Bridge, M. (2012) Locating the origins of wood resources: a review of dendroprovenancing. Journal of Archaeological Science, 39, 2828-2834.

Briffa, K.R., Jones, P.D. \& Schweingruber, F.H. (1988) Summer temperature patterns over Europe: a reconstruction from $1750 \mathrm{AD}$ based on maximum latewood density indices of conifers. Quaternary Research, 30, 36-52.

Briffa, K.R., Jones, P. \& Schweingruber, F. (1992) Tree-ring density reconstructions of summer temperature patterns across western North America since 1600. Journal of Climate, 5, 735-754.

Briffa, K.R., Schweingruber, F.H., Jones, P.D., Osborn, T.J., Shiyatov, S.G. \& Vaganov, E.A. (1998) Reduced sensitivity of recent tree-growth to temperature at high northern latitudes. Nature, 391, 678-682.

Briffa, K.R., Osborn, T.J., Schweingruber, F.H., Jones, P.D., Shiyatov, S.G. \& Vaganov, E.A. (2002) Tree-ring width and density data around the Northern Hemisphere: Part 1, local and regional climate signals. The Holocene, 12, 737-757.

Buckley, B.M., Hansen, K.G., Griffin, K.L., Schmiege, S., Oelkers, R., D’Arrigo, R.D., Stahle, D.K., Davi, N., Nguyen, T.Q.T. \& Le, C.N. (2018) Blue intensity from a tropical conifer's annual rings for climate reconstruction: An ecophysiological perspective. Dendrochronologia, 50, 10-22.

Bunn, A.G. (2010) Statistical and visual crossdating in R using the dplR library. Dendrochronologia, 28, 251-258.

Büntgen, U., Frank, D., Grudd, H. \& Esper, J. (2008) Long-term summer temperature variations in the Pyrenees. Climate Dynamics, 31, 615-631.

Büntgen, U., Tegel, W., Nicolussi, K., McCormick, M., Frank, D., Trouet, V., Kaplan, J.O., Herzig, F., Heussner, K.-U. \& Wanner, H. (2011) 2500 years of European climate variability and human susceptibility. Science, 331, 578-582.

Buras, A., Schunk, C., Zeiträg, C., Herrmann, C., Kaiser, L., Lemme, H., Straub, C., Taeger, S., Gößwein, S. \& Klemmt, H.-J. (2018) Are Scots pine forest edges particularly prone to drought-induced mortality? Environmental Research Letters, 13, 025001.

Buras, A., van der Maaten-Theunissen, M., van der Maaten, E., Ahlgrimm, S., Hermann, P., Simard, S., Heinrich, I., Helle, G., Unterseher, M., Schnittler, M., Eusemann, P. \& Wilmking, M. (2016) Tuning the Voices of a Choir: Detecting Ecological Gradients in Time-Series Populations. Plos One, 11

Callesen, F. (2019) Bygningsarkæologisk Rapport. HOM2393, Nørregade 12. Tidl. Skanderborg Amt, Nim Herred, Horsens Sogn, matrikelnr.: 428a. In. Horsens Museum 
Camarero, J.J., Guerrero-Campo, J. \& Gutiérrez, E. (1998) Tree-ring Growth and Structure of Pinus uncinata and Pinus sylvestris in the Central Spanish Pyrenees. Arctic and Alpine Research, 30, 1-10.

Camarero, J.J., Manzanedo, R.D., Sanchez-Salguero, R. \& Navarro-Cerrillo, R.M. (2013) Growth response to climate and drought change along an aridity gradient in the southernmost Pinus nigra relict forests. Annals of forest science, 70, 769-780.

Caminero, L., Génova, M., Camarero, J.J. \& Sánchez-Salguero, R. (2018) Growth responses to climate and drought at the southernmost European limit of Mediterranean Pinus pinaster forests. Dendrochronologia, 48, 20-29.

Campbell, R., McCarroll, D., Loader, N.J., Grudd, H., Robertson, I. \& Jalkanen, R. (2007) Blue intensity in Pinus sylvestris tree-rings: developing a new palaeoclimate proxy. Holocene, 17, 821-828.

Cano, R.J. (1996) Analysing ancient DNA. Endeavour, 20, 162-167.

Castagneri, D., Regev, L., Boaretto, E. \& Carrer, M. (2017) Xylem anatomical traits reveal different strategies of two Mediterranean oaks to cope with drought and warming. Environmental and Experimental Botany, 133, 128-138.

Castro, F. (2008) In search of unique Iberian ship design concepts. Historical Archaeology, 42, 63-87.

Chen, K., Dorado-Liñán, I., Akhmetzyanov, L., Gea-Izquierdo, G., Zlatanov, T. \& Menzel, A. (2015) Influence of climate drivers and the North Atlantic Oscillation on beech growth at marginal sites across the Mediterranean. Climate Research, 66, 229-242.

Cook, E., Briffa, K., Shiyatov, S. \& Mazepa, V. (1992) Tree-ring standardization and growth trend estimation. Methods of Dendrochronology: Application in the Environmental Science (ed. by E.R. Cook and L.A. Kairiukstis ), pp. 104-122. Kluwer Academic publisher Dordrecht.

Cook, E.R. (1985) A time series analysis approach to tree ring standardization. University of Arizona Tucson,

Copini, P., den Ouden, J., Robert, E.M.R., Tardif, J.C., Loesberg, W.A., Goudzwaard, L. \& Sass-Klaassen, U. (2016) Flood-Ring Formation and Root Development in Response to Experimental Flooding of Young Quercus robur Trees. Frontiers in Plant Science, 7

Crivellaro, A., Schweingruber, F.H., Christodoulou, C.S., Papachristophorou, T., Tsintides, T., Da Ros, A. \& Ohio Library and Information Network (2013) Atlas of wood, bark and pith anatomy of Eastern Mediterranean trees and shrubs : with a special focus on Cyprus. In, pp. 1 online resource (xii, 583 pages)

Čufar, K., De Luis, M., Zupančič, M. \& Eckstein, D. (2008) A 548-year tree-ring chronology of oak (Quercus spp.) for southeast Slovenia and its significance as a dating tool and climate archive. Tree-Ring Research, 64, 3-15.

Čufar, K., Grabner, M., Morgós, A., del Castillo, E.M., Merela, M. \& de Luis, M. (2014) Common climatic signals affecting oak tree-ring growth in SE Central Europe. Trees-Structure and Function, 28, 1267-1277.

Cuny, H.E., Rathgeber, C.B.K., Frank, D., Fonti, P., Mäkinen, H., Prislan, P., Rossi, S., del Castillo, E.M., Campelo, F., Vavrčík, H., Camarero, J.J., Bryukhanova, M.V., Jyske, T., Gričar, J., Gryc, V., De Luis, M., Vieira, J., Čufar, K., Kirdyanov, A.V., Oberhuber, W., Treml, V., Huang, J.-G., Li, X., Swidrak, I., Deslauriers, A., Liang, E., Nöjd, P., Gruber, A., Nabais, C., Morin, H., Krause, C., King, G. \& Fournier, M. (2015) Woody biomass production lags stem-girth increase by over one month in coniferous forests. Nature Plants, 1, 15160. 
Cybus

(2018)

Available

at: https://www.cybis.se/forfun/dendro/helpcoorecorder7/bluechannel80/inde x.htm (accessed 4 December 2018).

Daly, A. (2007a) Timber, Trade and Tree-rings. A dendrochronological analysis of structural oak timber in Northern Europe, c. AD 1000 to c. AD 1650. University of Southern Denmark,

Daly, A. (2007b) The Karschau ship, Schleswig-Holstein: Dendrochronological results and timber provenance. International Journal of Nautical Archaeology, 36, 155166.

Daly, A. (2019) Dendrokronologisk undersøgelse af tømmer fra bygning, Nørregade 12, Horsens (HOM 2393). In, Copenhagen.

de Luis, M., Novak, K., Raventós, J., Gričar, J., Prislan, P. \& Čufar, K. (2011) Climate factors promoting intra-annual density fluctuations in Aleppo pine (Pinus halepensis) from semiarid sites. Dendrochronologia, 29, 163-169.

Deguilloux, M.F., Pemonge, M.H. \& Petit, R.J. (2002) Novel perspectives in wood certification and forensics: dry wood as a source of DNA. Proceedings of the Royal Society B-Biological Sciences, 269, 1039-1046.

Deguilloux, M.F., Pemonge, M.H. \& Petit, R.J. (2004) DNA-based control of oak wood geographic origin in the context of the cooperage industry. Annals of Forest Science, 61, 97-104.

Deguilloux, M.F., Dumolin-Lapegue, S., Gielly, L., Grivet, D. \& Petit, R.J. (2003a) A set of primers for the amplification of chloroplast microsatellites in Quercus. Molecular Ecology Notes, 3, 24-27.

Deguilloux, M.F., Pemonge, M.H., Bertel, L., Kremer, A. \& Petit, R.J. (2003b) Checking the geographical origin of oak wood: molecular and statistical tools. Molecular Ecology, 12, 1629-1636.

Deguilloux, M.F., Bertel, L., Celant, A., Pemonge, M.H., Sadori, L., Magri, D. \& Petit, R.J. (2006) Genetic analysis of archaeological wood remains: first results and prospects. Journal of Archaeological Science, 33, 1216-1227.

Dolgova, E. (2016) June-September temperature reconstruction in the Northern Caucasus based on blue intensity data. Dendrochronologia, 39, 17-23.

Domínguez-Delmás, M., Alejano-Monge, R., Wazny, T. \& García-González, I. (2013) Radial growth variations of black pine along an elevation gradient in the Cazorla Mountains (South of Spain) and their relevance for historical and environmental studies. European journal of forest research, 132, 635-652.

Domínguez-Delmás, M., Trapaga-Monchet, K., Nayling, N. \& García-González, I. (2017) Natural hazards and building history: Roof structures of Segovia cathedral (Spain) reveal its history through tree-ring research. Dendrochronologia, 46, 113.

Domínguez-Delmás, M., van Daalen, S., Alejano-Monge, R. \& Wazny, T. (2018) Timber resources, transport and woodworking techniques in post-medieval Andalusia (Spain): Insights from dendroarchaeological research on historic roof structures. Journal of Archaeological Science, 95, 64-75.

Domínguez-Delmás, M., Alejano-Monge, R., Van Daalen, S., Rodríguez-Trobajo, E., García-González, I., Susperregi, J., Wazny, T. \& Jansma, E. (2015) Tree-rings, forest history and cultural heritage: current state and future prospects of dendroarchaeology in the Iberian Peninsula. Journal of Archaeological Science, 57, 180-196. 
Domínguez-Delmás, M., Nayling, N., Ważny, T., Loureiro, V. \& Lavier, C. (2013) Dendrochronological Dating and Provenancing of Timbers from the Arade 1 Shipwreck, Portugal. International Journal of Nautical Archaeology, 42, 118-136.

Domínguez-Delmás, M., Driessen, M., García-González, I., van Helmond, N., Visser, R. \& Jansma, E. (2014) Long-distance oak supply in mid-2nd century AD revealed: the case of a Roman harbour (Voorburg-Arentsburg) in the Netherlands. Journal of Archaeological Science, 41, 642-654.

Dorado-Liñán, I., Akhmetzyanov, L. \& Menzel, A. (2017) Climate threats on growth of rear-edge European beech peripheral populations in Spain. International Journal of Biometeorology, 61, 2097-2110.

Dumolin-Lapegue, S., Pemonge, M.H., Gielly, L., Taberlet, P. \& Petit, R.J. (1999) Amplification of oak DNA from ancient and modern wood. Molecular Ecology, 8, 2137-2140.

Eaton, E., Caudillo, G., Oliveira, S., de Rigo, D. (2016) Quercus robur and Quercus petraea in Europe: distribution, habitat, usage and threats. European Atlas of Forest Tree Species (ed. by J. San-Miguel-Ayanz, De Rigo, D., Caudullo, G., Houston Durrant, T., Mauri, A.), pp. 160-163. Publication Office of the European Union, Luxembourg.

Eckstein, D. (2004) Change in past environments - secrets of the tree hydrosystem. New Phytologist, 163, 1-4.

Eckstein, D., Brongers, J.A. \& Bauch, J. (1975) Tree-ring research in the Netherlands.

Eckstein, D., Bauch, J. (1969) Beitrag zur Rationalisierung eines dendrochronologischen Verfahrens und zur Analyse seiner Aussagesichereit. Forstwissenschaftliches Centralballt, 88, 230-250.

Eckstein, D., Wrobel, S. (2007) Dendrochronological proof of origin of historic timberretrospect and perspectives. Dendrosymposium 2006 (ed by K. Haneca, Verheyden, A., Beeckman, H., Gärtner, H., Helle, G., Schleser, G.), pp. 8-20. Tervuren, Belgium.

Eilmann, B., Zweifel, R., Buchmann, N., Pannatier, E.G. \& Rigling, A. (2011) Drought alters timing, quantity, and quality of wood formation in Scots pine. Journal of Experimental Botany, 62, 2763-2771.

Eilmann, B., Buchmann, N., Siegwolf, R., Saurer, M., Cherubini, P. \& Rigling, A. (2010) Fast response of Scots pine to improved water availability reflected in tree-ring width and delta 13C. Plant Cell and Environment, 33, 1351-1360.

Ellenberg, H. (1988) Vegetation ecology of Central Europe, 4th edn. Cambridge University Press, Cambridge.

Esteban, L.G., Martin, J.A., de Palacios, P. \& Fernandez, F.G. (2012) Influence of region of provenance and climate factors on wood anatomical traits of Pinus nigra Arn. subsp salzmannii. European Journal of Forest Research, 131, 633-645.

Fonti, P. \& García-González, I. (2004) Suitability of chestnut earlywood vessel chronologies for ecological studies. New Phytologist, 163, 77-86.

Fonti, P. \& García-González, I. (2008) Earlywood vessel size of oak as a potential proxy for spring precipitation in mesic sites. Journal of Biogeography, 35, 2249-2257.

Fonti, P., Solomonoff, N. \& García-González, I. (2007) Earlywood vessels of Castanea sativa record temperature before their formation. New Phytologist, 173, 562570.

Fonti, P., von Arx, G., García-González, I., Eilmann, B., Sass-Klaassen, U., Gärtner, H. \& Eckstein, D. (2010) Studying global change through investigation of the plastic responses of xylem anatomy in tree rings. New Phytologist, 185, 42-53. 
Förstel, H., Boner, M., Höltken, A., Fladung, M., Degen, B. \& Zahnen, J. (2011) Fighting illegal logging through the introduction of a combination of the isotope method for identifying the origins of timber and DNA analysis for differentiation of tree species. Deutsche Bundesstiftung Umwelt,

Fowler, A.M. \& Bridge, M.C. (2017) Empirically-determined statistical significance of the Baillie and Pilcher (1973) t statistic for British Isles oak. Dendrochronologia, 42, 51-55.

Fritts, H.C. (1976) Tree Rings and Climate. Academic Press, London.

Fuentes, M., Salo, R., Björklund, J., Seftigen, K., Zhang, P., Gunnarson, B., Aravena, J.C. \& Linderholm, H.W. (2018) A 970-year-long summer temperature reconstruction from Rogen, west-central Sweden, based on blue intensity from tree rings. Holocene, 28, 254-266.

Fukuda, H. (2004) Signals that control plant vascular cell differentiation. Nature Reviews Molecular Cell Biology, 5, 379-391.

Galván, J.D., Büntgen, U., Ginzler, C., Grudd, H., Gutiérrez, E., Labuhn, I. \& Camarero, J.J. (2015) Drought-induced weakening of growth-temperature associations in high-elevation Iberian pines. Global and Planetary Change, 124, 95-106.

García-González, I. \& Eckstein, D. (2003) Climatic signal of earlywood vessels of oak on a maritime site. Tree Physiology, 23, 497-504.

García-González, I. \& Fonti, P. (2006) Selecting earlywood vessels to maximize their environmental signal. Tree Physiology, 26, 1289-1296.

García-González, I., Souto-Herrero, M. \& Campelo, F. (2016) Ring-Porosity and Earlywood Vessels: A Review on Extracting Environmental Information through Time. Iawa Journal, 37, 295-314.

Gärtner, H. \& Nievergelt, D. (2010) The core-microtome: A new tool for surface preparation on cores and time series analysis of varying cell parameters. Dendrochronologia, 28, 85-92.

Gazol, A., Camarero, J.J., Anderegg, W.R.L. \& Vicente-Serrano, S.M. (2017) Impacts of droughts on the growth resilience of Northern Hemisphere forests. Global Ecology and Biogeography, 26, 166-176.

Gea-Izquierdo, G., Fonti, P., Cherubini, P., Martin-Benito, D., Chaar, H. \& Canellas, I. (2012) Xylem hydraulic adjustment and growth response of Quercus canariensis Willd. to climatic variability. Tree Physiol, 32, 401-13.

González-González, B.D., García-González, I. \& Vazquez-Ruiz, R.A. (2013) Comparative cambial dynamics and phenology of Quercus robur L. and Q-pyrenaica Willd. in an Atlantic forest of the northwestern Iberian Peninsula. Trees-Structure and Function, 27, 1571-1585.

González-González, B.D., Rozas, V. \& García-González, I. (2014) Earlywood vessels of the sub-Mediterranean oak Quercus pyrenaica have greater plasticity and sensitivity than those of the temperate $Q$. petraea at the Atlantic-Mediterranean boundary. Trees-Structure and Function, 28, 237-252.

González-González, B.D., Vazquez-Ruiz, R.A. \& García-González, I. (2015) Effects of climate on earlywood vessel formation of Quercus robur and Q. pyrenaica at a site in the northwestern Iberian Peninsula. Canadian Journal of Forest Research, 45, 698-709.

Gori, Y., Wehrens, R., La Porta, N. \& Camin, F. (2015) Oxygen and Hydrogen Stable Isotope Ratios of Bulk Needles Reveal the Geographic Origin of Norway Spruce in the European Alps. Plos One, 10 
Gričar, J., Čufar, K., Oven, P. \& Schmitt, U. (2005) Differentiation of terminal latewood tracheids in silver fir during autumn. Annals of Botany, 95, 959-965.

Gričar, J., de Luis, M., Hafner, P. \& Levanič, T. (2013) Anatomical characteristics and hydrologic signals in tree-rings of oaks (Quercus robur L.). Trees-Structure and Function, 27, 1669-1680.

Grissino-Mayer, H.D. (2001) Evaluating Crossdating Accuracy: A Manual and Tutorial for the Computer Program COFECHA. Tree-Ring Research, 57, 205-221.

Grudd, H. (2008) Tornetrask tree-ring width and density AD 500-2004: a test of climatic sensitivity and a new 1500-year reconstruction of north Fennoscandian summers. Climate Dynamics, 31, 843-857.

Guada, G., Camarero, J.J., Sánchez-Salguero, R. \& Cerrillo, R.M.N. (2016) Limited growth recovery after drought-induced forest dieback in very defoliated trees of two pine species. Frontiers in Plant Science, 7, 418.

Guada, G., García-González, I., Pérez-de-Lis, G., Vázquez-Ruiz, R.A. \& Montserrat-Martí, G. (2018) Dry matter content during extension of twigs, buds and leaves reflects hydraulic status related to earlywood vessel development in Quercus pyrenaica Willd. European Journal of Forest Research, 137, 307-319.

Guibal, F. (1996) Dendrochronological studies in the French Mediterranean area. Tree Rings, Environment and Humanity (ed by J.S. Dean, Meko, D.M., Swetnam, T.W.), pp. 505-513. Tucson, Arizona.

Gutiérrez, A.G., Snell, R.S. \& Bugmann, H. (2016) Using a dynamic forest model to predict tree species distributions. Global Ecology and Biogeography, 25, 347358.

Hacke, U.G., Sperry, J.S., Pockman, W.T., Davis, S.D. \& McCulloch, K.A. (2001) Trends in wood density and structure are linked to prevention of xylem implosion by negative pressure. Oecologia, 126, 457-461.

Hajj, F., Poszwa, A., Bouchez, J. \& Guerold, F. (2017) Radiogenic and "stable" strontium isotopes in provenance studies: A review and first results on archaeological wood from shipwrecks. Journal of Archaeological Science, 86, 24-49.

Haneca, K. \& Beeckman, H. (2005) Growth trends reveal the forest structure during Roman and Medieval times in Western Europe: a comparison between archaeological and actual oak ring series (Quercus robur and Quercus petraea). Annals of Forest Science, 62, 797-805.

Haneca, K. \& Debonne, V. (2012) Precise tree-ring dating of building activities despite the absence of bark: A case-study on medieval church roofs in Damme, Belgium. Dendrochronologia, 30, 23-34.

Haneca, K., Čufar, K. \& Beeckman, H. (2009) Oaks, tree-rings and wooden cultural heritage: a review of the main characteristics and applications of oak dendrochronology in Europe. Journal of Archaeological Science, 36, 1-11.

Haneca, K., Wazny, T., Van Acker, J. \& Beeckman, H. (2005) Provenancing Baltic timber from art historical objects: success and limitations. Journal of Archaeological Science, 32, 261-271.

Haneca, K., Boeren, I., Van Acker, J. \& Beeckman, H. (2006) Dendrochronology in suboptimal conditions: tree rings from medieval oak from Flanders (Belgium) as dating tools and archives of past forest management. Vegetation History and Archaeobotany, 15, 137-144.

Harris, I., Jones, P.D., Osborn, T.J. \& Lister, D.H. (2014) Updated high-resolution grids of monthly climatic observations - the CRU TS3.10 Dataset. International Journal of Climatology, 34, 623-642. 
Hillam, J. \& Tyers, I. (1995) Reliability and repeatability in dendrochronological analysis: tests using the Fletcher archive of panel-painting data. Archaeometry, 37, 395-405.

Holmes, R.L. (1983) Computer-assisted quality control in tree-ring dating and measurement.

Holz, A., Hart, S.J., Williamson, G.J., Veblen, T.T. \& Aravena, J.C. (2018) Radial growth response to climate change along the latitudinal range of the world's southernmost conifer in southern South America. Journal of Biogeography, 45, 1140-1152.

Horacek, M. (2012) Christmas tree production in Europe: Control of declared geographical origin by stable isotope analysis - a pilot study. Die Bodenkultur, 63, 35-41.

Horacek, M., Jakusch, M. \& Krehan, H. (2009) Control of origin of larch wood: discrimination between European (Austrian) and Siberian origin by stable isotope analysis. Rapid Communications in Mass Spectrometry, 23, 3688-3692.

Hoshino, Y., Okochi, T. \& Mitsutani, T. (2008) Dendrochronological dating of vernacular folk crafts in northern central Japan. Tree-Ring Research, 64, 109-115.

Houston Durrant, T., de Rigo, D., Caudullo, G., (2016) Pinus sylvestris in Europe: distribution, habitat, usage and threats. . European Atlas of Forest Tree Species (ed. by J. San-Miguel-Ayanz, De Rigo, D., Caudullo, G., Houston Durrant, T., Mauri, A.). Publication Office of the European Union, Luxembourg.

Hughes, M., Schweingruber, F., Cartwright, D. \& Kelly, P. (1984) July-August temperature at Edinburgh between 1721 and 1975 from tree-ring density and width data. Nature, 308, 341.

Isajev, V., Fady, B., Semerci, H. \& Andonovski, V. (2004) EUFORGEN Technical guidelines for genetic conservation and usefor European black pine (Pinus nigra).

Jensen, J.S., Gillies, A., Csaikl, U., Munro, R., Madsen, S.F., Roulund, H. \& Lowe, A. (2002) Chloroplast DNA variation within the Nordic countries. Forest Ecology and Management, 156, 167-180.

Jiao, L.C., Yin, Y.F., Cheng, Y.M. \& Jiang, X.M. (2014) DNA barcoding for identification of the endangered species Aquilaria sinensis: comparison of data from heated or aged wood samples. Holzforschung, 68, 487-494.

Jiao, L.C., Liu, X.L., Jiang, X.N. \& Yin, Y.F. (2015) Extraction and amplification of DNA from aged and archaeological Populus euphratica wood for species identification. Holzforschung, 69, 925-931.

Jiménez Sancho, M.P., Díaz Fernández, P.M., Martín Albertos,S., Gil Sánchez, L. (1998) Regiones de procedencia: Quercus pyrenaica Willd., Quercus faginea Lam. y Quercus canariensis Willd. OAPN, Madrid.

Kagawa, A. \& Leavitt, S.W. (2010) Stable carbon isotopes of tree rings as a tool to pinpoint the geographic origin of timber. Journal of Wood Science, 56, 175-183.

Kagawa, A., Aoki, T., Okada, N. \& Katayama, Y. (2002) Tree-ring strontium-90 and cesium-137 as potential indicators of radioactive pollution. Journal of environmental quality, 31, 2001-2007.

Kagawa, A., Kuroda, K., Abe, H., Fujii, T. \& Itoh, Y. (2007) Stable isotopes and inorganic elements as potential indicators of geographic origin of Southeast Asian timber. International Symposium on Development of Improved Methods to Identify Shorea Species Wood and its Origin (ed by, p. 39. 
Kepinski, S. (2006) Integrating hormone signaling and patterning mechanisms in plant development. Current Opinion in Plant Biology, 9, 28-34.

Kim, Y., Son, B.-H., Imamura, M. \& Park, W.-K. (2013) Tree-ring dating and radiocarbon wiggle matching of Buddhist arhat statues at Heungkuksa temple in Namyangju, South Korea. Dendrochronologia, 31, 286-289.

Kitin, P. \& Funada, R. (2016) Earlywood Vessels in Ring-Porous Trees Become Functional for Water Transport after Bud Burst and before the Maturation of the Current-Year Leaves. Iawa Journal, 37, 315-331.

Körner, C. \& Paulsen, J. (2004) A world-wide study of high altitude treeline temperatures. Journal of Biogeography, 31, 713-732.

Kudo, K., Nabeshima, E., Begum, S., Yamagishi, Y., Nakaba, S., Oribe, Y., Yasue, K. \& Funada, R. (2014) The effects of localized heating and disbudding on cambial reactivation and formation of earlywood vessels in seedlings of the deciduous ring-porous hardwood, Quercus serrata. Annals of Botany, 113, 1021-1027.

Läänelaid, A. \& Nurkse, A. (2006) Dating of a 17th century painting by tree rings of Baltic oak. Baltic Forestry, 12, 117-121.

Larsson, L. (2018) CooRecorder and Cdendro programs of the CooRecorder/Cdendro package version 9.0.1 [Online]. 3 December 2018.

Lebourgeois, F. (2000) Climatic signals in earlywood, latewood and total ring width of Corsican pine from western France. Annals of Forest Science, 57, 155-164.

Lévesque, M., Rigling, A., Bugmann, H., Weber, P. \& Brang, P. (2014) Growth response of five co-occurring conifers to drought across a wide climatic gradient in Central Europe. Agricultural and Forest Meteorology, 197, 1-12.

Liepelt, S., Sperisen, C., Deguilloux, M.F., Petit, R.J., Kissling, R., Spencer, M., Beaulieu, J.L., Taberlet, P., Gielly, L. \& Ziegenhagen, B. (2006) Authenticated DNA from ancient wood remains. Annals of Botany, 98, 1107-1111.

Lindahl, T. (1993) Instability and Decay of the Primary Structure of DNA. Nature, 362, 709-715.

Lowe, A., Jardine, D., Cross, H., Degen, B., Schindler, L. \& Hoeltken, A. (2015) A method of extracting plant nucleic acids from lignified plant tissue. International Patent Number WO/2015/070279,

Martin-Benito, D. \& Pederson, N. (2015) Convergence in drought stress, but a divergence of climatic drivers across a latitudinal gradient in a temperate broadleaf forest. Journal of Biogeography, 42, 925-937.

Martin-Benito, D., Beeckman, H. \& Cañellas, I. (2013) Influence of drought on tree rings and tracheid features of Pinus nigra and Pinus sylvestris in a mesic Mediterranean forest. European Journal of Forest Research, 132, 33-45.

Martínez Ruiz, E. (1999) Los montes en la cultura islámica. El bosque de al-Andalus desde el siglo VIII al XIII. Collectanea 27, 63-87.

McCarroll, D., Pettigrew, E., Luckman, A., Guibal, F. \& Edouard, J.L. (2002) Blue reflectance provides a surrogate for latewood density of high-latitude pine tree rings. Arctic Antarctic and Alpine Research, 34, 450-453.

McCarroll, D., Loader, N.J., Jalkanen, R., Gagen, M.H., Grudd, H., Gunnarson, B.E., Kirchhefer, A.J., Friedrich, M., Linderholm, H.W., Lindholm, M., Boettger, T., Los, S.O., Remmele, S., Kononov, Y.M., Yamazaki, Y.H., Young, G.H.F. \& Zorita, E. (2013) A 1200-year multiproxy record of tree growth and summer temperature at the northern pine forest limit of Europe. Holocene, 23, 471-484.

McDowell, N., Pockman, W.T., Allen, C.D., Breshears, D.D., Cobb, N., Kolb, T., Plaut, J., Sperry, J., West, A., Williams, D.G. \& Yepez, E.A. (2008) Mechanisms of plant 
survival and mortality during drought: why do some plants survive while others succumb to drought? New Phytologist, 178, 719-739.

Mitrakos, K. (1980) A Theory for Mediterranean Plant Life. Acta Oecologica-Oecologia Plantarum, 1, 245-252.

Mokhov, I. \& Akperov, M. (2006) Tropospheric lapse rate and its relation to surface temperature from reanalysis data. Izvestiya, Atmospheric and Oceanic Physics, 42, 430-438.

Morris, H., Gillingham, M.A.F., Plavcová, L., Gleason, S.M., Olson, M.E., Coomes, D.A., Fichtler, E., Klepsch, M.M., Martínez-Cabrera, H.I., McGlinn, D.J., Wheeler, E.A., Zheng, J., Ziemińska, K. \& Jansen, S. (2018) Vessel diameter is related to amount and spatial arrangement of axial parenchyma in woody angiosperms. Plant, Cell \& Environment, 41, 245-260.

Nieto Quintano, P., Caudillo, G., de Rigo, D. (2016) Quercus pyrenaica in Europe: distribution, habitat, usage and threats. European Atlas of Forest Tree Species (ed. by J. San-Miguel-Ayanz, De Rigo, D., Caudullo, G., Houston Durrant, T., Mauri, A.). Publication Office of the European Union, Luxembourg.

Nikolić, Đ. \& Tucić, N. (1983) Isoenzyme variation within and among populations of European black pine (Pinus nigra Arnold). Silvae Genetica, 32, 80-89.

Nobuchi, T., Tokuchi, N. \& Harada, H. (1987) Variability of Heartwood Formation and Cytological Features in Broad-Leaved Trees. Mokuzai Gakkaishi, 33, 596-604.

Nola, P. (1996) Climatic signal in earlywood and latewood of deciduous oaks from northern Italy. Tree rings, environment, and humanity (ed by J.S. Dean, Meko, D.M., Swetnam, T.W.), pp. 149-258. Tucson, Arizona, USA.

Olano, J.M., Linares, J.C., García-Cervigón, A.I., Arzac, A., Delgado, A. \& Rozas, V. (2014) Drought-induced increase in water-use efficiency reduces secondary tree growth and tracheid wall thickness in a Mediterranean conifer. Oecologia, 176, 273-283.

Pääbo, S., Poinar, H., Serre, D., Jaenicke-Després, V., Hebler, J., Rohland, N., Kuch, M., Krause, J., Vigilant, L. \& Hofreiter, M. (2004) Genetic analyses from ancient DNA. Annu. Rev. Genet., 38, 645-679.

Paredes-Villanueva, K., Espinoza, E., Ottenburghs, J., Sterken, M.G., Bongers, F. \& Zuidema, P.A. (2018) Chemical differentiation of Bolivian Cedrela species as a tool to trace illegal timber trade. Forestry: An International Journal of Forest Research, 91, 603-613.

Paredes-Villanueva, K., de Groot, G.A., Laros, I., Bovenschen, J., Bongers, F. \& Zuidema, P.A. (2019) Genetic differences among Cedrela odorata sites in Bolivia provide limited potential for fine-scale timber tracing. Tree Genetics \& Genomes, 15, 33.

Park, Y.-I.D. \& Spiecker, H. (2005) Variations in the tree-ring structure of Norway spruce (Picea abies) under contrasting climates. Dendrochronologia, 23, 93104.

Pasho, E., Camarero, J.J., de Luis, M. \& Vicente-Serrano, S.M. (2011a) Impacts of drought at different time scales on forest growth across a wide climatic gradient in north-eastern Spain. Agricultural and Forest Meteorology, 151, 1800-1811.

Pasho, E., Camarero, J.J., de Luis, M. \& Vicente-Serrano, S.M. (2011b) Spatial variability in large-scale and regional atmospheric drivers of Pinus halepensis growth in eastern Spain. Agricultural and Forest Meteorology, 151, 1106-1119.

Pearson, C.L., Griggs, C.B., Kuniholm, P.I., Brewer, P.W., Ważny, T. \& Canady, L. (2012) Dendroarchaeology of the mid-first millennium AD in Constantinople. Journal of Archaeological Science, 39, 3402-3414. 
Pérez-de-Lis, G., Rossi, S., Vazquez-Ruiz, R.A., Rozas, V. \& García-González, I. (2016) Do changes in spring phenology affect earlywood vessels? Perspective from the xylogenesis monitoring of two sympatric ring-porous oaks. New Phytologist, 209, 521-530.

Pérez-de-Lis, G., Olano, J.M., Rozas, V., Rossi, S., Vázquez-Ruiz, R.A. \& García-González, I. (2017) Environmental conditions and vascular cambium regulate carbon allocation to xylem growth in deciduous oaks. Functional Ecology, 31, 592-603.

Petit, G., Anfodillo, T., Carraro, V., Grani, F. \& Carrer, M. (2011) Hydraulic constraints limit height growth in trees at high altitude. New Phytologist, 189, 241-252.

Petit, R.J., Brewer, S., Bordacs, S., Burg, K., Cheddadi, R., Coart, E., Cottrell, J., Csaikl, U.M., van Dam, B., Deans, J.D., Espinel, S., Fineschi, S., Finkeldey, R., Glaz, I., Goicoechea, P.G., Jensen, J.S., Konig, A.O., Lowe, A.J., Madsen, S.F., Matyas, G., Munro, R.C., Popescu, F., Slade, D., Tabbener, H., de Vries, S.G.M., Ziegenhagen, B., de Beaulieu, J.L. \& Kremer, A. (2002a) Identification of refugia and post-glacial colonisation routes of European white oaks based on chloroplast DNA and fossil pollen evidence. Forest Ecology and Management, 156, 49-74.

Petit, R.J., Csaikl, U.M., Bordacs, S., Burg, K., Coart, E., Cottrell, J., van Dam, B., Deans, J.D., Dumolin-Lapegue, S., Fineschi, S., Finkeldey, R., Gillies, A., Glaz, I., Goicoechea, P.G., Jensen, J.S., Konig, A.O., Lowe, A.J., Madsen, S.F., Matyas, G., Munro, R.C., Olalde, M., Pemonge, M.H., Popescu, F., Slade, D., Tabbener, H., Taurchini, D., de Vries, S.G.M., Ziegenhagen, B. \& Kremer, A. (2002b) Chloroplast DNA variation in European white oaks - Phylogeography and patterns of diversity based on data from over 2600 populations. Forest Ecology and Management, 156, 5-26.

Poorter, L., McDonald, I., Alarcón, A., Fichtler, E., Licona, J.C., Peña-Claros, M., Sterck, F., Villegas, Z. \& Sass-Klaassen, U. (2010) The importance of wood traits and hydraulic conductance for the performance and life history strategies of 42 rainforest tree species. New phytologist, 185, 481-492.

$\mathrm{R}$ Development Core Team (2017) R: A language and environment for statistical computing R Foundation for Statistical Computing.

Rachmayanti, Y., Leinemann, L., Gailing, O. \& Finkeldey, R. (2006) Extraction, amplification and characterization of wood DNA from Dipterocarpaceae. Plant Molecular Biology Reporter, 24, 45-55.

Rachmayanti, Y., Leinemann, L., Gailing, O. \& Finkeldey, R. (2009) DNA from processed and unprocessed wood: Factors influencing the isolation success. Forensic Science International-Genetics, 3, 185-192.

Rackham, O. (1982) The growing and transport of timber and underwood. S. McGrail (red.), Woodworking techniques before $A D, 1500,199-217$.

Rehschuh, R., Mette, T., Menzel, A. \& Buras, A. (2017) Soil properties affect the drought susceptibility of Norway spruce. Dendrochronologia, 45, 81-89.

Reich, P.B. (2014) The world-wide 'fast-slow' plant economics spectrum: a traits manifesto. Journal of Ecology, 102, 275-301.

Revelle, W. (2017) psych: Procedure for Personality and Psychological Research.

Rich, S., Manning, S.W., Degryse, P., Vanhaecke, F. \& Van Lerberghe, K. (2016a) Provenancing East Mediterranean cedar wood with the $87 \mathrm{Sr} / 86 \mathrm{Sr}$ strontium isotope ratio. Archaeological and Anthropological Sciences, 8, 467-476.

Rich, S., Manning, S.W., Degryse, P., Vanhaecke, F., Latruwe, K. \& Van Lerberghe, K. (2016b) To put a cedar ship in a bottle: Dendroprovenancing three ancient East Mediterranean watercraft with the Sr-87/Sr-86 isotope ratio. Journal of Archaeological Science-Reports, 9, 514-521. 
Richter, K. \& Eckstein, D. (1986) Estudio dendrocronológico en Espana. Dendrochronologia, 59-71.

Richter, K. \& Rodriguez Trobajo, E. (1986) El Banco de datos dendrocronologicos para la Península Ibérica. Koiné, 66-77.

Rozas, V. (2001) Detecting the impact of climate and disturbances on tree-rings of Fagus sylvatica L. and Quercus robur L. in a lowland forest in Cantabria, Northern Spain. Annals of Forest Science, 58, 237-251.

Rozas, V. (2005) Dendrochronology of pedunculate oak (Quercus robur L.) in an oldgrowth pollarded woodland in northern Spain: tree-ring growth responses to climate. Annals of Forest Science, 62, 209-218.

Rozas, V., Garcia-Gonzalez, I., Perez-de-Lis, G. \& Arevalo, J.R. (2013) Local and largescale climatic factors controlling tree-ring growth of Pinus canariensis on an oceanic island. Climate Research, 56, 197-207.

Rydval, M., Druckenbrod, D., Anchukaitis, K.J. \& Wilson, R. (2015) Detection and removal of disturbance trends in tree-ring series for dendroclimatology. Canadian Journal of Forest Research, 46, 387-401.

Rydval, M., Gunnarson, B.E., Loader, N.J., Cook, E.R., Druckenbrod, D.L. \& Wilson, R. (2017) Spatial reconstruction of Scottish summer temperatures from tree rings. International Journal of Climatology, 37, 1540-1556.

Rydval, M., Larsson, L.A., McGlynn, L., Gunnarson, B.E., Loader, N.J., Young, G.H.F. \& Wilson, R. (2014) Blue intensity for dendroclimatology: Should we have the blues? Experiments from Scotland. Dendrochronologia, 32, 191-204.

Sala, A., Woodruff, D.R. \& Meinzer, F.C. (2012) Carbon dynamics in trees: feast or famine? Tree Physiology, 32, 764-775.

Sánchez-Salguero, R., Camarero, J.J., Hevia, A., Madrigal-González, J., Linares, J.C., Ballesteros-Canovas, J.A., Sánchez-Miranda, A., Alfaro-Sánchez, R., SangüesaBarreda, G., Galván, J.D., Gutiérrez, E., Génova, M. \& Rigling, A. (2015) What drives growth of Scots pine in continental Mediterranean climates: Drought, low temperatures or both? Agricultural and Forest Meteorology, 206, 151-162.

Sass-Klaassen, U., Vernimmen, T. \& Baittinger, C. (2008) Dendrochronological dating and provenancing of timber used as foundation piles under historic buildings in the Netherlands. International Biodeterioration \& Biodegradation, 61, 96-105.

Sass-Klaassen, U., Fonti, P., Cherubini, P., Gričar, J., Robert, E.M.R., Steppe, K. \& Bräuning, A. (2016) A Tree-Centered Approach to Assess Impacts of Extreme Climatic Events on Forests. Front Plant Sci, 7

Schlumbaum, A., Tensen, M. \& Jaenicke-Després, V. (2008) Ancient plant DNA in archaeobotany. Vegetation History and Archaeobotany, 17, 233-244.

Schneider, C.A., Rasband, W.S. \& Eliceiri, K.W. (2012) NIH Image to ImageJ: 25 years of image analysis. Nature Methods, 9, 671-675.

Schofield, M.R., Barker, R.J., Gelman, A., Cook, E.R. \& Briffa, K.R. (2016) A Model-Based Approach to Climate Reconstruction Using Tree-Ring Data. Journal of the American Statistical Association, 111, 93-106.

Scholz, A., Klepsch, M., Karimi, Z. \& Jansen, S. (2013) How to quantify conduits in wood? Frontiers in plant science, 4, 56-56.

Schrader, J., Baba, K., May, S.T., Palme, K., Bennett, M., Bhalerao, R.P. \& Sandberg, G. (2003) Polar auxin transport in the wood-forming tissues of hybrid aspen is under simultaneous control of developmental and environmental signals. Proceedings of the National Academy of Sciences of the United States of America, 100, 10096-10101. 
Schroeder, H., Kersten, B., Yanbaev, Y. \& B., D. (2018) DNA-marker sets for determination of white oaks (section Quercus) in wood products. ThünenReport, 62, 107-112.

Schroeder, H., Cronn, R., Yanbaev, Y., Jennings, T., Mader, M., Degen, B. \& Kersten, B. (2016) Development of Molecular Markers for Determining Continental Origin of Wood from White Oaks (Quercus L. sect. Quercus). Plos One, 11

Schweingruber, F.H. (1996) Tree rings and environment. Dendroecology. Haupt, Berne.

Schweingruber, F.H. \& Baas, P. (1990) Anatomie europäischer Hölzer ein Atlas zur Bestimmung europäischer Baum-, Strauch- und Zwergstrauchhölzer. Haupt, Bern.

Sorce, C., Giovannelli, A., Sebastiani, L. \& Anfodillo, T. (2013) Hormonal signals involved in the regulation of cambial activity, xylogenesis and vessel patterning in trees. Plant Cell Reports, 32, 885-898.

Souto-Herrero, M., Rozas, V. \& García-González, I. (2017) A 481-year chronology of oak earlywood vessels as an age-independent climatic proxy in NW Iberia. Global and Planetary Change, 155, 20-28.

Souto-Herrero, M., Rozas, V. \& García-González, I. (2018a) Earlywood vessels and latewood width explain the role of climate on wood formation of Quercus pyrenaica Willd. across the Atlantic-Mediterranean boundary in NW Iberia. Forest Ecology and Management, 425, 126-137.

Souto-Herrero, M., Rozas, V. \& García-González, I. (2018b) Chronologies of earlywood vessels and latewood width disentangle climate drivers of oak growth in a mild oceanic region. Dendrochronologia, 51, 40-53.

Speer, J.H. (2010) Fundamentals of tree-ring research. University of Arizona Press, Tucson.

Speirs, A.K., McConnachie, G. \& Lowe, A.J. (2009) Chloroplast DNA from 16th century waterlogged oak in a marine environment: initial steps in sourcing the Mary Rose timbers. Archaeological Science Under a Microscope (ed. by R.G. Haslam M., Crowther A., Nugent S., Kirkwood L.), pp. 175-189. ANU Press.

Sperry, J.S., Nichols, K.L., Sullivan, J.E.M. \& Eastlack, S.E. (1994) Xylem Embolism in Ring-Porous, Diffuse-Porous, and Coniferous Trees of Northern Utah and Interior Alaska. Ecology, 75, 1736-1752.

Steppe, K., Sterck, F. \& Deslauriers, A. (2015) Diel growth dynamics in tree stems: linking anatomy and ecophysiology. Trends in plant science, 20, 335-343.

Swetha, V.P., Parvathy, V.A., Sheeja, T.E. \& Sasikumar, B. (2014) Isolation and amplification of genomic DNA from barks of Cinnamomum spp. Turkish Journal of Biology, 38, 151-155.

Taberlet, P., Gielly, L., Pautou, G. \& Bouvet, J. (1991) Universal primers for amplification of three non-coding regions of chloroplast DNA. Plant molecular biology, 17, 1105-1109.

Tardif, J. \& Conciatori, F. (2006) Influence of climate on tree rings and vessel features in red oak and white oak growing near their northern distribution limit, southwestern Quebec, Canada. Canadian Journal of Forest Research, 36, 23172330.

Tegel, W., Elburg, R., Hakelberg, D., Stäuble, H. \& Büntgen, U. (2012) Early Neolithic Water Wells Reveal the World's Oldest Wood Architecture. Plos One, 7

Tessier, L., Nola, P. \& Serrebachet, F. (1994) Deciduous Quercus in the Mediterranean Region - Tree-Ring/Climate Relationships. New Phytologist, 126, 355-367. 
Tossavainen, J. (1994) Dutch forest products' trade in the Baltic from the Late Middle Ages to the peace of Munster in 1648.

Touchan, R., Shishov, V.V., Tychkov, I.I., Sivrikaya, F., Attieh, J., Ketmen, M., Stephan, J., Mitsopoulos, I., Christou, A. \& Meko, D.M. (2016) Elevation-layered dendroclimatic signal in eastern Mediterranean tree rings. Environmental Research Letters, 11

Traore, M., Kaal, J. \& Cortizas, A.M. (2018) Differentiation between pine woods according to species and growing location using FTIR-ATR. Wood Science and Technology, 52, 487-504.

Trasobares, A. \& Pukkala, T. (2004) Using past growth to improve individual-tree diameter growth models for uneven-aged mixtures of Pinus sylvestris L. and Pinus nigra Arn. in Catalonia, north-east Spain. Annals of forest science, 61, 409417.

Treydte, K., Frank, D., Esper, J., Andreu, L., Bednarz, Z., Berninger, F., Boettger, T., D'Alessandro, C.M., Etien, N., Filot, M., Grabner, M., Guillemin, M.T., Gutierrez, E., Haupt, M., Helle, G., Hilasvuori, E., Jungner, H., Kalela-Brundin, M., Krapiec, M., Leuenberger, M., Loader, N.J., Masson-Delmotte, V., Pazdur, A., Pawelczyk, S., Pierre, M., Planells, O., Pukiene, R., Reynolds-Henne, C.E., Rinne, K.T., Saracino, A., Saurer, M., Sonninen, E., Stievenard, M., Switsur, V.R., Szczepanek, M., Szychowska-Krapiec, E., Todaro, L., Waterhouse, J.S., Weigl, M. \& Schleser, G.H. (2007) Signal strength and climate calibration of a European tree-ring isotope network. Geophysical Research Letters, 34

Trobajo, E.R. (2008) Procedencia y uso de madera de pino silvestre y pino laricio en edificios históricos de Castilla y Andalucía. Arqueología de la Arquitectura, 3353.

Tucker, S. (2017) Smoke on the water: an historical archaeological assessment of maritime sources of productivity change in the early English tobacco trade. University of Southampton,

Uggla, C., Moritz, T., Sandberg, G. \& Sundberg, B. (1996) Auxin as a positional signal in pattern formation in plants. Proceedings of the National Academy of Sciences of the United States of America, 93, 9282-9286.

van der Maaten, E., Hamann, A., van der Maaten-Theunissen, M., Bergsma, A., Hengeveld, G., van Lammeren, R., Mohren, F., Nabuurs, G.J., Terhürne, R. \& Sterck, F. (2017) Species distribution models predict temporal but not spatial variation in forest growth. Ecol Evol, 7, 2585-2594.

Vicente-Serrano, S.M., Beguería, S. \& López-Moreno, J.I. (2010) A multiscalar drought index sensitive to global warming: the standardized precipitation evapotranspiration index. Journal of climate, 23, 1696-1718.

Vicente-Serrano, S.M., Camarero, J.J. \& Azorin-Molina, C. (2014) Diverse responses of forest growth to drought time-scales in the Northern Hemisphere. Global Ecology and Biogeography, 23, 1019-1030.

Vitas, A. \& Zunde, M. (2007) Dendrochronological investigation on historical English oak (Quercus robur L.) in Lithuania and Latvia: problems and potential. TRACE: Tree Rings in Archaeology, Climatology and Ecology, Assoc. for Tree Ring Research. Potsdam, 6, 124-127.

Vlam, M., de Groot, G.A., Boom, A., Copini, P., Laros, I., Veldhuijzen, K., Zakamdi, D. \& Zuidema, P.A. (2018) Developing forensic tools for an African timber: Regional origin is revealed by genetic characteristics, but not by isotopic signature. Biological Conservation, 220, 262-271. 
von Arx, G. \& Carrer, M. (2014) ROXAS - A new tool to build centuries-long tracheidlumen chronologies in conifers. Dendrochronologia, 32, 290-293.

Wagner, S., Lagane, F., Seguin-Orlando, A., Schubert, M., Leroy, T., Guichoux, E., Chancerel, E., Bech-Hebelstrup, I., Bernard, V., Billard, C., Billaud, Y., Bolliger, M., Croutsch, C., Cufar, K., Eynaud, F., Heussner, K.U., Koninger, J., Langenegger, F., Leroy, F., Lima, C., Martinelli, N., Momber, G., Billamboz, A., Nelle, O., Palomo, A., Pique, R., Ramstein, M., Schweichel, R., Stauble, H., Tegel, W., Terradas, X., Verdin, F., Plomion, C., Kremer, A. \& Orlando, L. (2018) High-Throughput DNA sequencing of ancient wood. Molecular Ecology, 27, 1138-1154.

Walthert, L. \& Meier, E.S. (2017) Tree species distribution in temperate forests is more influenced by soil than by climate. Ecology and Evolution, 7, 9473-9484.

Ważny , T. (2001) Dendrochronological evidence of timber trade. In: Tree Rings and People. International Conference on the Future of Dendrochronology (ed. M. Kaennel-Dobbertin, Braeker, O.U.), Davos,Birmensdorf, Swiss Federal Research Institute.

Ważny, T. (2002) Baltic timber in Western Europe - an exciting dendrochronological question. Dendrochronologia, 20, 313-320.

Wheeler, E.A. (2011) Inside Wood-A web resource for hardwood anatomy. Iawa Journal, 32, 199-211.

Wigley, T.M.L., Briffa, K.R. \& Jones, P.D. (1984) On the Average Value of Correlated Time-Series, with Applications in Dendroclimatology and Hydrometeorology. Journal of Climate and Applied Meteorology, 23, 201-213.

Williams, A.P., Michaelsen, J., Leavitt, S.W. \& Still, C.J. (2010) Using Tree Rings to Predict the Response of Tree Growth to Climate Change in the Continental United States during the Twenty-First Century. Earth Interactions, 14

Wilson, R., Rao, R., Rydval, M., Wood, C., Larsson, L.-Å. \& Luckman, B.H. (2014) Blue Intensity for dendroclimatology: The BC blues: A case study from British Columbia, Canada. The Holocene, 24, 1428-1438.

Wilson, R., Anchukaitis, K., Briffa, K.R., Büntgen, U., Cook, E., D'arrigo, R., Davi, N., Esper, J., Frank, D. \& Gunnarson, B. (2016) Last millennium northern hemisphere summer temperatures from tree rings: Part I: The long term context. Quaternary Science Reviews, 134, 1-18.

Wilson, R., Wilson, D., Rydval, M., Crone, A., Büntgen, U., Clark, S., Ehmer, J., Forbes, E., Fuentes, M., Gunnarson, B.E., Linderholm, H.W., Nicolussi, K., Wood, C. \& Mills, C. (2017) Facilitating tree-ring dating of historic conifer timbers using Blue Intensity. Journal of Archaeological Science, 78, 99-111.

Wilson, R.J. \& Hopfmueller, M. (2001) Dendrochronological investigations of Norway spruce along an elevational transect in the Bavarian Forest, Germany. Dendrochronologia, 19, 67-79.

Wright, S.J., Kitajima, K., Kraft, N.J.B., Reich, P.B., Wright, I.J., Bunker, D.E., Condit, R., Dalling, J.W., Davies, S.J., Diaz, S., Engelbrecht, B.M.J., Harms, K.E., Hubbell, S.P., Marks, C.O., Ruiz-Jaen, M.C., Salvador, C.M. \& Zanne, A.E. (2010) Functional traits and the growth-mortality trade-off in tropical trees. Ecology, 91, 3664-3674.

Yang, B., He, M.H., Melvin, T.M., Zhao, Y. \& Briffa, K.R. (2013) Climate Control on Tree Growth at the Upper and Lower Treelines: A Case Study in the Qilian Mountains, Tibetan Plateau. Plos One, 8

Yoshida, K., Kagawa, A.., Nishiguchi, M. (2007) Extraction and Detection of DNA from Wood for Species Identification. International Symposium on Development of 
References

Improved Methods to Identify Shorea Species Wood and its Origin (ed by T. Fujji). Tokyo, Japan.

Zang, C. \& Biondi, F. (2015) treeclim: an R package for the numerical calibration of proxy-climate relationships. Ecography, 38, 431-436. 
References 
Summary 
Trees are affected by a set of spatially and/or temporarily varying biotic and abiotic factors. The effect of these factors is reflected in the width and structure of tree rings, which are widely used to study species ecology and their responses to climate. Moreover, tree-ring width time series are also used for dating and identification of the geographical origin of archaeological or historical timber - dendroprovenancing. The latter is usually done by statistical matching of tree-ring width sequence of a given timber to a network of regional and local chronologies from the same species or genera. However, despite multiple successful applications, this method also has clear pitfalls, such as lack of long reference tree-ring width chronologies from areas with intensive logging history; or possible strong teleconnections between reference chronologies over large distances leading to coarse-scale results. Therefore, to overcome these limitations and to improve dendroprovenancing results, other wood-anatomical features or chemical characteristics have to be used.

The potential of additional variables retrieved from the wood has been recently tested and showed promising results for timber tracking, e.g. its chemical composition or DNA. However, until now time series of xylem-anatomical features have been largely ignored in timber-provenancing studies. This is most likely due to the time-consuming and labourintensive data acquisition and challenging preparation of archaeological timber for precise wood-anatomical measurements. But with recent improvements in wood- preparation techniques and image-analysis software, it became possible to acquire a sufficient amount of data derived from various xylem-anatomical features in an efficient way.

This thesis aims to evaluate the value of xylem-anatomical features as well as of archaeological DNA (aDNA) in addition to TRW for timber-provenancing studies. In the context of the ForSEAdiscovery project, the potential of vessel size of ring-porous oak, blue intensity variables derived from pine trees, and aDNA extracted from historical oak timber to enhance dendroprovenancing precision was assessed. Moreover, a conceptually new method, i.e. based on individual time-series rather than on average chronologies, was applied. This was done by means of Principal Component Gradient Analyses (PCGA). A description is provided for each of the chapters on their research and findings below.

To assess the potential of oak earlywood vessels for timber provenancing, samples from nine oak stands in Northern Spain (Cantabria and the Basque country) were collected (Chapter 2). From this set of samples, vessel size and latewood-width time series were created. Based on variation in latewood-width time series, it was possible to differentiate between 
Cantabrian and Basque forest stands, i.e. in East-West direction. The difference in response to the summer temperature was found to be the main factor leading to such a differentiation. At the same time, variation in vessels size enabled the grouping of trees from the Basque country according to the continentality gradient, i.e. North-South direction, based on a difference in response of vessel size to winter and spring temperatures. These results suggest that the approach of combining latewood width with vessel size leads to a higher precision dendroprovenancing and pinpointing the origin of oak timber on a finer scale. Leave-oneout analyses confirmed this conclusion.

In Chapter 3, the potential of wood-density related Blue Intensity (BI) variables in addition to TRW for dendroprovenancing pine timber in drought limited areas was evaluated. The network of the BI and TRW time series was created from six pine forests from Central Spain and Southern Spain. PCGA of the derived time series revealed a grouping of trees according to their elevation category based on the BI time series. However, it failed to group trees according to their geographical provenance both for the TRW and BI series. Trees were correctly assigned to their origin based on TRW, but only within the predefined by the BI elevation groups. Based on these results, it is possible to conclude that a multi-variable approach comprising of BI and TRW assists in enhancing pine-timber dendroprovenancing in dry areas.

In Chapter 4, the potential of extracting and using aDNA for oak-timber provenancing on different scales was evaluated. Thirty samples from historical buildings from Spain, Latvia and Denmark were analysed. Two different extraction protocols in two genetic laboratories were tested. Furthermore, two different haplotype identification methods were applied. From $60 \%$ of the samples, at least one marker showed the presence of the aDNA with a varying percentage per extraction protocol. An existing haplotype distribution map was used to identify the potential source area of material from two study cases. The results suggest that genetic analyses have a strong potential for pinpointing timber origin, though until now only in combination with the TRW based method. Improvements in DNA extraction from degraded wood and amplification protocols are essential for future applications in dendroprovenancing studies.

In Chapter 5, the main outcomes of each of the core chapters are discussed and contextualized in a broader perspective of dendroprovenancing. The potential of oak earlywood vessels in solving actual timber provenancing challenges in other regions in 
Europe is discussed. The added value of using the individual tree approach was tested and its strong potential in improving timber provenancing is confirmed. Based on the results derived from the core chapters, and from other studies conducted in the framework of the ForSEAdiscovery project on the same samples, a decision tree was created in order to facilitate oak and pine timber provenancing in the region.

In conclusion, the multivariable approach has demonstrated a strong potential to enhance the precision of timber provenancing. However, for a successful application, specific climatic gradients were required for both genera (Chapters $2 \& 3$ ). Therefore, the decision on a suitable approach should be based on the specific provenancing conditions and should be comprised of multiple variables. 



\section{Acknowledgements}


Doing a $\mathrm{PhD}$ is a long journey full of joy, achievements but also of failures and disappointments. Having support from people around is crucial and cannot be overestimated. Here I want to express my gratefulness to all those who were next to me during these five years and have contributed to this thesis or were involved in my personal life.

I had a pleasure and honour of having quite a diverse team of co(promotors). Without them this thesis would have never been finished (or ready?). I would like to thank Frits and Jan for their critical opinion and support from start to finish of this $\mathrm{PhD}$. I will remember BBQs and sauna in Bennekom for a long time. Many thanks to Ignacio for introducing me to the world of oak wood anatomy, all the support and help I got during my stay in Spain and for the large input into this thesis. Life in Lugo was one of the highlights of this $\mathrm{PhD}$ journey. And of course churrasco from Fonte de Rei will never be forgotten. Special thanks to Ute, my daily supervisor, first of all for taking me on board and being there when it was needed. Your optimism and inspiration were always motivating and driving me to work harder and dig deeper. You taught me how to remain calm when things don't work as expected and to creatively find answers to complex questions.

This research was carried out within the ForSEAdiscovery project. We had a huge team and each member of it has contributed to this thesis in one way or another. Many thanks to Mohamed "Tatar" Traoré, Peter Groenendijk, Fadi Hajj and Marta Domínguez Delmás for all the discussions, meetings and of course the fun we had together. Thanks to you each of our field campaigns was special (and successful!). I will always remember dinners ("una super grande cerveza, por favor") and trips we had together.

I was lucky to carry out my research in a multinational group (FEM) where I met a lot of great and inspiring people. Pleasant and fruitful discussions while sharing lots of cakes and chocolates were always inspiring me. For this I want to thank Aldicir Osni Scariot, Alejandra Hernández Guzmán, Ambra Tosto, Bárbara Rocha Venancio Meyer-Sand, Carlos Moreira Miquelino Eleto Torres, Carolina Levis, Carolina Berget Moreno, Catarina Jakovac, Danaë Rozendaal, Estela Quintero Vallejo, Etienne Thomassen, Frank Sterck, Frans Bongers, Ha van Tiep, Heitor Mancini Teixeira, Huicui Lu, Jamir Alfonso, Juan Ignacio Ramírez, Koen Kramer, Kwame Oduro, Lan Zhang, Laura Boeschoten, Leo Goudzwaard, Louis König, Lourens Poorter, Madelon Lohbeck, Meike Bouwman, Marielos Peña-Claros, Marleen Vos, Marlene Soriano, Mart Vlam, Masha van der Sande, Mathieu Decuyper, Merel Jansen, Monique Weemstra, Paul Copini, Peter van der Sleen, Pieter Zuidema, Qi Liu, Richard 


\section{Acknowledgements}

Sikkema, Rodrigo Muñoz Aviles, Shanshan Yang, Sophie Zwartsenberg, Surya Maharjan, Ursula Salome Revilla Gonzalez and Yanjun Song. Many thanks to Ellen Wilderink for your help in the dendrolab and for coordinating it. Also many thanks to Joke Jansen for helping to solve all the unexpected administrative issues and problems.

Special thanks to Alan Heinze, José Medina, Kathelyn Paredes and Federico Alice for all the long non-science related discussions deep in the night (in the morning?). Thanks a lot for sharing your experiences, opinions and tips on many things! I have learned a lot from you guys and hope will keep on learning in the future.

I am also grateful to all my family members. You were far away, but I always felt your support assuring me that eventually it will all be fine.

Diana, it is hard to express how grateful I am and how much I appreciate all the things you have done for me and for us as a couple. Only you know all the small details of the journey to get my $\mathrm{PhD}$ done. Your unconditional love and support inspire and empower me in every aspect of my life. 


\section{Short biography}

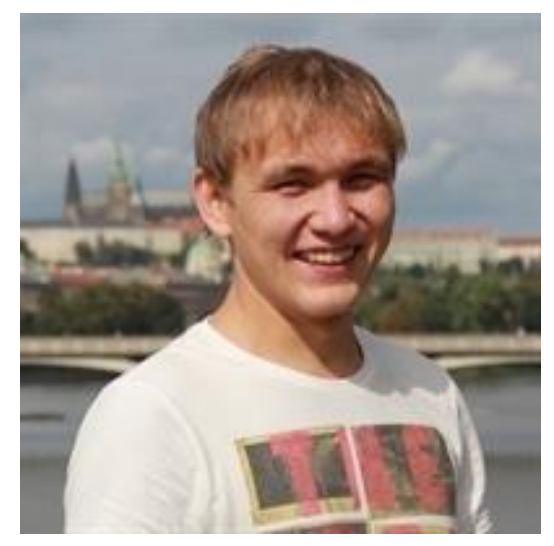

Linar Akhmetzyanov was born on September $5^{\text {th }}, 1989$ in the Republic of Tatarstan, USSR. He studied Ecology and Resource Management (BSc) at Kazan State University between 2006 and 2011. In his BSc thesis he studied the effect of the oil industry on groundwater quality in the Republic of Tatarstan. In 2011 he started his MSc study in Sustainable Resource Management at the Technical University of Munich, Germany. There, for the first time, he was introduced to the world of wood sciences and dendrochronology. His thesis research explored climate threats on growth of rear-edge European beech peripheral populations in Spain. He completed his master's in 2014 and immediately started his $\mathrm{PhD}$ research project aimed at exploring the potential of wood-anatomical features and wood DNA for use in timber provenancing studies. This $\mathrm{PhD}$ was embedded in the ForSEAdiscovery project (Forest Resources for Iberian Empires: Ecology and Globalization in the Age of Discovery). 


\section{List of publications}

Akhmetzyanov, L., Buras, A., Sass-Klaassen, U., den Ouden, J., Mohren, F., Groenendijk, P. \& García-González, I. (2019) Multi-variable approach pinpoints origin of oak wood with higher precision. Journal of Biogeography, 46, 1163-1177.

Dorado-Liñán, I., Akhmetzyanov, L. \& Menzel, A. (2017) Climate threats on growth of rear-edge European beech peripheral populations in Spain. Int J Biometeorol, 61, 2097-2110.

Chen, K., Dorado-Liñán, I., Akhmetzyanov, L., Gea-Izquierdo, G., Zlatanov, T., \& Menzel, A. (2015). Influence of climate drivers and the North Atlantic Oscillation on beech growth at marginal sites across the Mediterranean. Climate Research, 66, 229-242. 


\section{Affiliations of co-authors}

\section{Buras, Allan}

Land Surface-Atmosphere Interactions

Technical University of Munich

Freising, Germany

\section{Copini, Paul}

Wageningen Environmental Research

Wageningen University and Research

Wageningen, The Nether

Daly, Aoife

SAXO - Institute

University of Copenhagen

Copenhagen, Denmark

de Groot, G. Arjen

Wageningen Environmental Research

Wageningen University and Research

Wageningen, The Nether

\section{Domínguez-Delmás, Marta}

Faculty of Humanities

University of Amsterdam

Amsterdam, The Netherlands

\section{Den Ouden, Jan}

Forest Ecology and Forest Management Group

Wageningen University and Research

Wageningen, The Netherlands

\section{García-González, Ignacio}

Departamento de Botánica, Escola Politécnica Superior de Enxeñaría, Campus Terra Universidade de Santiago de Compostela

Lugo, Spain 


\section{Groenendijk, Peter}

Department of Plant Biology

University of Campinas

Campinas, Brazil

\section{Mohren, Frits}

Forest Ecology and Forest Management Group

Wageningen University and Research

Wageningen, The Netherlands

\section{Sánchez-Salguero, Raúl}

Departamento de Sistemas Físicos

Universidad Pablo de Olavide

Sevilla, Spain

\section{Sass-Klaassen, Ute}

Forest Ecology and Forest Management Group

Wageningen University and Research

Wageningen, The Netherlands

\section{Schroeder, Hilke}

Thuenen-Insitute of Forest Genetics

Grosshansdorf, Germany 


\section{PE\&RC training and Education Statement}

PE\&RC Training and Education Statement

With the training and education activities listed below the $\mathrm{PhD}$ candidate has complied with the requirements set by the C.T. de Wit Graduate School for Production Ecology and Resource Conservation (PE\&RC) which comprises of a minimum total of 32 ECTS (= 22 weeks of activities)

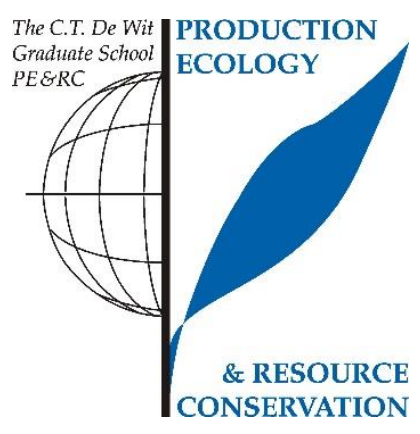

\section{Review of literature (5 ECTS)}

- Potential wood-anatomical features for dendroprovenancing of oak and pine

\section{Writing of project proposal (3 ECTS)}

- Application of ecological wood anatomy for provenancing oak and pine wood from Atlantic Iberia

\section{Post-graduate courses (3.9 ECTS)}

- Training school: quantitative wood anatomy: from sample to data; WSL, Switzerland (2014)

- History of wooden shipbuilding \& books and treatises on shipbuilding; CSIC, Madrid, Spain (2015)

- Application of Geographic Information System (GIS) to maritime history and archaeology; CSIC, Madrid, Spain (2015)

- Historiography and archive research; University of Groningen, the Netherlands (2015) 


\section{Laboratory training and working visits (4 ECTS)}

- Potential of oaks' xylem features for dendroprovenancing; Universidad de Santiago de Compostela, Spain (2016)

- Potential of Strontium isotope analyses for dendroprovenancing; Université de Lorraine, France (2017)

Competence strengthening / skills courses (2.2 ECTS)

- Essentials in scientific writing and presenting; WGS, WUR

- Spanish language for beginners; Wageningen in'to Languages, WUR

PE\&RC Annual meetings, seminars and the PE\&RC weekend (2.1 ECTS)

- $\quad$ PE\&RC First year weekend (2014)

- PE\&RC Middle year weekend (2016)

- PE\&RC Last year weekend (2017)

Discussion groups / local seminars / other scientific meetings (4.5 ECTS)

- Ecological theory and application (2015)

- FEM Journal club $(2016,2017)$

International symposia, workshops and conferences (10.1 ECTS)

- European Dendroecological Fieldweek; Oviedo, Spain (2014)

- EuroDendro; Lugo, Spain (2014)

- $\quad$ TRACE $(2017,2018,2019)$

Lecturing / supervision of practicals / tutorials (0.9 ECTS)

- Habitat analyses (2016)

\section{Supervision of MSc students (3 ECTS)}

- Wood anatomical features of pedunculated oak are sensitive indicators of climate environmental conditions 
The research described in this thesis was financially supported by by the Marie Curie Actions programme of the European Union (PITN-2013-607545)

Financial support from the project TIMBER: Northern Europe's timber resource chronology, origin and exploitation (ERC, grant agreement No. 677152) and by the PE\&RC graduate school projects "DEXTRO" and "Vessel to vessel" is acknowledged.

\section{Cover design:}

Fenna Schaap

\section{Photography:}

Peter Groenendijk

\section{Printed by:}

Digiforce || ProefschriftMaken

Ede, The Netherlands 


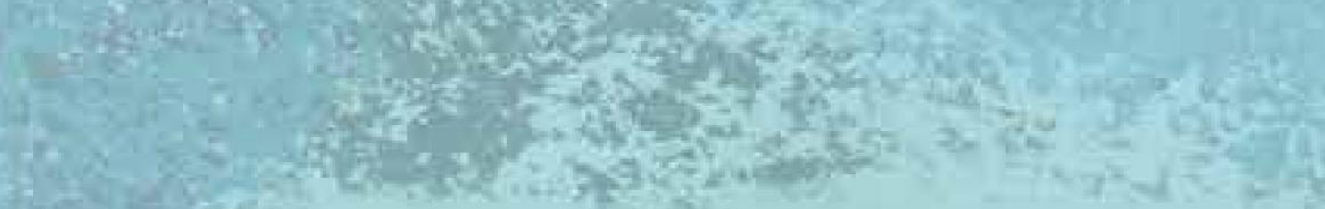

$$
\begin{aligned}
& \text { 5. 20 }
\end{aligned}
$$

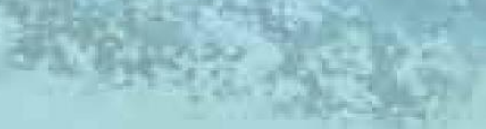

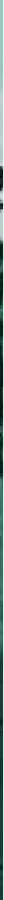

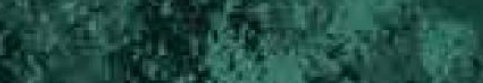

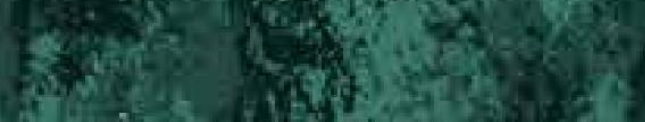

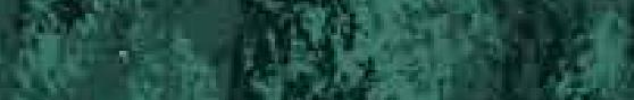

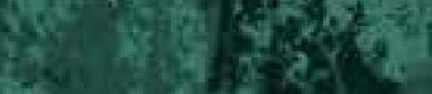

368

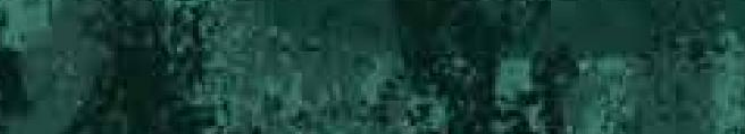

6.

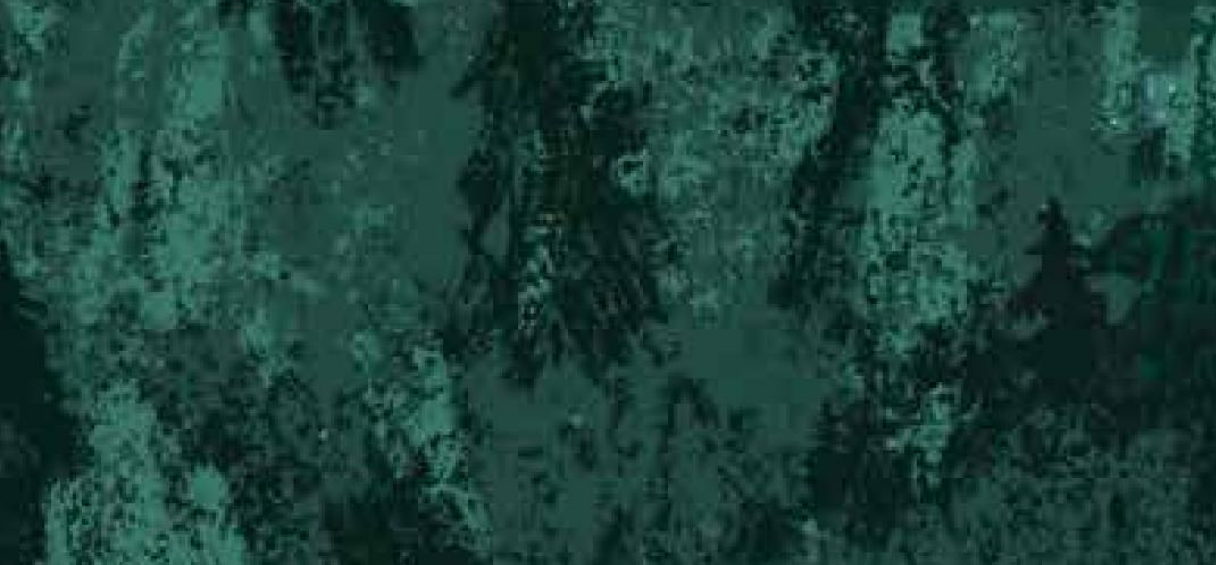

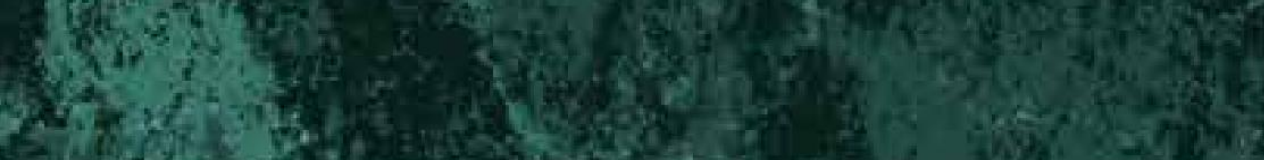

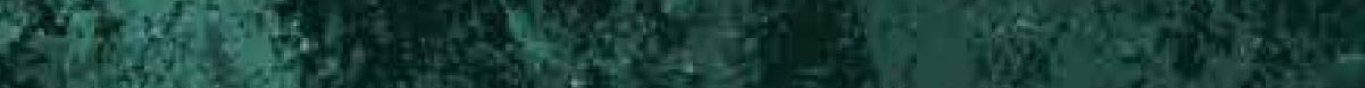

30
4
4

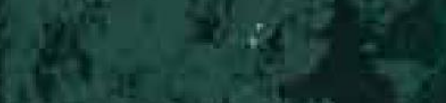

ationstion

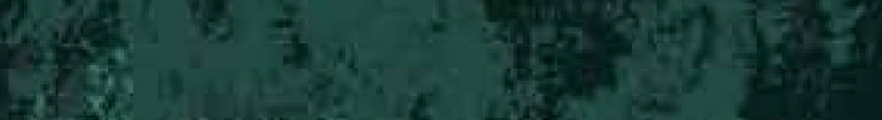

